\title{
The Use of Concept Mapping/Pattern Matching to Determine the Content Domain for Information Literacy in Baccalaureate Education
}

\author{
Eleanor M. Messman-Mandicott \\ West Virginia University
}

Follow this and additional works at: https://researchrepository.wvu.edu/etd

\section{Recommended Citation}

Messman-Mandicott, Eleanor M., "The Use of Concept Mapping/Pattern Matching to Determine the Content Domain for Information Literacy in Baccalaureate Education" (2012). Graduate Theses,

Dissertations, and Problem Reports. 276.

https://researchrepository.wvu.edu/etd/276

This Dissertation is protected by copyright and/or related rights. It has been brought to you by the The Research Repository @ WVU with permission from the rights-holder(s). You are free to use this Dissertation in any way that is permitted by the copyright and related rights legislation that applies to your use. For other uses you must obtain permission from the rights-holder(s) directly, unless additional rights are indicated by a Creative Commons license in the record and/ or on the work itself. This Dissertation has been accepted for inclusion in WVU Graduate Theses, Dissertations, and Problem Reports collection by an authorized administrator of The Research Repository @ WVU.

For more information, please contact researchrepository@mail.wvu.edu. 
The Use of Concept Mapping/Pattern Matching to Determine the Content Domain for Information Literacy in Baccalaureate Education

Eleanor M. Messman-Mandicott

Dissertation submitted to the

College of Human Resources and Education

at West Virginia University

in partial fulfillment of the requirements

for the degree of

Doctor of Education

in

Educational Leadership Studies

Sebastián R. Díaz, Ph.D., J.D., Chair

Elizabeth A. Jones, Ph.D.

Ernest R. Goeres, Ph.D.

Patricia A. Obenauf, Ed.D.

David M. Gillespie, Ph.D.

Department of Educational Leadership Studies

Morgantown, West Virginia

2012

Keywords: Information Literacy; Standards; Assessment; Higher Education; Association of College and Research Libraries; ACRL; Student Learning Outcomes Copyright 2010-2012 Lea M. Messman-Mandicott 


\begin{abstract}
The Use of Concept Mapping/Pattern Matching to Determine the Content Domain for Information Literacy in Baccalaureate Education
\end{abstract}

Eleanor M. Messman-Mandicott

This study assessed the relevance of a national association's standards for developing information literacy competency in undergraduate students at a mid-sized, regional university in Maryland. Key stakeholders responsible for ensuring student success in achieving information literacy competency at the institution were solicited for their expertise to identify the outcomes they consider to indicate information literacy competency. The group of 14 participants included six faculty, three librarians, three student affairs professionals, and two students. Trochim's Concept Mapping/Pattern Matching methodology was used for gathering and analyzing the data to conceptualize the domain of information literacy competencies. The key stakeholders generated 80 student learning outcomes for information literacy. Using multidimensional scaling and hierarchical cluster analysis, the outcomes were grouped into eight clusters representing the content domain for information literacy. Following the creation of the concept maps, the resulting priorities and their conceptualization schema were compared to the national organization's standards for similarities and differences in a qualitative document analysis. They were also compared to the learning outcomes for information literacy currently associated with the institution's general education curriculum and the library's instruction program.

The study revealed four conclusions. First, the national standards for information literacy are relevant at the local level. Second, there is a need for academic libraries to reevaluate their existing information literacy outcomes to reflect changes in information dissemination from a textual bias to include multi-media. Third, it is important for academic institutions to include representation of all stakeholders when developing student learning outcomes. Fourth, ambiguity still exists among stakeholders in regard to the effectiveness of teaching information literacy. 
CONTENT DOMAIN FOR INFORMATION LITERACY

\section{Acknowledgments}

First, I must thank God for His inspiration and steadying hand. He helped me overcome personal barriers that stood in the way of my attempting to do this years ago. I thank Him for giving me the endurance to continue on despite the endless writing and worrying.

Of the people in my life, now and forever, I must first thank my husband, William Mandicott over and over again. If it hadn't been for Bill's encouragement to attempt this, his unwavering support throughout, and his belief in me, I would not be writing this today. Bill took on all of the responsibilities that we normally would share, despite his own extraordinarily busy schedule, and yet when I would come home at night from writing in my office, dinner would always be waiting for me no matter how late it was.

I also want to thank my parents, Frederick and Emily Messman, who taught their four children to love to read, to value their education, to love each other, and to respect everyone. They gave us the greatest gifts that parents can give their children - love, education, and our independence. My only wish is that they could be here so they could help me celebrate this accomplishment. I also want to thank my sisters, Ruth and Martha, and my brother Chris; as well as Ruth's husband Jimmy and Chris' wife Lynn and all of their beautiful families. I hope you all know that despite my infrequent communications, you are always in my heart and never out of my thoughts. This is also true of my other parents, James and Lucy Mandicott, who have loved me like a daughter, and not just a daughter-in-law.

Next, I need to thank my mentor, friend, and director, Dr. David Gillespie. His wisdom, patience, and support while I persevered with this project are invaluable to me. I also appreciate his willingness to serve on my committee and the insightful ideas he has given me.

I want to thank all of the members of my committee, starting with Dr. Sebastián Díaz, my 


\section{CONTENT DOMAIN FOR INFORMATION LITERACY}

chair. He endured my worrying with fortitude and provided me with the encouragement that I needed. He also helped me through the most difficult challenges: statistics and this dissertation. I want to thank Dr. Elizabeth Jones for accepting me into the program and her willingness to continue on as a member of my committee despite the distance and her own new responsibilities. Many thanks go to Dr. Ernest Goeres, not just for serving on my committee, but for all of the help he continues to give to all of the students. His warm smile and cheerful voice never fail to brighten our days. For Dr. Patricia Obenauf, I want to thank her for stepping in as a member of the committee when she did and for always responding immediately with important feedback.

I owe a special thank you to each of the members of my focus group at Frostburg State University. Your participation in the study was extremely valuable and humbling to me. I am most appreciative of the fact that you were willing to come together on the only snowy and blustery day we had this winter, when most of you were off for intersession break.

I know there are many other colleagues and friends that I need to thank for their kind words of support and their understanding when I couldn't give them my fullest attention. I am looking forward to extending those in person.

Finally, I want to thank Bill again. This is for you. 


\section{Table of Contents}

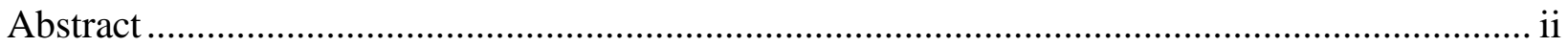

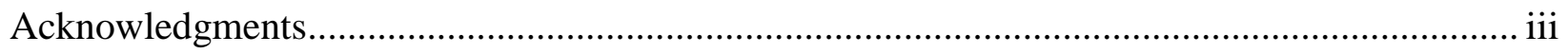

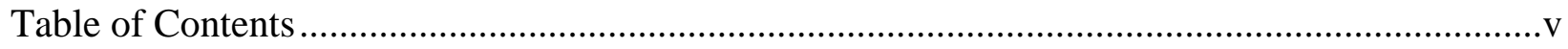

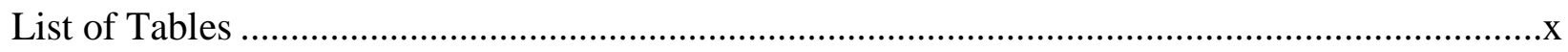

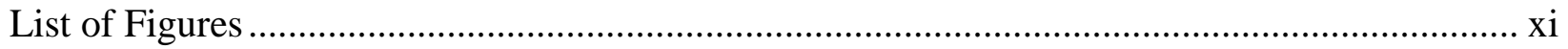

Chapter One: Introduction of the Study ........................................................................

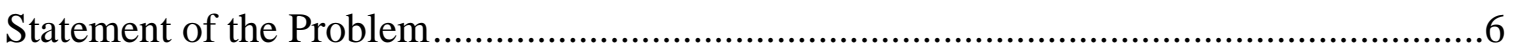

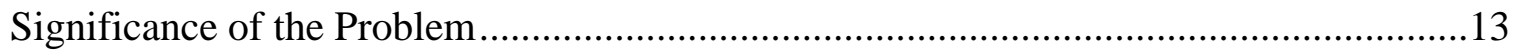

Purpose of Study and Research Questions.............................................................18

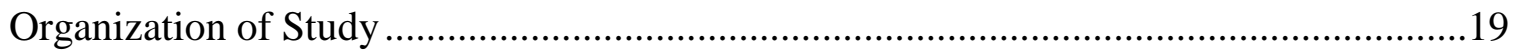

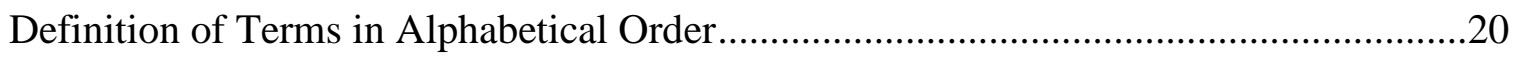

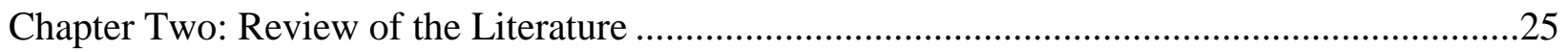

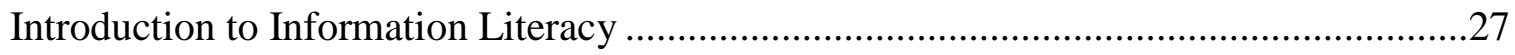

Research Related to Information Literacy at Institutions of Higher Education.................31

The Role of the Academic Library in Developing Information Literacy Skills in

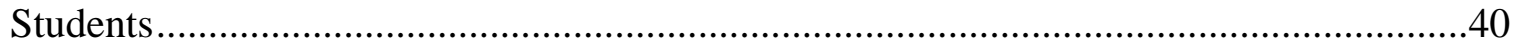

The Importance of Assessing Library and Information Literacy Instruction ..................43

Establishment of Standards for Measuring Information Literacy Competency ...............45

Emergence of the Knowledge Society and the Needs of the Knowledge Worker ...........46

Concept Mapping/Pattern Matching as an Assessment Methodology ............................54

The Contribution of This Study to the Literature .....................................................64

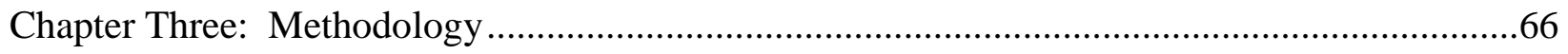

Restatement of the Problem .....................................................................................66 


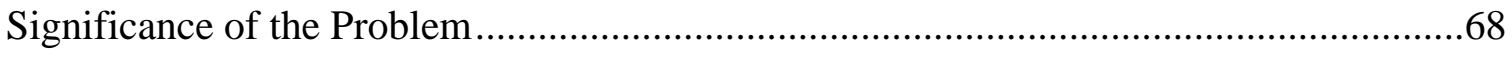

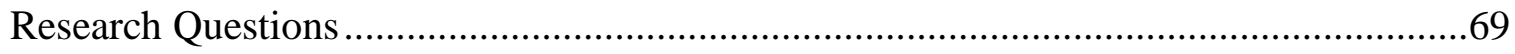

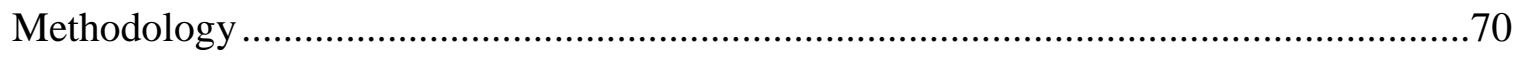

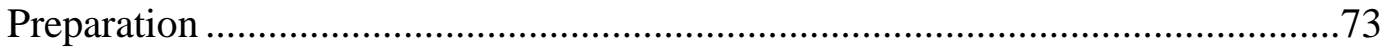

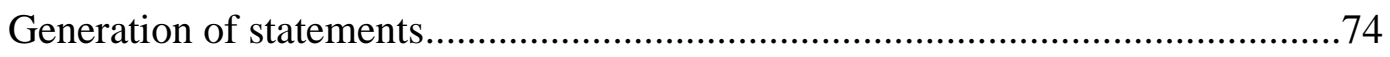

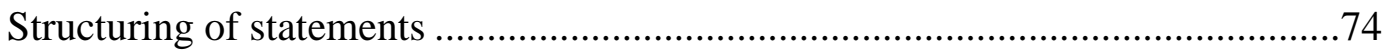

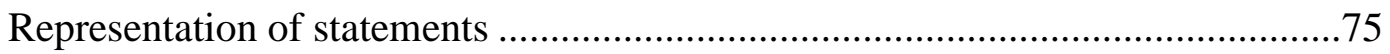

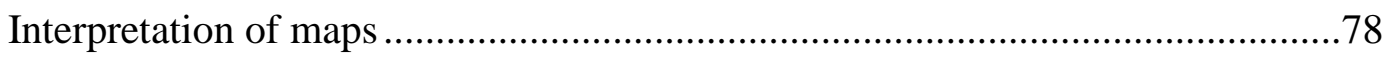

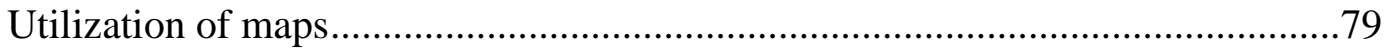

Benefits to using Concept Mapping/Pattern Matching ..........................................79

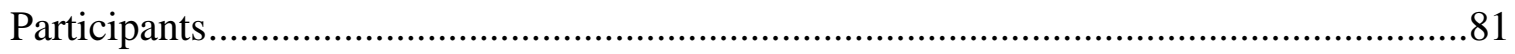

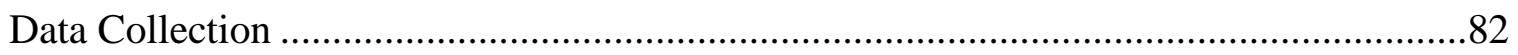

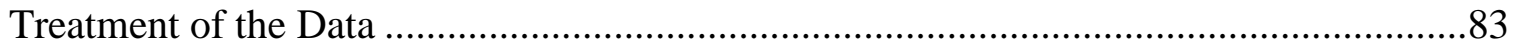

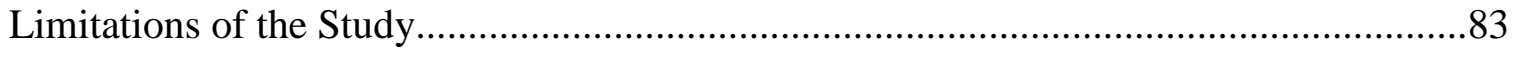

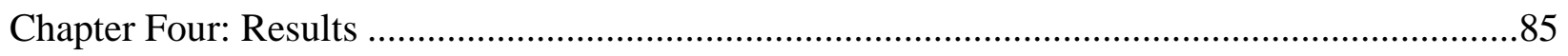

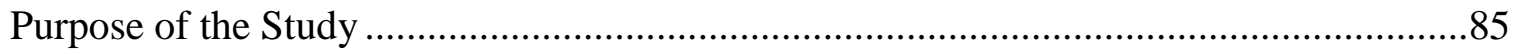

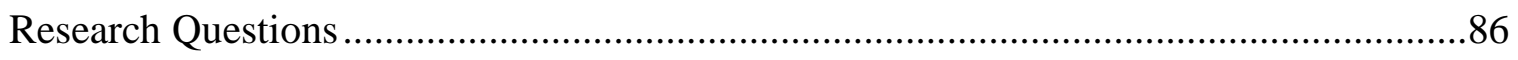

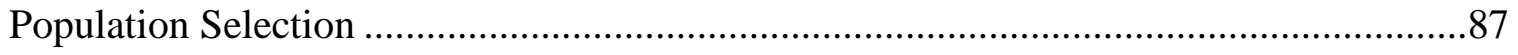

Implementation of the Concept Mapping/Pattern Matching Process .................................90

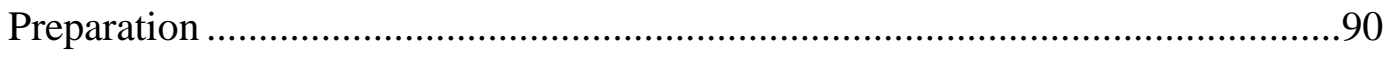

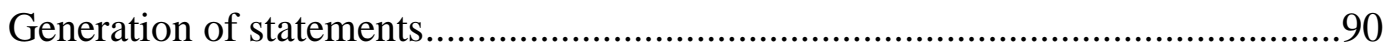

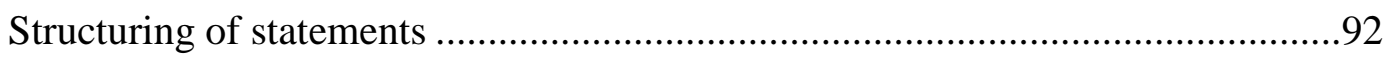

Data Analysis of the Results of the Concept Mapping/Pattern Matching Methodology 


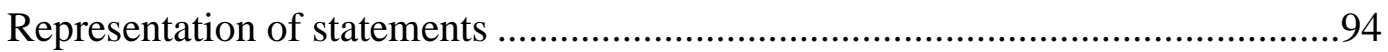

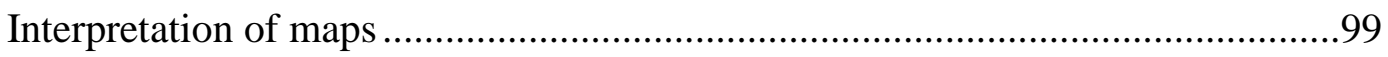

Applying the survey results to the Concept Mapping/Pattern Matching results

Analysis of Resulting Data as It Relates to Research Question 1...................................102

Research Process Cluster .............................................................................104

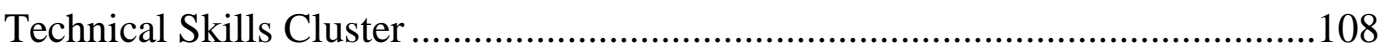

Selecting Sources Cluster …………...........................................................109

Information Ethics Cluster ........................................................................111

Communication Cluster …………………..................................................113

Evaluating Information Cluster.....................................................................115

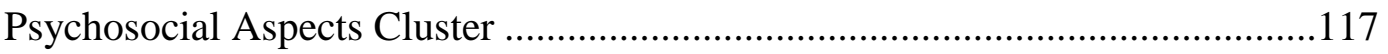

Information Utilization Cluster .......................................................................118

The total importance and efficacy mean scores for each cluster .........................120

Document Analysis Results as They Relate to Research Question 2 ..............................122

Similarities between the two documents..........................................................125

Differences between the two documents .......................................................131

Comparison of Results with Information Literacy Outcomes Currently Utilized At Mid-Atlantic University ........................................................................................134

Limitations of the Study.........................................................................................140

Chapter Five: Summary, Conclusions, Implications, and Future Research ...............................144

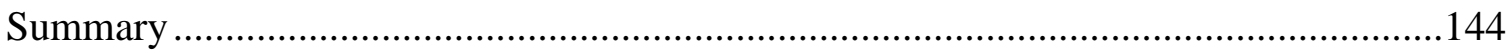

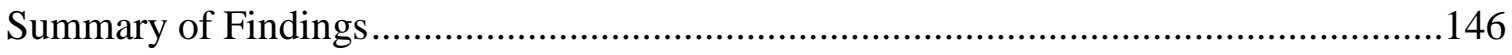

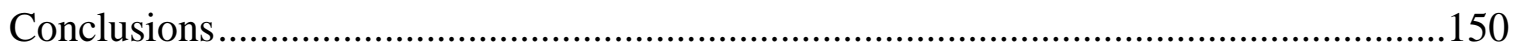


Application of national standards for information literacy at the local level

Relevance of current information literacy standards both nationally and locally

Importance of including key stakeholders in developing learning outcomes

Ambiguity in regard to effectiveness in teaching information literacy skills ......156

Implications of the Findings

Academic librarians should assume more proactive roles in promoting their services and successes to their campus community.....

Academic libraries should include representation from key stakeholders when establishing information literacy outcomes

Academic libraries should reevaluate their information literacy outcomes periodically

The Association of College and Research Libraries should consider reevaluating its multiple information literacy documents for currency and consolidation into one.....

Mid-Atlantic University should reevaluate all student learning outcomes for information literacy to include skills rated as important to multiple stakeholders.

Mid-Atlantic University's library faculty should increase the promotion of their information literacy instruction program and its success to the campus community

Curriculum development at Mid-Atlantic University should reflect collaboration between academic affairs and student affairs

Graduate programs for student personnel should consider incorporating discussions about information literacy within the context of student development into their curriculum .166

Effectiveness of using Trochim's Concept Mapping/Pattern Matching methodology for developing standards and outcomes.

Recommendations for Future Research..... 
Appendix A: List of ACRL Standards, Performance Indicators, and Outcomes for Information Literacy

Appendix B: Letter Confirming Mid-Atlantic University Key Stakeholder's Participation in the Concept Mapping/Pattern Matching Study

Appendix C: List of Statements Generated by Key Stakeholders at Mid-Atlantic University Using Concept Mapping/Pattern Matching

Appendix D: Survey to Key Stakeholders for Rating of 80 Outcomes by Importance and Efficacy Using Survey Monkey

Appendix E: Hierarchical Cluster Tree or Dendrogram Created by the Hierarchical Cluster Analysis Showing Where the Clusters Split....

Appendix F: Excel Spreadsheet Grouping Outcomes into Clusters

Ranging from 5 to 10

Appendix G: Mean Scores for Importance and Efficacy for the 80 Outcomes after Rating by Key Stakeholders

Appendix H: Comparing Similarities between Concept Mapping/Pattern Matching Outcomes and the ACRL Information Literacy Competency Standards

Appendix I: Survey Monkey Results for Importance of Each Outcome by Number of Responses .226

Appendix J: Survey Monkey Results for Efficacy of Each Outcome by Number of Responses 


\section{List of Tables}

Table 1: Participants in the Concept Mapping/Pattern Matching Focus Group by

Division, College and/or Department

Table 2: List of 80 Outcomes Generated by Focus Group, Organized into Clusters using

Hierarchical Cluster Analysis, and Labeled.

Table 3: List of Eight Clusters Created by Concept Mapping/Pattern Matching with

Labels and Definitions

Table 4: List of Statements in the Research Process Cluster and Their Mean Ratings

in Terms of Importance and Efficacy

Table 5: List of Statements in the Technical Skills Cluster and Their Mean Ratings

in Terms of Importance and Efficacy

Table 6: List of Statements in the Selecting Sources Cluster and Their Mean Ratings in Terms of Importance and Efficacy

Table 7: List of Statements in the Information Ethics Cluster and Their Mean Ratings in Terms of Importance and Efficacy

Table 8: List of Statements in the Communication Cluster and Their Mean Ratings in Terms of Importance and Efficacy

Table 9: List of Statements in the Evaluating Information Cluster and Their Mean Ratings in Terms of Importance and Efficacy

Table 10: List of Statements in the Psychosocial Aspects Cluster and Their Mean Ratings in Terms of Importance and Efficacy

Table 11: List of Statements in the Information Utilization Cluster and Their Mean Ratings in Terms of Importance and Efficacy

Table 12: The Importance and Efficacy Mean Scores for Each Cluster.....

Table 13: Comparison of the Concept Mapping/Pattern Matching Generated Clusters and The ACRL (2000) Information Literacy Competency Standards for Higher Education.

Table 14: ACRL Outcomes that Could Not be Matched to Mid-Atlantic University's Outcomes for Information Literacy

Table 15: Comparison of Two Groups of Student Learning Outcomes for Information Literacy Utilized at Mid-Atlantic University and the Content Domain Conceptualized by the Key Stakeholders in the Study 


\section{List of Figures}

Figure 1: Point map with the 80 Concept Mapping/Pattern Matching statements

Figure 2: Numbered point map with the 80 Concept Mapping/Pattern Matching statements.......96

Figure 3: The Concept Mapping/Pattern Matching cluster map with the eight clusters identified

Figure 4: The Concept Mapping/Pattern Matching cluster map with the eight clusters named

Figure 5: Laddergram chart showing the mean ratings of importance and efficacy for the eight clusters generated by the key stakeholders using Concept Mapping/Pattern Matching .....12 


\section{Chapter One}

\section{Introduction of the Study}

This study assessed the relevance of a national association's standards designed to assist institutions of higher education in establishing learning outcomes for developing information literacy competency in undergraduate college students at a Master's L Carnegie Classified university (Carnegie Foundation for the Advancement of Teaching, 2006) in Maryland. To accomplish this analysis, the researcher solicited the expertise of key stakeholders responsible for ensuring student success in achieving information literacy competency at the aforementioned institution to identify the outcomes they consider to indicate information literacy competency. The researcher used Concept Mapping/Pattern Matching as the methodology, specifically the process advanced by William Trochim (1989b), for gathering and analyzing the data to conceptualize the domain of desired information literacy competencies. Following the creation of the concept maps by the study's participants, the resulting priorities and their conceptualization schema were compared to the national organization's standards and to the student learning outcomes associated with information literacy currently incorporated in the institution's general education curriculum and the library's instruction program. The objective of this process was to begin to validate the relevancy of the existing outcomes at the national level to those applied locally through a comparison and contrast of precepts as they relate to the local student population.

The first use of the phrase information literacy was attributed to Paul Zurkowski, in a report he submitted to the National Commission on Libraries and Information Science (NCLIS) in 1974 as the president of the U.S. Information Industry Association (Badke, 2010; Behrens, 1994; Horton, 2007; McAdoo, 2010). To Zurkowski (1974), "people trained in the application of 


\section{CONTENT DOMAIN FOR INFORMATION LITERACY}

information resources to their work can be called information literates. They have learned techniques and skills for utilizing the wide range of information tools as well as primary sources in molding information solutions to their problems" (p. 6). However, the concept and its importance, particularly in education, is considered to have been brought to the nation's attention in 1989 by the American Library Association's (ALA) Presidential Committee on Information Literacy's Final Report presented in Washington, D.C. (Eisenberg, Lowe, \& Spitzer, 2004; Rockman, 2004; Samson, 2010). The significance of this publication is that it formalized the purpose and goal of what academic libraries had been trying to achieve in their orientation or instruction programs for decades.

Earlier in the 1980s, traditional library orientation had evolved into bibliographic instruction, during which the interaction between the librarian and the students in a subject related class focused on specific research tools that were introduced within the context of a search strategy framework (Grassian \& Kaplowitz, 2009). The outcome of these early instruction classes resulted primarily in students learning how to organize their approach to research and allowed librarians to disseminate bibliographies of reference tools relevant to the subject of the course and promote resources available in the library's collections. However, these lecturebased sessions that were designed to teach library skills should not be confused with information literacy instruction, though even into the earlier part of the $21^{\text {st }}$ Century the difference between the two concepts was often misunderstood and the terms were frequently co-mingled (Costantino, 2003; Snavely \& Cooper, 1997).

Following the release of ALA's Final Report, not all educators accepted it immediately. The definition, application, standards and expected learning outcomes were argued by librarians and faculty for the next ten years and beyond (Donova, \& Zeld, 1999; Grassian \& Kaplowitz, 


\section{CONTENT DOMAIN FOR INFORMATION LITERACY}

2009; Snavely \& Cooper, 1997; VanderPol, Brown, \& Iannuzzi, 2008). Librarians in the United States and Europe were in the forefront promoting the need to incorporate information literacy into the K-12 and higher education curricula. The American Association of School Librarians (AASL), a division of ALA and the Association for Educational Communications and Technology (AECT) took the lead and published the first information literacy standards for K-12 in 1998 entitled Information Literacy Standards for Student Learning. "These detailed and wellwritten standards had an enormous impact on school librarians and school library media specialists" (Grassian \& Kaplowitz, p. 14). Concurrently, the president of the Association of College and Research Libraries (ACRL), another division of ALA, created the Multi-Association Information Literacy Competency Task Force. With the exception of a representative from the Middle States Commission on Higher Education and a vice president for academic affairs, the remaining eight members of the ten-member task force were library professionals representing institutions of higher education from three different regions of the United States: the East, West and Midwest.

Two years later in 2000, the Task Force, under the leadership of ACRL issued Information Literacy Competency Standards for Higher Education:

- Standard 1: The information literate student determines the nature and extent of the information needed.

- Standard 2: The information literate student accesses needed information effectively and efficiently.

- Standard 3: The information literate student evaluates information and its sources critically and incorporates selected information into his or her knowledge base and value system. 


\section{CONTENT DOMAIN FOR INFORMATION LITERACY}

- Standard 4: The information literate student, individually or as a member of a group, uses information effectively to accomplish a specific purpose.

- Standard 5: The information literate student understands many of the economic, legal, and social issues surrounding the use of information and accesses and uses information ethically and legally. (ACRL, 2000, pp. 8-14)

Twenty-two performance indicators further define the five broad standards. Each performance indicator has at least two, but often more, very specific outcomes designed to illustrate the achievement of competency in information literacy. There are 87 recommended total outcomes (ACRL, 2000). A complete list of the outcomes is provided in Appendix A.

Since their publication, the ACRL Standards have been adopted by institutions of higher education; professional organizations in education and librarianship; and by state, regional, and national accrediting agencies.

This document has had widespread influence on colleges and universities across the nation, as well as internationally, with translations into Spanish and Greek. A year after its publication, it was endorsed by the American Association for Higher Education. (Rockman, 2004, p. 6)

In 2002, the provost of the university in Maryland where this study was conducted charged a group of faculty to coordinate a three-year comprehensive review of the institution's undergraduate program. Through fall 2004, faculty, staff, and students participated in focus groups, sub-committees, and open-agenda meetings to explore every aspect of undergraduate education offered by the university. Finally, in February 2005, the Faculty Senate approved the final report entitled: Undergraduate Education Initiative: Recommendations for a Distinctive Undergraduate Experience (Frostburg State University, 2004). This strategy established a 


\section{CONTENT DOMAIN FOR INFORMATION LITERACY}

framework for developing new curriculum, experiential and co-curricular opportunities, and interdisciplinary courses. Following this process, existing student learning outcomes underwent minute scrutiny, while for those departments, programs, or activities where specific student learning outcomes were lacking, extensive research and discussion took place among key stakeholders in order to establish meaningful and relevant outcomes.

A sub-committee composed of three library faculty, a teaching faculty member from the College of Education and the coordinator of the Undergraduate Education Initiative (UEI) project identified eight skills that a student should be knowledgeable about and be competent with in order to be considered information literate (Frostburg State University, 2005). Since then, the University library's instruction program adopted six specific student learning goals associated with the ACRL information literacy standards:

- Students will frame a research question and identify main concepts and corresponding keywords that can be used during the search process.

- Students will learn to understand the differences between information sources.

- Students will learn to use catalog USMAI (the online catalog of the University System of Maryland and Affiliated Institutions) to identify appropriate books and items within the library and the University system.

- Students will learn to use Research Port to identify and find appropriate articles for their research.

- Students will learn to efficiently and effectively access information and identify credible sources, including information from the World Wide Web.

- Students will understand that there are different documentation styles for citing sources. (Frostburg State University, no date) 


\section{CONTENT DOMAIN FOR INFORMATION LITERACY}

\section{Statement of the Problem}

Information literacy competency, like critical thinking and other student learning outcomes often associated with general education programs that encompass a broad spectrum of an institution's curriculum, will mean different things to different academic disciplines. Therefore, information literacy instruction, by design, necessitates the input of diverse stakeholders throughout the university. In the process utilized at the university subject to this research study, which from this point forward will be referred to as Mid-Atlantic University, it was unclear whether the formulation of existing outcomes included adequate diversity of perspectives from a sufficient array of interested practitioners.

Within the past ten years most regional higher education accrediting commissions incorporated information literacy as one of the many student learning outcomes to be assessed and reported by colleges and universities seeking reaccreditation (Albrecht \& Baron, 2002; Costantino, 2003; Samson, 2010; Thompson, 2002). The New England Association of Schools and Colleges (2005) had a standard devoted specifically to assessing the academic library, its information resources and the information literacy instruction programs of the institution. Four of the remaining five regional commissions, the Northwest Commission on Colleges and Universities (2010), the Southern Association of Colleges and Schools (2009), the Western Association of Schools and Colleges (2008) and the Middle States Commission on Higher Education (2009) include the assessment of the library and information literacy instruction in other standards related to student learning. In 2003, the Middle States Commission on Higher Education (MSCHE) published a document separate from its accreditation standards manual that offers guidelines for integrating information literacy throughout the curriculum (MSCHE). Interestingly, the sixth accrediting agency, the Higher Learning Commission, under the auspices 


\section{CONTENT DOMAIN FOR INFORMATION LITERACY}

of the North Central Association of Colleges and Schools (2003), does not make reference to information literacy per se, but instead describes the skills needed by the knowledge worker:

The knowledge worker will be technologically literate, to be sure, but what is valued is the knowledge worker's capacity to sift and winnow massive amounts of information in order to discover or create new or better understandings of ourselves and the world we live in. (The Higher Learning Commission, 2003, p. 3.2.13)

Although the emphasis placed on information literacy varies considerably between the different publications of the six regional commissions, with the Middle States Commission providing the most detailed guidelines, it is evident that "they all seem to place a high value on the skills associated with information literacy" (Saunders, 2007, p. 323).

Accrediting agencies are not the only formal organizations that brought to the forefront the need for significant changes in the focus of all levels of education to improve student learning and to develop standards for assessing the achievement of general competencies beyond discipline-specific knowledge. Since the 1980's, the federal government has produced several important studies publishing the work and recommendations of various commissions convened under the direction of different presidents, almost unanimously projecting the same concerns: the emergence of a knowledge society for which our work force will not be adequately trained unless our education systems are changed.

In 1983, the National Commission on Excellence in Education published A Nation at Risk: The Imperative for Education Reform. The intent of the report was to alert the American public to serious concerns regarding the apparent decline in the quality of education in the United States and to make recommendations for improvement. Recognizing a downward shift in 


\section{CONTENT DOMAIN FOR INFORMATION LITERACY}

the country's global dominance in industry and the emergence of the need for skilled workers, the Commission wrote:

The people of the United States need to know that individuals in our society who do not possess the levels of skill, literacy, and training essential to this new era will be effectively disenfranchised, not simply from the material rewards that accompany competent performance, but also from the chance to participate fully in our national life. $(1983$, p. 7)

Six years later, in 1990, U.S. Secretary of the Department of Labor Elizabeth Dole responded to similar concerns from leaders in commerce and industry about changes in the skills and competencies required of the future workforce in the United States by creating the Secretary's Commission on Achieving Necessary Skills (SCANS). The commission, composed of leaders in business and education, was charged "to examine the demands of the workplace and whether our young people are capable of meeting those demands" (Secretary's Commission on Achieving Necessary Skills, 1991, viii).

The presidents of the National Academy of Sciences, National Academy of Engineering, and the Institute of Medicine were asked in 2005 by members of Congress to assess what it would "take to enhance the science and technology enterprise so that the United States can successfully compete, prosper, and be secure in the global community of the $21^{\text {st }}$ Century," (Rising Above the Gathering Storm, Revisited, 2010, p. ix). They created a committee of 20 highly respected Americans who, at that time, were either current or former CEOs, university presidents, scientists, philanthropists, former government officials, and education leaders to consider the issue. 


\section{CONTENT DOMAIN FOR INFORMATION LITERACY}

The committee responded to their charge by producing a report entitled Rising Above the Gathering Storm: Energizing and Employing America for a Brighter Economic Future (2005).

Within the report, they identified four principal recommendations of which improving the United States' K-12 education system, particularly in science and mathematics, was their highest priority. In addition to the four recommendations, the members of the original committee suggested 20 implementing actions, ten of which were related specifically to education (Rising Above the Gathering Storm, Revisited, 2010). Heavily supported bi-partisan legislation was introduced following the release of the committee's report and the America COMPETES authorization act was passed in 2007.

As a result of these organizations' efforts and the increased attention to information literacy highlighted by the professional literature dedicated to education and library science (Samson, 2010), the achievement of information literacy competency is frequently incorporated as one of the key student learning outcomes in general education programs, specific course syllabi, and even in institutional mission statements; as well as governing boards' or public mandates (Davidson, McMillan, \& Maughan, 2002; Louisiana Board of Regents, no date; Maryland Higher Education Commission, 2010). There are many stakeholders at institutions of higher education who have a vested interest in or specific responsibility for teaching information literacy skills to undergraduates such as faculty, librarians, student affairs administrators, student development counselors, and assessment coordinators to name a few (Rockman, 2004). However, academic and student affairs administrators have become more keenly aware of the role of the library in satisfying this requirement; partly due to the recognition the regional accrediting agencies are giving the library as a partner with academic discipline-based departments in major teaching and learning activities (Gratch-Lindauer, 2002; Thompson, 2002). 


\section{CONTENT DOMAIN FOR INFORMATION LITERACY}

Library instruction has been an important function included in the many services offered by reference or public service librarians for over a century (Grassian \& Kaplowitz, 2009). Academic librarians provide orientation sessions to introduce all levels of college students to the ever increasing array of information resources, as well as to instruct them in recommended strategies for conducting research or for completing specific assignments. Evaluating the quality of the sources of information; determining the relevancy of the results of a search; and explaining the ethical use of the information identified for inclusion in an assignment are also critical components of most information literacy or library instruction classes. As a result, on many college campuses, the library may still be the sole organization fulfilling the responsibility of teaching information literacy skills (Badke, 2005), though at an increasing number of institutions librarians are being actively included in campus-wide initiatives to promote information literacy as a student learning goal. Library instruction coordinators have had some success in establishing collaborative programs with faculty in specific academic departments or integrating information literacy instruction into cross-curricular programs such as learning communities, core courses in general education programs, and first year experience programs (Eschedor Voelker, 2006; Gardner, Decker, \& McNairy, 1986; Lindstrom \& Shonrock, 2006). Research shows that the most successful examples of students developing information literacy competency are the result of teaching faculty and librarians working collaboratively to inculcate the skills into the curriculum (Booth \& Fabian, 2002; McAdoo, 2010).

All of these efforts recognized that for "on ground" and "online" students to acquire necessary information literacy skills, discipline-based faculty must be collaborative partners in the learning process across the curriculum, courses must be intellectually linked to each other whenever possible, information literacy skills must be reinforced and 


\section{CONTENT DOMAIN FOR INFORMATION LITERACY}

developed over time, and students must have built-in opportunities for success from freshman to senior levels. (Rockman, 2002, p. 187)

Assessing the effect of library instruction on the development of information literacy skills in the undergraduate student is the focus of many recent research studies (Maughan, 2001; Oakleaf, 2009; Samson, 2010; Warner, 2008). In addition, numerous guides providing best practices for assessing the achievement of these competencies appear regularly in the professional literature marketed primarily to librarians (ACRL, 2003; Avery, 2003; Baldwin, 2008; Lindauer, Arp, \& Woodard, 2004; Neely, 2006; Warner, 2008). To assist in the assessment process, instruction librarians have adopted some or all of the ACRL's (2000) Information Literacy Competency Standards for Higher Education as learning outcomes for their instruction programs. Yet, the ACRL task force that developed these standards included only two members who were not associated with the library profession. Costantino (2003) reported that the task force actively solicited and received input from higher education administrators, educators, and other librarians from around the country before releasing their recommendations. The fact that the American Association for Higher Education (AAHE) endorsed the standards soon after their publication is an indication that they cross the boundaries beyond the academic library and are applicable to the university as a whole (Costantino, 2003). However, it is difficult to determine that the process utilized included a fair representation of all types of stakeholders who have some affiliation with or responsibility for promoting or assessing information literacy at institutions of higher education outside of the library. The inclusion of broad representation from the various groups of stakeholders is an important step when designing competency-based assessment plans (Huba \& Freed, 2000; Suskie, 2004). In their list of "Principles of Strong Practice" for defining, implementing and assessing competency-based initiatives; Jones, 


\section{CONTENT DOMAIN FOR INFORMATION LITERACY}

Voorhees, and Paulson (2002) recommended as the second principle that: "the appropriate stakeholders fully participate in identifying, defining, and reaching a consensus about important competencies" (p. 22).

Similarly, very few of the studies conducted at individual colleges and universities included information related to the process by which the specific outcomes these institutions utilized were selected. For example, at the institution where this study was conducted, the resources associated with or generated by the UEI do not provide any background information as to how the Faculty Planning Group for Information Literacy, the group of three library faculty and a teaching faculty member decided upon the eight learning outcomes they chose to recommend. As a result, one may question the reasoning the practitioners used to establish the existing outcomes? Do the selected outcomes represent agreement among all stakeholders at the institution in regard to the skills that constitute information literacy competency? Finally, while a review of the current literature related to the assessment of information literacy revealed that some libraries have reevaluated the continued relevance of the student outcomes they had implemented earlier, the studies are limited in number (Gullikson, 2006). This study sought to address these issues and add to this weak body of existing literature. An underlying objective of this study was to determine whether the inclusion of more stakeholders representing other segments of the university with vested interests in information literacy, such as students, student affairs professionals, and faculty from varying disciplines would facilitate a better understanding of the importance of information literacy competency for all participants, as well as result in the selection of different, more suitable outcomes than those currently adopted by the library and the institution. 


\section{CONTENT DOMAIN FOR INFORMATION LITERACY}

\section{Significance of the Problem}

1n 1999, as the industrialized world was preparing for the advent of the $21^{\text {st }}$ Century, Donovan and Zald summed up the importance of information literacy by simply stating that "it is no longer possible to dismiss 'the information revolution' as hype” (p. 1). A person does not have to look far to encounter evidence of the cosmic changes that have transformed how we learn, work, communicate and entertain ourselves by networked information technologies (Donovan \& Zald, 1999). It is difficult to ascertain when and by whom the phrase information explosion was first used. The Oxford English Dictionary Online (OEDO) attributed its origin to a 1941 article in the Lawton (Oklahoma) Constitution, followed by an article published in 1960 in the Oshkosh (Wisconsin) Northwestern. The definition of the term as quoted from the OEDO is that an information explosion "is a rapid increase in the amount of information available, (now) esp. [sic] as a result of the increased use, availability, and sophistication of information technology" (OEDO, information explosion, 2010).

In 2006, Karl Fisch published in his popular PowerPoint presentation Did You Know that there were approximately 540,000 words in the English language, almost five times as many as during Shakepeare's time. According to the Global Language Monitor, the "English Language passed the Million Word threshold on June 10, 2009 at 10:22 a.m. (GMT). . . Currently there is a new word created every 98 minutes or about 14.7 words per day" (November 8, 2010). Google software engineers Alpert and Hajaj (2008) wrote on The Official Google Blog that when the first Google index was created in 1998, it had already indexed 26 million web pages; and in 2000, over one billion pages. At the time of their writing, on July 25, 2008, Google's search system recorded one trillion unique URLs. In 2009, there were over 131 billion Internet searches conducted worldwide, and Google's search engines were used for 87.8 billion of them, (Alpert \& 


\section{CONTENT DOMAIN FOR INFORMATION LITERACY}

Hajaj, 2008). Fisch (2007) asked "To whom were these questions addressed B.G.? (Before Google)" (Did You Know, slide 48). However, Kurzweil (2005) pointed out that, while the word "Google" has matured from a proper noun to a verb, search engines are flawed because they cannot understand how words are used in context. "Although an experienced user learns how to design a string of keywords to find the most relevant sites ... what we would really like to be able to do is converse with our search engines in natural language" (Kurzweil, 2005, p. 286).

Drucker predicted in an article published in 1994 that, just as the United States experienced a major shift from an agrarian society to the industrial age at the beginning of the $20^{\text {th }}$ Century (Drucker, 1994; Kurzweil, 2005); the U.S. would evolve into the Knowledge Society in the $21^{\text {st }}$ Century, where the vast majority of workers would be employed in the Knowledge Industry.

The rise of the class succeeding industrial workers is not an opportunity for industrial workers. It is a challenge. The newly emergent dominant group is "knowledge workers." The very term was unknown forty years ago. (I [Drucker] coined it in a 1959 book, Landmarks of Tomorrow.) By the end of this century knowledge workers will make up a third or more of the work force in the United States - as large a proportion as manufacturing workers ever made up, except in wartime. The majority of them will be paid at least as well as, or better than, manufacturing workers ever were. And the new jobs offer much greater opportunities.

But — and this is a big but — the great majority of the new jobs require qualifications the industrial worker does not possess and is poorly equipped to acquire. They require a good deal of formal education and the ability to acquire 


\section{CONTENT DOMAIN FOR INFORMATION LITERACY}

and apply theoretical and analytical knowledge. They require a different approach to work and a different mind-set. Above all, they require a habit of continuous learning. (Drucker, 1994, pp. 5-6)

Candy (2000) reinforced Drucker's prediction of the evolution of the knowledge worker and the need for future generations of the workforce to pursue lifelong learning. He placed the responsibility on institutions of higher education for teaching the skills needed by these new professionals in order to continue to seek and be able to apply knowledge.

Although this concept means different things in different cultural contexts, there is more or less general agreement that graduation really only marks the beginning of the graduate's need for continuing personal and professional learning, and, moreover, that it is the responsibility of universities and other institutions of higher education to equip their graduates with the skills and attitudes to help them to continue learning throughout their lives. The emergence of an information-rich "knowledge society" has made this even more imperative. The rapid and pervasive spread of information and communication technologies, coupled with increasing globalization, the democratisation [sic] of knowledge productiononce assumed to be largely the preserve of universities - and what has been dubbed the "information explosion" collectively mean that most citizens of advanced industrialised [sic] countries are, or will soon become, "knowledge workers". Accordingly, many graduates, whether they work in educational or other contexts, are likely to be involved in "knowledge-intensive" activities, for which they need to be prepared. (Candy, 2000, Abstract) 


\section{CONTENT DOMAIN FOR INFORMATION LITERACY}

For Candy (2000), the skills that graduates will need include the ability to find "things out for themselves through disciplined inquiry;" the ability to "apply what they know;" the ability to understand "insights and methods derived from various field [sic] of study and practice;" and the ability to "explain what they know" (p. 275). Each of these outcomes compare very closely to the competencies that are associated with information literacy and critical thinking. Identifying and incorporating the correct outcomes needed for an information-literate, knowledge-based society is a critical step in the development of curriculum and programs that will adequately prepare higher education graduates to succeed in their future occupations and personal fulfillment.

In 2010, all but three of the original committee members who produced the report Rising Above the Gathering Storm: Energizing and Employing America for a Brighter Economic Future (2005) agreed to reconvene as a group to evaluate global conditions and events that occurred during the five years following the completion of the first report and to assess the level of progress made, if any, in the accomplishment of the 20 implementing actions designed to establish a foundation for the United States to create quality jobs so it can compete and prosper in the future. The revised report, Rising Above the Gathering Storm, Revisited: Rapidly Approaching Category 5, published in 2010 was populated throughout with indications of decline in the nation's manufacturing and industrial base, education system, and potential for economic development. Yet, the members of the committee identified one factor, that being innovation, that may assist future American populations in maintaining acceptable levels of existence. They confirmed the earlier predictions of Drucker (1994) and Candy (2000) in their report by defining the main components of innovation will be new knowledge or knowledge capital, an educated workforce that can adapt to rapid advances in knowledge, and an 


\section{CONTENT DOMAIN FOR INFORMATION LITERACY}

environment that fosters innovation. "Employers indicate that knowledge demands on all employees are higher than ever. . . It has increasingly become recognized that to be competitive in the global technology-dominated marketplace requires a highly qualified workforce" (Rising Above the Gathering Storm, Revisited, 2010, p. 47).

During the first decade of the $21^{\text {st }}$ Century, publications appeared frequently (Prensky, 2001; Tapscott, 1999) describing the newest generation of students, then pre-K through high school, and the characteristic that makes them unique from previous generations - they have lived entirely in a digital age. As a result, anyone born in the past two decades is considered to have a distinct advantage in using technology and has inherited the title of digital native (Goldgehn, 2004; Palfrey \& Gasser, 2008; Prensky, 2001). Prensky (2001) is credited with creating the terms digital native and digital immigrants. He defined a digital native to be anyone who was born following the implementation of digital technology.

An assumption that many authors and educators made in these earlier attempts to define the students in this age group was, that because they could learn and adapt to various technologies more quickly, they were more savvy when it came to identifying and satisfying their information needs for personal and educational purposes using the latest technology (Combes, 2006; Long, 2005; McHale, 2005). Teachers and administrators were warned they were in danger of losing these students if changes weren't made quickly to pedagogy, curriculum content, and teaching methodology to emulate the high-tech, fast-paced environments and devices that had shaped their earlier worlds. Some articles suggested that the students should teach the teachers or digital immigrants (Prensky, 2001) how to use the latest gadgetry. The professional literature in the field of academic librarianship began to question the relevancy of libraries in the digital age (Crawford, 2009; Dougherty, 2009; Shuler, 2004) and whether 


\section{CONTENT DOMAIN FOR INFORMATION LITERACY}

traditional library and information literacy instruction is still needed in order to assist our current constituents in the use of digital research tools, particularly when Google appears to be the search engine of choice for so many (Harris, 2003).

More recently, however, research has shown that while Millennials can quickly learn to use technology for entertainment purposes and to find general information on a topic, they do not have the knowledge or skills to differentiate between authoritative and unreliable sources of information, interpret accurately the content that is provided to them, or to fully understand the value and how to utilize that material to solve a problem (Becker, 2009). In other words, digital natives lack the critical thinking skills that are often conveyed in library instruction programs that focus on information literacy.

\section{Purpose of Study and Research Questions}

The purpose of this study was to assess the relevance of a national association's standards designed to assist institutions of higher education in establishing learning outcomes for developing information literacy competency in undergraduate college students at Mid-Atlantic University, a Master's L Carnegie Classified university (Carnegie Foundation for the Advancement of Teaching, 2006) in Maryland. To accomplish this analysis, the researcher solicited the expertise of key stakeholders responsible for ensuring student success in achieving information literacy competency at the aforementioned institution to identify the outcomes they consider to indicate information literacy competency. The researcher used Concept Mapping/Pattern Matching as the methodology, specifically the process advanced by William Trochim (1989b), for gathering and analyzing the data to conceptualize the domain of desired information literacy competencies. Following the creation of the concept maps by the study's participants, the resulting priorities and their conceptualization schema were compared to the 


\section{CONTENT DOMAIN FOR INFORMATION LITERACY}

national organization's standards and to the student learning outcomes associated with information literacy currently incorporated in the institution's general education curriculum and the library's instruction program. The objective of this process was to begin to validate the relevancy of the existing outcomes at the national level to those applied locally through a comparison and contrast of precepts as they relate to the local student population.

By collecting the perceptions of key stakeholders at Mid-Atlantic University who are responsible for ensuring that the undergraduate students at that institution succeed in achieving the student learning outcomes for information literacy competency and comparing them to standards established by a national organization, it was the goal of the researcher that academic administrators may understand better the relevancy and significance of the recommended standards to the general education program at a mid-sized university community. Therefore, this study attempted to answer the following research questions:

RQ 1: When using Concept Mapping/Pattern Matching methodology, how do key stakeholders at a mid-sized regional Mid-Atlantic university conceptualize student outcomes for information literacy?

RQ 2: How does conceptualization generated through Concept Mapping/Pattern Matching at a mid-sized regional Mid-Atlantic university compare and contrast with the framework established by the Association of College and Research Libraries?

\section{Organization of Study}

This research study began with the overview of the problem and its significance to higher education that was presented in this chapter. The second chapter followed this synopsis with an extensive review of the literature describing the history of information literacy theory, research related to its integration into undergraduate education, the role of the academic library in 


\section{CONTENT DOMAIN FOR INFORMATION LITERACY}

teaching information literacy skills to college students, the importance of assessing information literacy competency, and the development of standards for that assessment. The methodology used for conducting the study was explained in detail in Chapter Three, including descriptions of the methods of how the data was going to be collected and analyzed, and any limitations to the study that were anticipated from the methodology. The procedures and results of the actual study were described fully in the fourth chapter and limitations to the study encountered during the process, followed by the fifth chapter that reported the researcher's conclusions based on the findings, the implications of the findings, and recommendations for future research.

\section{Definition of Terms in Alphabetical Order}

Concept mapping. The definition of concept mapping/pattern matching used throughout this study refers specifically to William Trochim's (1989b) methodology: Concept mapping is a structured process, focused on a topic or construct of interest, involving input from one or more participants, that produces an interpretable pictorial view (concept map) of their ideas and concepts and how these are interrelated. (Trochim, 2006, Concept Mapping website)

Information literacy. Numerous definitions of the term information literacy have been offered since 1974 when Zurkowski first presented the concept in his report to the National Commission on Libraries and Information Science. Behrens' (1994) historical analysis of when and how the phrase was used during the 1970s, 1980s, and early 1990s, particularly how it has changed in meaning and importance, provides an impressive sampling of the most significant instances of its appearance in the literature or incorporation into presentations. In their 1997 article "The Information Literacy Debate," Snavely and Cooper highlighted the better publicized definitions that were being heavily debated by librarians at the time and the arguments from 


\section{CONTENT DOMAIN FOR INFORMATION LITERACY}

proponents and opponents regarding the coupling of the terms information and literacy, confusion between information literacy and bibliographic instruction, and the lack of clarity or standards as to what defined an information literate person. Most of these definitions originated in articles and books generated by professionals and practitioners in the fields of library and information science. In his research study, McAdoo (2008) contended it is that factor that compounds the problem of educating faculty of all academic disciplines as to the meaning of information literacy and hinders its incorporation across the higher education curriculum. For that reason, he encouraged the use of a definition of information literacy that is representative of non-specific, cross-curricular applications, such as that offered by the 2002 edition of the Middle States Commission on Higher Education's Characteristics of Excellence in Higher Education: Eligibility Requirements and Standards for Accreditation and reprinted by the same agency in Developing Research \& Communication Skills: Guidelines for Information Literacy in the Curriculum (2003):

... an intellectual framework for identifying, finding, understanding, evaluating and using information. It includes determining the nature and extent of needed information; accessing information effectively and efficiently; evaluating critically information and its sources; incorporating selected information in the learner's knowledge base and value system; using information effectively to accomplish a specific purpose; understanding the economic, legal and social issues surrounding the use of information and information technology; and observing laws, regulations, and institutional policies related to the access and use of information (p. 32). (as cited in MSCHE, 2003, p. 1) 
CONTENT DOMAIN FOR INFORMATION LITERACY

Association for College and Research Libraries. Since this study used ACRL's Information Literacy Competency Standards for Higher Education as a theoretical framework upon which the research was focused, it was logical to use ACRL's definition of information literacy which states that "information literacy is a set of abilities requiring individuals to recognize when information is needed and have the ability to locate, evaluate, and use effectively the needed information" (Association of College \& Research Libraries, 2000).

Knowledge worker. Drucker (1994) took credit for coining the label knowledge workers in his 1959 book, Landmarks of Tomorrow:

The rise of the class succeeding industrial workers is not an opportunity for industrial workers. It is a challenge. The newly emergent dominant group is "knowledge workers." The very term was unknown forty years ago. (I [Drucker] coined it in a 1959 book, Landmarks of Tomorrow.) (p. 5)

Actually, the phrase he initiated was knowledge work to describe the type of jobs most employees had at the time: "Today the majority of the personnel employed even in manufacturing industries...are...people doing knowledge work, however unskilled" (Drucker, 1959, p. 122).

According to the Oxford English Dictionary Online (OEDO), the definition of a knowledge worker is "a person whose job involves handling or using information" (OEDO, knowledge worker, 2010). The dictionary attributed the first use of that title to appearing in Drucker's (1962) article, “The Economic Race: A Forecast for 1980” published in the New York Times: "The United States of 1980 will be...a society of 'knowledge workers', rather than manual workers" (as cited in OEDO, knowledge worker). In the article, Drucker (1962) explained: 


\section{CONTENT DOMAIN FOR INFORMATION LITERACY}

The dominant position of the knowledge worker in American society will have profound political and social impact. Twenty years hence a college degree —or at least some years of college-will be a requirement for any but the lowliest job, and for any advancement beyond it. As a result, education, not only of the young, but of adults, may well become the outstanding "growth industry." (p. 66)

However, it is in his 1994 article "The Age of Social Transformation," that Drucker described more fully the qualifications of a knowledge worker:

But — and this is a big but — the great majority of the new jobs require qualifications the industrial worker does not possess and is poorly equipped to acquire. They require a good deal of formal education and the ability to acquire and apply theoretical and analytical knowledge. They require a different approach to work and a different mind-set. Above all, they require a habit of continuous learning. (p. 6)

Library instruction. Since library instruction programs vary considerably among academic libraries, from the mission, the size of the program, the content, the format, instructional mode, and target audience, there is not a standard definition. For the purpose of this study, library instruction was defined as "the systematic nature of the effort to teach something — a set of principles or search strategies relating to the library, its collections or services - using predetermined methods in order to accomplish a pre-defined set of objectives" (Salony, 1995).

Pattern matching. "Pattern matching allows for the combination of any two measures aggregated at the cluster level to see to what degree the measures match or whether they 
disconnect. By examining such combinations of measures, similarities and differences between stakeholder groups can be identified" (Michalski, 1999, p. 108).

Student learning outcomes. According to Suskie (2004), "learning outcomes, also referred to as learning goals, are the knowledge, skills, attitudes, and habits of mind that students take with them from a learning experience" (p. 75). 
CONTENT DOMAIN FOR INFORMATION LITERACY

\section{Chapter Two}

\section{Review of the Literature}

Although academic librarians have practiced various forms of library instruction for over a century, the principles of information literacy have only been advocated widely for approximately forty years. Yet even back in the mid-1990's there was already an abundance of literature related to the concept (Behrens, 1994). In March 2011, when searching EBSCOhost's Education Research Complete database with the phrase information literacy and no other subject terms or limiters, 3058 citations were retrieved, the oldest with a publication date of 1915 . Limiting the search to using the phrase in the subject field only, decreased the number of relevant articles to 1911. A similar search in EBSCOhost's Academic Search Complete database resulted in a list of 1817 titles when the phrase information literacy was restricted to the subject field, shortening the list from the original group of 2902 sources that appeared when the terms were not limited. A search of ProQuest Dissertations \& Theses (PQDT) limiting the phrase information literacy to the citation and abstract retrieved 155 English-language dissertations published between 1986 and 2010. When combined with the phrase higher education in all fields including the text, the resulting list was reduced to ninety dissertations. Contrary to these searches conducted in databases targeting specific disciplines or types of literature, a Google search of the exact phrase reported approximately 5.5 million hits.

Therefore in preparation for conducting this study, a systematic rather than comprehensive review of the research literature related to the application of information literacy theories to higher education and the assessment and achievement of information literacy competency as a student learning outcome was performed. Since ACRL's Information Literacy Competency Standards for Higher Education (2000) established the conceptual framework for 


\section{CONTENT DOMAIN FOR INFORMATION LITERACY}

this study, a particular focus was included on the development, acceptance and relevance of national standards to guide faculty and librarians in incorporating information literacy skills in the classroom.

This review of literature starts with an overview of the most frequently cited documents related to information literacy that created the foundation for the thousands of theoretical, practical, or research publications that have followed in the past four decades. Therefore, the first section provides an introduction to information literacy and a chronological summary of the leading works and the issues that were predominate at the time of their publication. The second section of this review presents research that has been conducted related to information literacy theory and its application in higher education, followed by an analysis in the third section of publications describing the role of the academic library in information literacy instruction. The fourth part of this chapter identifies more recent publications that discuss the importance of assessing library and information literacy instruction programs. The development and application of standards related to information literacy for assessing these programs and students' achievement in learning these skills is addressed in the fifth section of the chapter. Much of the literature arguing the importance of incorporating information literacy instruction in education reference the ever-expanding amount of information that is generated in today's world, therefore it is necessary to include a review of the important publications describing the needs of the knowledge worker in the emerging knowledge society. These documents are presented in the sixth section of this chapter. The final sections of the review of literature include a detailed examination of publications explaining Trochim's Concept Mapping/Pattern Matching methodology and its application to research studies with similar purposes of identifying 


\section{CONTENT DOMAIN FOR INFORMATION LITERACY}

standards or criteria for assessment in various professions; followed by a summary of the contributions this study has made to the literature.

\section{Introduction to Information Literacy}

Prior to reviewing foundational research specific to the focus of this study, it was important to consider the significant milestones related to the development of information literacy theories and practice that were published in the past four decades. As mentioned previously, the first use of the phrase information literacy was attributed to Paul Zurkowski, in a report he submitted to the National Commission on Libraries and Information Science (NCLIS) in 1974 as the president of the U.S. Information Industry Association (Badke, 2010; Behrens, 1994; Horton, 2007; McAdoo, 2010). To Zurkowski (1974), "people trained in the application of information resources to their work can be called information literates. They have learned techniques and skills for utilizing the wide range of information tools as well as primary sources in molding information solutions to their problems" (p. 6). At the time Zurkowski presented his report, he considered only a small segment of the population to be information literate. The vast remainder he called "information illiterates." While describing the relationship between libraries and the information industry, Zurkowski identified several organizations in the private sector with mechanisms in place to create and organize information. As a businessman, his understanding regarding the need to promote information literacy was primarily from the industry perspective. In fact, Zurkowski illustrated specific instances where the library is a threat to the private information generating sector. Yet, he felt that an important role of the NCLIS should be to achieve total information literacy on a national scale.

Other uses or definitions of the phrases information literate or information literacy appeared in the 1970s and 1980s. In the article, "A Conceptual Analysis and Historical 


\section{CONTENT DOMAIN FOR INFORMATION LITERACY}

Overview of Information Literacy,” Behrens (1994) provided a chronological review of the evolution of various information literacy definitions and issues dominating the relevant professional literature of each decade. The author documented when and how the terms were used, describing the significance of the person who introduced the phrase or the event where it was applied, and placed the importance of the concept in the context of how society viewed the amount, reliability, access to, and use of information at the time. She provided a timeline starting with the 1970s when the phrase first emerged from a variety of sources advocating the importance of the information literate worker. In the 1980s, information literacy related publications focused on trying to find the definitive meaning of the term and how to differentiate information literacy from computer or technology literacy (Behrens, 1994; Snavely \& Cooper, 1997). Among a list of the most cited works to appear on the topic during the 1980s are Demo's (1986) publication The Idea of "Information Literacy" in the Age of High-Tech; Breivik and Gee's (1989) book Information Literacy: Revolution in the Library; and the American Library Association Presidential Committee on Information Literacy's Final Report, also published in 1989.

Recognizing the increasing importance that emerging computing and communication technologies were placing on the need for information literacy across all facets of society, Demo (1986) was one of the first authors to approach the complex problems associated with trying to instill information literacy skills in members of society outside of the academic community. Writing at a time when the new technologies were being promoted as efficient tools for managing the vast amounts of new information being generated daily, Demo identified some of the potential problems created by the technology, such as the over-load of information, the quality of which is questionable; the cost of the new technologies for non-profit organizations 


\section{CONTENT DOMAIN FOR INFORMATION LITERACY}

like the academic, school, and public libraries on which blue collar workers and many other members of society are dependent for their access to these expensive tools; and the fact that for the average person at that time, the information age did not affect them because they couldn't take advantage of what the tools had to offer, perhaps forecasting the beginning of the digital divide (Demo, 1986). The author reinforced the logic of libraries retaining their predominate role of teaching users the new skills of information literacy, including the need for public libraries to become involved since they are one of the few places the public would be able to go to use these technologies.

When they wrote their important work in 1989 as a commentary on their concerns for the quality of education at the time, Breivik and Gee (1989) demonstrated their respect for the role that librarians held for decades in teaching users how to locate and utilize information resources efficiently and effectively. They visualized the new role library professionals could play in promoting student learning and teaching information literacy skills. These were significant points for them to make, because E. Gordon Gee was not a librarian, but rather a president of a university. Even in 2011, very little of the literature published for the library profession included non-librarians, let alone high-level university administrators. Not only did the topic of their book have an impact on librarians, but also Gee's acknowledgement of the importance of the library within the academy. With increasing discussions related to the need for a clearer understanding of what constitutes information literacy, Breivik and Gee recognized the opportunity for a major paradigm shift in the library and that academic librarians needed to be encouraged to capitalize on the changes. Understanding the benefits of their own collaborative effort, they emphasized the need for partnerships between librarians and faculty, particularly in regard to teaching information literacy. 


\section{CONTENT DOMAIN FOR INFORMATION LITERACY}

The ALA (1989) Final Report captured the attention of library professionals all over the country because it was a first attempt at broadly defining the concept of information literacy and promoting its importance, particularly in education, at the national level. As mentioned previously, the significance of this publication was that it formalized the purpose and goal of what academic libraries had been trying to achieve in their orientation or instruction programs for decades. Although the definition, application and standards were argued by librarians and faculty for years (Donova, \& Zeld, 1999; Grassian \& Kaplowitz, 2009; Snavely \& Cooper, 1997; VanderPol et al., 2008), the Final Report placed librarians in the forefront of advocating the need to incorporate information literacy into the K-12 and higher education curricula. The American Association of School Librarians (AASL), a division of ALA and the Association for Educational Communications and Technology (AECT) took the lead and published the first information literacy standards for K-12 in 1998 entitled: Information Literacy Standards for Student Learning. Concurrently, the president of the Association of College and Research Libraries (ACRL), another division of ALA, created the Multi-Association Information Literacy Competency Task Force. With the exception of a representative from the Middle States Commission on Higher Education and a vice president for academic affairs, the remaining eight members of the ten-member task force were library professionals representing institutions of higher education from three different regions of the United States: the East, the West and the Midwest (ACRL, 2000). Two years later in 2000, the Task Force, under the leadership of ACRL issued Information Literacy Competency Standards for Higher Education.

According to Behrens (1994), “three main trends are apparent in the 1990's literature to date: educating for information literacy . . . ; information literacy is being considered as part of the wider literacy continuum; and librarians are evaluating their role in the information literacy 


\section{CONTENT DOMAIN FOR INFORMATION LITERACY}

movement" (p. 317). Following on the work that was done in the earlier decade to define information literacy, and in reference to teaching the concepts, much of the relevant literature of the 1990's focused on identifying student learning outcomes that could be used for measuring information literacy competency.

\section{Research Related to Information Literacy at Institutions of Higher Education}

As mentioned previously, several research studies were conducted over the years related to various issues associated with information literacy. Many of them reflected the trends of discussion taking place in the professional literature at the time the study was performed, such as defining the concept of information literacy, the role and responsibilities of the academic library in providing information literacy instruction, establishing standards for assessing the achievement of information literacy competency, the importance of incorporating information literacy instruction into the entire curriculum, and how to assess information literacy skills.

One of three earlier studies that set the foundation for this recent research study was completed in 1992 by Christina Doyle as partial fulfillment for her doctorate. The purpose of Doyle's study was to attempt to establish consensus from expert stakeholders to develop a cohesive definition and a model of outcome measures for information literacy. The framework for her study was the National Education Goals of 1990, a set of six goals related to American education and lifelong learning that were published in 1989 by President Bush and the National Governors' Council (Doyle, 1992). It was the intent of the researcher to develop for the first time on a national level an agreed upon set of outcomes for measuring information literacy and a definition acceptable to all practitioners with vested interests in the concept. Similar to this research project recently conducted, Doyle was interested in using stakeholders with expert opinions regarding information literacy to identify appropriate outcomes for measuring 


\section{CONTENT DOMAIN FOR INFORMATION LITERACY}

information literacy competency through consensus. Instead of using Concept Mapping/Pattern Matching, the methodology that was utilized in the current study, Doyle employed the Delphi Technique "to pool informed opinions of a group of knowledgeable participants. There is no interaction among the participants so that interpersonal dynamics are minimized" (Doyle, 1992, p. 34). To establish her sample, Doyle invited all of the members of the National Forum on Information Literacy (NFIL) to participate in the project and to contribute three to six names of other experts in their organizations to be included as potential participants. NFIL members represent forty-six national education and information industry related organizations. These representatives were expected "to have an above average awareness of the issues and applications of information literacy" (Doyle, 1992, p. 35). Out of the 125 people invited to participate, 58 or $(48 \%)$ agreed to join the project. The sample was composed of professionals from all over the United States with diverse backgrounds in education and the information industry. During each of the first two rounds of information seeking, the participants were each sent a packet of information with a questionnaire to which they were asked to respond. Following the receipt of the first round of feedback, the information was combined according to similarities in the responses before being resubmitted for a second review. In round two, participants were also asked to prioritize the six National Education Goals, from which goals 1, 3 , and 5 rose to the top for the group's focus. Finally, a third round of materials was sent to the participants including all 124 suggested outcomes for them to indicate via a Likert scale their agreement or disagreement. The first two rounds required qualitative input from panel members and the third requested quantifiable feedback reviewing and "voting" on those outcomes with which they agreed or disagreed. As intended, Doyle's study produced a comprehensive definition of information literacy that included the attributes of an information literate person: 


\section{CONTENT DOMAIN FOR INFORMATION LITERACY}

Information literacy is the ability to access, evaluate, and use information from a variety of sources.

An information literate person is one who:

- Recognizes the need for information

- Recognizes that accurate and complete information is basis for intelligent decisionmaking

- Formulates questions based on information needs

- Identifies potential sources of information

- Develops successful search strategies

- Accesses sources of information including computer-based and other technologies

- Evaluates information

- Integrates new information into existing body of knowledge

- Uses information in critical thinking and problem solving. (Doyle, p. 94)

Doyle (1992) acknowledged there were a few limitations to her study, such as handselecting the sample to establish a panel of participants considered to be experts on information literacy, and that due to the timeliness of the study and the rapid increase of information and changes in technology, the outcomes and definitions would become dated quickly. However, it was an important first step in establishing a unified understanding of information literacy on the national level. It is interesting to note that many of the same characteristics that Doyle attributed to the information literate person are reflected in the current ACRL information literacy standards (see Appendix A).

A review of the literature since the advent of the $21^{\text {st }}$ Century revealed a definite focus on the assessment of information literacy competency skills (Maughan, 2001; Oakleaf, 2009; 


\section{CONTENT DOMAIN FOR INFORMATION LITERACY}

Samson, 2010; Warner, 2008). This trend mirrors a predominant theme in the literature being published in the education fields; a reflection of the high level of importance regional accreditation agencies and national professional organizations are placing on the need for assessment of all types of learning (Breivik, 1998; Gratch-Lindauer, 2002). To assist in the assessment process, instruction librarians have adopted some or all of the ACRL's (2000) Information Literacy Competency Standards for Higher Education as learning outcomes for their instruction programs.

The second of the three earlier studies that were considered the foundation for this current research study fit into this category. In 2003, Connie Costantino completed her dissertation entitled Stakeholders' Perceptions of the Importance of Information Literacy Competencies Within Undergraduate Education. The purpose of Costantino's study was to "determine the extent that undergraduate students, faculty, and administrators perceive information literacy competencies are important and if these skills are being taught/learned" (Abstract). Her study focused on the outcomes identified in Standard Two of the ACRL's (2000) Information Literacy Competency Standards for Higher Education (Costantino, 2003). Costantino pointed out the fact that, although academic librarians are generally unified in advocating that information literacy skills should be integrated into the curriculum, faculty and administrators may not recognize the need. She identified some of the barriers to incorporating information literacy throughout the institution to include: stakeholders are not aware of the existence of the standards; there are numerous other competencies and outcomes that must be addressed in the curriculum-information literacy doesn't necessarily get recognized outside of the library; some faculty recognize the need for information literacy, but don't necessarily have the time or want to give the time to collaborate with librarians to develop methods for teaching the skills; and the 


\section{CONTENT DOMAIN FOR INFORMATION LITERACY}

problem that some faculty don't require their students to use the library or do research. While students recognize the importance of having these skills when they are explained to them, they are reluctant to ask for help from a librarian willing to provide the instruction or they want to use the easiest methods for finding information. Costantino used the following research questions to guide her study:

1) To what extent is it important that undergraduate students understand the skills in Standard Two of the Information Literacy Competency Standards for Higher Education (2000) as perceived by stakeholders at "Private University?" and 2) To what extent do these stakeholders perceive "Private University" students have learned the skills in Standard Two of the Information Literacy Competency Standards for Higher Education (2000)? (2003, p. 30)

Similar to Doyle's (1992) dissertation and this current research study, Costantino (2003) wanted to directly involve the stakeholders at "Private University" to acknowledge their perceptions of the importance of specific information literacy competencies and to assess the extent to which they thought students at the institution were developing these skills. Costantino's study was particularly important because it was the" first study to thoroughly examine the 'Performance Indicators' and 'Outcomes' of a Standard from the Information Literacy Competency Standards for Higher Education" (2003, p. 31) and their application and relevance at the local institutional level.

The methodology used in the study was primarily quantitative, though follow-up interviews were conducted with participants. Two self-designed questionnaires, one for faculty and one geared for students, each having twenty similar questions (the wording was changed to reflect the role of the participant as instructor or learner) and using a Likert scale were distributed 


\section{CONTENT DOMAIN FOR INFORMATION LITERACY}

on campus and by email. The researcher then followed up with interviews. Costantino (2003) used nonprobability or convenience sampling to identify volunteer participants, assuming they would be more motivated. The researcher interviewed the students and another interviewer was hired to meet with the faculty. Ten interview questions were used. The entire undergraduate population of 428 students from all levels (freshmen, sophomores, juniors, and seniors) and 71 undergraduate faculty and administrators were invited to participate. The final sample consisted of 33 percent of the student population completing the survey with eighteen percent being interviewed. Several interesting findings resulted from the study:

Finding 1: Students [sic] first choice for research was the Internet;

Finding 2: No formal plan existed at the institution to teach information literacy;

Finding 3: Stakeholders [sic] perceptions differed in regard to technology;

Finding 4: Confusion existed between understanding the meaning of information literacy/computer literacy;

Finding 5: Librarians were an untapped resource [students do not ask librarians for assistance];

Finding 6: Students lacked knowledge about performing effective online searches; Finding 7: Many faculty did not assess students' references;

Finding 8: Faculty requirements impacted students' choice of references; Finding 9: Students and administrators provided more feedback than faculty;

Finding 10: Stakeholder collaboration was needed. (Costantino, 2003, pp. 277289)

Her recommendations included implementing an Information Literacy Action Plan for which she outlined very specific stages. 


\section{CONTENT DOMAIN FOR INFORMATION LITERACY}

As with all studies, there were limitations identified with this one. Costantino (2003) admitted that the use of qualitative data rather than quantitative created cause to question the objectivity of the responses. She also pointed out that the respondents were not randomly selected, so there could be some bias in the participants' responses. The fact that only undergraduate students and faculty were selected to participate in the project, while library professionals were excluded indicates that not all stakeholders invested in information literacy were involved.

The third study that was examined closely in preparation for this current research follows up on Costantino's (2003) fourth finding that confusion exists on the part of faculty in regards to the definition of information literacy. In his research study, A Case Study of Faculty Perceptions of Information Literacy and Its Integration into the Curriculum, McAdoo (2008) contended that confusion compounds the problem of educating faculty of all academic disciplines as to the meaning of information literacy and hinders its incorporation across the higher education curriculum. Because of the numerous definitions and interpretations of the term information literacy, and the fact that the substantial amount of literature related to the subject is predominantly generated from within the library and information science fields, McAdoo argued that non-library faculty have a limited understanding of the concept (McAdoo, 2008, p. 1). The author cited the information explosion and a movement toward a "knowledge economy" as reasons for a growing interest in information literacy in higher education, as well as the recent emphasis placed on student learning outcomes and information literacy by accrediting agencies and other external reviewers. However, attempts to inculcate information literacy instruction across the curriculum and involve faculty from other academic disciplines is hampered by a common misperception that instruction in information literacy is the responsibility of librarians. 


\section{CONTENT DOMAIN FOR INFORMATION LITERACY}

The purpose of McAdoo's research was twofold: 1) to develop an understanding of how faculty members conceptualize the meaning of information literacy; and 2) to identify faculty perceptions in regard to their responsibilities and those of librarians when it comes to providing instruction in information literacy. He attempted to answer several research questions:

1. What are faculty members' beliefs and attitudes towards incorporating information literacy into the curriculum?

2. What are the obstacles in the implementation of information literacy instruction faced by the faculty?

3. What are the best approaches to information literacy instruction perceived by the faculty?

4. Who is perceived by the faculty to have primary responsibility for providing information literacy instruction?

5. How do the faculty members' demographic characteristics relate to their understandings and perceptions of information literacy and information literacy instruction?

6. How do the understandings and perceptions of information literacy and information literacy instruction differ among the faculty from different academic disciplines? (McAdoo, 2008, p. 6)

The theoretical framework or foundation for the study was his premise that the concepts related to information literacy parallel those of "learning organizations" because both are instrumental in encouraging lifelong learning (McAdoo, 2008). The author described the significance of his study: 


\section{CONTENT DOMAIN FOR INFORMATION LITERACY}

While much has been written about students' information skills and about existing information literacy programs, little has been written about faculty understanding of information literacy and its integration into the curriculum. This study attempts to contribute to the literature of information literacy by providing an evidence-based foundation for both discussion and subsequent study of faculty perceptions and understandings of information literacy in higher education.

(McAdoo, 2008, p. 10)

Choosing to use a case study method, McAdoo utilized both quantitative and qualitative methodologies for collecting his data. To assess faculty perceptions of information literacy and their understanding of their roles, as well as those of librarians, in information literacy instruction, he utilized a 12-question survey designed internally. To improve the validity of the survey, McAdoo used several reviewers to analyze the questions and evaluate the relationship of the survey questions to the study's research questions. The final survey was electronically administered via email to all faculty members who had an assigned university email address. SPSS was used to analyze the survey responses.

The qualitative component of his research was conducted in the form of a document analysis, during which he examined institutional documents to identify if and how information literacy had been incorporated into the existing general education curriculum and other important academic materials that describe the university, such as its latest self-study for a recent reaccreditation review.

The study was conducted at Edinboro University of Pennsylvania (EUP) that had a student population of less than 8,000 undergraduates and graduates combined, as well as over 


\section{CONTENT DOMAIN FOR INFORMATION LITERACY}

400 faculty members. A sample of 166 faculty or approximately $38 \%$ of the 400 -plus faculty participated as respondents in the survey component of the study.

McAdoo identified seven major findings as a result of his research:

Despite a clear and consistent definition at the institutional level, ..., most faculty perceive IL and existing IL instruction as being a more technology, skillsbased concept than a process, cognitive-based one. In terms of incorporating IL into the curriculum, faculty seemed to have mixed understandings about the importance of IL and curricular expectations regarding such. Even so, there seems to be general agreement that it should be a part of all levels of the curriculum. Similarly, faculty generally agree that the best approach to providing IL instruction is one that is integrated into the entire curriculum and that all faculty should share responsibility for such. However, the key challenge to doing so is a lack of knowledge about IL. (McAdoo, 2008, p. 163)

McAdoo's (2008) research study was particularly important in helping this researcher to identify issues that had to be addressed in regard to how faculty misperceptions of the concepts of information literacy affected the results of the Concept Mapping/Pattern Matching process utilized in this study. These concerns were addressed in Chapter 5, in the conclusion to this study.

\section{The Role of the Academic Library in Developing Information Literacy Skills in Students}

Library instruction has been an important function included in the many services offered by reference or public service librarians for over a century (Grassian \& Kaplowitz, 2009). For decades, academic librarians have provided orientation sessions to introduce all levels of college students to the ever increasing array of information resources, as well as to instruct them 


\section{CONTENT DOMAIN FOR INFORMATION LITERACY}

in recommended strategies for conducting research or for completing specific assignments. Early in the 1980s, library orientation had become bibliographic instruction, during which the class sessions focused on specific research tools that were introduced within the context of a search strategy framework (Grassian \& Kaplowitz, 2009). The outcome of these early instruction classes resulted primarily in students learning how to organize their approach to research and allowed librarians to disseminate bibliographies of reference tools relevant to the subject of the course and promote resources available in the library's collections. However, evaluating the quality of the sources of information, determining the relevancy of the results of a search, and explaining the ethical use of the information identified for inclusion in an assignment are also critical components of many library instruction classes. Therefore, academic librarians in the United States and Europe were more readily prepared to weave the concepts of information literacy into their instruction sessions and took the lead in promoting the need to incorporate it across the K-12 and higher education curricula. As a result, on many college campuses, the library may still be the sole organization for fulfilling the responsibility of teaching information literacy skills (Badke, 2005), though in many cases librarians are actively involved in collaborative programs to promote information literacy as a student learning goal. The literature on library instruction and information literacy includes a continually expanding number of reports from library instruction coordinators or reference librarians demonstrating increasing success in establishing collaborative programs with faculty in specific academic departments or integrating information literacy instruction into cross-curricular programs such as learning communities, core courses in general education programs, and first year experience programs (Breivik, 1998; Eschedor Voelker, 2006; Gardner et al., 1986; Lindstrom \& Shonrock, 2006; Warner, 2008). Research has shown that the most successful examples of students developing 


\section{CONTENT DOMAIN FOR INFORMATION LITERACY}

information literacy competency are the result of teaching faculty and librarians working collaboratively to inculcate the skills into the curriculum (Booth \& Fabian, 2002; McAdoo, 2010).
All of these efforts recognized that for "on ground" and "online" students to acquire necessary information literacy skills, discipline-based faculty must be collaborative partners in the learning process across the curriculum, courses must be intellectually linked to each other whenever possible, information literacy skills must be reinforced and developed over time, and students must have built-in opportunities for success from freshman to senior levels. (Rockman, 2002, p. 187)
In Raspa and Ward's (2000) book, The Collaborative Imperative: Librarians and Faculty Working Together in the Information Universe, the chapter by Walter, Ariew, Beasley, Tillman, and Ver Steeg (2000) presented five case studies of exemplary programs that demonstrated different ways library professionals and faculty created successful partnerships and the benefits they achieved. They included collaboration through course-integrated instruction at Earlham College; the creation of instructional teams in a first-year experience program at Indiana University-Purdue University at Indianapolis; a faculty rotation program at Evergreen State College that "requires librarians to rotate onto a faculty team for one quarter out of every nine" (Walter, pp. 56-67) and places librarians in the classroom and faculty members in the library; by the librarians offering workshops on the use of instructional technology tools such as web-page creation to faculty at the University of Washington; and through the position of faculty outreach librarian at Virginia Polytechnic Institute and State University.

For those libraries that have not been proactive or successful in developing joint programs with faculty in other academic departments, there are a number of publications 


\section{CONTENT DOMAIN FOR INFORMATION LITERACY}

advocating the need to integrate information literacy theory throughout the campus culture by partnering with faculty and administrators (Booth \& Fabian, 2002; Breivik, 1998; Breivik \& Gee, 1989). McAdoo (2010) argued that the most important purpose for building relationships between faculty and librarians is to create more effective assignments for student learning. "Assignments are the bridges between the classroom and true learning" (p. vii).

\section{The Importance of Assessing Library and Information Literacy Instruction}

Library instruction services and, more recently, recommended practices for teaching information literacy skills have been common topics of higher education publications for over forty years, particularly in the professional literature for librarians. In her survey article that reviewed the literature on information literacy up to 2002, Rader (2002) stated that more than 5,000 publications related to library instruction and information literacy had been published and reviewed since 1973. The majority of these articles and books were written by librarians and concentrate on the importance of and best practices for providing these services to library users. Until recently, relatively few of these earlier publications from library practitioners addressed the need for and difficulties in assessing the effectiveness of library instruction programs in fostering library or information literacy skills in students (Rader). That does not mean that research and recommended guidelines in that area did not exist. Since information literacy is often incorporated as one of several student learning outcomes recommended for general education programs and lifelong learning, discussions of their importance in the curriculum and methods for their assessment are often incorporated into literature generated by education assessment specialists and student development theorists (Jones, E. A., 2002; Kuh \& Gonyea, 2003).

Evaluating the quality of library instruction programs and the results of information literacy education on the development of these skills in the undergraduate student were the focus 


\section{CONTENT DOMAIN FOR INFORMATION LITERACY}

of many recent research publications from practitioners in the profession (Avery, 2003;

Davidson et al., 2002; Maughan, 2001; Oakleaf, 2009; Rabine \& Cardwell, 2000; Samson, 2010). These studies were conducted at different types of institutions of higher education varying in size and levels of programming. The subject of the research also varied, some evaluated the effectiveness of the instruction program by surveying key stakeholders on campus; or assessed the achievement of information literacy skills in the student through the use of assignments or tests. In addition, numerous guides providing best practices for establishing assessment programs appear regularly in the professional literature marketed primarily to librarians (ACRL, 2003; Baldwin, 2008; Lindauer et al., 2004; Neely, 2006; Warner, 2008). In 2003, Avery and several other colleagues in the library profession produced one of the most noteworthy compilations of recommended assessment practices centering specifically on information literacy instruction written by and targeted for academic librarians. The book, Assessing Student Learning Outcomes for Information Literacy Instruction in Academic Institutions, began by explaining in detail how to plan for assessment, what to consider when selecting and creating assessment tools, and how to analyze resultant data and report results. Several chapters then provided suggestions, guidelines and sample tools that library staff can apply to assessing information literacy instruction in specific disciplines or general education programs. This comprehensive resource concluded with numerous examples of assessment practices implemented at various institutions of higher education.

The creation of consistent and valid assessment tools for measuring the achievement of information literacy outcomes is also steadily increasing. Maughan (2001) reported on one of the earliest assessment programs initiated in 1994 at the University of California-Berkeley. The Survey of Information Literacy Competencies, as it is called, is administered to graduating 


\section{CONTENT DOMAIN FOR INFORMATION LITERACY}

seniors in selected academic departments to measure their basic information literacy skills. Maughan summarized the long-term results of conducting the survey over a period of years by concluding that students think they know more about accessing information and library resources than they are able to demonstrate. Neely (2006) included two chapters in her book Information Literacy Assessment: Standards-Based Tools and Assignments on the complex process of developing reliable instruments for assessing information literacy and the possibilities of automating them.

\section{Establishment of Standards for Measuring Information Literacy Competency}

Zurkowski (1974) was attributed with being the first to use the phrase information literacy in the report he submitted to the National Commission on Libraries and Information Science (NCLIS) and described the type of individual he believed to be information literate. To Zurkowski, "people trained in the application of information resources to their work can be called information literates. They have learned techniques and skills for utilizing the wide range of information tools as well as primary sources in molding information solutions to their problems" (p. 6). The American Library Association's (ALA) Presidential Committee on Information Literacy's (1989) Final Report not only established a definition that has been adopted by and cited in numerous publications, though predominately within the library field (Eisenberg et al., 2004), but it also created a foundation for the organization's standards for information literacy competency that were to follow in 2000 . "To be information literate, a person must be able to recognize when information is needed and have the ability to locate, evaluate, and use effectively the needed information" (p. 1).

Using the ALA definition as a spring board, Doyle (1992) focused her research study on trying to achieve consensus from expert stakeholders to develop a cohesive definition and a 


\section{CONTENT DOMAIN FOR INFORMATION LITERACY}

model of outcome measures for information literacy. By obtaining the feedback and opinions of participants representing the then 46 organizations of the National Forum on Information Literacy (NFIL), Doyle was able to develop for the first time on a national level a set of outcomes in the form of ten attributes for measuring information literacy.

Not all educators accepted ALA's Final Report immediately. The definition, application, standards and expected learning outcomes were argued by librarians for the next ten years (Grassian \& Kaplowitz, 2009; Snavely \& Cooper, 1997). In their 1997 article "The Information Literacy Debate," Snavely and Cooper highlighted many of definitions that were being heavily debated by librarians at the time and the arguments from proponents and opponents regarding the coupling of the terms information and literacy, confusion between information literacy and bibliographic instruction, and the lack of clarity or standards as to what defined an information literate person. In an effort to satisfy the need for standards, the American Association of School Librarians (AASL), a division of ALA took the lead and in 1998 published the first information literacy standards for K-12. In 2000, the Association of College and Research Libraries (ACRL), another division of ALA, issued Information Literacy Competency Standards for

\section{Higher Education.}

\section{Emergence of the Knowledge Society and the Needs of the Knowledge Worker}

Publications advocating for a reformation of the nation's education system or the development of information literacy standards and its instruction in the schools and across the curriculum often cite the same driving force, no matter what name they use - the information explosion, the Information Age, or the emergence of the Knowledge Society (Breivik \& Gee, 1989; Breivik \& Gee, 2006; Demo, 1986; Jones, 2002;). When explaining the demand for information literacy, Demo (1986) wrote: 


\section{CONTENT DOMAIN FOR INFORMATION LITERACY}

What unites most forecasters is a sense that the full benefits of an information age - primarily economic in nature — will be available only to those possessing the necessary tools. In fact, if there is one common prescriptive thread that runs through the writings of futurists and forecasters, it is the repeated admonition that what we badly need is a new intellectual skill, an "information literacy," that will enable us to be masters of the new communications and information technologies, whether for our personal success or wellbeing, for the greater good of the larger information society, or for the benefit of the power elite in whose employ we might well find ourselves. (pp. 5-6)

As the end of the $20^{\text {th }}$ Century approached, many leaders in government, industry, and education joined in the emerging trend to prognosticate possible changes in society, the economy, global politics, and their own areas of expertise. Peter F. Drucker was one of the most prolific in publishing the effect that a major shift from the industrial age to the Knowledge Society, where the majority of workers would be employed in the Knowledge Industry, would have on the United States and other industrialized nations in the latter half of the 20th Century.

By the end of this century knowledge workers will make up a third or more of the work force in the United States — as large a proportion as manufacturing workers ever made up, except in wartime. The majority of them will be paid at least as well as, or better than, manufacturing workers ever were. And the new jobs offer much greater opportunities. (Drucker, 1994, p. 5)

According to Drucker (1993), the one institution that may have the greatest impact in preparing the new knowledge workers, but could also experience the most significant change as a result of the new society is the education system - the nation's schools: "Indeed, no other 


\section{CONTENT DOMAIN FOR INFORMATION LITERACY}

institution faces challenges as radical as those that will transform the school. The greatest change, and the one we are least prepared for, is that the school will have to commit itself to results" (Drucker, p. 209).

Spurred on by the adoption of and general acknowledgment that the world had moved into the Information Age and the obvious influence that information and computing technologies were having on nearly every function of the populations of advanced nations, the federal and state governments funded several studies examining current trends in areas of national importance resulting in various publications of note, some of them mentioned previously. Of those reviewed, all of them pointed in one way or another to the shift from an economy dependent upon a manufacturing or an industrial-based labor force to that of a highly-skilled, information or knowledge-based personnel and demanded significant improvements in the U.S. education systems to develop a more literate and competent workforce.

The nation's schools must be transformed into high-performance organizations in their own right. Despite a decade of reform efforts, we can demonstrate little improvement in student achievement. We are failing to develop the full academic abilities of most students and utterly failing the majority of poor, disadvantaged, and minority youngsters. (Secretary’s Commission on Achieving Necessary Skills, 1991, p. ii)

An important and controversial report, A Nation at Risk: The Imperative for Education Reform was published by the National Commission on Excellence in Education, a group of 18 current or former practitioners in leadership positions in education, industry, or public office selected by the Secretary of Education, then T. H. Bell. The charge of the Commission included “assessing the quality of teaching and learning in our Nation's public and private schools, 


\section{CONTENT DOMAIN FOR INFORMATION LITERACY}

colleges, and universities; ... assessing the degree to which major social and educational changes in the last quarter century have affected student achievement; and defining problems which must be faced and overcome ...” (pp. 1-2). Recognizing a downward shift in the country's global dominance in industry and the emergence of the Knowledge Society, the Commission wrote:

Knowledge, learning, information, and skilled intelligence are the new raw materials of international commerce and are today spreading throughout the world as vigorously as miracle drugs, synthetic fertilizers, and blue jeans did earlier. If only to keep and improve on the slim competitive edge we still retain in world markets, we must dedicate ourselves to the reform of our educational system for the benefit of all—old and young alike, affluent and poor, majority and minority. Learning is the indispensable investment required for success in the "information age" we are entering. (p. 7)

At the end of their study, the Commission presented five groups of recommendations with several components attached to each. Although the report did not make any specific references to information literacy, the commission included key outcomes often associated with achieving information literacy in their first group of recommendations dealing with curriculum content: "The teaching of English in high school should equip graduates to: (a) comprehend, interpret, evaluate, and use what they read; (b) write wellorganized, effective papers; ...” (p. 25).

Six years later in 1990, the U.S. Secretary of the Department of Labor, Elizabeth Dole, responded to similar concerns from leaders in commerce and industry about changes in the skills and competencies required of the future workforce in the United States by creating the 


\section{CONTENT DOMAIN FOR INFORMATION LITERACY}

Secretary's Commission on Achieving Necessary Skills (SCANS). The commission, composed of leaders in business and education, was charged to appraise the changing work environment and determine whether young people entering the workforce will be equipped with the skills to meet the needs of those workplaces. In their 1991 report, What Work Requires of Schools: A SCANS Report for America 2000, members of the commission predicted a future that "depends on high-performance work organizations and a highly competent workforce" (Secretary's Commission on Achieving Necessary Skills, p. 2). For a student to graduate with the know-how they need in order to be ready to enter this newly defined workforce or to continue on with their education, the commission identified five competencies and a three-part foundation of skills and personal qualities that they believed are essential for success. These characteristics are the minimum requirements; they do not represent the attributes necessary for excelling. The five competencies included:

- Resources: Identifies, organizes, plans, and allocates resources

- Interpersonal: Works with others

- Information: Acquires and uses information

- Systems: Understands complex inter-relationships

- Technology: Works with a variety of technologies (SCANS, 1991, p. 10)

The three-part foundation was sub-divided into Basic Skills, Thinking Skills, and Personal Qualities. Basic Skills represented reading, writing, performing arithmetic and math, listening and speaking. Thinking Skills were defined as "thinks creatively, makes decisions, solves problems, visualizes, knows how to learn, and reasons" (SCANS, 1991, p. 14). Personal Qualities were displayed when the person demonstrated responsibility, self-esteem, sociability, self-management, and integrity and honesty. 


\section{CONTENT DOMAIN FOR INFORMATION LITERACY}

Each of the five competencies and the three elements of the foundation were accompanied by additional criteria or examples that represent the expected skills a high school graduate should be able to demonstrate. While the report did not refer specifically to information literacy, the outcomes that were included to measure Information Competency are very similar to those standards incorporated in later documents, like the ACRL Standards, that attempt to establish specific outcomes. The following skills were enumerated:
A. Acquires and Evaluates Information
B. Organizes and Maintains Information
C. Interprets and Communicates Information
D. Uses Computers to Process Information (SCANS, 1991, p. 10)

More recently, when the presidents of the National Academy of Sciences, National Academy of Engineering, and the Institute of Medicine were asked in 2005 by members of Congress to assess what it would "take to enhance the science and technology enterprise so that the United States can successfully compete, prosper, and be secure in the global community of the $21^{\text {st }}$ Century," (Rising Above the Gathering Storm, Revisited, 2010, p. ix) they created a committee of 20 highly respected Americans who, at that time, were either current or former CEOs, university presidents, scientists, philanthropists, former government officials, and education leaders to consider the issue.

The committee responded to their charge by producing a report entitled Rising Above the Gathering Storm: Energizing and Employing America for a Brighter Economic Future. Within the report, they identified four principal recommendations of which improving the United States' K-12 education system, particularly in science and mathematics, was their highest priority. In 


\section{CONTENT DOMAIN FOR INFORMATION LITERACY}

addition to the four recommendations, the members of the original Gathering Storm committee suggested 20 implementing actions, ten of which were related specifically to education. They argued:

If Americans are to compete for quality jobs in such a world-one where three billion new would-be capitalists entered the job market upon the restructuring of many of the world's political systems late in the last century - they will need help from their government . . . at all levels . . . as well as from themselves. The latter includes preparing for the growing educational demands of quality jobs and continuing to maintain their skills in a circumstance where the half-life of new technical knowledge may be measured in terms of a few years or, in some cases, even a few months. (Rising Above the Gathering Storm, Revisited, 2010, p. 19)

Heavily supported bi-partisan legislation was introduced following the release of the committee's report and the America COMPETES authorization act was passed in 2007, but very little funding was approved in the 2008 fiscal year budget to support their recommendations.

In 2010, all but three of the original committee members agreed to reconvene as a group to evaluate global conditions and events that had occurred during the five years following the completion of the first report and to assess the level of progress made, if any, in the accomplishment of the 20 implementing actions designed to establish a foundation for the United States to create quality jobs so it can compete and prosper in the future. As they conducted research to determine the condition of various factors within the United States, such as economic growth, quality of education, support for research and development, and job creation to name a few; and how the country 


\section{CONTENT DOMAIN FOR INFORMATION LITERACY}

compared to other industrialized nations in the global community, the committee identified several issues for concern, some of them summarized in a list of 64 world facts that included:

- The World Economic Forum ranks the United States $48^{\text {th }}$ in quality of mathematics and science education. ...

- In 2000 the number of foreign students studying the physical sciences and engineering in the United States graduate schools for the first time surpassed the number of United Students. ... .

- GE has now located the majority of its R\&D personnel outside the United States. ... .

- Manufacturing employment in the U.S. computer industry is now lower than when the first personal computer was built in $1975 \ldots$

- The United States ranks $20^{\text {th }}$ in high school completion rate among industrialized nations and $16^{\text {th }}$ in college completion rate. ..

- Almost one-third of U.S. manufacturing companies responding to a recent survey say they are suffering from some level of skills shortage... . (Rising Above the Gathering Storm, Revisited, 2010, pp. 6-11)

The revised report from the committee was populated throughout with similar indications of decline in the nation's manufacturing and industrial base, education system, and potential for economic development. Yet, the members of the committee identified one factor, that being innovation, that may assist future American populations in maintaining acceptable levels of existence. Historically, innovation has been a characteristic commonly attributed to the economic success of the United States. The authors of The Gathering Storm, Revisited (2010) 


\section{CONTENT DOMAIN FOR INFORMATION LITERACY}

confirmed the earlier predictions of Drucker (1994), Candy (2000), etc. in their report by defining the main components of innovation to be new knowledge or knowledge capital, an educated workforce that can adapt to rapid advances in knowledge, and an environment that fosters innovation. "Employers indicate that knowledge demands on all employees are higher than ever. . It has increasingly become recognized that to be competitive in the global technology-dominated marketplace requires a highly qualified workforce" (Rising Above the Gathering Storm, Revisited, 2010, p. 47).

Unfortunately, the overall assessment summarized at the end of the report by the committee is that "in balance, it would appear that overall the United States long-term competitiveness outlook (read jobs) has further deteriorated since the publication of the Gathering Storm report five years ago" (Rising Above the Gathering Storm, Revisited, 2010, p. $65)$.

\section{Concept Mapping/Pattern Matching as an Assessment Methodology}

The name concept mapping has been used by different researchers to describe several variations in the methodology, though the actual processes and results differ. A review of the literature related to the use of conceptualization methods and pattern matching revealed that there have been numerous studies conducted since 1960 offering various recommended procedures. Trochim (1985) provided a detailed survey of a number of the conceptualization methods that were published and in use in the 1960s, 1970s and early 1980s. Lawless, Smee, and O'Shea (1998) updated and added considerably to the catalog of researchers who published studies using variations of concept mapping and concept sorting. In general, individuals or a group of key stakeholders generate a number of statements linked specifically to the issue being addressed. The statements are classified according to similarities in wording or ideas and 


\section{CONTENT DOMAIN FOR INFORMATION LITERACY}

clustered together. Borders are drawn around the clusters to create a map or picture of the main concepts or priorities associated with the topic as they were identified by the participants, providing a conceptual representation of what the participants were thinking (Trochim, 1985). Some of the techniques are more informal and focus on identifying individuals' mental models of concepts (Jackson \& Trochim, 2002). However, Trochim also described "a more formal group process tool that includes a sequence of structured group activities linked to a series of multivariate statistical analyses that process the group input and generate maps" (Jackson \& Trochim, p. 312). It is this formal approach to concept mapping/pattern matching that was applied to this study. Trochim is the Director of the Cornell Office for Research on Evaluation and Director of Evaluation for the Weill Cornell Clinical and Translational Science Center at Cornell University located in Ithaca, NY. He is the 2009 Past-President of the American Evaluation Association (AEA) and is the Chair of the AEA Evaluation Policy Task Force (Cornell University, 2009).

Trochim has authored or co-authored several research studies related to a wide array of issues in education, health care, conflict management, mental health, psychology, and public policy in which he used this methodology. In 2003, he assisted the Hawaii Department of Health $(\mathrm{HDOH})$ in a project designed "to engage local stakeholders and national subject area experts in defining the community and system factors that affect individuals' behaviors related to tobacco, nutrition, and physical activity" (Trochim, Milstein, Wood, Jackson \& Pressler, 2003, Abstract). An underlying purpose of the project was to gather feedback from as many expert stakeholders as possible in a very short period of time to shape the decisions to be made in determining the use of Hawaii's tobacco settlement funds that could benefit the overall future health of the population. In 1998, 46 states received a portion of the $\$ 206$ billion settlement negotiated from 


\section{CONTENT DOMAIN FOR INFORMATION LITERACY}

the tobacco industry by the U.S. Attorneys General. Each state used different methods for determining how the funds would be utilized and for what purpose. Using Trochim's method of concept mapping, "the officials of the Hawaii Department of Health (HDOH), while working under intense time pressure, were able to meaningfully involve multiple stakeholders in setting outcome objectives for their portion of the tobacco settlement fund" (Trochim et al., p. 1). Eighty participants were selected for the project, 34 health professionals and community agency and coalition leaders from within Hawaii; and a group of 46 participants made up of experts in community and systems change from outside of the state, including representatives from the Centers for Disease Control and Prevention and the American Evaluation Association. At the end of the first stage of the process, a list of 496 statements consisting of community and systems factors related to tobacco use, nutrition, and physical activity was generated from live brainstorming discussions and via a project website. Once sorted by $\mathrm{HDOH}$ staff to remove redundant statements, the list was condensed to 90 unique statements (Kane \& Trochim, 2007). Out of the original group of eighty participants, eleven conducted their own individual sorts of the statements by grouping them into piles of similar statements, and then between 14 and 19 participants rated the statements according to importance and feasibility. Following a quantitative analysis of the scores, the concepts were mapped into clusters and a label was assigned to each cluster, thereby identifying the primary categories with which the factors were associated, as well as their order of priority and feasibility. This allowed participants to determine which factors were of a higher priority and more likely achievable. The groups were labeled: Policies and Laws, Environment Infrastructure, Access, Children and School, Coalitions/Collaborations, Community Infrastructure, and Information Communication. "The 


\section{CONTENT DOMAIN FOR INFORMATION LITERACY}

process was perceived by multiple stakeholders to have a high degree of credibility" (Trochim et al., p. 9).

This approach to concept mapping/pattern matching has been successfully utilized in an increasing number of studies conducted by other researchers, particularly in the social sciences, health sciences, and education. Brown (2008) used Trochim's methodology in several studies related to the placement of children in foster homes, particularly in identifying the issues encountered by foster parents (also Brown \& Calder, 1999). In their 1999 study, Brown and Calder used concept mapping to examine the challenges of foster parents. Brown's independent study (2008) examined the factors that foster parents perceived to be necessary for foster placements to be successful. Using telephone interviews with foster families identified on a randomized list, Brown was able to establish a sample of 63 foster parents to participate in his study. The parents were asked to describe "what would make them end a foster placement and what they needed for a successful foster placement?" (Brown, 2008, p. 543). The first question about ending a foster placement was addressed in a separate article published in 2006 (Brown \& Bednar, 2006). For the second question related to the successful foster placement, the initial number of statements collected was 221; however after these were de-duped and redundant statements were removed, 79 statements remained. Twenty of the participants continued with the next phase of the study to sort the responses according to similarities. "Multidimensional scaling placed the statements spatially on a map and cluster analysis placed the points into aggregates" (Brown, p. 544). The statements that appeared closer together on the map were those sorted in similar groups by the majority of the participants. Those that were farther apart were judged to be dissimilar by more participants. Using the quantitative data generated by the 


\section{CONTENT DOMAIN FOR INFORMATION LITERACY}

cluster analysis and labeling the groups of statements suggested by the concept map, the following criteria pointing to successful foster placements were identified:

Cluster \#1-Personality and Skills [of foster parents]

Cluster \#2-[Need for] Information About Child

Cluster \#3-Relationship with Agency

Cluster \#4-Personalized Services [help at the right time]

Cluster \#5-Community Support

Cluster \#6-Foster Family Networking [with other foster parents]

Cluster \#7-Supportive Family [extended family]

Cluster \#8-Look After [one’s] Self (Brown, 2008, pp. 545-549)

An example of concept mapping being used in the health sciences was reported by Rao, Alongi, Anderson, Jenkins, Stokes, and Kane (2005) whose study focused on developing public health priorities for End-of-Life (EOL) initiatives. Over 200 key stakeholders with expertise in EOL issues such as aging, cancer, chronic disease, etc. were invited to participate. Interestingly, instead of coming together as a group, the participants used a secure website, mail or a fax to accomplish the brainstorming and sorting sessions. As a result of the process, 124 statements regarding EOL issues were generated and sorted into nine clusters. From the nine, five clusters were selected because they were considered to be the most feasible. The complete process involved two similar studies, the results of which aided the stakeholders in developing short and long term recommendations for public agencies dealing with EOL issues to consider.

Kane and Trochim (2007) include a list of 66 dissertations that were completed between 1985 and 2006 using Trochim's method of Concept Mapping/Pattern Matching. A review of the titles indicated that the purpose of several of these studies was to elicit stakeholders' perceptions 


\section{CONTENT DOMAIN FOR INFORMATION LITERACY}

of concrete components of their home, work, or school environments with which they have a particular relationship or vested interest; or abstract concepts or issues they encounter in the same environments (Kane \& Trochim, 2007). One such study, of a very complex nature was Michalski's (1999) dissertation entitled Stakeholder Variation in Perceptions About Training Program Evaluation. The researcher, Michalski, was interested in knowing if the type of specific stakeholder group would be an influence on the perceptions a member of that group has of training results and the relative importance an individual places on specific types of training. In addition, he was trying to assess the effect that a stakeholder's training results impact that person's evaluation of the training. His investigation included whether stakeholders preferences vary in regard to specific evaluation methods in relation to their perceptions of training results (Michalski, 1999).

For his study, Michalski (1999) chose a department that is part of the research and development division of a multinational network design and engineering company. The division has a population of approximately 13,000 employees. "The purpose of this study was to add to the limited knowledge of stakeholder variation in training program evaluation particularly in a complex organization of knowledge workers" (Michalski, Abstract). The author identified three training stakeholder groups - training program sponsors, training participants or trainees, and training program providers. The type of training generally offered to the employees in this department consisted "primarily of policies, procedures, products, and services in the areas of training needs assessment, design/development, instructional deployment, course-level evaluation, and administrative support" (Michalski, p. 98). The author used two research questions, though both included follow-up questions: 


\section{CONTENT DOMAIN FOR INFORMATION LITERACY}

To what extent do training stakeholder groups differ in their perceptions of training results and the relative importance of such? What are the key dimensions of divergence? (Michalski, p. 5)

Do stakeholder views about training evaluation depend on the training results they perceive? If so, in what ways? (Michalski, p. 7)

The population of the division used as a focus group included approximately 800 local, full-time technical and managerial personnel. In the first part of the study involving concept mapping/pattern matching, Michalski (1999) used a sample of 39 stakeholders represented by 13 program sponsors, 13 training specialists, 13 training participants. For phase two, 15 program stakeholders randomly selected from the phase one sample, including five program sponsors, five training managers, five training participants, were invited for one-on-one semi-structured interviews. Finally, the third phase involved mailing 415 four-page surveys to randomly selected members of the population. Out of the 415 who received surveys, 280 (a $70 \%$ response rate) engineers and general line managers responded (Michalski, 1999).

The methodology used in the study consisted of three phases. In the first phase, Michalski (1999) used Trochim’s Concept Mapping/Pattern Matching to identify individual stakeholder group perceptions of training results for the first research question. Participants were asked to "generate statements ... that describe specific training program results that would contribute to the success of [the organization] over the next 12 to 24 months" (p. 105). Research question two was addressed directly in the second phase of the study by a series of one-on-one, private interviews involving members from each stakeholder group. The interviews were semistructured using an interview guide to facilitate the interviews. During the interviews, participants were asked to share their views and ideas about the purpose, processes, and 


\section{CONTENT DOMAIN FOR INFORMATION LITERACY}

outcomes of training program evaluation. They were also asked how well the concept map for their group represented their personal views about training results. All of the interviews were taped, transcribed, and coded for analysis. Phase 3 of the research involved the use of a questionnaire administered to two large stakeholder groups - management who sponsor the training and training participants. The purpose of the survey was to corroborate results across phases and to further address the second research question by focusing on the relationship between stakeholder views about training program evaluation and the training results.

The product of the first stage in the Concept Mapping/Pattern Matching process was 219 raw response statements being generated. After removing redundant statements and clarifying terminology, the results were reduced to 100 statements. These were delivered to the 39 participants for sorting and rating. Respondents were asked to rate each statement according to their perception of the statement's importance as a training result and as a training evaluation criterion. After the sorted and rated results were received, the data were entered into a database so it could be compared within (intra) a group and between (inter) groups (Michalski, 1999). Labels were provided for the participants to name the piles according to how the statements were sorted. As a result of the data analysis and the interpretation session for participants to discuss the output, six cluster maps were created. According to Michalski (1999), the study findings suggest that stakeholder groups varied in the relative emphases and importance they placed upon a similar set of perceived training results. This set of results was characterized by both traditional and emergent indicators and reflected themes and concepts related to customer satisfaction, market competitiveness, product design and development, quality, business results, 


\section{CONTENT DOMAIN FOR INFORMATION LITERACY}

employee satisfaction, and productivity through the development of the intellectual capital of the organization. (p. 256)

Michalski (1999) identified the following limitations with his study: the study population did not include the perspectives of the most powerful individuals within the organization hierarchy - the CEO, the Board, etc.; and, while the researcher used three separate methodologies to thoroughly assess a broad response and corroborate his findings between the three phases, the study represents only one organization. In order to validate the research, the study should have been conducted across a range of organizational settings. Third, although the three methodologies used had been utilized individually before, there was no evidence at the time he conducted his research that the three were used in combination in any other single study, so it is impossible to compare the integrated results with another study. While the methods used for the first and third phases were based primarily on quantitative data, the second phase used a semi-structured interview involving qualitative analysis based on interpretations (Michalski, 1999).

A study that provided a very relevant foundation for the use of this methodology in the research study currently being described is Kronour's (2004) dissertation entitled Preservice Teaching Standards: What Skills Should First-Year Teachers Possess as They Enter the Field. Similar to this recent study, Kronour wanted to utilize the expertise of practitioners in a profession to identify criteria or standards they agreed were necessary for developing and demonstrating competency in a specific outcome and then compare the practitioners' list to a set of national standards established earlier by an international organization and adopted by professional accrediting organizations for similarities and differences in attributes. Kronour wrote that "the purpose of this research project was to develop a set of practitioner generated 


\section{CONTENT DOMAIN FOR INFORMATION LITERACY}

technology guides by employing the research methodology concept mapping/pattern matching $(\mathrm{CM} / \mathrm{PM})$ and then to compare those guides with the International Society for Technology Education/National Education Technology Standards (ISTE/NETS)” (Abstract). The ISTE published the NETS standards to prepare preservice teachers to assume a leadership role in using technology in the PK-12 classroom and by 2002, 43 states had adopted them to some degree, including the National Council for Accreditation of Teacher Education (NCATE). The researcher wanted to determine if these standards were effective in meeting the needs of new teachers "as compared to what practicing teachers, administrators, and faculty members in higher education see as the 'real' standards that teachers should practice in their classrooms" (p. 4).

The only research question asked was: "What are the technology related skills, attitudes, and abilities expected of preservice teachers upon graduation?" (Kronour, 2004, p. 6). To collect the data, Kronour assembled a group of eleven PK-12 and higher education practitioners comprised of 3 PK-12 teachers, 2 preservice teachers, 2 building administrators, 1 technology coordinator for a PK-12 school, and 3 higher education faculty members (p. 51). The six steps outlined in Trochim's (1989b) Concept Mapping/Pattern Matching process were conducted. As a result of the brainstorming session conducted by the focus group, the first step in the methodology, and the subsequent de-duping of redundant statements, the list of criteria that was developed included approximately 95 skills that a preservice teacher should possess upon graduation. After the data were sorted into similar piles by the focus group and they rated them according to importance and perceptions of success (Kronour, p. 63), six clusters of responses were created using the $\mathrm{CM} / \mathrm{PM}$ process. The researcher completed the analysis by conducting a comparative evaluation that examined how those clusters compared with the ISTE/NETS standards. 
CONTENT DOMAIN FOR INFORMATION LITERACY

Kronour identified five conclusions from the results of the comparative analysis of the CM/PM Practitioner Clusters (the feedback from the practitioners) and ISTE/NETS Standards:

First, positive disposition/ attitude was not mentioned in the ISTE/NETS Standards at all. Second, skills and applications are viewed in the CM/PM Practitioner Clusters as key elements. Third, communication was viewed as critical in both sets of guides. Fourth, diversity was given much focus in the ISTE/NETS Standards. Finally, specific examples were given that may improve the ISTE/NETS Standards based on the results of the CM/PM Practitioner Clusters. (Kronour, 2004, Abstract)

Limitations to Kronour's (2004) study included the fact the participants were selected and not randomly assigned to one of the two focus groups. This factor could have biased the results and limit the objectivity of the answers. Another issue with the focus group was that the members were selected without the researcher's knowledge of their level of technology training. During the data collection, the focus group's responses were coded so the interpretation became subject to the coding by the recorder (Kronour, 2004).

\section{The Contribution of This Study to the Literature}

The significance of this research study is the fact that it adds to a relatively small body of information that attempts to assess the relevance of national standards established to measure information literacy skills in college students when they are applied to a mid-sized regional university. Conducting this study at this time was particularly appropriate since the most noted and applied national standards for information literacy were finalized and published in 2000, over a decade ago. Since then, many organizations and institutions of higher education have adopted the standards as a framework for establishing local student learning outcomes related to 
CONTENT DOMAIN FOR INFORMATION LITERACY

achieving information literacy competency, however very few institutions have reexamined their adoption of those standards. 
CONTENT DOMAIN FOR INFORMATION LITERACY

\section{Chapter Three}

\section{Methodology}

The purpose of this study was to evaluate the relevance of national standards established to assist institutions of higher education in identifying learning outcomes for teaching and achieving information literacy competency in undergraduate college students.

\section{Restatement of the Problem}

Within the past ten years, most regional higher education accrediting commissions incorporated information literacy as one of the many student learning outcomes to be assessed and reported by colleges and universities seeking reaccreditation. Four of the six commissions include the assessment of the library and information literacy instruction in with standards related to student learning. One commission had a standard devoted specifically to assessing the academic library, its resources and the information literacy programs of the institution (NEASC, 2005). In keeping up with other literature describing the future learner, the sixth commission predicts the information and technology literacy needs of the knowledge worker (HLC, 2003). In 2003, the Middle States Commission on Higher Education (MSCHE) published a document separate from its accreditation standards manual that offers guidelines for integrating information literacy throughout the curriculum.

The regional accrediting agencies are not the only formal organizations that brought to the forefront the need for significant changes in the focus of all levels of education to improve student learning and to develop standards for assessing the achievement of general competencies beyond discipline-specific knowledge. Government agencies and task forces at the national and state level, professional accrediting organizations, and industrial leaders have published their concerns. 


\section{CONTENT DOMAIN FOR INFORMATION LITERACY}

As a result of these efforts and the increased attention to information literacy highlighted by the professional literature dedicated to education and library science (Samson, 2010), the achievement of information literacy competency is frequently incorporated as one of the student learning outcomes in general education programs, course syllabi, institutional mission statements and public mandates (Davidson et al., 2002; Louisiana Board of Regents, no date; \& Maryland Higher Education Commission, 2010). Among the many stakeholders at colleges and universities with vested interest in or responsibility for instilling information literacy skills in students, academic and student affairs administrators have become more keenly aware of the role of the library in satisfying this requirement, either individually or in collaboration with other faculty. To assist in the assessment process, instruction librarians have adopted some or all of the Association for College and Research Libraries' (ACRL) Information Literacy Competency Standards for Higher Education as learning outcomes for their instruction sessions. Evaluating the effectiveness of these outcomes is an important component of the assessment process. Yet, as reported earlier, the ACRL task force that developed these standards included only two members who were not associated with the library profession. It is possible to question whether the process for establishing the standards included a fair representation of all of the types of stakeholders with responsibility for teaching or evaluating information literacy at institutions of higher education. Similarly, very few of the studies conducted at individual colleges and universities included information related to the process by which the specific outcomes these institutions are utilizing were selected. Finally, a review of the current literature related to the assessment of information literacy revealed that very few libraries have reevaluated the continued relevance of the student outcomes they had implemented earlier. 


\section{CONTENT DOMAIN FOR INFORMATION LITERACY}

\section{Significance of the Problem}

1n 1999, as the industrialized world was preparing for the advent of the $21^{\text {st }}$ Century, Donovan and Zald summed up the importance of information literacy by simply stating that "it is no longer possible to dismiss 'the information revolution' as hype” ( p. 1). A person does not have to look far to encounter evidence of the cosmic changes that have transformed how we learn, work, communicate and entertain ourselves by networked information technologies (Donovan \& Zald, 1999).

In 2006, Karl Fisch published in his popular PowerPoint presentation Did You Know that there were approximately 540,000 words in the English language, almost five times as many as during Shakepeare's time. According to the Global Language Monitor, the "English Language passed the Million Word threshold on June 10, 2009 at 10:22 a.m. (GMT). . . Currently there is a new word created every 98 minutes or about 14.7 words per day" (November 8, 2010). Google software engineers Alpert and Hajaj (2008) wrote on The Official Google Blog that when the first Google index was created in 1998, it had already indexed 26 million web pages; and in 2000, over one billion pages. At the time of their writing, on July 25, 2008, Google's search system recorded one trillion unique URLs. In 2009, there were over 131 billion Internet searches conducted worldwide, and Google's search engines were used for 87.8 billion of them, (Alpert \& Hajaj, 2008). Fisch (2007) asked "To whom were these questions addressed B.G.? (Before Google)" (Did You Know, slide 48). However, Kurzweil (2005) pointed out that, while the word "Google" has matured from a proper noun to a verb, search engines are flawed because they cannot understand how words are used in context. "Although an experienced user learns how to design a string of keywords to find the most relevant sites ... what we would really like to be able to do is converse with our search engines in natural language" (Kurzweil, 2005, p. 286). 
CONTENT DOMAIN FOR INFORMATION LITERACY

Drucker predicted in an article published in 1994 that, just as the United States experienced a major shift from an agrarian society to the industrial age at the beginning of the $20^{\text {th }}$ Century (Drucker, 1994; Kurzweil, 2005); the U.S. would evolve into the Knowledge Society in the $21^{\text {st }}$ Century, where the vast majority of workers would be employed in the Knowledge Industry.

Candy (2000) reinforced Drucker's prediction of the evolution of the knowledge worker and the need for future generations of the workforce to pursue lifelong learning. He placed the responsibility for teaching the skills needed by these new professionals in order to continue to seek and be able to apply knowledge on institutions of higher education.

For Candy (2000), the skills that graduates will need include the ability to find "things out for themselves through disciplined inquiry;" the ability to "apply what they know;" the ability to understand "insights and methods derived from various field of study and practice;" and the ability to "explain what they know" (p. 275). Each of these outcomes compare very closely to the competencies that are associated with information literacy and critical thinking. Identifying and incorporating the correct outcomes needed for an information-literate, knowledge-based society is a critical step in the development of curriculum and programs that will adequately prepare higher education graduates to succeed in their future occupations and personal fulfillment.

\section{Research Questions}

This study attempted to answer the following research questions:

RQ 1: When using Concept Mapping/Pattern Matching methodology, how do key stakeholders at a mid-sized regional Mid-Atlantic university conceptualize student outcomes for information literacy? 


\section{CONTENT DOMAIN FOR INFORMATION LITERACY}

RQ 2: How does conceptualization generated through Concept Mapping/Pattern Matching at a mid-sized regional Mid-Atlantic university compare and contrast with the framework established by the Association of College and Research Libraries?

\section{Methodology}

As mentioned previously, the purpose of this study was to assess the relevancy of national standards for information literacy when applied to the establishment of student learning outcomes for achieving information literacy at a mid-sized regional university. Evaluating the effect of library instruction on the development of information literacy skills in the undergraduate student was the focus of many recent research studies (Maughan, 2001; Oakleaf, 2009; Samson, 2010; Warner, 2008). Increasingly, assessment tools have been developed by college and university libraries to evaluate the success of their instruction programs in instilling information literacy competency to students (ACRL, 2003; Avery, 2003; Baldwin, 2008; Lindauer et al., 2004; Neely, 2006; Warner, 2008). Upon close review, the majority of these tools only measured achievement, they did not necessarily validate whether the objectives established by the institution were applicable. One approach for evaluating the appropriateness of student learning outcomes is to gather input from those individuals in the organization or a representative sample that have a specific interest in ensuring student success in achieving information literacy competency. A few quantitative studies using surveys that provided a means for stakeholders such as faculty, librarians, students, and administrators to rate the applicability of existing student learning outcomes were conducted previously (Davidson et al., 2001; Doyle, 1992; Gullikson, 2006). However, surveying participants can limit the opportunity for interested practitioners to identify other, perhaps more appropriate measures for the institution. On the other hand, the use of a qualitative methodology involving interviews may not 


\section{CONTENT DOMAIN FOR INFORMATION LITERACY}

supply the quantifiable data that would validate the resulting consensus of objectives. With these issues in mind, this researcher decided to use Concept Mapping/Pattern Matching as the methodology for collecting and analyzing the research data. Unlike the Delphi Technique which requires the participants to respond to follow-up surveys in order to come to a consensus of opinion (Brewer, 2007), when using Trochim's (1989b) Concept Mapping/Pattern Matching methodology, the results of each participant's card sort and rankings are considered to be of equal importance, so participants can retain their individual perceptions throughout the process.

The name concept mapping has been used by different researchers to describe several variations in the methodology, though the actual processes and results differ. Trochim (1985) provided a brief summary of a number of the conceptualization methods that were published and in use in the 1960s, 1970s and early 1980s. Lawless, Smee, and O'Shea (1998) updated and added considerably to the catalog of researchers who published studies using variations of concept mapping and concept sorting. In general, individuals or a group of key stakeholders generate a number of statements linked specifically to the topic being addressed. The statements are classified according to similarities in wording or ideas and clustered together. Borders are drawn around the clusters to create a map or picture of the main concepts or priorities associated with the topic as they were identified by the participants, providing a conceptual representation of what the participants were thinking (Trochim, 1985). Some of the techniques are more informal and focus on identifying individuals' mental models of concepts (Jackson \& Trochim, 2002). However, Trochim described "a more formal group process tool that includes a sequence of structured group activities linked to a series of multivariate statistical analyses that process the group input and generate maps" (Jackson \& Trochim, 2002, p. 312). It is this formal approach to concept mapping/pattern matching that was applied to this study. Trochim is the Director of the 


\section{CONTENT DOMAIN FOR INFORMATION LITERACY}

Cornell Office for Research on Evaluation and Director of Evaluation for the Weill Cornell

Clinical and Translational Science Center at Cornell University located in Ithaca, NY. He is the 2009 Past-President of the American Evaluation Association (AEA) and is the Chair of the AEA Evaluation Policy Task Force (Cornell University, 2009).

According to Trochim (1989b), concept mapping is a "type of structured conceptualization," using a process by which "ideas are represented in the form of a picture or map" (p. 1). Describing the potential of concept mapping, Trochim (1989a) explained that it could be used to clarify the relationship between social research theory and practice:

From the outset it was important to establish: 1) that the concept mapping process provided an accurate representation of what people were thinking (i.e., reliability and validity), and; 2) that the concept maps could be integrated into scientific theory-building and experimentation. (p. 23)

This methodology has been found to be particularly useful in strategic or program planning and evaluation (Trochim, 1989b), or similar activities that generally seek group participation in an organized, collaborative environment yet offer statistical reinforcement of the results.

A six step process, the end result of Concept Mapping/Pattern Matching is a conceptual framework (Trochim, 1989b) or a visualization of the interrelationship between relevant concepts, phrases, and terms; such as goals, objectives, standards, and policies; and their individual importance. Trochim defined a concept map to be "a pictorial representation of the group's thinking which displays all of the ideas of the group relative to the topic at hand, shows how these ideas are related to each other and, optionally, shows which ideas are more relevant, important, or appropriate" (p. 2). One of the many advantages to using this methodology is that it allows the participants, usually people who have an expertise in the focus of the study or a 


\section{CONTENT DOMAIN FOR INFORMATION LITERACY}

specific interest in the outcome of the process, to work toward consensus while maintaining their own individuality.

Typically, there are six steps associated with Trochim's methodology for Concept Mapping/Pattern Matching: 1) Preparation; 2) the Generation of statements; 3) the Structuring of statements [including rating the statements]; 4) the Representation of Statements in the form of a concept map; 5) the Interpretation of maps; and 6) the Utilization of Maps (1989b, Abstract). Each of these steps includes multiple procedures that are described in greater detail in Chapter Four describing how the methodology was used to gather the data and analyze the results for this study. "The analysis includes a two-dimensional multidimensional scaling (MDS) of the sort data and a hierarchical cluster analysis of the MDS coordinates" (Jackson \& Trochim, 2002, p. 312). The following is a description of Trochim's Concept Mapping/Pattern Matching process as it is generally applied in research.

Preparation. The first step in the process of developing a concept map, as in the case of many research studies, is preparation. Two major activities must occur during the preparation stage: selecting the participants and defining the focus of conceptualization or concentration for the group. Selecting the participants of the study is the first and one of the most important steps in the Preparation stage of the concept mapping process. Trochim (1989b) pointed out that "the scenario with which concept mapping is applied assumes that there is an identifiable group responsible for guiding the evaluation or planning effort" (p. 2). Due to the nature of the study in which relevant input is being solicited from those who have a vested interest in the issue being addressed, the number of participants can vary widely depending on the focus of the project; as well as the selection process used to assemble the members of the group. 


\section{CONTENT DOMAIN FOR INFORMATION LITERACY}

Identifying the focus of the study and clarifying it for the group is required for two stages of the process: the brainstorming session where the statements are generated and the structuring of the statements during which time they are rated based on specific criteria such as importance or level of relevance. "It is essential that the focus for both the brainstorming and the ratings be worded as statements which give the specific instruction intended so that all of the participants can agree in advance" (Trochim, 1989b, p. 4).

Generation of statements. The concept mapping process starts with the brainstorming session, during which the members of the group generate statements which "ideally should represent the entire conceptual domain for the topic of interest" (Trochim, 1989b, p. 4). Participants may express their ideas or statements in any order without fear of criticism or questions regarding relevance to the topic. The group may be given a limit as to the number of statements they can suggest for practical reasons. Trochim (1989b) recommended a predetermined limit of one hundred or less statements. The facilitator of the process records each statement as it is announced, assigning it a sequential number, and projecting the results in a manner that allows all those involved to view the entire set as it is being created. When all of the statements have been generated, the group conducts a final review of the set for clarity and understanding.

Structuring of statements. The third step requires the participants to identify how the statements interrelate by working independently to sort like statements together and rating each statement using the rating criteria defined in step one. Following the process utilized by Trochim (1989b), each of the statements generated in step two is printed on a separate card and each participant receives a complete set of cards. All members are asked to sort their individual set of the cards into piles "in a way that makes sense to [them]" (p. 5). The results of the individual 


\section{CONTENT DOMAIN FOR INFORMATION LITERACY}

sorts are recorded in a matrix that illustrates which statements were placed together in each of the member's piles. Then, a combined group similarity matrix is created by adding the individual matrices together so that the value in the group matrix represents how many people placed that pair of statements together in a pile. "This final similarity matrix is considered the relational structure of the conceptual domain because it provides information about how the participants grouped the statements" (Trochim, 1989b, p. 7).

Included in step three is the process whereby the participants are asked to rate each statement using the criteria identified in the rating focus statement that was established earlier. As mentioned before, these criteria may be based on importance, priority, or some other dimension established in step one. For Caracelli's study (1989) on the success of women participating in a college reentry program, the rating was based on the relevance of specific personality descriptors the respondents selected when completing the California Q-set. Trochim (1989b) pointed out the importance of this step for determining the arithmetic mean of the ratings for each statement and for gathering other statistical information. For this study, participants were asked to rate each of the items generated using two scales: 1) the relative importance of each item, and; 2) the overall efficacy with which Mid-Atlantic University is addressing that item in the curriculum.

Representation of statements. This step is the most complex, because it results in the creation of the conceptual maps using the data collected during step three. Trochim (1989b) described the process as having three stages:

First, we conduct an analysis which locates each statement as a separate point on a map (i.e., the point map). Statements which are closer to each other on this map were likely to have been sorted together more frequently; more distant statements on the map were in 


\section{CONTENT DOMAIN FOR INFORMATION LITERACY}

general sorted together less frequently. Second, we group or partition statements on this map in clusters (i.e., the cluster map) which represent higher order conceptual groupings of the original set of statements. Finally, we can construct maps which overlay the averaged ratings either by point (i.e., the point rating map) or by cluster (i.e., the cluster rating map. (p. 7)

To aid a researcher in fully understanding his methodology for Concept Mapping/Pattern Matching, Trochim (1989b) explained in great detail how to conduct each phase of the Representation of Statements. Due to the complexity of the process, it is important to cite his description exactly:

To accomplish the first step, the mapping process, we typically conduct a twodimensional nonmetric multidimensional scaling of the similarity matrix obtained from step 3. Nonmetric multidimensional scaling is a technique which takes a proximity matrix and represents it in any number of dimensions as distances between the original items in the matrix. (p. 7)

Trochim (1989b) expounded on this part of the analysis:

Multidimensional scaling is a multivariate analysis which accomplishes this task. It takes a table of similarities or distances and iteratively places points on a map so that the original table is fairly represented as possible. In concept mapping, the multidimensional scaling analysis creates a map of points which represent the set of statements which were brainstormed based on the similarity matrix which resulted from the sorting task. (p. 7) While presenting the next phase of the analysis, Trochim (1989b) provided a brief overview of some of the issues related to cluster analysis and the problems he and his associates 


\section{CONTENT DOMAIN FOR INFORMATION LITERACY}

encountered using different approaches to cluster analysis. In addition to explaining the purpose of the second phase of analysis, Trochim recommended how best to proceed:

The second analysis which is conducted to represent the conceptual domain is called hierarchical cluster analysis (Anderberg, 1973; Everitt, 1980). This analysis is used to group individual statements on the map into clusters of statements which presumably reflect similar concepts. ... We found that this could be accomplished by using the X-Y multidimensional scaling coordinate values for each point (rather than the original similarity matrix) as input to the cluster analysis. In addition, we also found that Ward's algorithm for cluster analysis (Everitt, 1980) generally gave more sensible and interpretable solutions than other approaches (e.g., single linkage, centroid). Therefore, we have moved to an approach which uses Ward's hierarchical cluster analysis on the XY coordinate data obtained from multidimensional scaling as the standard procedure. This in effect partitions the multidimensional scaling map into any number of clusters. (p. 8)

At this stage, it is necessary for the analyst to decide the number of clusters in which to group the statements. Trochim (1989b) recommended using a cluster tree to illustrate the possible clusters that can be created. He also suggested that the researcher should consider more clusters than fewer.

The final analysis involves obtaining average ratings across participants for each statement and for each cluster. These can then be overlayed [sic] graphically on the maps to produce the point rating map and the cluster rating map . . (Trochim, 1989b, p. 9) 
CONTENT DOMAIN FOR INFORMATION LITERACY

Interpretation of maps. The fifth step of interpreting the maps and labeling the clusters also involves many stages. Trochim (1989b) listed six products that are usually generated from the first four steps of the methodology:

1. The Statement List or the original list of statements generated from the brainstorming session.

2. The Cluster List, which is the Statement List rearranged into clusters by the cluster analysis.

3. The Point Map showing the numbers of the statements placed on the map as a result of the multidimensional scaling that occurred in Step Four.

4. The Cluster Map that shows how statements are grouped as a result of the cluster analysis.

5. The Point Rating Map which is described as "the number point map with average statement rating overlayed [sic]" (Trochim, 1989b, p. 9).

6. The Cluster Rating Map, similar to the cluster map but overlaid with the average cluster ratings. (p. 9)

When describing this step in his introductory article, Trochim (1989b) explained that in the first phase of this step, the participants were given copies of the original statements compiled in Step Two: the Generation of Statements. They were then given copies of the Cluster List, in which the original statements were rearranged into the clusters as a result of their sorting process that took place in Step Three: the Structuring of Statements. The members of the group were asked to review the statements associated with each cluster and to create a name or label describing the cluster. The participants were expected to work together to decide on one name for each cluster. When they reached a consensus, they were presented with copies of the Point 


\section{CONTENT DOMAIN FOR INFORMATION LITERACY}

Map and given time to examine the map to develop an understanding of the logic of where and why statements were placed as they were. On the Cluster Map, the group wrote the labels they agreed upon for each cluster. Following an examination of the Cluster Map and in discussion the participants may discover other groupings or clusters of clusters which can also be "combined" into regions and labeled. Trochim (1989b) explained that "this final named cluster map constitutes the conceptual framework and the basic result of the concept mapping process" (p. 11). Further discussion among the members of the group may be encouraged by sharing the Point Rating Maps and the Cluster Rating Maps. While some or all of these procedures are often included in this particular step; for this research study, the researcher determined the number of resulting clusters, similar to Kronour's (2004) study.

Utilization of maps. The final step in Trochim's (1989b) methodology for Concept Mapping/Pattern Matching involves additional input and discussion from the participants on "how the final concept map might be used to enhance either the planning or evaluation effort." (p. 12). For this particular study in which the focus was on identifying appropriate student learning outcomes for achieving information literacy at Mid-Atlantic University, the concept map could also be used in the development of specific measurement tools (Trochim, 1989b).

Benefits to using Concept Mapping/Pattern Matching. Trochim (1989b) enumerated several advantages to using his methodology for Concept Mapping/Pattern Matching:

"First, it encourages the participant group to stay on task and to lay out relatively quickly a framework for a planning and evaluation study. Second, it expresses the conceptual framework in the language of the participants rather than in terms of the evaluator's or planner's language or the language of social science theorizing. Third, it results in a graphic representation which at a glance shows 


\section{CONTENT DOMAIN FOR INFORMATION LITERACY}

all of the major ideas and their interrelationships. Fourth, this graphic product is comprehensible to all of the participants and can be presented to other audiences relatively easily. Finally, we have observed over many concept mapping projects that one of the major effects of the process is that it appears to increase group cohesiveness and morale." (pp. 15-16)

While the primary purpose of this particular research study was not to assist a group of stakeholders in planning or evaluation of a program, the researcher chose this approach to Concept Mapping/Pattern Matching for other specific reasons.

In order to determine the relevance of external standards established by a national organization to the achievement of outcomes identified at Mid-Atlantic University, it was necessary to seek input from the stakeholders at that institution who have a vested interested in information literacy. Other options for soliciting this kind of information included surveys or interviews.

As mentioned previously, the use of a survey might have generated more valid quantitative results that would have been useful in substantiating the statistical analysis. However, the participants' involvement would have been limited to evaluating the appropriateness of ACRL's standards for information literacy or the outcomes currently utilized by Mid-Atlantic University. There would have been little opportunity for the participants to suggest alternative outcomes unless the use of open-ended survey questions was included. In studies that include open-ended survey questions, the coding of participants' answers can be difficult and subjective. In fact, Jackson and Trochim (2002) argue for the use of concept mapping when analyzing open-ended survey responses. 


\section{CONTENT DOMAIN FOR INFORMATION LITERACY}

Interviews would have allowed participants the opportunity to suggest alternative outcomes for the institution should they feel there is a need. However, individual interviews conducted in isolation would have removed the collaborative benefit of having the entire group, all of whom are considered experts in their fields and having a vested interest in ensuring the success of undergraduates in achieving information literacy comprehension, discuss and substantiate or select together those outcomes that are appropriate. While individual recommendations may be identified in the transcripts of the interviews, coding the responses would have taken considerably longer to isolate those statements than would the entire concept mapping process and the results may not have been as significant.

\section{Participants}

Selecting the participants of the study is the first and one of the most important steps in the Preparation stage of the concept mapping process. Trochim (1989b) pointed out that "the scenario with which concept mapping is applied assumes that there is an identifiable group responsible for guiding the evaluation or planning effort" (p. 2). Due to the nature of a study in which relevant input is being solicited from those who have a vested interest in the issue being addressed, the number of participants can vary widely depending on the focus of the project; as well as the selection process used to assemble the members of the group.

For this particular study, the researcher identified a group of 18 individuals affiliated with Mid-Atlantic University to be invited to participate in the data generation stage, of which 14 agreed. Each of these invitees were selected because it was assumed that he or she had a responsibility or interest in ensuring that undergraduate students at the institution are being exposed to instruction designed to develop information literacy competency and that the students are achieving the appropriate outcomes associated with measuring their success with these skills. 


\section{CONTENT DOMAIN FOR INFORMATION LITERACY}

The composition of the group consisted of six teaching faculty who have actively incorporated information literacy into their course content or have collaborated with the University's library instruction faculty to develop ways in which the student learning outcomes for information literacy can be instilled and measured; three of the University's library instruction faculty, including the coordinator for library instruction; two students; and three professionals from the student affairs division. One of the representatives from student affairs was the director for career services who collaborates with the local business community and brought a perspective on what is expected by employers in regard to information literacy competency.

\section{Data Collection}

For the initial stage of data collection, the researcher followed Trochim's (1989b) six steps as they were outlined in the Methodology above. The participants were invited to meet in a room on Mid-Atlantic University's campus. Every effort was made to ensure the group members' physical needs were accommodated and that the environment was comfortable. It is essential that a collaborative and relaxing atmosphere is fostered to encourage participation and collegiality. Since the brainstorming session and sorting/rating session took a considerable period of time, refreshments were provided.

The researcher also solicited input via email from the two remaining library faculty and the one teaching faculty member who participated on the UEI Faculty Planning Group for Information Literacy in 2004 to collect information regarding the process they used to identify the eight student learning outcomes they recommended in their final report. Their responses, also by email, are summarized in Chapter Four along with the rest of the results from the study. 


\section{CONTENT DOMAIN FOR INFORMATION LITERACY}

\section{Treatment of the Data}

When Trochim (1989b) first described in detail his methodology for Concept Mapping/Pattern Matching, he included instructions on how readily accessible word processing software applications (i.e., Microsoft Word or WordPerfect, which was still popular at the time) and common statistical analysis software such as SAS or SPSS could be used to record the statements generated by the group, print them on the individual card sets, and provide the multivariate analysis to generate the cluster data. However, to utilize these programs, the researcher had to spend considerable time creating the necessary files and applications. The results of the data were analyzed using these programs and are described in detail in Chapter 4 of this study.

\section{Limitations of the Study}

This study had several limitations that were identified prior to the research being conducted. Additional limitations were discovered following the implementation of the research study and they are included in Chapter 4.

1. Although the use of Concept Mapping/Pattern Matching is gaining in frequency and popularity as a methodology very appropriate for planning and evaluation; as well as helping to discern meaningful inferences from data when univariate statistical tests do not reach statistical significance (Caracelli, 1989), there are stages of the process that require subjective involvement on the part of the analyst that could cause critics to question the validity of the study (Trochim, 1989a).

2. One of the limitations of this study includes the generalizability of the study. Although the data to be collected for this study may be applied to similar research related to the effectiveness of the academic library in improving information literacy 
skills, it may not be relevant to other studies assessing information literacy competency. Also, since the study will be conducted at a medium sized Master's L institution in a rural and geographically isolated environment, care will need to be taken when generalizing the data to another institution or overall population.

3. Much like emerging data mining techniques, Concept Mapping/Pattern Matching deviates from traditional Western epistemologies that employ Null Hypothesis Testing. Furthermore, Concept Matching/Pattern Matching does not involve sampling. This limitation is not methodological in nature, as Concept Matching/Pattern Matching utilizes credible and complex statistical techniques like multidimensional scaling and hierarchical cluster analysis. Regardless, Concept Matching/Pattern Matching is a methodology that mixes both quantitative and qualitative techniques. 
CONTENT DOMAIN FOR INFORMATION LITERACY

\section{Chapter Four}

\section{Results}

In this chapter, the results of the data collection process are reported and analyzed as they relate to the research questions. There are six sections to the chapter, beginning with a review of the purpose of the study, followed by the research questions in section two. The third section describes the population utilized in the study, how the Concept Mapping/Pattern Matching methodology was implemented resulting in the generation of the outcomes list and cluster map, and the subsequent rating of the outcomes by the participants. Analysis of the data produced by the Concept Mapping/Pattern Matching process and by surveying the focus group members is presented in the fourth section. In the fifth section, the researcher describes the process and results of a document analysis comparing the clusters generated by the study to the ACRL standards published in 2000. The final section of the chapter includes a discussion of the limitations of the study.

\section{Purpose of the Study}

The purpose of this study was to assess the relevance of a national association's standards designed to assist institutions of higher education in establishing learning outcomes for developing information literacy competency in undergraduate college students at Mid-Atlantic University, a Master's L Carnegie Classified university (Carnegie Foundation for the Advancement of Teaching, 2006) in Maryland. To accomplish this analysis, the researcher solicited the expertise of key stakeholders responsible for ensuring student success in achieving information literacy competency at the aforementioned institution to identify the outcomes they considered to indicate information literacy competency. The researcher used Concept Mapping/Pattern Matching as the methodology, specifically the process advanced by William 


\section{CONTENT DOMAIN FOR INFORMATION LITERACY}

Trochim (1989b), for gathering and analyzing the data to conceptualize the domain of desired information literacy skills. Following the creation of the concept maps by the study's participants, the resulting priorities and their conceptualization schema were compared to the national organization's standards and to the student learning outcomes associated with information literacy currently incorporated in Mid-Atlantic University's general education curriculum and the library's instruction program. The objective of this process was to begin to validate the relevancy of the existing outcomes at the national level to those applied locally through a comparison and contrast of precepts as they relate to the local student population.

\section{Research Questions}

By collecting the perceptions of key stakeholders at Mid-Atlantic University who were responsible for ensuring that the undergraduate students at that institution succeeded in achieving the student learning outcomes for information literacy competency and comparing them to standards established by a national organization, academic administrators may understand better the relevancy and significance of the recommended standards to the general education program at a mid-sized university community. Therefore, this study attempted to answer the following research questions:

RQ 1: When using Concept Mapping/Pattern Matching methodology, how do key stakeholders at a mid-sized regional Mid-Atlantic university conceptualize student outcomes for information literacy?

RQ 2: How does conceptualization generated through Concept Mapping/Pattern Matching at a mid-sized regional Mid-Atlantic university compare and contrast with the framework established by the Association of College and Research Libraries? 


\section{CONTENT DOMAIN FOR INFORMATION LITERACY}

\section{Population Selection}

Selecting the participants of the study is the first and one of the most important steps in the Preparation stage of the concept mapping process (Trochim, 1989b). Due to the nature of the study in which relevant input is being solicited from those who have a vested interest in the issue being addressed, the number of participants can vary widely depending on the focus of the project; as well as the selection process used to assemble the members of the group.

For this study, the researcher initially identified 18 individuals affiliated with MidAtlantic University to be invited to participate in the data generation stage. Each of these invitees were purposefully selected because it was assumed that he or she had a responsibility or interest in ensuring that undergraduate students at the institution were being exposed to instruction designed to develop information literacy competency. While the original intent of the researcher was to convene a focus group of approximately 12 people, it was decided that additional stakeholders should be asked in case someone declined the invitation or discovered later that he or she could not meet the time commitment. The resultant group of participants numbered 14.

The composition of the focus group consisted of six teaching faculty who had actively incorporated information literacy into their course content or had collaborated with the university's library instruction faculty to develop ways in which the student learning outcomes for information literacy could be instilled and measured; three of the university's library instruction faculty, including the coordinator for library instruction; two students; and three professionals from the student affairs division. As reported earlier, an underlying objective of this study was to determine whether the inclusion of more stakeholders representing other segments of the university with vested interests in teaching or achieving information literacy, 


\section{CONTENT DOMAIN FOR INFORMATION LITERACY}

such as students, student affairs professionals, and faculty from varying disciplines would facilitate a better understanding of the importance of information literacy competency for all participants, as well as result in the selection of different, more suitable outcomes than those currently adopted by the library and the institution. It had been noted that the type of information needed, the relevant resources to be consulted, and the skills required to seek, gather, and analyze data may differ between academic disciplines. Therefore, care was taken to solicit faculty members from each of the three colleges of Mid-Atlantic University: business, education, and liberal arts and sciences. Efforts were also made to ensure that the three faculty members from the College of Liberal Arts and Sciences represented the physical sciences, humanities, and the social sciences.

It had been shown in the review of literature that there is evidence of faculty and librarian collaboration in providing information literacy instruction; however, inclusion of input from student affairs administrators was noticeably missing both in the literature and in practice. While issuing invitations to prospective academic participants, the researcher was asked several times why members of the Mid-Atlantic University student affairs staff were included. The reasoning behind the question was that the academicians often thought of the student affairs division to consist primarily of administrative offices such as the registrar's office, financial aid, residence life, and student involvement. When reminded that the student affairs division at Mid-Atlantic University includes several educational support services for those students who are academically challenged, the faculty acknowledged the importance of including the staff responsible for providing that assistance in a study related to identifying student competency skills. Careful consideration based on job function was given as to which student affairs professionals would be invited to participate. For example, the researcher solicited the director of the university's career 
services since this individual collaborated with members of the business community and would have a perspective on what was expected by employers in regard to information literacy competency in Mid-Atlantic University graduates. Table 1 identifies the number of faculty, staff, and students that participated in the study and the administrative division, college when relevant, and the department with which they were affiliated:

Table 1

Participants in the Concept Mapping/Pattern Matching Focus Group by Division, College and/or Department

University Division, College, and/or Department

Participants

Academic Affairs Division

College of Business

College of Education $\quad 2$

College of Liberal Arts and Sciences

Biology Department

English Department

Political Science Department 1

University Library 3

Student Affairs Division

Assistant Vice President for Educational Services \& Registrar $\quad 1$

$\begin{array}{ll}\text { Career Services } & 1\end{array}$

PASS (Programs Advancing Student Success) 1

Undergraduate Students (in $4^{\text {th }}$ Year)

English 1

Political Science $\quad 1$ 
CONTENT DOMAIN FOR INFORMATION LITERACY

\section{Implementation of the Concept Mapping/Pattern Matching Process}

Preparation. The first step in the process of developing a concept map is preparation. Two major activities must occur during the preparation stage: selecting the participants and defining the focus of conceptualization or concentration for the group.

The selection of potential members to invite to participate in the focus group was based on the researcher's personal knowledge of specific faculty and staff at Mid-Atlantic University who indicated an interest or understanding of the importance of information literacy competency for undergraduates through their active participation in the library's instruction program, their involvement in the university's Center for Teaching Excellence, or their job responsibilities as outlined in the campus directory. Invitations were offered in person by the researcher who met with individuals in their offices to explain the purpose of the study, the procedures to be utilized, and the responsibilities of the focus group members. In those meetings and all subsequent communications with the participants, the researcher assured each individual that he or she was free to disassociate from the study for any reason at any time without any negative consequences.

Identifying the focus of the study and clarifying it for the group was required for two stages of the process: the brainstorming session where the statements were generated and the structuring of the statements during which time they were rated based on specific criteria such as importance and efficacy. For this particular study, the focus of conceptualization as it was the explained to participants was to answer one question: "What are the student learning outcomes for information literacy that the University should expect of its graduates?"

Generation of statements. The second phase of the concept mapping process started with the brainstorming session, during which the members of the group generated statements which "ideally should represent the entire conceptual domain for the topic of interest" (Trochim, 


\section{CONTENT DOMAIN FOR INFORMATION LITERACY}

1989 b, p. 4). For the generation of the statements, the Mid-Atlantic University faculty, staff, and students who agreed to participate in the focus group were invited to meet in a conference room in the campus library. Effort was made to ensure the group members' physical needs were accommodated and that the environment was comfortable. It was essential that a collaborative and relaxing atmosphere was fostered to encourage participation and collegiality since the brainstorming session and sorting process would take a considerable period of time.

The group was assembled prior to 9:00 a.m. on January 18, 2012. Upon their arrival, they were given a letter thanking them for their willingness to participate in the study, instructing them of the procedures, and formalizing their responsibilities and what they could expect during the process (see Appendix B for a copy of the letter). Again, they were reassured that if at any time they wished to conclude their involvement in the study they were free to do so without negative consequences. Following welcoming remarks, the facilitator of the session provided instructions to the group. Participants were encouraged to express their ideas or statements in any order without fear of criticism or questions regarding relevance to the topic. As is recommended by Trochim (1989b), the group was given a pre-determined limit of one hundred or less statements to generate in approximately one hour. The researcher fulfilled the role of recorder using a computer with a projector and screen to display the statements to the group as they were being recorded. Occasionally discussion between focus group members ensued and someone was asked for clarification of terminology, but generally the items were recorded verbatim as they were stated, which accounts for differences in voice and often incomplete sentences. A sequential number was assigned to each statement for reference. The brainstorming session lasted the previously determined hour and produced a final list composed of a total of 80 outcomes (see Appendix C). When all of the statements had been created, the group conducted a 


\section{CONTENT DOMAIN FOR INFORMATION LITERACY}

final review of the set for clarity and understanding. Following a short break, the facilitator began the next step of the Concept Mapping/Pattern Matching process.

Structuring of statements. The third step of Trochim's methodology requires the participants to identify how the statements interrelate by working independently to sort like statements together. During the brief break following the brainstorming session, the researcher printed each of the statements generated in step two on separate cards and each participant received a complete set of 80 cards. In addition to the card sets, each person received a pen, a stack of at least ten size-10 envelopes and a large manila envelope. All members were then asked to sort their individual set of cards into piles "in a way that makes sense to [them]" (Trochim, 1989b, p. 5). Four stipulations were given in the instructions from the facilitator: (a) the members had to work independently of each other, (b) each statement could only be used once, (c) the end result could not be one pile of 80 items, and (d) though there may be piles consisting of one statement, there could not be 80 piles of one card each.

Once the cards were sorted, the participants were instructed to put each pile in a separate size-10 envelope, seal the envelope, and record their name and a word or phrase on it that they felt represented or summarized the contents of that particular envelope. They placed all of their smaller envelopes inside their individual manila envelope, sealed it and wrote their name on the front. The researcher collected these larger envelopes and secured the data. As the focus group members completed this entire process, they were reminded that an email with a link to a survey would be sent to them in the next few days. The survey would include all 80 outcomes and the participants would be asked to rate each item according to its importance and the efficacy to which they think students are instructed in achieving these competency skills at Mid-Atlantic 


\section{CONTENT DOMAIN FOR INFORMATION LITERACY}

University. Finally, the members were thanked for completing the first phase of the data gathering process and given permission to leave.

Included in step three of the Concept Mapping/Pattern Matching process is the final responsibility of the focus group members whereby they are asked to rate each of the items generated according to two scales: the relative importance of each item and the overall efficacy with which Mid-Atlantic University is addressing that item in the curriculum. In some studies using this methodology, this activity takes place immediately following the card sort, while the group is still assembled. For this study, the researcher decided to use an Internet-based survey instrument, Survey Monkey, to create the survey so participants could respond to it online at their convenience, thus allowing them to leave after they completed sorting their cards and securing them in the envelopes. Trochim (1989b) points out the importance of this step for determining the arithmetic mean of the ratings for each statement which can be used to identify those clusters of outcomes that are deemed to be more important.

Six days after the brainstorming session, the 14 participants of the focus group were sent an email explaining the purpose of the survey and the link to Survey Monkey for accessing it. Using an ordinal scale, the respondents were asked two questions:

1. How relatively important do you believe this student learning outcome is for undergraduate students at [name of institution]? (very unimportant; unimportant; neutral; important; very important).

2. Overall, how well does [name of institution]'s curriculum help students develop this particular student learning outcome? (very poorly, poorly, neutral, well, very well). In the email, they were given six days to respond. Initially, 11 of the 14 focus group members responded to the survey by the deadline. A follow-up email was sent the day after the original 
CONTENT DOMAIN FOR INFORMATION LITERACY

due date and by February 13, 2012 all of the participants had responded. A copy of the survey is included in Appendix D.

\section{Data Analysis of the Results of the Concept Mapping/Pattern Matching Methodology}

Representation of statements. While waiting for the survey responses, the researcher recorded the results of the individual card sorts into an Excel spreadsheet that illustrated which statements were placed together in each of the member's piles. This was a time consuming process that required care to ensure that none of the envelopes were accidentally assigned to the wrong member or that the cards were mixed up between categories, and accuracy in manually typing the individual card numbers into the spreadsheet. The researcher worked with only one member's packet of envelopes at a time, and then opened only one of the size-10 envelopes to enter the card numbers exactly as they were sorted, sealing that envelope very securely before going onto the next. As the contents of each of the smaller envelopes were entered and the envelope was sealed, the researcher returned it to the large envelope and when all were back in the large envelope, it was sealed as well before starting on the next person's responses. To ensure that the researcher didn't miss a number or mistype a number, care was taken to account for numbers 1 through 80 for each participant and to make sure that exactly 80 numbers were listed in case the researcher typed an extra number twice by mistake.

The data was loaded into SAS (version 9.3), and using multidimensional scaling (MDS) a combined group similarity matrix was created so that the value in the group matrix represented how many people placed particular statements together in a pile. "This final similarity matrix is considered the relational structure of the conceptual domain because it provides information about how the participants grouped the statements. A high value in this matrix indicates that many of the participants put that pair of statements together in a pile and implies that the 
statements are conceptually similar in some way." (Trochim, 1989b, p. 7) The MDS function generated $\mathrm{x}$ and $\mathrm{y}$ coordinates for each item so it could be assigned a location on a twodimensional graph or point map (see Figure 1).

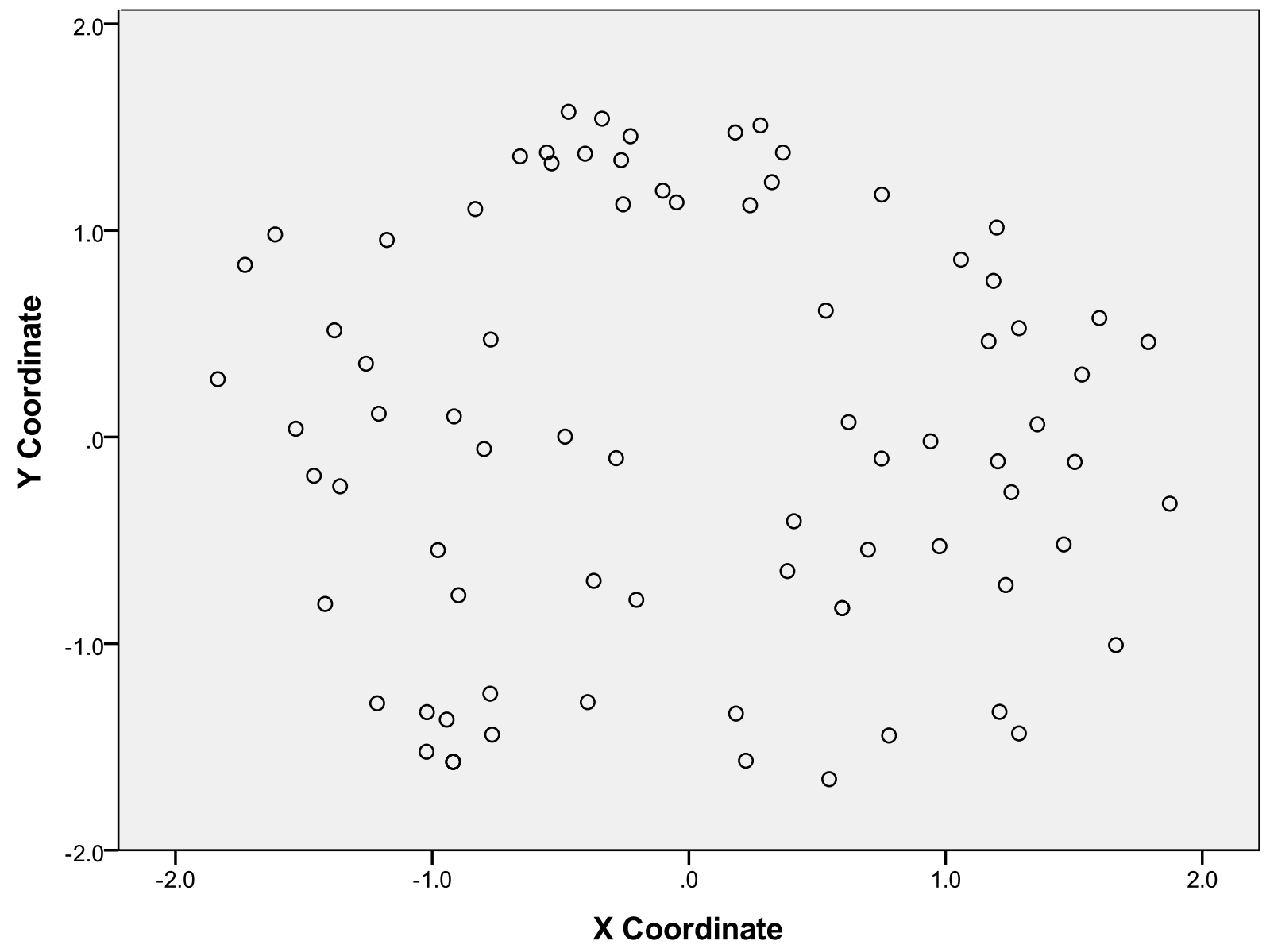

Figure 1. Point map with the 80 Concept Mapping/Pattern Matching statements.

Statements that were sorted together into the same pile by more participants appear closer to each other on the point map. Points that are separated by a distance on the map were less likely to have been sorted together. Figure 2 illustrates where the specific statements are located on the point map according to their $\mathrm{x}$ and $\mathrm{y}$ coordinates. The statements are identified by the sequential numbers they were assigned at the time they were created by the stakeholders. The complete list of the statements arranged in the order of their number is included in Appendix C. 


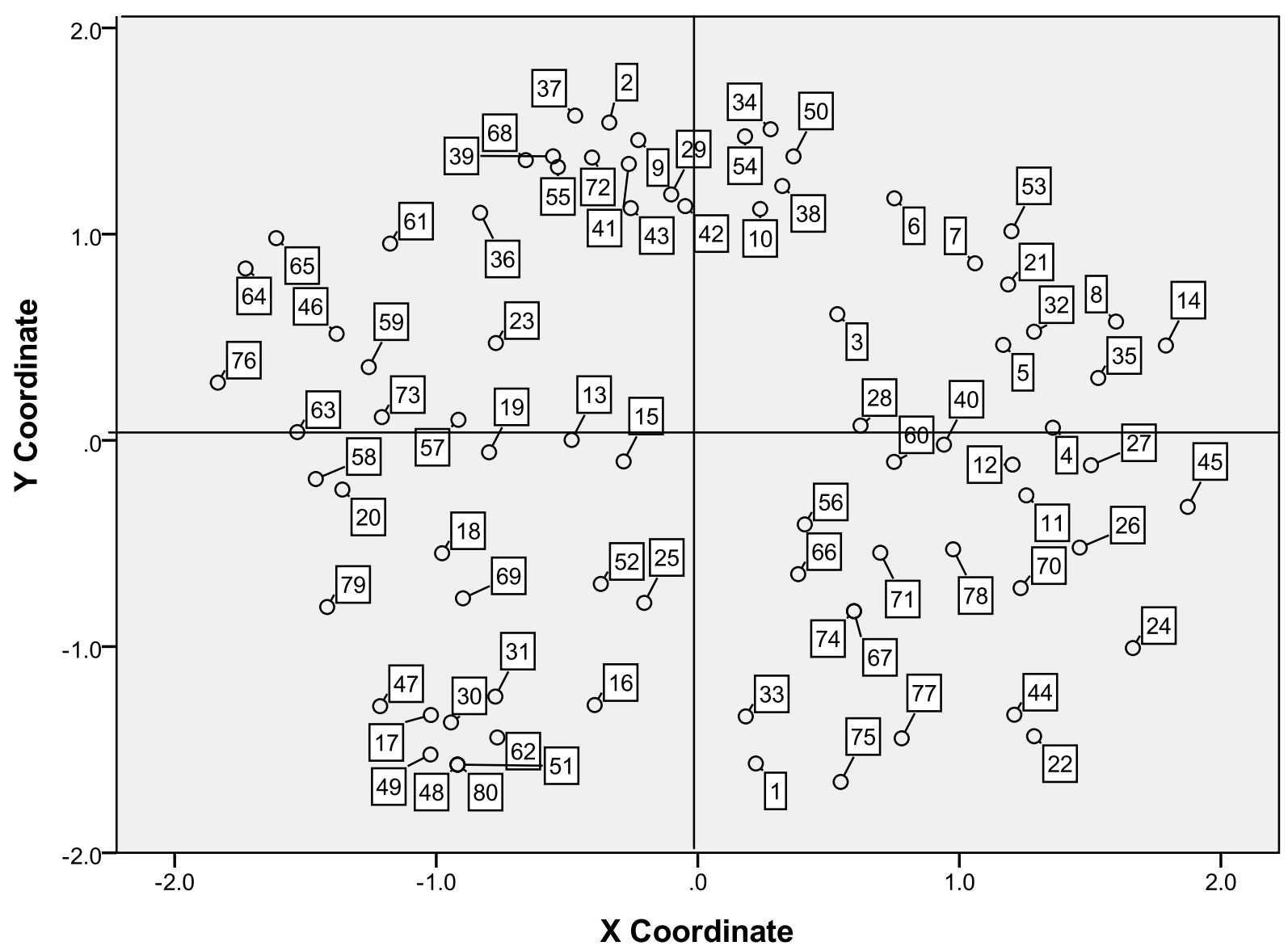

Figure 2. Numbered point map with the 80 Concept Mapping/Pattern Matching statements.

When looking at the upper left quadrant, it appears that items 39, 55, and 68 were grouped together frequently by the participants in their individual card sorts. Item 39 states "be able to corroborate information," item 55 is "evaluating the quality of evidence," and item 68 reads "look for credible evidence of both sides of an argument." All three of these statements refer to the ability to evaluate information for quality, accuracy, and credibility. However, the point map also demonstrates that item 76 (recognize the limits of their knowledge) in the upper left quadrant and item 45 (protocols for accessing private information) in the lower right quadrant are not in close proximity, therefore they were not sorted together by the participants. 


\section{CONTENT DOMAIN FOR INFORMATION LITERACY}

The $\mathrm{x}$ and $\mathrm{y}$ coordinates were also utilized to conduct a second analysis in IBM SPSS Statistics (version 20) called hierarchical cluster analysis (HCA). "This analysis is used to group individual statements on the map into clusters of statements which presumably reflect similar concepts." (Trochim, 1989b, p. 7) In his explanation of Concept Mapping/Pattern Matching, Trochim specifically identified using Ward's hierarchical cluster analysis (p. 8) which was applied in this study. The resulting output from the HCA, called the hierarchical cluster tree (HCT) or a dendrogram, showed how the items were arranged in clusters of similarly grouped statements, where each cluster splits from the other, and lists the specific items located in each cluster (see Appendix E).

The data analysis up to this point was quantitative, using complex statistical techniques like multidimensional scaling and hierarchical cluster analysis to generate the results. However, the next step in the Concept Mapping/Pattern Matching process required the researcher to decide the number of clusters in which to group the statements. As stated in chapter 3 describing the methodology, because Trochim’s Concept Mapping/Pattern Matching process necessitates subjective decision-making by the analyst it combines both quantitative and qualitative methodology. Although this was a qualitative decision on the part of the researcher, the decision was not made arbitrarily. The researcher was aided significantly by the cluster tree. The tree allowed the analyst to identify the possible clusters that existed and to evaluate them according to the items assigned to them. For this study, the researcher consulted with the focus group facilitator to determine the most logical number of clusters. The initial review of the HCT considered groupings ranging from five to ten clusters. By carefully analyzing the contents of each cluster, the researcher and facilitator concluded that the data was most logically grouped into eight clusters, though there was sufficient reason to consider seven to nine clusters. To 


\section{CONTENT DOMAIN FOR INFORMATION LITERACY}

make this determination, the researcher compared which clusters were combined to make seven and which cluster was divided to make nine (see Appendix F). In both comparisons it was decided that the items that were combined in the seven cluster grouping were sufficiently different to warrant two separate clusters and those items in the first cluster that were separated to create nine clusters showed a definite interrelationship that explained why they were grouped together in the 8-cluster configuration. Once the logical number of clusters was decided, each grouping was depicted on the point map by drawing lines between interrelated numbers to create borders around the clusters. The new map that resulted from this activity is called the cluster map. Figure 3 is an illustration of the cluster map with the eight clusters identified.

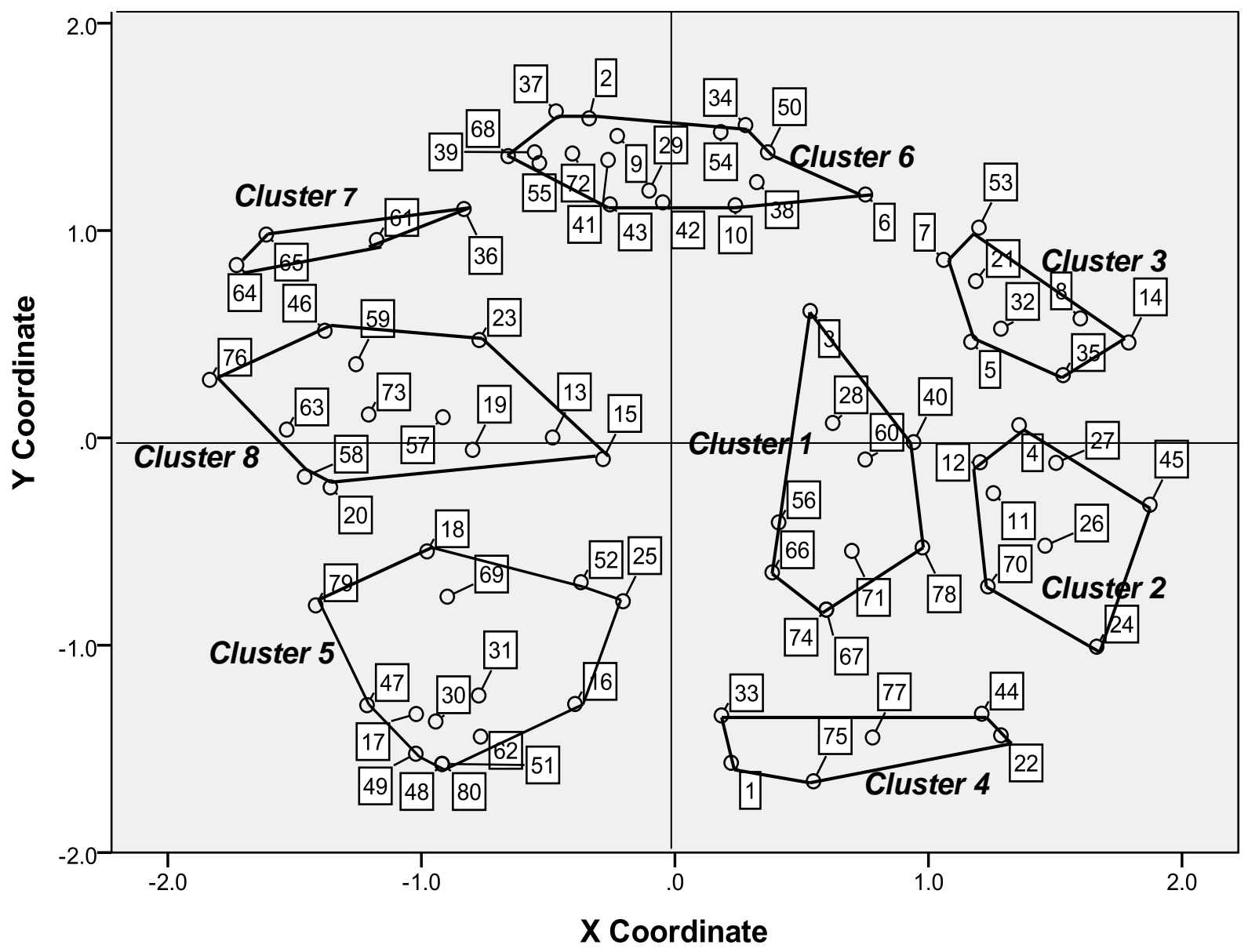

Figure 3. The Concept Mapping/Pattern Matching cluster map with the eight clusters identified. 


\section{Interpretation of maps. The fifth step of the Concept Mapping/Pattern Matching}

methodology required the researcher to interpret the list of statements sorted by cluster and label each cluster with a unique term or phrase that accurately reflects the primary concept identified by the items grouped within that cluster. The researcher, again in consultation with the facilitator, identified a label for each of the eight clusters (see Table 2).

Table 2

List of 80 Outcomes Generated by Focus Group, Organized into Clusters using Hierarchical Cluster Analysis, and Labeled

\begin{tabular}{|c|c|}
\hline Outcomes Generated by Focus Group & Cluster Label \\
\hline 67. Primary scientific discovery - identify the topic first & \multirow{10}{*}{ Research Process } \\
\hline 74. How to structure the information needed at the beginning - formulating a research question & \\
\hline 56. Understand the components of a research paper & \\
\hline 66. Ability to conduct an inquiry & \\
\hline 71. Being able to do basic information seeking or research on anything & \\
\hline 78. Autonomous in seeking information & \\
\hline 40. Narrow or revise search strategy and results & \\
\hline 60. Sequence of the scientific process & \\
\hline 28. Learning to pick out what extra resources can help them & \\
\hline 3. Proper date of an article & \\
\hline 26. Organizing, storing and backing up information & \multirow{8}{*}{ Technical Skills } \\
\hline 70. Avoiding information overload & \\
\hline 24. Awareness of security and personal privacy issues & \\
\hline 11. Understanding what they need to find & \\
\hline 12. A basic search strategy & \\
\hline 4. Using search terms effectively & \\
\hline 27. Being able to access the internet & \\
\hline 45. Protocols for accessing private information & \\
\hline 8. Online catalog & \multirow{8}{*}{ Selecting Sources } \\
\hline 14. Understanding the physical space and content of the library & \\
\hline 35. Able to manage information results electronically & \\
\hline 5. Where to look to find information & \\
\hline 32. Effective use of research tools in print and digital (i.e., indexes, etc.) & \\
\hline 7. Identifying appropriate discipline databases \& resources & \\
\hline 21. Assessing internet pages (.com, .gov) & \\
\hline 53. Understanding the difference between a database and the Internet & \\
\hline 22. Understanding the ethics of information use & \multirow{6}{*}{ Information Ethics } \\
\hline 44. Legal issues in the use of sources, copyright & \\
\hline 1. Proper documentation & \\
\hline 33. Manual citation of references & \\
\hline 75. Finding information for life after graduation & \\
\hline 77. Time management \& prioritization of tasks & \\
\hline
\end{tabular}




\section{CONTENT DOMAIN FOR INFORMATION LITERACY}

Table 2 (continued)

List of 80 Outcomes Generated by Focus Group, Organized into Clusters using Hierarchical
Cluster Analysis, and Labeled

25. Being able to formulate a strong thesis

52. Be able to construct attributive tags or signal phrases

16. Balance to your paper in what you present

31. Spelling \& grammar, correct punctuation, etc.

62. Ability to use language for the appropriate audience

17. Effective communication of the information

30. Ability to communicate information in a variety of ways to match learning style

48. Organizing information for an effective oral presentation

51. Understand their medium and their audience to adjust information

80. Ability to present personal information orally

49. Oral communication skills

47. Effective personal interviewing

18. Integrate the materials into a knowledge base

69. Reevaluate drafts and the "finished" product, conclusions, etc.

79. Confidence

29. Being able to analyze a text format (content,)

42. Understand the difference between statistical versus practical significance

43. Difference between quantitative and qualitative methods

39. Be able to corroborate information

55. Evaluating the quality of evidence

68. Look for credible evidence of both sides of an argument

2. Evaluating sources critically

37. Being able to identify bias in a resource

9. Critically assessing the credibility and thoroughness of a resource

41. Being able to evaluate the substantiality of the study

72. Be able to look for and find multiple explanations for the argument

10. Balance of the resource in regard to coverage

38. Be able to evaluate the results of a web search

34. Distinguishing between types of resources \& publications

54. Distinguish between abstracts, review articles and original research

50. Understanding of scholarly versus popular resources

6. Definition of primary, secondary, tertiary sources

64. The ability to accept challenges of their own perspectives and respond appropriately

65. The ability to challenge their own perspective

36. Have a healthy dose of skepticism

61. Identifying competing perspectives and responding to them effectively

13. Effective use of the materials found

15. Synthesizing the content of the article

19. Interpret the data and findings

57. Ability to summarize and synthesize the information in a resource

23. Using different strategies for understanding and comprehension

20. Drawing conclusions

58. Data driven decision-making for some disciplines

63. The ability to form an opinion

46. Social or scientific implications of the research being used

59. Recognizing that the answer is a combination of many resources

73. Be able to integrate new, multiple types of information

76. Recognize the limits of their knowledge

\section{Communication}

Evaluating Information

\section{Psychosocial Aspects}

\section{Information Utilization}


The labels were then overlaid on the corresponding cluster on the map to create the named cluster map (see Figure 4).

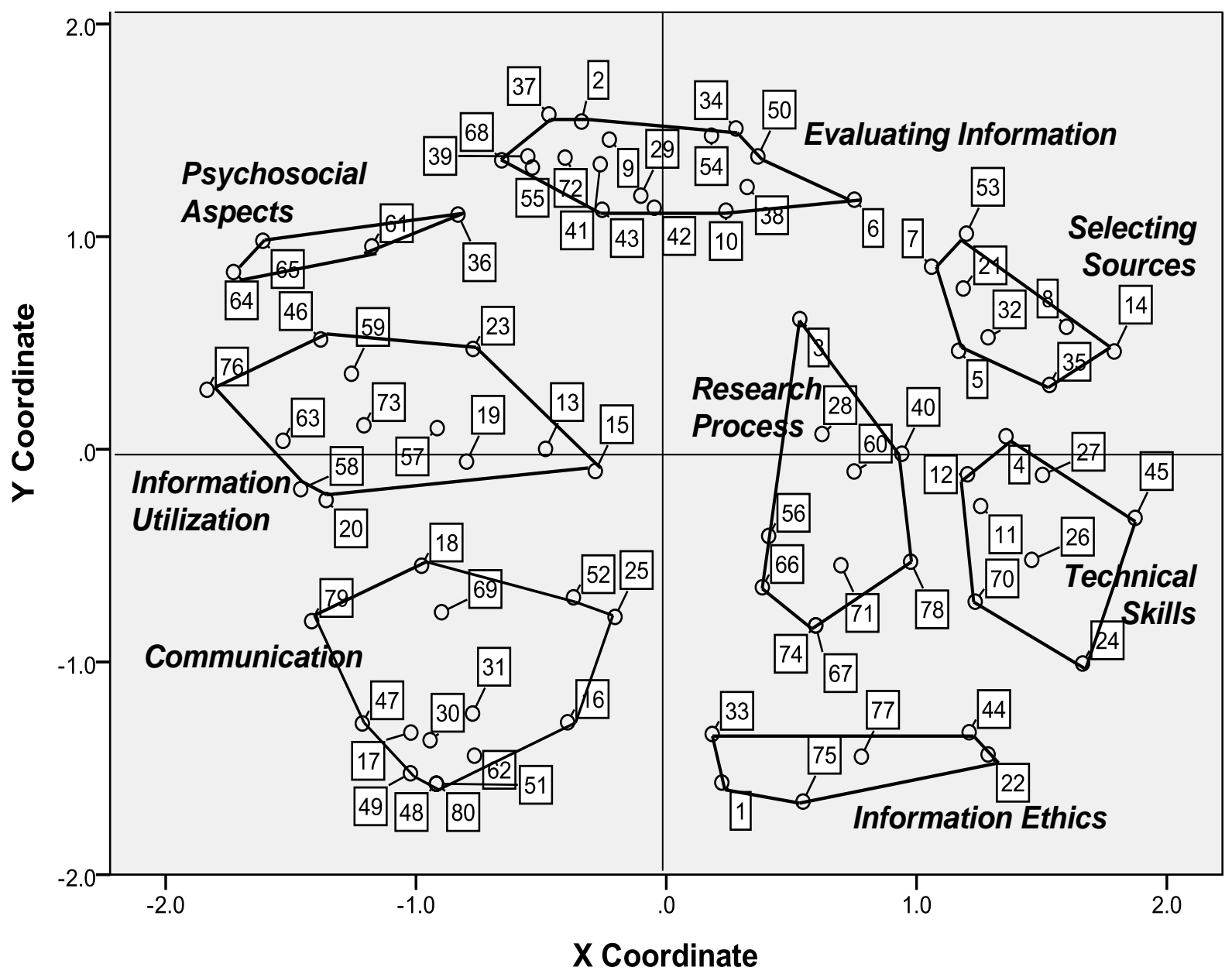

Figure 4. The Concept Mapping/Pattern Matching cluster map with the eight clusters named.

An examination of the named cluster map could result in identifying that other groupings or clusters of clusters could be "combined" into regions and also labeled. Trochim (1989b) explains that "this final named cluster map constitutes the conceptual framework and the basic result of the concept mapping process" (p. 11). The possibility of associating similar clusters within regions is examined more closely in Chapter 5 as a recommendation for future research. 
CONTENT DOMAIN FOR INFORMATION LITERACY

Applying the survey results to the Concept Mapping/Pattern Matching results. All

14 members of the focus group completed the survey in which they were asked to respond to the following questions as they related to the 80 statements they had generated:

1. How relatively important do you believe this student learning outcome is for undergraduate students at [name of institution]? (very unimportant; unimportant; neutral; important; very important).

2. Overall, how well does [name of institution]'s curriculum help students develop this particular student learning outcome? (very poorly, poorly, neutral, well, very well).

The survey responses were downloaded as an Excel spreadsheet and the mean score was calculated for every item in each question (see Appendix G). This data was uploaded into IBM SPSS Statistics (version 20) in order to calculate the arithmetic mean for each cluster from the statements' mean scores. The results allowed the researcher to sort the lists of outcomes and clusters by the scores to determine which skills the participants thought were more important and how effective the curriculum at Mid-Atlantic University is in developing these skills.

\section{Analysis of Resulting Data as It Relates to Research Question 1}

The first research question for this study asked "when using Concept Mapping/Pattern Matching methodology, how do key stakeholders at a mid-sized regional Mid-Atlantic university conceptualize student outcomes for information literacy?" The data for this research question was generated by the focus group during the brainstorming session. When asked the question: "What are the student learning outcomes for information literacy that the University should expect of its graduates?" the participants responded with 80 statements. These statements represented the student learning outcomes that were conceptualized by the key stakeholders at Mid-Atlantic University who participated in the study (see Appendix C). The numbers assigned 


\section{CONTENT DOMAIN FOR INFORMATION LITERACY}

to the outcomes identify the sequence in which they were generated by the focus group members. In the analysis that follows, the outcomes will also be referred to as statements or items.

Although there were a few similar statements, these reinforced some of the concepts and, when grouped together into the same cluster, often helped to strengthen the phrase used to name the cluster and its definition. Table 3 identifies the label assigned to each cluster and the definition created by the researcher to summarize the primary concept that emerged from synthesizing the statements in the group. These definitions represent the overarching goals for information literacy competency that can be used to organize the stakeholders' outcomes. The clusters are not arranged in any particular order other than how they were listed by the HCT. Table 3

List of Eight Clusters Created by Concept Mapping/Pattern Matching with Labels and Definitions

\begin{tabular}{|c|c|c|}
\hline Cluster & Label & Definition \\
\hline Cluster 1 & Research Process & $\begin{array}{l}\text { Understanding the stages of the research process } \\
\text { and having the ability to complete them. }\end{array}$ \\
\hline Cluster 2 & Technical Skills & $\begin{array}{l}\text { Basic technical skills associated with knowing } \\
\text { how to access information sources, select search } \\
\text { terms, and manage results. }\end{array}$ \\
\hline Cluster 3 & Selecting Sources & $\begin{array}{l}\text { The ability to evaluate, select and utilize the } \\
\text { appropriate information sources and tools } \\
\text { depending on the type of information needed. }\end{array}$ \\
\hline Cluster 4 & Information Ethics & $\begin{array}{l}\text { Understanding the legal and ethical issues related } \\
\text { to information use and the ability to apply rules } \\
\text { for safeguarding others' intellectual property. }\end{array}$ \\
\hline Cluster 5 & Communication & $\begin{array}{l}\text { The ability to communicate information } \\
\text { effectively to others, including selecting the } \\
\text { appropriate format and media for conveying the } \\
\text { information, and applying correct rules of } \\
\text { grammar, spelling, and punctuation. }\end{array}$ \\
\hline
\end{tabular}

(continued) 
CONTENT DOMAIN FOR INFORMATION LITERACY

Table 3 (continued)

List of Eight Clusters Created by Concept Mapping/Pattern Matching with Labels and Definitions

\begin{tabular}{ccl} 
Cluster & \multicolumn{1}{c}{ Label } & \multicolumn{1}{c}{ Definition } \\
\hline Cluster 6 & Evaluating Information & $\begin{array}{l}\text { The ability to evaluate information critically for } \\
\text { relevance, quality, credibility, balance, and } \\
\text { reliability. }\end{array}$ \\
Cluster 7 & Psychosocial Aspects & $\begin{array}{l}\text { Demonstrating development psychologically } \\
\text { and/or socially to critically evaluate one's own } \\
\text { work, to accept others' critical evaluations for } \\
\text { improvement and to keep an open mind. }\end{array}$ \\
Cluster 8 & Information Utilization & $\begin{array}{l}\text { The ability to analyze and synthesize information } \\
\text { retrieved as search results to formulate opinion, } \\
\text { support or disprove hypotheses, and to add to } \\
\text { one's knowledge base. }\end{array}$ \\
\hline
\end{tabular}

The card sort resulted in grouping together most of the items that are obviously similar. However, because there were 14 people with different interpretations of information literacy competency skills sorting the cards, there were some combinations that resulted in statements being placed unexpectedly in other clusters after the hierarchical cluster analysis. A series of tables listing the statements that were associated with each cluster will help to illustrate why the label was selected and the reasoning behind the definition assigned to that cluster. The mean scores calculated from the survey responses that reflected how important the participants viewed each outcome and the efficacy with which they thought the outcome was addressed at MidAtlantic University are also given. In each table, the outcomes are sorted in priority order from highest to lowest according to the mean score for the importance of the outcome.

Research Process Cluster. The Research Process Cluster was assigned ten statements as a result of the cluster analysis (see Table 4). The researcher gave this cluster the label Research Process because the majority of the statements represent either an understanding of 


\section{CONTENT DOMAIN FOR INFORMATION LITERACY}

conducting an inquiry in general or the ability to complete specific stages of the process such as formulating a research question and developing or revising a search strategy. The cluster definition or goal that was written for this cluster is: "Understanding the stages of the research process and having the ability to complete them."

Table 4

List of Statements in the Research Process Cluster and Their Mean Ratings in Terms of Importance and Efficacy.

\begin{tabular}{|c|c|c|c|}
\hline \multirow[b]{2}{*}{$\begin{array}{c}\text { Item } \\
\text { Number }\end{array}$} & \multirow[b]{2}{*}{ Statement } & \multicolumn{2}{|c|}{ Rating } \\
\hline & & Importance & $\begin{array}{l}\text { Efficacy in } \\
\text { Instruction }\end{array}$ \\
\hline 66 & Ability to conduct an inquiry. & 4.50 & 3.14 \\
\hline 74 & $\begin{array}{l}\text { How to structure the information needed at the } \\
\text { beginning--formulating a research question. }\end{array}$ & 4.43 & 2.93 \\
\hline 71 & $\begin{array}{l}\text { Being able to do basic information seeking or } \\
\text { research on anything. }\end{array}$ & 4.36 & 2.93 \\
\hline 3 & Proper date of an article. & 4.21 & 3.64 \\
\hline 40 & Narrow or revise search strategy and results. & 4.14 & 3.00 \\
\hline 56 & Understand the components of a research paper. & 4.07 & 3.08 \\
\hline 28 & $\begin{array}{l}\text { Learning to pick out what extra resources can help } \\
\text { them. }\end{array}$ & 4.07 & 3.07 \\
\hline 78 & Autonomous in seeking information. & 4.00 & 2.93 \\
\hline 67 & $\begin{array}{l}\text { Primary scientific discovery--identify the topic } \\
\text { first. }\end{array}$ & 3.71 & 2.93 \\
\hline 60 & Sequence of the scientific process. & 3.57 & 2.78 \\
\hline
\end{tabular}

The survey results indicated that the stakeholders participating in the focus group believed the majority of these outcomes were important as evidenced by the number of mean scores calculated from their survey responses that were 4.0 or above. However, the number of scores for efficacy that fell below 3.0 reflected a possible concern that Mid-Atlantic University 


\section{CONTENT DOMAIN FOR INFORMATION LITERACY}

was addressing these outcomes poorly. The fact that three of the outcomes had average efficacy ratings that are close to 3.0 was an indication that the majority of the respondents selected the neutral option from the ordinal scale for those items. The three outcomes closest to 3.0 in efficacy were 40 (narrow or revise search strategy and results), 56 (understand the components of a research paper), and 28 (learning to pick out what extra resources can help them).

Of the ten statements in the Research Process Cluster, statement 3 stands out as an anomaly. The statement: Proper date of an article implies that the student should be able to identify the correct descriptive information required for citing a resource, in this case an article, and formatting accurately the specific details of the reference. If the researcher were to evaluate the statements without the aid of the focus group's card sort, the quantitative processing of data using multidimensional scaling, and the hierarchical cluster analysis, item 3 would probably have been placed in the Information Ethics Cluster (Cluster 4) in which many of the statements or outcomes relate to the ability to cite information properly. However, the cluster map (see Figure 3) shows number 3 to be placed a distance from the other statements in Cluster 1, so by using only a visible analysis of the placement of the statements on the point map, statement 3 would probably be considered an outlier in other studies. When the researcher reviewed the entire list of 80 statements, number 3 also appeared to be considerably different from the others because of its level of specificity. As the number indicates, this outcome was generated very early in the brainstorming process when the focus group members were still new to the process.

It was stated earlier that during the description of the data collection method, step four of the process required the researcher and facilitator to identify the most logical number of clusters that appear to represent the differentiation in meaning between the statements. A careful study of the hierarchical cluster tree or dendrogram (see Appendix E) indicated the possibility of using a 


\section{CONTENT DOMAIN FOR INFORMATION LITERACY}

range of seven to nine clusters. If the researcher and facilitator had agreed to use either seven or nine clusters, the Research Process Cluster would have been one of the clusters that would have changed. On a cluster map composed of seven clusters, the items currently grouped in the Technical Skills Cluster would have been merged with the Research Process Cluster. The Technical Skills Cluster includes items 26, 70, 24, 11, 12, 4, 27, and 45 (see Table 5 for the text of the statements.) Although the researcher and facilitator agreed that some of the statements refer to an understanding of the research process in general, such as items 11 (understanding what they need to find), 12 (a basic search strategy), and 4 (using search terms effectively) or specific stages of the inquiry, there was logic to keeping the other statements in Cluster 2 together, as they were identified by the HCA, because they represent the technical skills, particularly those related to the use of information technology, that are often required when conducting research. Again, by consulting the numbered point map (see Figure 2) to view the locations of the Technical Skills Cluster items, the researcher understood why a 7-cluster analysis would have included the above mentioned statements, 11, 12 and 4; as well as statement 26 (organizing, storing and backing up information) in the Research Process Cluster due to their close proximity to statements 40 and 78 in that cluster (see Figure 3). The numbered point map also clarifies why the researcher decided that eight clusters were needed because the distances of items 27 (being able to access the Internet), 45 (protocols for accessing private information), 24 (awareness of security and personal privacy issues) and 70 (avoiding information overload) from the other items warranted another cluster.

A similar analysis was used in evaluating the difference between the 8-cluster or 9-cluster configurations. If nine clusters had been decided upon by the researcher and facilitator, statements 40 (narrow or revise search strategy and results), 60 (sequence of the scientific 


\section{CONTENT DOMAIN FOR INFORMATION LITERACY}

process), 28 (learning to pick out what extra resources can help them), and 3 (proper date of an article) would have been assigned a separate cluster, Cluster 9, according to the cluster tree. By comparing these statements to the contents of the Research Process Cluster, the two evaluators agreed that items 40, 60, and 28 were definitely related to other items in Cluster 8 that to split it into two clusters was not logical.

Technical Skills Cluster. Eight statements were grouped into the Technical Skills Cluster as a result of the HCA. A review of the statements in this cluster revealed a combination of skills focusing on the ability to use information technology effectively to conduct a search and manage the results. Several of the outcomes refer to developing specific technical skills (i.e., items 4, 26, 27 and 45). The definition assigned to this cluster by the researcher is: Basic technical skills associated with knowing how to access information sources, select search terms, and manage results. This was one of the clusters that would have been affected by the decision regarding the number of clusters to utilize for the study.

Table 5

List of Statements in the Technical Skills Cluster and Their Mean Ratings in Terms of Importance and Efficacy.

\begin{tabular}{clcc}
\hline \multirow{2}{*}{$\begin{array}{c}\text { Item } \\
\text { Number }\end{array}$} & \multicolumn{1}{c}{ Statement } & \multicolumn{2}{c}{ Rating } \\
\cline { 3 - 4 } 11 & Understanding what they need to find. & 4.71 & 2.93 \\
12 & A basic search strategy. & 4.28 & 3.28 \\
27 & Being able to access the Internet. & 4.21 & 4.43 \\
4 & Using search terms effectively. & 4.07 & 2.86 \\
26 & Organizing, storing and backing up information. & 3.86 & 2.93 \\
24 & Awareness of security and personal privacy issues. & 3.78 & 2.86 \\
45 & Protocols for accessing private information. & 3.78 & 2.57 \\
70 & Avoiding information overload. & 3.28 & 2.78 \\
\hline
\end{tabular}




\section{CONTENT DOMAIN FOR INFORMATION LITERACY}

The survey results for the Technical Skills Cluster indicated that the focus group participants rated the outcomes associated with the ability to effectively search for information as being important with mean scores above 4.00; as opposed to the outcomes supporting the need to be technologically literate. The mean scores for the majority of the technology related outcomes: 26 (organizing, storing and backing up information), 24 (awareness of security and personal privacy issues), and 45 (protocols for accessing private information) fell short of being considered important implying that several respondents may have selected more of a neutral or unimportant position for these outcomes. The majority of the scores for efficacy fell below 3.0, again reflecting a possible conviction that Mid-Atlantic University may not be addressing most of these outcomes effectively in the curriculum. Interestingly, the only technology related outcome that was rated equally to be important and that the university was promoting effectively was 27 (the ability to access the Internet). A review of all 80 of the efficacy mean scores revealed that this outcome was the only one the stakeholders rated above a 4.0 for effectiveness (see Appendix G).

Selecting Sources Cluster. The third cluster on the cluster map is the Selecting Sources Cluster. It was defined by the researcher to be "the ability to evaluate, select and utilize the appropriate information sources and tools depending on the type of information needed." It is composed of eight outcomes, the majority of which describe having the knowledge to differentiate between the content of information sources as they relate to type or subject of the information needed, the ability to identify and locate the correct source, or having the skills necessary to effectively use specific types of resources (see Table 6). 


\section{CONTENT DOMAIN FOR INFORMATION LITERACY}

Table 6

List of Statements in the Selecting Sources Cluster and Their Mean Ratings in Terms of Importance and Efficacy.

\begin{tabular}{|c|c|c|c|}
\hline \multirow[b]{2}{*}{$\begin{array}{c}\text { Item } \\
\text { Number }\end{array}$} & \multirow[b]{2}{*}{ Statement } & \multicolumn{2}{|c|}{ Rating } \\
\hline & & Importance & $\begin{array}{l}\text { Efficacy in } \\
\text { Instruction }\end{array}$ \\
\hline 5 & Where to look to find information. & 4.36 & 2.93 \\
\hline 32 & $\begin{array}{l}\text { Effective use of research tools in print and digital } \\
\text { (i.e., indexes, etc.). }\end{array}$ & 4.28 & 2.64 \\
\hline 7 & $\begin{array}{l}\text { Identifying appropriate discipline databases and } \\
\text { resources. }\end{array}$ & 4.21 & 3.00 \\
\hline 53 & $\begin{array}{l}\text { Understanding the difference between a database } \\
\text { and the Internet. }\end{array}$ & 4.07 & 3.21 \\
\hline 21 & Assessing Internet pages (i.e., .com, .gov). & 3.93 & 2.93 \\
\hline 8 & Online catalog. & 3.71 & 3.21 \\
\hline 35 & Able to manage information results electronically. & 3.50 & 2.86 \\
\hline 14 & $\begin{array}{l}\text { Understanding the physical space and content of } \\
\text { the library. }\end{array}$ & 3.36 & 2.69 \\
\hline
\end{tabular}

A comparison of the eight outcomes in the Selecting Sources Cluster using the assigned definition: The ability to evaluate, select and utilize the appropriate information sources and tools depending on the type of information needed resulted in the researcher observing that seven of the statements demonstrate a definite relationship: numbers $8,14,5,32,7,21$, and 53 . The inclusion of statement 35 (able to manage information results electronically) in this group could be questioned because it is referring to information results that would not have been known when the sources utilized in the search were selected. If the statement had been more inclusive to refer to managing information electronically, then it would fit more concretely. If the researcher were to evaluate the statements without the aid of the focus group's card sort, the quantitative processing of data using multidimensional scaling, and the hierarchical cluster analysis, item 35 


\section{CONTENT DOMAIN FOR INFORMATION LITERACY}

would probably have been placed in the Technical Skills Cluster (Cluster 2). However, when the named cluster map is consulted (see Figure 4), the distance between number 35 and the statements in the Technical Skills Cluster (see Table 5), particularly number 26 (organizing, storing and backing up information) that is similar, explains why 35 was not grouped in Cluster

2. The distance between the locations of the statements on the numbered point map indicates whether fewer or more focus group members combined the same statements together in one pile.

The mean scores for the importance ratings associated with the Selecting Sources Cluster indicated that the focus group participants found half or four of the eight outcomes to be important. The outcomes for which the importance ratings were above 4.0 were primarily related to the ability to identify and use appropriate research tools. The other four outcomes that were below a 4.0 importance rating were tied specifically to accessing the holdings of the library or managing search results. In regard to the mean scores for efficacy, again the participants' ratings fell below 3.0 for the majority of the outcomes, thereby continuing the pattern that the stakeholders felt that Mid-Atlantic University may not be addressing most of these outcomes effectively in the curriculum. The researcher did not fail to note the 2.69 efficacy rating for outcome 14 (understanding the physical space and content of the library). This low rating was surprising because of the university library's active information literacy instruction program and the librarians' participation in the institution's first year experience and student orientation programs.

Information Ethics Cluster. When the groupings of statements on the hierarchical cluster tree were analyzed to determine the logical number of clusters to use to represent the learning goals, the researcher and facilitator compared the statements in each group as they were divided between five to ten clusters. The contents of three of the clusters remained the same 


\section{CONTENT DOMAIN FOR INFORMATION LITERACY}

regardless of the number of times the list of 80 statements was split (see Appendix F). Cluster 4, named the Information Ethics Cluster by the researcher was the first of the three consistent clusters (see Table 7).

Table 7

List of Statements in the Information Ethics Cluster and Their Mean Ratings in Terms of Importance and Efficacy.

\begin{tabular}{clcc}
\hline \multirow{2}{*}{$\begin{array}{c}\text { Item } \\
\text { Number }\end{array}$} & Statement & \multicolumn{2}{c}{ Rating } \\
\cline { 3 - 4 } 1 & Proper documentation & Importance & $\begin{array}{c}\text { Efficacy in } \\
\text { Instruction }\end{array}$ \\
22 & Understanding the ethics of information use & 4.64 & 3.86 \\
77 & Time management and prioritization of tasks & 4.36 & 2.86 \\
44 & Legal issues in the use of sources, copyright & 4.21 & 3.00 \\
75 & Finding information for life after graduation & 4.07 & 3.07 \\
33 & Manual citation of references & 3.71 & 2.71 \\
\hline
\end{tabular}

The researcher noted this to be an interesting result because two out of the six statements in this cluster were considered to be very different from the other four, and the researcher expected that they would have been grouped in another cluster. The four similar statements: 22 , 44, 1, and 33 were interrelated because they addressed the legal and ethical use of information, particularly the ability to properly document and cite sources and an understanding of copyright issues. The researcher evaluated the context of the two remaining statements, 75 (finding information for life after graduation) and 77 (time management and prioritization of tasks) to fit more naturally in the Psychosocial Aspects Cluster because they represented less defined outcomes that applied to other cognitive or psychosocial development and life-long learning skills. Prior to consulting the named cluster map (Figure 4), the researcher also considered the possibility that these two items were located on the outer edge of the cluster and they were 


\section{CONTENT DOMAIN FOR INFORMATION LITERACY}

incorporated into Cluster 4 because they were closer in distance than to any other cluster. By examining the named cluster map, the researcher discovered statements 75 and 77 were centrally located between the other four statements in the Information Ethics Cluster and were clearly meant to be included in the cluster.

This unique combination of outcomes made naming the cluster and developing a definition for it difficult for the researcher. The definition assigned to this cluster was: Understanding the legal and ethical issues related to information use and the ability to apply rules for safeguarding others' intellectual property. Although all six of the statements referred to life-long learning skills, the researcher decided that the predominant theme of the cluster statements was related to the ethical use of information.

An analysis of the mean scores from the survey in regard to the importance of the items in this cluster indicated that the focus group members agreed that almost all of the outcomes were important. In fact, outcome 1 (proper documentation) received the second highest importance rating in the analysis to this point; the first being outcome 11 (understanding what they need to find) in the Technical Skills Cluster. The efficacy mean score for "proper documentation" also rated higher than most of the other scores for effectiveness at 3.86.

Communication Cluster. Containing 15 statements, the Communication Cluster was the second largest cluster created by the focus group as a result of the HCA (see Table 8). The researcher defined this cluster as the ability to communicate information effectively to others, including selecting the appropriate format and media for conveying the information, and applying correct rules of grammar, spelling, and punctuation. 


\section{CONTENT DOMAIN FOR INFORMATION LITERACY}

\section{Table 8}

List of Statements in the Communication Cluster and Their Mean Ratings in Terms of Importance and Efficacy.

\begin{tabular}{|c|c|c|c|}
\hline \multirow[b]{2}{*}{$\begin{array}{l}\text { Item } \\
\text { Number }\end{array}$} & \multirow[b]{2}{*}{ Statement } & \multicolumn{2}{|c|}{ Rating } \\
\hline & & Importance & $\begin{array}{l}\text { Efficacy in } \\
\text { Instruction }\end{array}$ \\
\hline 17 & Effective communication of the information. & 4.64 & 3.14 \\
\hline 51 & $\begin{array}{l}\text { Understand their medium and their audience to } \\
\text { adjust information. }\end{array}$ & 4.57 & 2.78 \\
\hline 49 & Oral communication skills. & 4.57 & 2.86 \\
\hline 69 & $\begin{array}{l}\text { Reevaluate drafts and the "finished" product, } \\
\text { conclusions, etc. }\end{array}$ & 4.57 & 2.93 \\
\hline 31 & Spelling and grammar, correct punctuation, etc. & 4.50 & 3.07 \\
\hline 62 & $\begin{array}{l}\text { Ability to use language for the appropriate } \\
\text { audience. }\end{array}$ & 4.50 & 3.07 \\
\hline 25 & Being able to formulate a strong thesis. & 4.46 & 3.57 \\
\hline 48 & $\begin{array}{l}\text { Organizing information for an effective oral } \\
\text { presentation. }\end{array}$ & 4.43 & 2.86 \\
\hline 18 & Integrate the materials into a knowledge base. & 4.28 & 2.93 \\
\hline 80 & Ability to present personal information orally. & 4.14 & 2.93 \\
\hline 16 & Balance to your paper in what you present. & 4.12 & 3.28 \\
\hline 30 & $\begin{array}{l}\text { Ability to communicate information in a variety of } \\
\text { ways to match learning style. }\end{array}$ & 3.93 & 2.71 \\
\hline 79 & Confidence. & 3.93 & 3.43 \\
\hline 47 & Effective personal interviewing. & 3.71 & 2.21 \\
\hline 52 & $\begin{array}{l}\text { Be able to construct attributive tags or signal } \\
\text { phrases. }\end{array}$ & 3.07 & 2.50 \\
\hline
\end{tabular}

The Communication Cluster was the second of the three clusters that did not change in size or content when the researcher contemplated the problem of deciding the number of clusters to use in the study. No matter how many segments between five and ten the statement list was 


\section{CONTENT DOMAIN FOR INFORMATION LITERACY}

divided into, this cluster remained constant. Unlike several of the other clusters described in the study, all of the outcomes included could be linked to some aspect of effectively communicating information either in general terms or specific actions.

With 11 of the 15 outcomes in the Communication Cluster having received a mean score for importance above 4.1, and six of those with ratings of 4.5 or higher, the stakeholders indicated that many of these statements were considered to be important information literacy outcomes for the students to learn. However, the average scores for efficacy for nine of the 15 outcomes fell below a rating of 3.0, continuing the pattern noted by the researcher for the previous clusters that the focus group members questioned the effectiveness of the curriculum at Mid-Atlantic University in addressing these skills.

Evaluating Information Cluster. With 17 outcomes, the sixth cluster generated from the statement list was the largest cluster. The researcher labeled it the Evaluating Information Cluster and described it as the ability to evaluate information critically for relevance, quality, credibility, balance, and reliability. The definition referred to evaluating "information" in general. The researcher interpreted the content of the statements to encompass the entire array of information dissemination methods regardless of format, purpose, and content; whether the investigation resulted in a periodical article or a monograph, in print format or digital, or a list of sources retrieved from a search engine or a subject specific database (see Table 9).

Similar to the preceding Communication Cluster, the Evaluating Information Cluster is the third of the three clusters that did not change in size or content regardless of the number of segments between five and ten the statement list was divided. This cluster remained constant. Also, all of the outcomes included in this cluster could be linked to evaluating information either in general terms or using specific criteria. 


\section{CONTENT DOMAIN FOR INFORMATION LITERACY}

\section{Table 9}

List of Statements in the Evaluating Information Cluster and Their Mean Ratings in Terms of Importance and Efficacy.

\begin{tabular}{|c|c|c|c|}
\hline \multirow[b]{2}{*}{$\begin{array}{l}\text { Item } \\
\text { Number }\end{array}$} & \multirow[b]{2}{*}{ Statement } & \multicolumn{2}{|c|}{ Rating } \\
\hline & & Importance & $\begin{array}{l}\text { Efficacy in } \\
\text { Instruction }\end{array}$ \\
\hline 2 & Evaluating sources critically. & 4.71 & 2.93 \\
\hline 55 & Evaluating the quality of evidence. & 4.57 & 2.64 \\
\hline 38 & Be able to evaluate the results of a web search. & 4.57 & 3.21 \\
\hline 9 & $\begin{array}{l}\text { Critically assessing the credibility and } \\
\text { thoroughness of a resource. }\end{array}$ & 4.50 & 3.08 \\
\hline 37 & Being able to identify bias in a resource. & 4.43 & 3.00 \\
\hline 29 & Being able to analyze a text format (content,). & 4.28 & 3.00 \\
\hline 39 & Be able to corroborate information. & 4.28 & 2.64 \\
\hline 68 & $\begin{array}{l}\text { Look for credible evidence of both sides of an } \\
\text { argument. }\end{array}$ & 4.28 & 3.07 \\
\hline 50 & $\begin{array}{l}\text { Understanding of scholarly versus popular } \\
\text { resources. }\end{array}$ & 4.28 & 3.14 \\
\hline 34 & $\begin{array}{l}\text { Distinguishing between types of resources and } \\
\text { publications. }\end{array}$ & 4.21 & 3.14 \\
\hline 54 & $\begin{array}{l}\text { Distinguish between abstracts, review articles and } \\
\text { original research. }\end{array}$ & 4.21 & 3.14 \\
\hline 41 & $\begin{array}{l}\text { Being able to evaluate the substantiality of the } \\
\text { study. }\end{array}$ & 4.14 & 2.78 \\
\hline 72 & $\begin{array}{l}\text { Be able to look for and find multiple explanations } \\
\text { for the argument. }\end{array}$ & 4.14 & 2.86 \\
\hline 43 & $\begin{array}{l}\text { Difference between quantitative and qualitative } \\
\text { methods. }\end{array}$ & 3.93 & 2.36 \\
\hline 6 & Definition of primary, secondary, tertiary sources. & 3.93 & 2.57 \\
\hline 10 & Balance of the resource in regard to coverage. & 3.93 & 3.00 \\
\hline 42 & $\begin{array}{l}\text { Understand the difference between statistical } \\
\text { versus practical significance. }\end{array}$ & 3.86 & 2.21 \\
\hline
\end{tabular}




\section{CONTENT DOMAIN FOR INFORMATION LITERACY}

An analysis of the mean scores from the survey in regard to the importance of the items in this cluster indicated that the focus group members agreed that almost all of the outcomes were important. Even the four items $(43,6,10$, and 43$)$ that received ratings for importance below 4.0 had scores that were very close to being rated important. Outcome 2 (evaluating sources critically) equaled the rating of 4.71 given to outcome 11 (understanding what they need to find) in the Technical Skills Cluster. Also, nine of the 17 outcomes or 53\% achieved efficacy ratings above 3.0, the highest percentage of outcomes with scores above poorly that were rated in that category. However, outcome 42 (understand the difference between statistical versus practical significance) tied outcome 47 (effective personal interviewing) in the Communication Cluster for the lowest efficacy rating of all 80 statements at 2.21.

Psychosocial Aspects Cluster. The smallest cluster of the eight, the Psychosocial Aspects Cluster was assigned four outcomes as a result of the cluster analysis. For the researcher, this cluster was one of the hardest to define because three of the statements referred to outcomes that were psychological or affective in nature, rather than actionable (see Table 10). Those outcomes were 36 (having a healthy dose of skepticism), 64 (the ability to accept challenges of their own perspective and respond appropriately) and 65 (the ability to challenge their own perspectives). The definition that the researcher finally developed for the Psychosocial Aspects Cluster was: Demonstrating development psychologically and/or socially to critically evaluate one's own work, to accept others' critical evaluations for improvement and to keep an open mind.

The focus group members rated all four of these outcomes to be important skills for information literacy. For outcomes 64 (the ability to accept challenges of their own perspective and respond appropriately) and 65 (the ability to challenge their own perspectives), the 


\section{CONTENT DOMAIN FOR INFORMATION LITERACY}

importance ratings equaled the highest scores given in the Technical Skills Cluster, the

Information Ethics Cluster and the Evaluating Information Cluster.

Table 10

List of Statements in the Psychosocial Aspects Cluster and Their Mean Ratings in Terms of Importance and Efficacy.

\begin{tabular}{clcc}
\hline \multirow{2}{*}{$\begin{array}{c}\text { Item } \\
\text { Number }\end{array}$} & \multicolumn{1}{c}{\begin{tabular}{c} 
Statement \\
\cline { 2 - 3 }
\end{tabular}} & $\begin{array}{c}\text { Rating } \\
\text { Importance }\end{array}$ & $\begin{array}{c}\text { Efficacy in } \\
\text { Instruction }\end{array}$ \\
\hline 64 & $\begin{array}{l}\text { The ability to accept challenges of their own } \\
\text { perspective and respond appropriately } \\
65\end{array}$ & 4.71 & 2.71 \\
61 & $\begin{array}{l}\text { The ability to challenge their own perspectives } \\
\text { Identifying competing perspectives and responding } \\
\text { to them effectively }\end{array}$ & 4.64 & 2.50 \\
36 & Have a healthy dose of skepticism & 4.00 & 2.71 \\
\hline
\end{tabular}

It was noted by the researcher that the efficacy ratings representing how well MidAtlantic University incorporated instruction for these skills into the curriculum was considered to be poorly by the stakeholders with mean scores consistently below 3.0. Outcome 65 (the ability to challenge their own perspectives) received one of the lowest efficacy ratings at 2.50 . The mean score for the entire cluster when averaging all of the means in regard to efficacy for the four statements is the lowest of all of the clusters at 2.70 (see Table 12).

Information Utilization Cluster. The last cluster identified from the statement list by the cluster analysis is the Information Utilization Cluster. With 12 items, it was the third largest cluster in size (see Table 11). After evaluating the context of the statements, the researcher developed the following definition: The ability to analyze and synthesize information retrieved as search results to formulate opinion, support or disprove hypotheses, and to add to one's knowledge base. 
Table 11

List of Statements in the Information Utilization Cluster and Their Mean Ratings in Terms of Importance and Efficacy.

\begin{tabular}{|c|c|c|c|}
\hline \multirow{3}{*}{$\begin{array}{l}\text { Item } \\
\text { Number }\end{array}$} & \multirow[b]{3}{*}{ Statement } & \multicolumn{2}{|c|}{ Rating } \\
\hline & & & Efficacy in \\
\hline & & Importance & Instruction \\
\hline 57 & $\begin{array}{l}\text { Ability to summarize and synthesize the } \\
\text { information in a resource }\end{array}$ & 4.64 & 3.28 \\
\hline 15 & Synthesizing the content of the article & 4.57 & 3.07 \\
\hline 20 & Drawing conclusions & 4.57 & 3.14 \\
\hline 13 & Effective use of the materials found & 4.43 & 3.14 \\
\hline 19 & Interpret the data and findings & 4.43 & 2.93 \\
\hline 73 & $\begin{array}{l}\text { Be able to integrate new, multiple types of } \\
\text { information }\end{array}$ & 4.36 & 3.00 \\
\hline 76 & Recognize the limits of their knowledge & 4.36 & 2.57 \\
\hline 23 & $\begin{array}{l}\text { Using different strategies for understanding and } \\
\text { comprehension }\end{array}$ & 4.28 & 2.93 \\
\hline 63 & The ability to form an opinion & 4.28 & 3.48 \\
\hline 59 & $\begin{array}{l}\text { Recognizing that the answer is a combination of } \\
\text { many resources }\end{array}$ & 4.21 & 2.78 \\
\hline 58 & Data driven decision-making for some disciplines & 3.78 & 2.64 \\
\hline 46 & $\begin{array}{l}\text { Social or scientific implications of the research } \\
\text { being used }\end{array}$ & 3.71 & 2.71 \\
\hline
\end{tabular}

The Information Utilization Cluster was another large cluster in which an overwhelming majority of the outcomes were rated to be important by the Concept Mapping/Pattern Matching participants. Of the 12 outcomes in the cluster, ten of which had importance ratings above 4.0, three or $25 \%$ were given scores above 4.5 . This cluster also had six outcomes with efficacy ratings of 3.0 or above. 
CONTENT DOMAIN FOR INFORMATION LITERACY

The total importance and efficacy mean scores for each cluster. After the

stakeholders survey responses were averaged to reveal the mean scores for the importance of each outcome and the efficacy with which Mid-Atlantic University's curriculum helps students develop each particular student learning outcome, the total mean score was calculated for each cluster in both categories: importance and efficacy (see Table 12).

Table 12

The Importance and Efficacy Mean Scores for Each Cluster.

\begin{tabular}{cccc}
\hline & & \multicolumn{2}{c}{ Rating } \\
\cline { 3 - 4 } Cluster & Label & Efficacy in \\
Cluster 1 & Research Process & 4.11 & 3.04 \\
Cluster 2 & Technical Skills & 4.00 & 3.08 \\
Cluster 3 & Selecting Sources & 3.93 & 2.93 \\
Cluster 4 & Information Ethics & 4.23 & 3.02 \\
Cluster 5 & Communication & 4.23 & 2.95 \\
Cluster 6 & Evaluating Information & 4.25 & 2.87 \\
Cluster 7 & Psychosocial Aspects & 4.41 & 2.70 \\
Cluster 8 & Information Utilization & 4.30 & 2.97 \\
\hline
\end{tabular}

Cluster 7, the Psychosocial Aspects Cluster, had the highest mean score for importance at 4.41 and, as mentioned previously, the lowest efficacy averaged score of 2.70 . These results demonstrate that although the stakeholders indicated the outcomes in this cluster to have been the most important on average, Mid-Atlantic University's curriculum is least effective in helping students to develop these student learning outcomes. The Selecting Sources Cluster resulted in having the lowest mean score for importance at 3.93, just below a 4.0. The mean scores for efficacy for five of the clusters were below 3.0 or considered poorly and the other three clusters each averaged a mean score barely above a 3.0. 
CONTENT DOMAIN FOR INFORMATION LITERACY

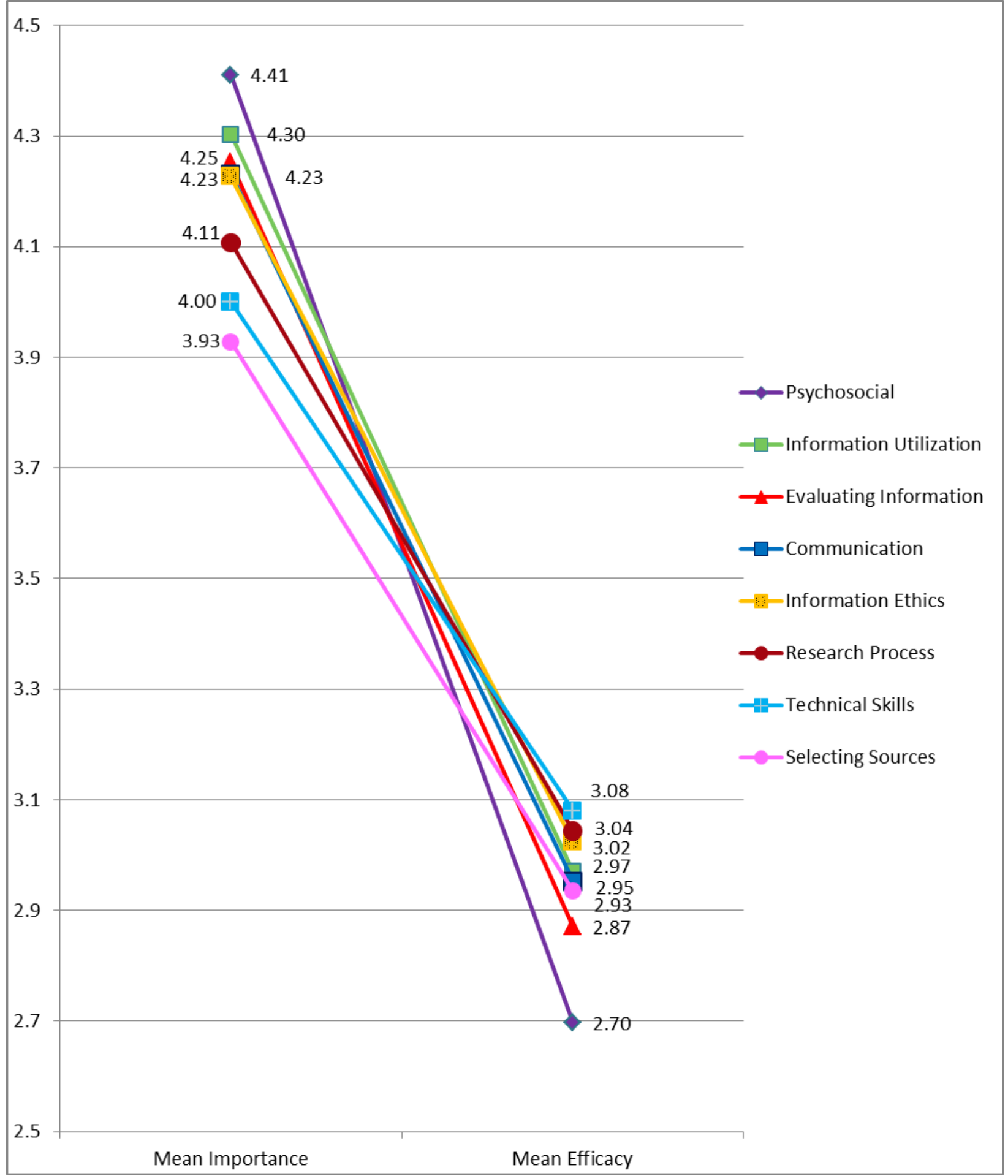

Figure 5. Laddergram chart showing the mean ratings of importance and efficacy for the eight clusters generated by the key stakeholders using Concept Mapping/Pattern Matching. 
CONTENT DOMAIN FOR INFORMATION LITERACY

\section{Document Analysis Results as They Relate to Research Question 2}

The second research question for this study asked "how does conceptualization generated through Concept Mapping/Pattern Matching at a mid-sized regional Mid-Atlantic university compare and contrast with the framework established by the Association of College and Research Libraries?" The researcher conducted a document analysis to generate the results for this research question. The documents that were analyzed for comparison were the list of eighty conceptualizations or outcomes generated using Concept Mapping/Pattern Matching for the first research question in this study (see Appendix C) and the standards, performance indicators and outcomes identified in the Association of College and Research Libraries' (2000) Information Literacy Competency Standards for Higher Education (see Appendix A).

The standards were developed by the Multi-Association Information Literacy Competency Task Force under the auspices of the Association of College and Research Libraries' (ACRL). With the exception of a representative from the Middle States Commission on Higher Education and a vice president for academic affairs, the remaining eight members of the ten-member task force were library professionals representing institutions of higher education from three different regions of the United States: the East, the West and the Midwest.

The Task Force issued Information Literacy Competency Standards for Higher Education in 2000, in which it identified five standards:

- Standard 1: The information literate student determines the nature and extent of the information needed.

- Standard 2: The information literate student accesses needed information effectively and efficiently. 


\section{CONTENT DOMAIN FOR INFORMATION LITERACY}

- Standard 3: The information literate student evaluates information and its sources critically and incorporates selected information into his or her knowledge base and value system.

- Standard 4: The information literate student, individually or as a member of a group, uses information effectively to accomplish a specific purpose.

- Standard 5: The information literate student understands many of the economic, legal, and social issues surrounding the use of information and accesses and uses information ethically and legally. (ACRL, 2000, pp. 8-14)

Twenty-two performance indicators help to define the five broad standards. Each performance indicator has at least two, but often more, very specific outcomes designed to illustrate the achievement of competency in information literacy. There are 87 recommended outcomes (see Appendix A for a complete list of the standards, performance indicators and the outcomes). Since their publication, the ACRL Information Literacy Standards have been adopted by institutions of higher education; professional organizations in education and librarianship; and by state, regional, and national accrediting agencies.

The researcher conducted four steps in the document comparison process. The first phase began with the researcher printing out the lists of outcomes from both sources. This was followed by a careful examination of each of the outcomes in the two documents and highlighting with the same color, the occurrences of like terms and similar concepts. During the second step, the researcher matched the outcomes on the Concept Mapping/Pattern Matching statement list to the outcomes associated with the ACRL (2000) Information Literacy Standards by recording the identifying numbers for both sets of outcomes next to their counterparts on each list. This process required some interpretation of the intent of the outcomes on the part of the 


\section{CONTENT DOMAIN FOR INFORMATION LITERACY}

researcher due to the differences in language use and the styles in which the outcomes were written in the two documents. The ACRL standards were deliberated by a task group over a period of approximately two years by information literacy practitioners considered to be experts on the topic. The style of writing is very professional and care was obviously taken to use the correct terminology in the field to describe the outcomes. Although the members of the focus group for this study were selected because of their demonstrated interest in teaching students information literacy competency skills, most of them would not claim to be experts in the theories or professional language, with the possible exception of the coordinator for library instruction. The outcomes generated by the focus group during the one-hour brainstorming session were stated quickly as they were thought of and, in most cases, were recorded verbatim. Due to the need for spontaneity and to maintain an atmosphere that encouraged freedom of expression, participants were not required to consider vocabulary, grammar, or syntax. The researcher did not make any changes to the statements, such as correct the grammar, voice, or choice of wording, because to do so could have altered the meanings of the outcomes as they were understood by the members of the focus group.

The third stage of the document analysis resulted in the creation of a table to demonstrate which of the statements produced from the Concept Mapping/Pattern Matching process could be paired with the ACRL outcomes (see Appendix H). Often, more than one statement from the study could be linked directly to an ACRL outcome. The researcher was able to use this table to determine if there was a correlation between the clusters and the ACRL standards (see Table 13). The final step of the process was to identify the differences in the two lists, particularly the appearance of outcomes in one document that did not match up with any outcomes in the other document. 


\section{CONTENT DOMAIN FOR INFORMATION LITERACY}

Similarities between the two documents. The first level of comparison the researcher conducted was between the 87 outcomes published in the ACRL (2000) Information Literacy Standards and the 80 outcomes generated by this study using the Concept Mapping/Pattern Matching process. Numerous examples of similarities exist between the outcomes identified in the ACRL Standards and the Mid-Atlantic University's focus group's list of outcomes.

Although the Mid-Atlantic University outcomes may not have been grouped in the same clusters that have similar themes to the ACRL Standards, 69 or $86 \%$ of the 80 statements generated by the focus group could be correlated to one or more of the ACRL outcomes (see Appendix H). Similarly, 70 of the ACRL outcomes or $80 \%$ were paired with one or more of the Mid-Atlantic University outcomes.

Despite the fact that the ACRL standards were fewer in number, the goal expressed by each of them was represented in at least one of the clusters, though the outcomes for an individual ACRL standard may have been assigned to different clusters (see Table 13). Table 13

Comparison of the Concept Mapping/Pattern Matching Generated Clusters and the ACRL (2000) Information Literacy Competency Standards for Higher Education.

\begin{tabular}{ll}
\hline \multicolumn{1}{c}{ Mid-Atlantic University Cluster Definition } & \multicolumn{1}{c}{ ACRL Standard } \\
\hline $\begin{array}{l}\text { Cluster 1 - Research Process: Understanding } \\
\text { the stages of the research process and having } \\
\text { the ability to complete them. }\end{array}$ & $\begin{array}{l}\text { Standard 1: The information literate } \\
\text { student determines the nature and } \\
\text { extent of the information needed. }\end{array}$ \\
$\begin{array}{ll}\text { Cluster } 2 \text { - Technical Skills: Basic technical } \\
\text { skills associated with knowing how to access } \\
\text { information sources, select search terms, and } \\
\text { manage results. }\end{array}$ & $\begin{array}{l}\text { Standard 2: The information literate student } \\
\text { accesses needed information effectively and } \\
\text { efficiently. }\end{array}$ \\
$\begin{array}{ll}\text { Cluster } 3 \text { - Selecting Sources: The ability to } \\
\text { evaluate, select and utilize the appropriate } \\
\text { information sources and tools depending on } \\
\text { the type of information needed. }\end{array}$ & $\begin{array}{l}\text { Standard 2: The information literate student } \\
\text { accesses needed information effectively and } \\
\text { efficiently. }\end{array}$ \\
\hline
\end{tabular}


Table 13 (continued)

Comparison of the Concept Mapping/Pattern Matching Generated Clusters and the ACRL (2000) Information Literacy Competency Standards for Higher Education.

Mid-Atlantic University Cluster Definition
Cluster 4 - Information Ethics: Understanding
the legal and ethical issues related to
information use and the ability to apply rules
for safeguarding others' intellectual property.

Cluster 5 - Communication: The ability to communicate information effectively to others, including selecting the appropriate format and media for conveying the information, and applying correct rules of grammar, spelling, and punctuation.

Cluster 6 - Evaluating Information: The ability to evaluate information critically for relevance, quality, credibility, balance, and reliability.

Cluster 7 - Psychosocial Aspects:

Demonstrating development psychologically and/or socially to critically evaluate one's own work, to accept others' critical evaluations for improvement and to keep an open mind.

Cluster 8 - Information Utilization: The ability to analyze and synthesize information retrieved as search results to formulate opinion, support or disprove hypotheses, and to add to one's knowledge base.
ACRL Standard

Standard 5: The information literate student understands many of the economic, legal, and social issues surrounding the use of information and accesses and uses information ethically and legally.

Standard 4: The information literate student, individually or as a member of a group, uses information effectively to accomplish a specific purpose.

Standard 3: The information literate student evaluates information and its sources critically and incorporates selected information into his or her knowledge base and value system.

Standard 3: The information literate student evaluates information and its sources critically and incorporates selected information into his or her knowledge base and value system.

Note. Adapted from Association of College \& Research Libraries, 2000, Information literacy competency standards for higher education, p. 8-14. Copyright 1997-2011 American Library Association. This document may be reprinted and distributed for non-commercial and educational purposes only, and not for resale. All other rights reserved. 


\section{CONTENT DOMAIN FOR INFORMATION LITERACY}

The first ACRL standard states: "The information literate student determines the nature and extent of the information needed" (2000, p. 8). The standard includes four performance indicators that further define this standard:

1. The information literate student defines and articulates the need for information.

2. The information literate student identifies a variety of types and formats of potential sources for information.

3. The information literate student considers the costs and benefits of acquiring the needed information.

4. The information literate student reevaluates the nature and extent of the information need. (ACRL, pp. 8-9)

Seventeen outcomes represent different skills associated with the performance indicators. A comparison of these outcomes to the 80 generated by the Mid-Atlantic University focus group resulted in pairing 16 of the stakeholders' outcomes to Standard 1. However, due to the number of phases of the research process covered by the first ACRL standard, including selecting sources and evaluating results, the majority of the Mid-Atlantic University statements that correlate to the outcomes in this standard come from clusters other than the Research Process Cluster. Outcomes 67 (primary scientific discovery-identify the topic first), 74 (how to structure the information needed at the beginning-formulating a research question), and 40 (narrow or revise search strategy and results), or $38 \%$ of the items in the Research Process Cluster match the outcomes in the first ACRL standard. Statements 6 (definition of primary, secondary, and tertiary sources), 34 (distinguishing between types of resources and publications), 50 (understanding of scholarly versus popular resources), and 54 (distinguish between abstracts, review articles and original research) from Cluster 6, the Evaluating 


\section{CONTENT DOMAIN FOR INFORMATION LITERACY}

Information Cluster can also be paired with the outcomes in ACRL Standard 1. These four statements represent $24 \%$ of the outcomes included in Cluster 6. On Table 13, the researcher linked Standard 1 with the Research Process Cluster because the concepts illustrated by the statements represent the beginning stages of the research process or a general understanding of what is required when conducting research.

The second ACRL standard: "The information literate student accesses needed information effectively and efficiently" (2000, p. 9) included 22 outcomes organized under five performance indicators. The performance indicators identified actions such as selecting the appropriate investigative methods or retrieval systems, constructing and implementing effective search strategies, using a variety of methods to retrieve information, revising the search strategy, and extracting and managing the results (ACRL, 2000). The researcher's comparison to the clusters generated by the focus group paired many of the outcomes located in the Technical Skills and Selecting Sources Clusters with the outcomes in ACRL's Standard 2. Of the eight outcomes grouped in the Technical Skills Cluster, five were linked to Standard 2 and seven of the eight outcomes in the Selecting Sources Cluster were also similar.

"The information literate student evaluates information and its sources critically and incorporates selected information into his or her knowledge base and value system" (ACRL, 2000, p. 10) is the third ACRL standard and it includes seven performance indicators and 25 outcomes. The performance indicators state:

1. The information literate student evaluates information and its sources critically and incorporates selected information into his or her knowledge base and value system.

2. The information literate student articulates and applies initial criteria for evaluating both the information and its sources. 


\section{CONTENT DOMAIN FOR INFORMATION LITERACY}

3. The information literate student synthesizes main ideas to construct new concepts.

4. The information literate student compares new knowledge with prior knowledge to determine the value added, contradictions, or other unique characteristics of the information.

5. The information literate student determines whether the new knowledge has an impact on the individual's value system and takes steps to reconcile differences.

6. The information literate student validates understanding and interpretation of the information through discourse with other individuals, subject-area experts, and/or practitioners.

7. The information literate student determines whether the initial query should be revised. (ACRL, pp. 10-12)

The researcher paired ACRL's third standard with Clusters 6 (Evaluating Information) and 8 (Information Utilization) following the document analysis (see Table 13). In addition to the similarity of the concepts articulated in the standard and the definitions of the two clusters, the researcher's comparison matched many of the statements located in the Evaluating Information and Information Utilization Clusters with the outcomes in ACRL's Standard 3. Of the 17 outcomes generated by the Mid-Atlantic University focus group in the Evaluating Information Cluster, 11 or $65 \%$ match outcomes listed under ACRL's third standard and $83 \%$ or ten of the 12 outcomes grouped in the Information Utilization Cluster can be assigned to different skills identified in the same standard (see Appendix H).

ACRL's fourth standard focuses on the effective use of information: "The information literate student, individually or as a member of a group, uses information effectively to accomplish a specific purpose" (2000, p. 12). It includes three performance indicators: 


\section{CONTENT DOMAIN FOR INFORMATION LITERACY}

1. The information literate student applies new and prior information to the planning and creation of a particular product or performance.

2. The information literate student revises the development process for the product or performance.

3. The information literate student communicates the product and performance effectively to others. (ACRL, pp. 12-13)

Ten outcomes describe the specific skills associated with the standard. The researcher's comparison to the clusters generated by the focus group matched many of the outcomes located in the Communication Cluster with the outcomes in ACRL's Standard 4. Of the fifteen outcomes grouped in the Communication Cluster, ten or $67 \%$ were linked to Standard 4.

The fifth ACRL standard states: "The information literate student understands many of the economic, legal, and social issues surrounding the use of information and accesses and uses information ethically and legally" (2000, p. 13). It is also defined by three performance indicators:

1. The information literate student understands many of the ethical, legal, and socioeconomic issues surrounding information and information technology.

2. The information literate student follows laws, regulations, institutional policies, and etiquette related to the access and use of information resources.

3. The information literate student acknowledges the use of information sources in communicating the product or performance. (ACRL, pp. 13-14)

Thirteen outcomes are attached to the standard; however the researcher could not find a correlation among the Mid-Atlantic University statements for five of the ACRL outcomes (see Table 14). For the other eight ACRL outcomes associated with the standard, four of the 
outcomes in the Information Ethics Cluster could be paired to the majority of them--statements 1, 22, 33, and 44 (see Table 7); and two from the Technical Skills Cluster were also positively matched to those outcomes related to security issues and privacy protocols (e.g., outcomes 24 and 45 in the Technical Skills Cluster).

Differences between the two documents. Further comparison between the ACRL (2000) Standards and the Mid-Atlantic University’s lists of outcomes revealed also several differences. It was noted that 70 of the 87 ACRL outcomes could be paired with one or more of the Concept Mapping/Pattern Matching outcomes generated by the study, leaving 17 that the researcher couldn't match. Those for which an equivalent outcome could not be found are listed in Table 14:

Table 14

ACRL Outcomes that Could Not be Matched to Mid-Atlantic University's Outcomes for Information Literacy

\begin{tabular}{llc}
\hline $\begin{array}{c}\text { ACRL } \\
\text { Outcome } \\
\begin{array}{c}\text { Reference } \\
\text { Number }\end{array}\end{array}$ & \multicolumn{1}{c}{ Outcome } & $\begin{array}{c}\text { Page } \\
\text { Number }\end{array}$ \\
\hline S1.P1.c. & $\begin{array}{l}\text { Explores general information sources to increase familiarity with the } \\
\text { topic }\end{array}$ & 8 \\
S1.P2.a. & $\begin{array}{l}\text { Knows how information is formally and informally produced, } \\
\text { organized, and disseminated }\end{array}$ & 8 \\
S1.P2.f. & $\begin{array}{l}\text { Realizes that information may need to be constructed with raw data } \\
\text { from primary sources }\end{array}$ & 8 \\
S1.P3.b. & $\begin{array}{l}\text { Considers the feasibility of acquiring a new language or skill (e.g., } \\
\text { foreign or discipline-based) in order to gather needed information and } \\
\text { to understand its context }\end{array}$ & 9 \\
S2.P1.c. & $\begin{array}{l}\text { Investigates the scope, content, and organization of information } \\
\text { retrieval systems }\end{array}$ & 9 \\
\hline
\end{tabular}

(continued) 
Table 14 (continued)

ACRL Outcomes that Could Not be Matched to Mid-Atlantic University's Outcomes for Information Literacy

\begin{tabular}{|c|c|c|}
\hline $\begin{array}{l}\text { ACRL } \\
\text { Outcome } \\
\text { Reference } \\
\text { Number }\end{array}$ & Outcome & $\begin{array}{l}\text { ACRL } \\
\text { Standards } \\
\text { Page } \\
\text { Number }\end{array}$ \\
\hline S2.P5.a. & $\begin{array}{l}\text { Selects among various technologies the most appropriate one for the } \\
\text { task of extracting the needed information (e.g., copy/paste software } \\
\text { functions, photocopier, scanner, audio/visual equipment, or } \\
\text { exploratory instruments) }\end{array}$ & 10 \\
\hline S3.P3.c. & $\begin{array}{l}\text { Utilizes computer and other technologies (e.g. spreadsheets, } \\
\text { databases, multimedia, and audio or visual equipment) for studying } \\
\text { the interaction of ideas and other phenomena }\end{array}$ & 11 \\
\hline S3.P6.a. & Participates in classroom and other discussions & 12 \\
\hline S3.P6.c. & $\begin{array}{l}\text { Seeks expert opinion through a variety of mechanisms (e.g., } \\
\text { interviews, email, listservs) }\end{array}$ & 12 \\
\hline S4.P1 b. & $\begin{array}{l}\text { Articulates knowledge and skills transferred from prior experiences } \\
\text { to planning and creating the product or performance }\end{array}$ & 13 \\
\hline S4.P2.a. & $\begin{array}{l}\text { Maintains a journal or log of activities related to the information } \\
\text { seeking, evaluating, and communicating process }\end{array}$ & 13 \\
\hline S4.P3.b. & $\begin{array}{l}\text { Uses a range of information technology applications in creating the } \\
\text { product or performance }\end{array}$ & 13 \\
\hline S5.P1.b. & $\begin{array}{l}\text { Identifies and discusses issues related to free vs. fee-based access to } \\
\text { information }\end{array}$ & 14 \\
\hline S5.P1.c. & $\begin{array}{l}\text { Identifies and discusses issues related to censorship and freedom of } \\
\text { speech }\end{array}$ & 14 \\
\hline S5.P2.a. & $\begin{array}{l}\text { Participates in electronic discussions following accepted practices } \\
\text { (e.g. "Netiquette") }\end{array}$ & 14 \\
\hline S5.P2.d. & $\begin{array}{l}\text { Preserves the integrity of information resources, equipment, systems } \\
\text { and facilities }\end{array}$ & 14 \\
\hline S5.P2.g. & $\begin{array}{l}\text { Demonstrates an understanding of institutional policies related to } \\
\text { human subjects research }\end{array}$ & 14 \\
\hline
\end{tabular}


Note. $\mathrm{S}=$ ACRL Standard; $\mathrm{P}=$ ACRL Performance Indicator; $\mathrm{C}=$ Cluster.

Page number refers to the page of the ACRL (2000) Standards on which the outcome appears.

Source: Adapted from Association for College \& Research Libraries, 2000, Information literacy competency standards for higher education, p. 8-14. Copyright 1997-2011 American Library Association. This document may be reprinted and distributed for non-commercial and educational purposes only, and not for resale.

An observation made by the researcher when reviewing this list was that many of these outcomes were associated specifically with the application of or knowledge of information technology.

During the same document comparisons, the researcher noted that 11 of the 80 student learning outcomes identified by the focus group using Concept Mapping/Pattern Matching also could not be paired with a counterpart from the 87 ACRL outcomes. The eleven outcomes were:

- 11 Understanding what they need to find;

- 21 Assessing internet pages (.com,.gov);

- 36 Have a healthy dose of skepticism;

- 47 Effective personal interviewing;

- 64 The ability to accept challenges of their own perspective and respond appropriately;

- 66 Ability to conduct an inquiry;

- 71 Being able to do basic information seeking or research on anything;

- 75 Finding information for life after graduation;

- 76 Recognize the limits of their knowledge;

- 78 Autonomous in seeking information;

- 79 Confidence. 


\section{CONTENT DOMAIN FOR INFORMATION LITERACY}

The numbers preceding the statements represent the sequential numbers that were assigned at the time the statements were generated by the participants.

Two of the statements were grouped together in the seventh cluster created by the hierarchical cluster analysis and labeled the Psychosocial Aspects Cluster by the researcher. These were 36 (have a healthy dose of skepticism) and 64 (the ability to accept challenges of their own perspective and respond appropriately). The other two statements that made up the Psychosocial Aspects Cluster were 65 (the ability to challenge their own perspectives) and 61(identifying competing perspectives and responding to them effectively). The Psychosocial Aspects Cluster is the only cluster for which the researcher could not interpret a counterpart in the list of ACRL standards (see Table 13). The researcher's definition of the cluster was “demonstrating development psychologically and/or socially to critically evaluate one's own work, to accept others' critical evaluations for improvement and to keep an open mind." Of the eight clusters, the Psychosocial Aspects Cluster had the highest mean score for importance at 4.41and the lowest efficacy averaged score of 2.70. These results demonstrate that although the stakeholders indicated the outcomes in this cluster to have been the most important on average for students to learn; however, Mid-Atlantic University's curriculum is least effective in helping students to develop these student learning outcomes.

\section{Comparison of Results with Information Literacy Outcomes Currently Utilized at Mid- Atlantic University}

In 2002, the provost of Mid-Atlantic University charged a group of faculty to coordinate a three-year comprehensive review of the institution's undergraduate program. Through fall 2004, faculty, staff, and students participated in focus groups, sub-committees, and open-agenda meetings to explore every aspect of undergraduate education offered by the university. This strategy established a framework for developing new curriculum, experiential and co-curricular 


\section{CONTENT DOMAIN FOR INFORMATION LITERACY}

opportunities, and interdisciplinary courses. Following this process, existing student learning outcomes underwent minute scrutiny, while for those departments, programs, or activities where specific student learning outcomes were lacking, extensive research and discussion took place among key stakeholders in order to establish meaningful and relevant outcomes. The Faculty Planning Group for Information Literacy, a sub-committee of the UEI that was composed of three library faculty, a teaching faculty member from the College of Education and the coordinator of the Undergraduate Education Initiative (UEI) project, recommended eight skills that a student should be knowledgeable about and able to demonstrate competency with in order to be considered information literate (Frostburg State University, 2005). According to the resources associated with or generated by the UEI in reference to information literacy, the members of the group selected the eight skills from the learning goals established by the Middle States Commission on Higher Education (2003):

- Recognizing the need to find information to support ideas and opinions

- Understanding that there are differences among information sources

- Searching several kinds of sources to retrieve information

- Evaluating the reliability of information sources

- Evaluating the probability of accuracy and reliability of information content

- Using information to complete assignments

- Understanding issues of plagiarism

- Citing sources using appropriate documentation style (Middle States Commission on Higher Education, pp. 11-12). 


\section{CONTENT DOMAIN FOR INFORMATION LITERACY}

Since then, the library faculty who are instructors for Mid-Atlantic University library's instruction program adopted six specific student learning goals they associated with the ACRL information literacy standards:

- Students will frame a research question and identify main concepts and corresponding keywords that can be used during the search process.

- Students will learn to understand the differences between information sources.

- Students will learn to use catalog USMAI (the online catalog of the University System of Maryland and Affiliated Institutions) to identify appropriate books and items within the library and the University system.

- Students will learn to use Research Port to identify and find appropriate articles for their research.

- Students will learn to efficiently and effectively access information and identify credible sources, including information from the World Wide Web.

- Students will understand that there are different documentation styles for citing sources. (Frostburg State University, 2004)

For both sets of learning goals, the researcher questioned whether the selected outcomes represent agreement among all stakeholders at the institution in regard to the skills that constitute information literacy competency? An underlying objective of this study was to determine whether the inclusion of more stakeholders representing other segments of the university with vested interests in information literacy, such as students, student affairs professionals, and faculty from varying disciplines would facilitate a better understanding of the importance of information literacy competency for all participants, as well as result in the selection of different, more suitable outcomes than those currently adopted by the library and the institution. 


\section{CONTENT DOMAIN FOR INFORMATION LITERACY}

The researcher solicited input via email from the two remaining library faculty and the one teaching faculty member who participated on the UEI Faculty Planning Group for Information Literacy to collect information regarding the process they used to identify the eight student learning outcomes they recommended in their final report. R. Lowe (personal communication, February 27, 2012) responded by email:

Our planning group was charged with more fully defining both information literacy and fluency (with an immediate emphasis on the former) in order to provide guidelines for skill development and standards upon which the skills could be assessed . . . Our group charged both [P. Williams] and me to conduct a bibliography and draft our definitions. [P. Williams] largely conducted the former and I drafted the initial definitions. .. our definitions were largely informed by the 2000 ACRL and 2003 Middle States standards. The definitions were expanded and revised as our planning group met, resulting in the skill definitions. . .

So, we did work as a group to finalize the definition and, while other institution's guidelines were reviewed, we did not stray from the ACRL or Middle States definitions (with the latter being of more importance to the faculty. . .).

The other librarian remaining at Mid-Atlantic University who participated in the UEI planning group for information literacy responded to the researcher's request for information as well. P. Williams (personal communication, February 26, 2012) supported R. Lowe’s description of the process that the two librarians worked together to draft the student learning outcomes that were vetted and approved by the other members of the committee.

Table 15 illustrates a comparison of the student learning definitions recommended by the UEI, the student learning goals developed by Mid-Atlantic University's librarians for the 
library's instruction program, and the content domain for information literacy conceptualized by the key stakeholders at the university using the Concept Mapping/Pattern Matching methodology.

Table 15

Comparison of Two Groups of Student Learning Outcomes for Information Literacy Utilized at Mid-Atlantic University and the Content Domain Conceptualized by the Key Stakeholders in the Study

\begin{tabular}{|l|l|l|}
\hline $\begin{array}{l}\text { Mid-Atlantic University's UEI } \\
\text { Student Learning Definitions } \\
\text { for Information Literacy }\end{array}$ & $\begin{array}{c}\text { Mid-Atlantic University's } \\
\text { Student Learning Goals for } \\
\text { Library Instruction }\end{array}$ & $\begin{array}{c}\text { Content Domain for } \\
\text { Information Literacy } \\
\text { Conceptualized by Study }\end{array}$ \\
\hline $\begin{array}{l}\text { Recognizing the need to find } \\
\text { information to support ideas } \\
\text { and opinions. }\end{array}$ & $\begin{array}{l}\text { Students will frame a research } \\
\text { question and identify main } \\
\text { concepts and corresponding } \\
\text { keywords that can be used } \\
\text { during the search process. }\end{array}$ & $\begin{array}{l}\text { Understanding the stages of } \\
\text { the research process and } \\
\text { having the ability to complete } \\
\text { them. }\end{array}$ \\
\hline $\begin{array}{l}\text { Understanding that there are } \\
\text { differences among information } \\
\text { resources. }\end{array}$ & $\begin{array}{l}\text { Students will learn to } \\
\text { understand the differences } \\
\text { between information sources. }\end{array}$ & $\begin{array}{l}\text { Basic technical skills } \\
\text { associated with knowing how } \\
\text { to access information sources, } \\
\text { select search terms, and } \\
\text { manage results. }\end{array}$ \\
\hline $\begin{array}{l}\text { Searching several kinds of } \\
\text { sources to retrieve } \\
\text { information. }\end{array}$ & $\begin{array}{l}\text { Students will learn to use } \\
\text { catalog USMAI (the online } \\
\text { catalog of the University } \\
\text { System of Maryland and } \\
\text { Affiliated Institutions) to } \\
\text { identify appropriate books and } \\
\text { items within the library and } \\
\text { the University system. }\end{array}$ & $\begin{array}{l}\text { The ability to evaluate, select } \\
\text { and utilize the appropriate } \\
\text { information sources and tools } \\
\text { depending on the type of } \\
\text { information needed. }\end{array}$ \\
\hline $\begin{array}{l}\text { Evaluating the reliability of } \\
\text { information sources. }\end{array}$ & $\begin{array}{l}\text { Students will learn to use } \\
\text { Research Port to identify and } \\
\text { find appropriate articles for } \\
\text { their research. }\end{array}$ & $\begin{array}{l}\text { Understanding the legal and } \\
\text { ethical issues related to } \\
\text { information use and the ability } \\
\text { to apply rules for safeguarding } \\
\text { others' intellectual property. }\end{array}$ \\
\hline
\end{tabular}

(continued) 
Table 15 (continued)

Comparison of Two Groups of Student Learning Outcomes for Information Literacy Utilized at Mid-Atlantic University and the Content Domain Conceptualized by the Key Stakeholders in the Study

\begin{tabular}{|l|l|l|}
\hline $\begin{array}{l}\text { Evaluating the probability of } \\
\text { the accuracy and reliability of } \\
\text { information content. }\end{array}$ & $\begin{array}{l}\text { Students will learn to } \\
\text { efficiently and effectively } \\
\text { access information and } \\
\text { identify credible sources, } \\
\text { including information from } \\
\text { the World Wide Web. }\end{array}$ & $\begin{array}{l}\text { The ability to communicate } \\
\text { information effectively to } \\
\text { others, including selecting the } \\
\text { appropriate format and media } \\
\text { for conveying the information, } \\
\text { and applying correct rules of } \\
\text { grammar, spelling, and } \\
\text { punctuation. }\end{array}$ \\
\hline $\begin{array}{l}\text { Using information to complete } \\
\text { assignments. }\end{array}$ & $\begin{array}{l}\text { Students will understand that } \\
\text { there are different } \\
\text { documentation styles for } \\
\text { citing sources. }\end{array}$ & $\begin{array}{l}\text { The ability to evaluate } \\
\text { information critically for } \\
\text { relevance, quality, credibility, } \\
\text { balance, and reliability. }\end{array}$ \\
\hline $\begin{array}{l}\text { Understanding issues of } \\
\text { plagiarism. }\end{array}$ & $\begin{array}{l}\text { Demonstrating development } \\
\text { psychologically and/or } \\
\text { socially to critically evaluate } \\
\text { one's own work, to accept } \\
\text { others' critical evaluations for } \\
\text { improvement and to keep an } \\
\text { open mind. }\end{array}$ \\
\hline $\begin{array}{l}\text { Citing sources using } \\
\text { appropriate documentation } \\
\text { style. }\end{array}$ & $\begin{array}{l}\text { The ability to analyze and } \\
\text { synthesize information } \\
\text { retrieved as search results to } \\
\text { formulate opinion, support or } \\
\text { disprove hypothesis, and to } \\
\text { add to one's knowledge base. }\end{array}$ \\
\hline
\end{tabular}

Note: ${ }^{1}$ Adapted from Middle States Commission on Higher Education. (2003). Developing research \& communication skills: Guidelines for information literacy in the curriculum. Philadelphia, PA: Middle States Commission on Higher Education. 


\section{Limitations of the Study}

This study has several potential limitations that must be addressed:

1. Although the use of Concept Mapping/Pattern Matching is gaining in frequency and popularity as a methodology very appropriate for planning and evaluation; as well as helping to discern meaningful inferences from data when univariate statistical tests do not reach statistical significance (Caracelli, 1989), there are stages of the process that require subjective involvement on the part of the analyst that could cause critics to question the validity of the study (Trochim, 1989a).

2. The generalizability of the study may be a limitation. Although the data to be collected for this study may be applied to similar research related to the effectiveness of an institution of higher education in improving information literacy skills, it may not be relevant to other studies assessing information literacy competency. Also, since the study was conducted at a medium sized Master's L institution in a geographically isolated environment, care will need to be taken when generalizing the data to another institution or overall population.

3. The use of a focus group for generating the data analyzed in this study could be considered a limitation to this study. The participants were purposefully selected by the researcher because of their demonstrated interest in teaching or exposing students to opportunities for achieving information literacy competency. This criterion was confirmed by the participant during the discussion that took place when the researcher met with each individual to invite him or her to join the study. The fact that the focus group was not composed of a random sample of faculty and administrators at Mid- 
Atlantic University could impact the ability to replicate the study in another environment.

4. Much like emerging data mining techniques, Concept Mapping/Pattern Matching deviates from traditional Western epistemologies that employ Null Hypothesis Testing. Furthermore, Concept Mapping/Pattern Matching does not involve sampling. This limitation is not methodological in nature, as Concept Mapping/Pattern Matching utilizes credible and complex statistical techniques like multidimensional scaling and hierarchical cluster analysis. Regardless, Concept Mapping/Pattern Matching is a methodology that mixes both quantitative and qualitative techniques.

5. In this particular type of study, spontaneity of the participants' responses is an important factor. However, that could also be a limitation. Had the participants been given some background information regarding the principles of information literacy, their responses may have been different. There may also be differences between academic affairs and student affairs professionals understanding of the meaning of information literacy that were not addressed in this study.

6. Using a focus group of highly involved professionals and students created limitations in regard to scheduling a convenient time to meet that would have allowed for more time to think before responding or the ability to discuss and format the responses for consistency. This may have impacted respondents understanding of the outcomes or in recalling the intent of the statement when responding to the survey.

7. The inclusion of a neutral rating in the survey, without determining its purpose, may have resulted in different interpretations of those responders who selected that option. 
8. The survey was generated by the results of the brainstorming session. The elements of the survey were prescribed. An opportunity for participants to add comments as to why they rated the items as they did was not available. This insight might have been invaluable to the researcher.

9. The clustering of outcomes into distinct groups was the combined result of the independent card sorts conducted by the focus group members and the hierarchical cluster analysis. It is difficult to determine and possibly unlikely that the resulting outcomes would be clustered the same way if the 80 cards were given to 14 different participants, even if they were selected using the same criteria followed in developing the first focus group.

10. The survey required responders to rate the same 80 items twice, using two different scales. The length of the survey could have encouraged the responders to move more quickly through the lists without carefully weighing each outcome, or to select neutral more often in order to finish the survey quickly. As a result, the validity of survey could be compromised.

11. The focus of the brainstorming session conducted during the study was to gather data that identified outcomes the participants perceived to reflect information literacy competency. To maintain an atmosphere that encouraged spontaneity and freedom of expression, participants were not requested to consider vocabulary, grammar, or syntax. Therefore, a limitation of this study is that some of the statements, referred to as outcomes in the reporting of the results may not be expressed in the prescribed format for student learning outcomes recommended by assessment experts (Huba \& Freed, 2000; Suskie, 2004). However, the researcher strove to ensure the integrity of 
participants' responses by documenting them verbatim. Changes were not made to the resulting data, such as correcting the grammar, voice, or choice of wording, because to do so could have altered the meanings of the statements as they were understood by the members of the focus group and could have affected their responses in completing the subsequent survey. 
CONTENT DOMAIN FOR INFORMATION LITERACY

\section{Chapter 5}

\section{Summary, Conclusions, Implications, and Future Research}

The purpose of this research study was to assess the relevance of a national association's standards designed to assist institutions of higher education in establishing learning outcomes for developing information literacy competency in undergraduate college students at Mid-Atlantic University in Maryland. The standards were published in 2000 by the Association of College and Research Libraries (ACRL) under the title Information Literacy Competency Standards for Higher Education. They have been adopted by institutions of higher education; professional organizations in education and librarianship; and by state, regional, and national accrediting agencies. During the eleven years since their publication, the amount of information generated by the world's population has increased exponentially.

The research questions that guided this study were:

1: When using Concept Mapping/Pattern Matching methodology, how do key stakeholders at a mid-sized regional Mid-Atlantic university conceptualize student outcomes for information literacy?

2: How does conceptualization generated through Concept Mapping/Pattern Matching at a mid-sized regional Mid-Atlantic university compare and contrast with the framework established by the Association of College and Research Libraries?

\section{Summary}

To accomplish an assessment of the relevance of ACRL's (2000) Information Literacy Competency Standards for Higher Education at Mid-Atlantic University, the researcher solicited the expertise of key stakeholders responsible for ensuring student success in achieving information literacy competency at the aforementioned institution to identify the outcomes they 


\section{CONTENT DOMAIN FOR INFORMATION LITERACY}

considered to indicate information literacy competency. The group of 14 participants included six faculty members, three librarians, three student affairs professionals, and two students in their fourth year of college. The researcher used Concept Mapping/Pattern Matching as the methodology, specifically the process advanced by William Trochim (1989b), for gathering and analyzing the data to conceptualize the domain of desired information literacy competencies. The stakeholders met as a focus group to brainstorm a list of information literacy competency skills they felt answered the question: "What are the student learning outcomes for information literacy that the University should expect of its graduates?" The participants generated 80 outcomes that they were then asked to sort independently into groups that made sense to them. They were also asked to complete a survey using ordinal scales to rate the 80 outcomes they had created. The survey was comprised of two questions:

1. How relatively important do you believe this student learning outcome is for undergraduate students at [name of institution]? (very unimportant; unimportant; neutral; important; very important)

2. Overall, how well does [name of institution]'s curriculum help students develop this particular student learning outcome? (very poorly, poorly, neutral, well, very well).

The resultant groupings of outcomes from the individual card sorts by the participants were analyzed using multidimensional scaling to plot the outcomes on a concept map (see Figure 1). Hierarchical cluster analysis was used to identify how the outcomes were grouped into clusters (see Figure 4). The responses from the survey were also analyzed to calculate the mean scores for the importance rating and the efficacy by which Mid-Atlantic University's curriculum fosters student development for each of the outcomes. Following the creation of the concept map using the data collected from the participants, the resulting priorities and their 


\section{CONTENT DOMAIN FOR INFORMATION LITERACY}

conceptualization schema were compared to the national organization's standards and to the student learning outcomes associated with information literacy currently incorporated in MidAtlantic University's general education curriculum and the library's instruction program. The objective of the qualitative document analysis was to begin to validate the relevancy of the existing outcomes at the national level to those applied locally through a comparison and contrast of precepts as they relate to the local student population. The researcher matched the outcomes on the Concept Mapping/Pattern Matching statement list (see Appendix C) to the outcomes associated with the ACRL (2000) Information Literacy Standards by recording the identifying numbers for both sets of outcomes next to their counterparts on each list (see Appendix H). This process required some interpretation of the intent of the outcomes on the part of the researcher due to the differences in language use and the styles in which the outcomes were written in the two documents.

\section{Summary of Findings}

A study of the hierarchical cluster tree or dendrogram (see Appendix E) created by the hierarchical cluster analysis revealed that the 80 student learning outcomes for information literacy that had been generated and sorted by the stakeholders at Mid-Atlantic University could be grouped together most logically into eight clusters or overarching goals. The clusters and their definitions included: the Research Process Cluster (understanding the stages of the research process and having the ability to complete them); the Technical Skills Cluster (basic technical skills associated with knowing how to access information sources, select search terms, and manage results); the Selecting Sources Cluster (the ability to evaluate, select and utilize the appropriate information sources and tools depending on the type of information needed); the Information Ethics Cluster (understanding the legal and ethical issues related to information use 


\section{CONTENT DOMAIN FOR INFORMATION LITERACY}

and the ability to apply rules for safeguarding others' intellectual property); the Communication Cluster (the ability to communicate information effectively to others, including selecting the appropriate format and media for conveying the information, and applying correct rules of grammar, spelling, and punctuation); the Evaluating Information Cluster (the ability to evaluate information critically for relevance, quality, credibility, balance, and reliability); the Psychosocial Aspects Cluster (demonstrating development psychologically and/or socially to critically evaluate one's own work, to accept others' critical evaluations for improvement and to keep an open mind); and the Information Utilization Cluster (the ability to analyze and synthesize information retrieved as search results to formulate opinion, support or disprove hypotheses, and to add to one's knowledge base). For each cluster, the mean scores for importance and efficacy were calculated by averaging the means for the outcomes associated with that cluster (see Table 11).

Cluster 7, the Psychosocial Aspects Cluster, had the highest mean score for importance at 4.41and the lowest efficacy averaged score of 2.70. These results demonstrate that although the stakeholders identified the student learning outcomes in this cluster to have been the most important overall, Mid-Atlantic University's curriculum is least effective in helping students to develop these competency skills. The Selecting Sources Cluster resulted in having the lowest mean score for importance at 3.93, just below a 4.0. The other six clusters had importance ratings ranging from 4.0 for the Technical Skills Cluster to 4.3 for Information Utilization. The mean scores for efficacy for five of the clusters were below 3.0 or considered poorly and the other three clusters each averaged a mean score barely above a 3.0.

The survey results indicated that the stakeholders in the focus group believed the majority of the outcomes were important as evidenced by the number of important and very important 


\section{CONTENT DOMAIN FOR INFORMATION LITERACY}

responses selected by the respondents for each outcome (see Appendix I) and the number of outcomes that had a means of 4.0 or above. However, the number of mean scores for efficacy that fell below 3.0, indicating a higher number of responses of poorly or very poorly, reflected that several of the participants shared the opinion that Mid-Atlantic University was not addressing these outcomes in the curriculum. The number of outcomes that had average efficacy ratings that were close to 3.0 could also have been attributed to the number of respondents who selected the neutral option from the ordinal scale for those items. This finding is substantiated by examining the actual number of survey responses for each rating (see Appendix $\mathrm{J}$ ). Out of the 1,120 possible responses for the survey question regarding the efficacy of information literacy development in the curriculum, the neutral option was chosen 439 times or for $39 \%$ of the responses. The option very poorly was selected for $8 \%$ of the efficacy responses and poorly was chosen for $24 \%$, as opposed to $23 \%$ of the responses indicating an efficacy level of well or $6 \%$ for very well.

The results of the document analysis comparing and contrasting the 80 outcomes generated by the stakeholders during the Concept Mapping/Pattern Matching process and the 87 outcomes published in ACRL's (2000) Information Literacy Competency Standards for Higher Education revealed that there are numerous examples of similarities that exist between the two lists (see Appendix H). Although the Mid-Atlantic University outcomes may not have been grouped in the same clusters that have similar themes to the ACRL Information Literacy Standards, 69 or $86 \%$ of the 80 statements generated by the focus group could be correlated to one or more of the ACRL outcomes. Similarly, 70 of the ACRL outcomes or $80 \%$ were paired with one or more of the Mid-Atlantic University outcomes. A comparison of the five ACRL Information Literacy Standards to the eight Concept Mapping/Pattern Matching clusters resulted 


\section{CONTENT DOMAIN FOR INFORMATION LITERACY}

in similar correlations. Despite the fact that the ACRL standards were fewer in number, the goal expressed by each of them was represented in at least one of the Mid-Atlantic University clusters (see Table 13).

Further comparison between the ACRL (2000) Information Literacy Standards and the Mid-Atlantic University's lists of outcomes also revealed several differences. Based on the researcher's interpretations, it was noted that 70 of the 87 ACRL outcomes could be paired with one or more of the Concept Mapping/Pattern Matching outcomes generated by the study, leaving 17 that the researcher couldn't match. Those for which an equivalent outcome could not be found are listed in Table 14. During the same document comparisons, the researcher noted that 11 of the 80 student learning outcomes identified by the focus group could not be paired with a counterpart from the 87 ACRL outcomes. Two of the statements without comparable outcomes were grouped together in the seventh cluster created by the hierarchical cluster analysis and labeled the Psychosocial Aspects Cluster by the researcher. The Psychosocial Aspects Cluster is the only cluster for which the researcher could not interpret a counterpart in the list of ACRL standards (see Table 13). Three of the four Mid-Atlantic University outcomes that were grouped into this cluster as a result of the hierarchical cluster analysis refer to development that is psychological or affective in nature, rather than outcomes that are actionable (see Table 10).

The student learning outcomes for information literacy that were conceptualized by the stakeholders during the Concept Mapping/Pattern Matching study were also compared to the outcomes that were adopted for the Mid-Atlantic University's general education program during the extensive revision of that program's curriculum between 2002 and 2005, and those selected by the university's library faculty for their information literacy instruction program. It was noted earlier that the process of selecting the student learning outcomes for information literacy for 


\section{CONTENT DOMAIN FOR INFORMATION LITERACY}

both of these programs was conducted predominantly by library professionals. The outcomes chosen clearly parallel a selection of competency skills from the ACRL's (2000) Information Literacy Competency Standards for Higher Education or the Middle States Commission on Higher Education's (2003) Developing Research \& Communication Skills: Guidelines for Information Literacy in the Curriculum (see Table 15). This inference is confirmed in the supporting documentation explaining the undergraduate education initiative (UEI), the library's website, and personal communications received by the researcher from two of the Mid-Atlantic University librarians who served on the planning group that recommended the information literacy outcomes (R. Lowe, personal communication, February 27, 2012; P. Williams, personal communication, February 26, 2012).

Several conclusions can be drawn from the findings that resulted from the various stages of research conducted for this study. The following section examines each of the conclusions.

\section{Conclusions}

\section{Application of national standards for information literacy at the local level. The} purpose of this research study was to assess the relevance of generally-accepted standards for information literacy competency created by a national association to the local student population at Mid-Atlantic University, a mid-sized institution in Maryland. A comparison of the Association of College and Research Libraries' (ACRL) outcomes to those generated by key stakeholders at Mid-Atlantic University who had demonstrated an interest in ensuring that students achieve information literacy resulted in a match for 70 of the 87 ACRL outcomes. This conclusion is important because the committee that developed the standards at the national level was composed predominantly of library professionals (ACRL, 2000) but the focus group of local stakeholders consisted primarily of faculty, student affairs professionals, students, and only three 


\section{CONTENT DOMAIN FOR INFORMATION LITERACY}

librarians. A review of the literature related to information literacy showed that academic librarians have been in the forefront as advocates for instilling information literacy competency skills in students for decades (ALA, 1989; Badke, 2005; Behrens, 1994; Breivik \& Gee, 1989; Demo, 1986; McAdoo, 2008; Rader, 2002). Therefore, it is understandable that the three librarians in the local group would have been familiar with ACRL's information literacy standards, particularly since one of the librarians is the coordinator for Mid-Atlantic University's library instruction program and the other two library faculty participate as instructors in that program. However, the remaining members of the focus group were not aware of the existence of the standards, let alone the specific outcomes associated with them. As a result of the researcher's document analysis comparing the two lists of outcomes for similarities (see Appendix $\mathrm{H}$ ), the assumption can be made that approximately $80 \%$ of the ACRL outcomes are relevant competency skills for demonstrating the achievement of information literacy at the local institution.

\section{Relevance of current information literacy standards both nationally and locally. An} argument that is made in the literature related to information literacy regarding its importance as a competency skill is the need for college graduates, in fact all members of the nation's workforce, to be able to navigate and utilize effectively the ever-expanding amount of information that is continuously being generated (Breivik, 1998; Candy, 2000; Demo, 1986; Drucker, 1994; Jones, 2002). New technologies for creating and displaying information, accessing it, and sharing it have also rapidly developed in the eleven years since the ACRL (2000) Information Literacy Competency Standards for Higher Education were published. The current generation of college students uses an array of digital and multi-media tools to communicate, to locate information, and to entertain themselves. They are considered by some 


\section{CONTENT DOMAIN FOR INFORMATION LITERACY}

to be far more technology literate than those who are teaching them (Combes, 2006; Long, 2005;

McHale, 2005; Prensky, 2001). However, research has shown that while Millennials can quickly learn to use technology for entertainment purposes and to find general information on a topic, they do not have the knowledge or skills to differentiate between authoritative and unreliable sources of information, interpret accurately the content that is provided to them, or to fully understand the value and how to utilize that material to solve a problem (Becker, 2009). In addition to assessing whether the ACRL Information Literacy Standards were relevant at a local mid-sized university, another objective of this study was to determine if student achievement of information literacy competency was considered important to the key stakeholders at MidAtlantic University and, if so, which competency skills were more important than others.

Following the creation of the 80 outcomes for information literacy by the Concept Mapping/Pattern Matching focus group, the participants were asked to respond to a survey that utilized an ordinal scale to rate the importance of the outcomes. The survey asked the question:

1. How relatively important do you believe this student learning outcome is for undergraduate students at [name of institution]? (very unimportant; unimportant; neutral; important; very important).

Nearly $75 \%$ (i.e., 59 out of 80) of the Mid-Atlantic University outcomes earned mean importance ratings of 4.0 or better. Of the 21 outcomes that had a means below 4.0, 18 scored between 3.5 and 3.93 on importance. Based on these results, the researcher concluded that a large majority of the outcomes generated by the focus group were considered to be important. However, an analysis of the outcomes after they were grouped into clusters indicated that the majority of them related to the ability to effectively retrieve, evaluate, and utilize information in the form of the written word, whether it is printed or in digital form, and only slightly addressed 


\section{CONTENT DOMAIN FOR INFORMATION LITERACY}

the ability to use other media. For example, the Technical Skills Cluster included eight statements grouped together as a result of the hierarchical cluster analysis. The survey results for this cluster indicated that the focus group participants rated the outcomes associated with the ability to effectively search for information as being important with mean scores above 4.0; as opposed to the outcomes supporting the need to be technologically literate. The mean importance ratings for the technology related outcomes: 26 (organizing, storing and backing up information), 24 (awareness of security and personal privacy issues), and 45 (protocols for accessing private information) fell short of being considered important implying that some of the respondents must have selected neutral or the unimportant options for these outcomes. The skills related to information technology, while still above 3.0 are not as important to the key stakeholders as those that reflect the ability to execute a search. An analysis of the 17 ACRL outcomes for which the researcher could not find a parallel among the Mid-Atlantic University outcomes, six were directly related to the use of information technology. Given the fact that much of the research and information gathering conducted currently requires some level of proficiency in the use of technology, these results reinforce a conclusion that the curriculum at Mid-Atlantic University may emphasize information literacy skills that are centered around text, whether in print or digital format, despite the increasing amount of information that is disseminated using a variety of multi-media or social-media technologies.

Following an examination of the outcomes associated with the ACRL (2000) Information Literacy Standards, the researcher concluded there is a similar bias to focusing predominantly on textual content and excluding other forms of media; however that is understandable since the current standards were published eleven years ago before many of the newer technologies for creating, storing, retrieving, and disseminating information existed. In 2010, ACRL's Image 


\section{CONTENT DOMAIN FOR INFORMATION LITERACY}

Resources Interest Group (IRIG), recognizing the vast emergence of information in visual and multi-media formats, proposed the development of Visual Literacy Competency Standards to rectify the omission of information literacy standards and outcomes that address the use of images and visual media materials. Using the Information Literacy Competency Standards for Higher Education as a foundational document and framework, the Visual Literacy Standards Task Force released the first public draft of the new standards in February 2011. The ACRL Board of Directors approved the Visual Literacy Competency Standards for Higher Education in October 2011.

\section{Importance of including key stakeholders in developing learning outcomes. An}

underlying objective of this study was to determine whether the inclusion of more stakeholders representing other segments of the university with vested interests in information literacy, such as students, student affairs professionals, and faculty from varying disciplines would facilitate a better understanding of the importance of information literacy competency for all participants, as well as result in the selection of different, more suitable outcomes than those currently adopted by the library and the institution. The findings of the study support the conclusion that the key stakeholders at Mid-Atlantic University who participated in the focus group to generate student learning outcomes for information literacy agreed that the skills they identified are important as evidenced in the discussion of previous conclusions.

To determine whether the inclusion of stakeholders representing segments of the university other than just the library encouraged the creation of student learning outcomes for information literacy that were more reflective of the broader population, it was necessary to look closely at the Mid-Atlantic University outcomes that differ from the ACRL outcomes. Although the majority of the 80 outcomes generated by the focus group were similar to the ACRL (2000) 


\section{CONTENT DOMAIN FOR INFORMATION LITERACY}

Information Literacy Standards, 11 were not. Five of those 11 outcomes were related to skills that could be considered developmental from a psychosocial perspective. They included 36 (have a healthy dose of skepticism); 64 (the ability to accept challenges of their own perspective and respond appropriately); 76 (recognize the limits of their knowledge); 78 (autonomous in seeking information); and 79 (confidence). Two other outcomes that were paired with ACRL outcomes but could also be related to the psychosocial development of college students were 61 (identifying competing perspectives and responding to them effectively) and 65 (the ability to challenge their own perspectives). Following the hierarchical cluster analysis conducted as a component of the Concept Mapping/Pattern Matching process, four of these outcomes were grouped together on the hierarchical cluster tree (see Appendix E) to create a seventh cluster that the researcher and facilitator labeled the Psychosocial Aspects Cluster. The Psychosocial Aspects Cluster was the only one of the eight clusters that could not be paired to a specific ACRL standard. Interestingly, this cluster was rated the highest in regard to importance and the lowest in relation to the efficacy of the curriculum helping students to develop this particular student learning outcome (see Table 12). The development of these outcomes and the importance given to them by all of the focus group members supports the conclusion that the participation of key stakeholders from various segments of the university in addition to the library resulted in identifying outcomes beyond those of the national standards.

As mentioned previously, of particular importance to the researcher in selecting the participants for the focus group was the inclusion of student affairs professionals because this group of university administrators has been generally excluded from discussion in previous literature related to information literacy. However, the staff of the various departments and programs affiliated with the student affairs division have responsibilities that focus specifically 


\section{CONTENT DOMAIN FOR INFORMATION LITERACY}

on developing the psychosocial skills of college students. The numerous theories related to college student development are often the framework around which student affairs professionals build their programs. For example, a comparison of the outcomes grouped in the Psychosocial Aspects Cluster reveals a possible affiliation with five of Chickering and Reisser's (1993) seven vectors of development: 1) Developing competence, 3) Moving through autonomy toward interdependence, 4) Developing mature interpersonal relationships, 5) Establishing identity, and 7) Developing integrity. Although some research has been published recently applying Perry’s theory of cognitive development to teaching information literacy competency skills (Jackson, 2008), it is recommended for further research that the psychosocial aspects of information literacy identified to be important by the participants involved in this study should be evaluated within the context of Chickering's seven vectors or other psychosocial development theories.

Ambiguity in regard to effectiveness in teaching information literacy skills. The researcher has argued that the results of this study support the conclusion that information literacy is an important competency skill as evidenced by the mean scores for importance that were calculated from the participants' responses to the survey. However, an analysis of the survey results also led the researcher to infer a conclusion that there is ambiguity on the part of key stakeholders regarding the effectiveness that these skills are being taught to students in the curriculum or by various departments at the university. This assumption is based on the predominate number of times respondents selected the neutral option 3 on the ordinal scale for the survey question that asked: Overall, how well does [name of institution]'s curriculum help students develop this particular student learning outcome. The majority (i.e., $57.5 \%$ or 46 ) of the 80 outcomes generated by the Mid-Atlantic University focus group of key stakeholders were given mean efficacy ratings below 3.0. Of the remaining 34 outcomes, 30 received mean scores 


\section{CONTENT DOMAIN FOR INFORMATION LITERACY}

between 3.0 and 3.5. A review of the actual survey results shows that out of the 1,120 possible responses for the question regarding the efficacy of information literacy development in the curriculum, the neutral option was chosen 439 times or for $39 \%$ of the responses. The option very poorly was selected for $8 \%$ of the efficacy responses and poorly was chosen for $24 \%$, as opposed to $23 \%$ of the responses indicating an efficacy level of well or $6 \%$ for very well (see Appendix J). The researcher concluded that the responses for very poorly, poorly, well, or very well virtually cancelled each other out, leaving the prevailing response of neutral with a slight proclivity for the two lower choices. The use of neutral as an option in an ordinal scale can have dual meanings - the respondent does not have an opinion or does not know the answer. In respect to evaluating efficacy of the curriculum, not having an opinion and not knowing the answer can be interpreted to mean that there is ambiguity regarding how well the curriculum helps students develop a particular student learning outcome. This affirms a conclusion by McAdoo (2008) that "faculty seem to have a mixed awareness of the importance of IL and curricular expectations regarding such" (p. 163).

\section{Implications of the Findings}

This study has identified several implications for those practitioners who teach information literacy competency skills in higher education, particularly academic librarians. It also reveals the need for broader representation of all stakeholders when establishing standards or student learning outcomes. In regard to the application of student learning outcomes in teaching competency, the periodic evaluation of the relevance of the outcomes is equally important as the assessment of outcome achievement.

Academic librarians should assume more proactive roles in promoting their services and successes to their campus community. The results of this study have serious implications 


\section{CONTENT DOMAIN FOR INFORMATION LITERACY}

for academic librarians, particularly since the professional literature still places college and university library professionals in the forefront of teaching information literacy skills. A review of the literature has demonstrated that librarians have been advocating the importance of information literacy instruction for nearly four decades. At various times throughout history, these programs were called bibliographic instruction, library orientation or library instruction. The more recent publications in the fields of education and librarianship have promoted strongly the need for collaboration between faculty and librarians to incorporate information literacy competency into the classroom and across the curriculum (Booth \& Fabian, 2002; Breivik, 1998; Breivik \& Gee, 1989; Raspa \& Ward, 2000).

The key stakeholders that were gathered together as a focus group for this study acknowledged the importance of teaching specific information literacy outcomes to students. However, their responses to a survey question asking them to rate the effectiveness of the local institution's curriculum in developing these skills in students resulted in ratings ranging predominantly between poorly and neutral. The use of neutral in regard to this question has been interpreted to mean "unknown," leading the researcher to the conclusion that there is still ambiguity on the part of faculty and administrators as to whether students are achieving these skills. The implication that can be made from this conclusion is that the library profession has not been overly successful in broadcasting their message and accomplishments in this area to their campus communities, despite numerous articles and studies published in the professional literature providing assessment data to verify the achievement of the skills by their students. More must be done on the part of academic librarians to promote their services and the success of their programs to their institutions, not just to their profession. 
CONTENT DOMAIN FOR INFORMATION LITERACY

\section{Academic libraries should include representation from key stakeholders when}

establishing information literacy outcomes. Although the document analysis that was

conducted for this study resulted in a favorable comparison between the outcomes and standards published in ACRL's (2000) Information Literacy Competency Standards for Higher Education

and the student learning outcomes generated by the key stakeholders at Mid-Atlantic University, an implication for academic libraries resulting from the findings is the need to include other university agents who have an interest in ensuring student success in the development of the learning outcomes for their information literacy programs. By asking faculty, student affairs professionals, and students to rate the importance of a large number of relevant outcomes, the library instruction coordinators and faculty may be able to select student learning outcomes for their programs that have more meaning to the university community as a whole, thus encouraging an element of collaboration the librarians are seeking and possibly promoting interest and awareness in the importance of information literacy as a competency skill.

\section{Academic libraries should reevaluate their information literacy outcomes}

periodically. A secondary implication resulting from this study is the need for academic libraries to periodically reevaluate the relevance of the student learning outcomes associated with their information literacy instruction programs. An evaluation of the desired skills targeted for achievement revealed a bias for the effective retrieval and utilization of information in a textual format, either print or digital, despite increasing evidence that the current generation of students seeks information in multiple formats including multi-media. Not only does this finding have implications for academic librarians who teach information literacy skills, but also those who provide reference services designed to assist students with locating information to support their research needs; as well as library administrators who decide what technology will be purchased 


\section{CONTENT DOMAIN FOR INFORMATION LITERACY}

to facilitate these services. Most of the electronic resources commonly purchased or subscribed to by libraries provide access to print and digitized documents. In addition to teaching students how to search the internet effectively when in need of print or non-print materials, it is becoming increasingly important for librarians to evaluate the quality of resources available in multi-media formats, such as the numerous instruction aids available on YouTube, blogs, and other forms of social media, in order to recommend them with confidence to faculty who may discriminate against the use of these types of resources in research. Hopefully, the recent publication of new competency standards for visual literacy from ACRL (2011) will encourage academic libraries to reevaluate their existing information literacy outcomes and provide a framework for adapting and incorporating standards that support all formats of information.

The Association of College and Research Libraries should consider reevaluating its multiple information literacy documents for currency and consolidation into one. The implications of the findings of this study in regard to academic librarians addressed briefly an issue that also has implications for the Association of College and Research Libraries (ACRL). That finding is the need to periodically reevaluate the relevance of the student learning outcomes associated with ACRL's (2000) Information Literacy Competency Standards for Higher

Education to reflect current trends in information dissemination. Referencing the vast amount of information that is being generated in today's global environment, a common argument advocating the importance of information literacy competency is the need for the knowledge worker to be able to navigate and utilize information effectively (Candy, 2000; Demo, 1986; Drucker, 1994). New technologies for creating and displaying information, accessing it, and sharing it have rapidly developed in the eleven years since the ACRL (2000) Information Literacy Standards were published. It has been mentioned previously that the current generation 


\section{CONTENT DOMAIN FOR INFORMATION LITERACY}

of college students uses a variety of digital and multi-media tools to communicate, to locate information, and to entertain themselves. They are considered by some to be far more technology literate than those who are teaching them (Combes, 2006; Long, 2005; McHale, 2005; Prensky, 2001). However, research has shown that while Millennials can quickly learn to use technology for entertainment purposes and to find general information on a topic, they do not have the knowledge or skills to differentiate between authoritative and unreliable sources of information, interpret accurately the content that is provided to them, or to fully understand the value and how to utilize that material to solve a problem (Becker, 2009), thereby reinforcing the need for information literacy instruction in this digital age. One of the findings in this study implied the existence of a bias for retrieving and utilizing information primarily in a textual format whether print or digital, as the result of an evaluation of the learning outcomes generated by Mid-Atlantic University stakeholders and those associated with the ACRL (2000) Standards. That finding in regard to the ACRL standards is understandable since the current standards were published eleven years ago before many of the newer technologies using multi-media for creating, storing, retrieving, and disseminating information existed. In 2010, ACRL's Image Resources Interest Group (IRIG), recognizing the vast emergence of information in visual and multi-media formats, proposed the development of Visual Literacy Competency Standards to rectify the omission of information literacy standards and outcomes that address the use of images and visual media materials. Using the Information Literacy Competency Standards for Higher Education as a foundational document and framework, the Visual Literacy Standards Task Force released the first public draft of the new standards in February 2011. The ACRL Board of Directors approved the Visual Literacy Competency Standards for Higher Education in October 2011. The implication for ACRL is to determine whether the two very distinct 


\section{CONTENT DOMAIN FOR INFORMATION LITERACY}

documents of standards: the well-known existing outcomes for developing information literacy competency published eleven years ago and the new standards for visual literacy competency, satisfy the need for relevant outcomes for the current or next generations of students; or should ACRL establish a task force to rewrite the original standards incorporating the visual literacy competency skills to create a new group of standards that encompass all forms of information. In 2007, the American Association of School Librarians (AASL), the other division of the American Library Association that had published the first information literacy standards for K12 in 1998 released Standards for the $21^{\text {st }}$-Century Learner. These standards represent a significant transformation in the development of student learning outcomes.

Learning in the twenty-first century has taken on new dimensions with the exponential expansion of information, ever-changing tools, increasing digitization of text, and heightened demands for critical and creative thinking, communication, and collaborative problem solving. To succeed in our rapid-paced, global society, our learners must develop a high level of skills, attitudes and responsibilities. All learners must be able to access high-quality information from diverse perspectives, make sense of it to draw their own conclusions or create knowledge, and share their knowledge with others.

In recognition of these demands, the American Association of School Librarians (AASL) has developed learning standards that expand the definition of information literacy to include multiple literacies, including digital, visual, textual, and technological, that are crucial for all learners to acquire to be successful in our information-rich society. (AASL, 2009, p. 5).

In addition to the recent publication of the Visual Literacy Competency Standards for Higher Education in 2011, different interest groups and task forces within ACRL have 


\section{CONTENT DOMAIN FOR INFORMATION LITERACY}

developed discipline specific standards and outcomes since 2000 when the general information literacy standards were published. The organization may want to consider a review of all of the existing standards with the possible intent to revise them within the framework similar to or established by the AASL (2007).

\section{Mid-Atlantic University should reevaluate all student learning outcomes for} information literacy to include skills rated as important to multiple stakeholders. The results of this study may have several implications for faculty, including librarians, and student affairs administrators at Mid-Atlantic University. The student learning outcomes for information literacy that were generated by the stakeholders during the Concept Mapping/Pattern Matching study were also compared to the outcomes that were adopted for the Mid-Atlantic University's general education program during the extensive revision of that program's curriculum between 2002 and 2005, and those selected by the university's library for their information literacy instruction program. It was noted earlier that the process of selecting the student learning outcomes for information literacy for both of these programs was conducted predominantly by library professionals. The outcomes chosen were adapted from the ACRL's (2000) Information Literacy Competency Standards for Higher Education or the Middle States Commission on Higher Education's (2003) Developing Research \& Communication Skills: Guidelines for Information Literacy in the Curriculum. The university library may need to reevaluate their student learning outcomes for information literacy to reflect the importance ratings from the key stakeholders to select outcomes that may take precedence over the older ones and to ensure inclusion of the ability to retrieve and disseminate information using a variety of forms of multimedia and social media, as suggested by ACRL's (2011) Visual Literacy Competency Standards for Higher Education. 


\section{CONTENT DOMAIN FOR INFORMATION LITERACY}

Additionally, the Mid-Atlantic University's faculty senate may want to charge the institution's advisory group responsible for student learning assessment to reevaluate the information literacy student learning outcomes for the university's general education program to incorporate the importance ratings from the key stakeholders to select outcomes that may take precedence over those that were established in 2004 and 2005. The advisory group should also address the fact that the key stakeholders in the Concept Mapping/Pattern Matching study identified student learning outcomes related to the psychosocial development of undergraduates that they recognized to be important but are not being addressed in the Mid-Atlantic University curriculum.

\section{Mid-Atlantic University's library faculty should increase the promotion of their} information literacy instruction program and its success to the campus community. Another implication of the findings related specifically to the Mid-Atlantic University library is the need to promote to the campus community the success of the library's information literacy program. When reviewing the efficacy ratings of the individual outcomes generated by the key stakeholders, the researcher did not fail to note the 2.69 efficacy rating for outcome 14 (understanding the physical space and content of the library). This low rating was surprising because of the university library's active information literacy instruction services and the librarians' participation in the institution's first year experience and student orientation programs. In 2011, the library reported in the Mid-Atlantic University's Periodic Review Report to the Middle States Commission on Higher Education:

Each semester since spring 2006, the library has administered an information literacy survey to first-year English 101 students to assess student learning outcomes as defined by the Association of College and Research Libraries (ACRL). Overall, correct response 
CONTENT DOMAIN FOR INFORMATION LITERACY

rates have increased beyond the established 70 percent benchmark since 2007. (Frostburg State University, p. 23)

\section{Curriculum development at Mid-Atlantic University should reflect collaboration}

between academic affairs and student affairs. It was stated previously that an underlying objective of this study was to determine whether the inclusion of more stakeholders representing other segments of the university with vested interests in information literacy, such as students, student affairs professionals, and faculty from varying disciplines would result in the selection of different, more suitable outcomes than those currently adopted by the library. The conclusion was made that the participation of key stakeholders from other departments of the university, in addition to the library, did result in identifying outcomes beyond those of the ACRL standards; and that these representatives from academic affairs and student affairs rated these new outcomes to be the most important in regard to information literacy competency. This finding has important implications for curriculum development at Mid-Atlantic University and other institutions of higher education in regard to the need for the two divisions responsible for student development and academic achievement to work together when establishing student learning outcomes. The faculty needs to lead the development of the curriculum, but student affairs professionals are generally given the responsibility for developing the psychosocial skills of college students. The theories related to college student development are often the framework around which student affairs professionals build their programs and should be taken into consideration by faculty when identifying the various stages that key development concepts should be addressed in the curriculum. 
CONTENT DOMAIN FOR INFORMATION LITERACY

Graduate programs for student personnel should consider incorporating discussions about information literacy within the context of student development into their curriculum. The participation of key stakeholders from other departments of the university outside of the academic affairs division resulted in identifying outcomes that pertain to psychosocial development not included in the ACRL standards. This finding may have implications for curriculum development at the graduate level, particularly for graduate programs that prepare student affairs professionals and other higher education leaders. While discussing the focus and procedures of this study with the Mid-Atlantic University student affairs administrators who were being invited to participate in the focus group, the researcher noted that, although there was understanding of the need for students to be instructed in conducting research and communicating information effectively, student affairs personnel may not have viewed information literacy competency as a formal skill that required development similar to other competency or cognitive skills. However, by studying existing information literacy standards, student affairs professionals and higher education leaders may see the relevance of promoting information literacy competency skills to facilitate successful cognitive and psychosocial development in students. For example, ACRL's third standard suggests there is a role for information literacy in cognitive and psychosocial development: "The information literate student evaluates information and its sources critically and incorporates information into his or her knowledge base and value system" (2000, p. 10). Two of the performance indicators associated with this standard are also relevant to student personnel theories:

Performance Indicator 4: the information literate student compares new knowledge with prior knowledge to determine the value added, contradictions, or other unique characteristics of the information, [and] 


\section{CONTENT DOMAIN FOR INFORMATION LITERACY}

Performance Indicator 5: the information literate student determines whether the new knowledge has an impact on the individual's value system and takes steps to reconcile differences. (ACRL, 2000, p. 11)

The researcher has recommended for future research that the content domain for information literacy as it was conceptualized into eight clusters by the key stakeholders at MidAtlantic University be examined within the context of Chickering's (1993) seven vectors and other student development theories.

\section{Effectiveness of using Trochim's Concept Mapping/Pattern Matching methodology}

for developing standards and outcomes. The success of the key stakeholders in generating eight clusters or goals with 80 outcomes to represent their conceptualization of a domain for information literacy in this study has implications for the future use of Trochim's Concept Mapping/Pattern Matching methodology in higher education for similar activities. As it has been described in the literature, this approach to concept mapping/pattern matching has been successfully utilized in an increasing number of studies conducted by other researchers, particularly in the social sciences, health sciences, and education. The purpose of several of these studies was to elicit stakeholders' perceptions of concrete components of their home, work, or school environments with which they have a particular relationship or vested interest (Kane $\&$ Trochim, 2007). Comments from the participants received by the researcher after the brainstorming session were very positive, with several of the focus group members stating how much they enjoyed the stimulating exercise between colleagues.

\section{Recommendations for Future Research}

The application of Trochim's Concept Mapping/Pattern Matching methodology to this study provided a framework within which the key stakeholders from different divisions and with 


\section{CONTENT DOMAIN FOR INFORMATION LITERACY}

various responsibilities for student success, several of whom had not met each other before, collaborated and succeeded in identifying a content domain for information literacy at a midsized university. Trochim (1989b) enumerates several advantages to using his methodology for Concept Mapping/Pattern Matching:

"First, it encourages the participant group to stay on task and to lay out relatively quickly a framework for a planning and evaluation study. Second, it expresses the conceptual framework in the language of the participants rather than in terms of the evaluator's or planner's language or the language of social science theorizing. Third, it results in a graphic representation which at a glance shows all of the major ideas and their interrelationships. Fourth, this graphic product is comprehensible to all of the participants and can be presented to other audiences relatively easily. Finally, we have observed over many concept mapping projects that one of the major effects of the process is that it appears to increase group cohesiveness and morale.” (pp. 15-16)

The researcher can make several recommendations for future research in higher education specifically using this methodology to compare and contrast results from other stakeholder groups with similar interests, to identify outcomes for other core competency skills, or to establish criteria for evaluation and assessment. Those recommendations include the following:

1. The resulting outcomes from this study established the content domain for information literacy from one group of stakeholders at Mid-Atlantic University. The membership of the group was selected with care to ensure representation from a diverse population of academic and student affairs perspectives. However, it is possible that the results would have been different if 


\section{CONTENT DOMAIN FOR INFORMATION LITERACY}

other stakeholders had been selected. One recommendation for future research is to replicate this same study with the same number of representatives from each division and college but invite an entirely different group of participants to compare and contrast the outcomes against those from this study.

2. Similar to the previous recommendation, another possibility that should be considered for future research would be to increase the number of participants to include as many faculty, student affairs staff, and students that indicate an interest and conduct several brainstorming sessions to generate as many concepts for consideration as possible. The resulting outcomes could then be combined for review and sorted by all participants in a separate phase of the study. The ratings of the concepts would be conducted using the same online survey mechanism that was used in the current study. The objective of opening the study up to the broadest population is to determine if the number of participants would affect the results in any way.

3. Included in the findings of the current study was the question of whether the local outcomes for developing information literacy competency are relevant for current students or will be for the next generations of students given the apparent bias toward retrieving and utilizing information in a textual format and not addressing fully multiple formats of information that may require other types of competency skills. The researcher recommends that a study be conducted using the same Concept Mapping/Pattern Matching methodology with a focus group composed solely of fourth year students representing different majors to see if the list of outcomes generated by students varies from the list generated by faculty and student affairs professionals.

\section{ACRL's (2000) Information Literacy Competency Standards for Higher Education} addressed the need for standards and outcomes for achieving and assessing information literacy 


\section{CONTENT DOMAIN FOR INFORMATION LITERACY}

competency specifically for undergraduate students. It is for this level that most formal academic library orientation and instruction programs are designed, whether they are incorporated into first year experience programs for orientation or one-credit courses, included in the curriculum for first and third year English courses, or integrated into discipline-specific advanced courses. However, for some academic disciplines, in-depth research skills may not be utilized until the student has moved on to a post-baccalaureate degree program. Graduate faculty and students may be the best judges of the information literacy skills that should be inculcated across the undergraduate curriculum and the efficacy to which colleges and universities achieve those goals. A recommendation for future research, again utilizing the Concept Mapping/Pattern Matching methodology, would be to invite graduate faculty and graduate students to participate in the study.

5. The review of the literature related to the emergence of the knowledge society in chapter two of this study presented several reports, primarily government funded, that published the serious concerns of industry leaders and educators regarding consistent assessments that demonstrate the lack of preparedness of recent and future college graduates to assume positions in the workforce, the knowledge industry. A recommendation for future research that could result in several studies is to replicate this study using Trochim's Concept Mapping/Pattern Matching methodology to identify information literacy skills considered important by experienced practitioners in various professional fields. Future researchers would select as their key stakeholders members of external advisory boards to develop the outcomes for information literacy related to the discipline. Professionals would inform educators of those skills necessary to actually practice law or medicine or to be successful in other professional roles. 


\section{CONTENT DOMAIN FOR INFORMATION LITERACY}

6. Due to the subject of the research and the methodology used, numerous other studies that replicate the format of the current study could be conducted by changing the location and population from which the key stakeholders were selected. For example, it would be interesting to compare and contrast the lists of outcomes generated by focus groups at an honors college, a large research institution, or a community college.

7. The results from this study established the content domain for information literacy competency from a group of interested stakeholders at Mid-Atlantic University. The researcher recommends the use of Trochim's Concept Mapping/Pattern Matching methodology to identify relevant outcomes for other core competency skills that are beyond the scope of one department's curriculum or area of responsibility, such as critical thinking, communication skills, or technology fluency, and that may require input from a diverse group of faculty, administrators, and/or students. A follow-up study to these activities would include a comparison between outcomes for different competencies to see if the amount of overlap warrants universities to treat these skills together as multiple literacies.

8. The purpose of the current study was to assess the relevance of national standards for information literacy competency at a mid-sized Mid-Atlantic university in Maryland. Secondary consequences of the study resulted in the stakeholders identifying which of the clusters and their associated outcomes were considered to be important and revealing their opinions on the efficacy by which the institution has helped students achieve these skills by incorporating them into the curriculum. A question that was not presented to the stakeholders group but warrants future research is to identify which job function at the university is responsible for teaching and/or assessing each of the individual outcomes. The results of a study of this nature could help to encourage collaboration between faculty and librarians, and academic affairs and student affairs 


\section{CONTENT DOMAIN FOR INFORMATION LITERACY}

practitioners. It may also substantiate previous research that identified confusion between campus entities as to who is responsible for teaching information literacy skills (McAdoo, 2008).

9. Although some research has been published recently applying Perry's theory of cognitive development to teaching information literacy competency skills (Jackson, 2008), it is

recommended for further research that the psychosocial aspects of information literacy identified to be important by the participants involved in this study should be evaluated within the context of Chickering's seven vectors or other psychosocial development theories.

10. As a result of the recent publication of new information literacy standards for K-12 students (AASL, 2007), a recommendation for future research that should be conducted relatively soon is a qualitative document analysis comparing and contrasting the new or revised standards of the AASL with those published in 2000 by ACRL, the Information Literacy Competency Standards for Higher Education, and the new standards entitled Visual Literacy Competency Standards for Higher Education published by ACRL in 2011, as well as the discipline-specific standards released by different interest groups under the auspices of ACRL.

11. Using Trochim's Concept Mapping/Pattern Matching Methodology, the current study should be replicated to determine the relevance of the AASL (2007) Standards for the $21^{\text {st }}$ Century Learner when applied at different elementary and secondary schools of varying sizes, locations, population, and other variables that may affect the generalizability of the standards.

12. The final stage in Trochim's Concept Mapping/Pattern Matching methodology is an examination of the named cluster map to determine if other groupings or clusters of clusters could be "combined" into regions and also labeled to show a possible interrelationship between clusters or goals. The generation of statements 36 (have a healthy dose of skepticism), 61(identifying competing perspectives and responding to them effectively), 64 (the ability to 


\section{CONTENT DOMAIN FOR INFORMATION LITERACY}

accept challenges of their own perspective and respond appropriately), and 65 (the ability to challenge their own perspectives) by the focus group and their inclusion in the separate cluster labeled Psychosocial Aspects suggested to the researcher the possibility of examining the eight clusters resulting from the study within the context of Bloom's (1956) Taxonomy of Educational Objectives for future research.

13. A final recommendation for future research is one that utilizes primarily qualitative methods rather than quantitative. The review of literature in the second chapter provides evidence that a known group of academicians, primarily librarians, has been teaching information literacy skills to college students for decades (ALA, 1989; Badke, 2005; Behrens, 1994; Breivik \& Gee, 1989; Rader, 2002). There are also publications that attest to the achievement of at least some of these skills (Maughan, 2001; Oakleaf, 2009; Samson, 2010; Warner, 2008). However, there are very few, if any, real-life testimonies from professional writers, people who practice research for a living, journalists, or other authors of non-fiction as to whether they were taught information literacy skills, and if so, were they benefited by them. The researcher proposes selecting several published researchers from different disciplines and interviewing them for their perspectives and practices in navigating the abundance of information. 


\section{CONTENT DOMAIN FOR INFORMATION LITERACY}

\section{References}

Albrecht, R., \& Baron, S. (2002). The politics of pedagogy: Expectations and reality for information literacy in librarianship. The Journal of Library Administration, 36(1/2), 7196.

Alpert, J., \& Hajaj, N. (2008). We knew the web was big ... [Web blog post]. Retrieved from http://googleblog.blogspot.com/2008/07/we-knew-web-was-big.html

American Association of School Librarians \& Association for Educational Communications and Technology. (1998). Information literacy standards for student learning: Standards and indicators. Retrieved from http://www.ala.org/ala/mgrps/divs/aasl/aaslarchive /pubsarchive/informationpower/InformationLiteracyStandards_final.pdf

American Association of School Librarians. (2007). Standards for the $21^{\text {st }}$-Century learner. Retrieved from http://www.ala.org/aasl/sites/ala.org.aasl/files/content /guidelinesandstandards/learningstandards/AASL_Learning_Standards_2007.pdf

American Association of School Librarians. (2009). Standards for the $21^{\text {st }}$-Century learner in action. Chicago, IL: American Association of School Librarians.

American Library Association. Presidential Committee on Information Literacy. Final report. Retrieved from http://www.ala.org/ala/mgrps/divs/acrl/publications/whitepapers /ALA_print_layout_1_126315_126315.cfm

Association for College \& Research Libraries. (2000). Information literacy competency standards for higher education. Retrieved from http://www.acrl.org/ala/mgrps /divs/acrl/standards/standards.pdf 


\section{CONTENT DOMAIN FOR INFORMATION LITERACY}

Association for College and Research Libraries (2003). Characteristics of programs of information literacy that illustrate best practices: A guideline. Retrieved from http://www.ala.org/ala/mgrps/divs/acrl/standards/characteristics.cfm

Association for College and Research Libraries (2011). ACRL visual literacy competency standards for higher education. Retrieved from http://www.ala.org/acrl/standards/visualliteracy

Avery, E. F. (2003). Assessing information literacy instruction. In E. F. Avery (Ed.), Assessing student learning outcomes for information literacy instruction in academic institutions (pp. 1-5). Chicago IL: Association of College and Research Libraries.

Badke, W. B. (2005). Can't get no respect: Helping faculty to understand the educational power of information literacy. The Reference Librarian, 43(89/90), 63-80.

Badke, W. B. (2010). Foundations of information literacy: Learning from Paul Zurkowski. Online, 34(1), 48-50.

Baldwin, V. (2008). Resources for assessment of information literacy. Science \& Technology Libraries, 28, 367-374. doi: 10.1080/01942620802204952

Becker, C. H. (2009). Student values and research: Are Millennials really changing the future of reference and research? The Journal of Library Administration, 49(4), 341-364.

Behrens, S. J. (1994). A conceptual analysis and historical overview of information literacy. College and Research Libraries, 55, 309-322.

Bloom, B. S., Engelhart, M. D., Furst, E. J., Hill, W. H., \& Krathwohl, D. R. (1956). Taxonomy of educational objectives: The classification of educational goals (Vols. 1 \& 2). New York, NY: David McKay Co. 


\section{CONTENT DOMAIN FOR INFORMATION LITERACY}

Board of Regents. State of Louisiana. (n.d.). Degree requirements. Retrieved from http://regents.louisiana.gov/index.cfm?md=pagebuilder\&tmp=home\&pid=136

Booth, A., \& Fabian, C. A. (2002). Collaborating to advance curriculum-based information literacy initiatives. The Journal of Library Administration, 36(1/2), 123-142.

Breivik, P. S. (1998). Student learning in the information age. Phoenix, AZ: The Oryx Press.

Breivik, P. S., \& Gee, E. G. (1989). Information literacy: Revolution in the library. New York, NY: Macmillan.

Brewer, E. W. (2007). Delphi technique. In N. J. Salkind \& K. Rasmussen (Eds.), The encyclopedia of measurement and statistics (pp. 240-246). Thousand Oaks, CA: Sage Publications, Inc.

Brown, J. D. (2008). Foster parents' perceptions of factors needed for successful foster placements. Journal of Child and Family Studies, 17, 538-554. doi: 10.1007/s10826-007$9172-\mathrm{z}$

Brown, J. D., \& Bednar, L. (2006). Foster parent perceptions of placement breakdown. Children and Youth Services Review, 28, 1497-1511.

Brown, J. D., \& Calder, P. (1999). Concept-mapping the challenges faced by foster parents. Children and Youth Services Review, 2, 481-495. doi:10.1016/S0190-7409(99)00034-1

Candy, P. C. (2000). Knowledge navigators and lifelong learners: Producing graduates for the information society. Higher Education Research \& Development, 19(3), 261-277. doi: $10.1080 / 07294360020021383$

Caracelli, V. (1989). Structured conceptualization: A framework for interpreting evaluation results. Evaluation and Program Planning, 12(1), 45-52. doi:10.1016/01497189(89)90021-9 


\section{CONTENT DOMAIN FOR INFORMATION LITERACY}

Carnegie Foundation for the Advancement of Teaching. (2006). Frostburg State University.

Retrieved from http://classifications.carnegiefoundation.org/lookup_listings-

/view_institution.php?unit_id=162584\&

Chickering, A. W., \& Reisser, L. (1993). Education and identity (2nd ed.). San Francisco: Jossey-Bass.

Combes, B. (July, 2006). Techno savvy and all-knowing or techno-oriented? Informationseeking behaviour and the Net generation? In I. Veiga (Chair), The multiple faces of literacy: Reading, knowing, doing. Paper presented at the $35^{\text {th }}$ annual conference of the International Association of School Librarianship, Lisbon, Portugal. Retrieved from http://search.proquest.com/docview/236099228?accountid=27669

Cornell University (2009). Cornell Office for Research on Evaluation. William Trochim. Retrieved from http://core.human.cornell.edu/about/people/trochim/

Costantino, C. E. (2003). Stakeholders' perceptions of the importance of information literacy competencies within undergraduate education (Doctoral dissertation, Alliant International University). Retrieved from ProQuest Dissertations \& Theses. (Order No. 3086813).

Crawford, W. (2009). Futurism and libraries. Online, 33(2), 58-60.

Davidson, J. R., McMillen, P. S., \& Maughan, L. S. (2002). Using the "ACRL Information Literacy Competency Standards for Higher Education” to assess a university library instruction program. The Journal of Library Administration, 36(1/2), 97-121.

Demo, W. (1986). The idea of "information literacy" in the age of high-tech. Dryden, NY: Tompkins Cortland Community College. (ERIC Document Reproduction Service No. ED 282537). Retrieved from http://www.eric.ed.gov/PDFS/ED282537.pdf 


\section{CONTENT DOMAIN FOR INFORMATION LITERACY}

Donovan, M. C., \& Zald, A. E. (1999). Defining moments: The role of information literacy in the $21^{\text {st }}$ Century construct of education. In K. Gresham (Ed.), Information literacy and the technological transformation of higher education: Papers and documents of the ACRL Instruction Section Think Tank III. ACRL Instruction Section Think Tank III held in New Orleans, Louisiana, June 24-25, 1999 (pp. 1-7). Ann Arbor: Pierian Press.

Dougherty, W. C. (2009). Virtualization and libraries: The future is now (or Virtualization: Whither libraries or libraries wither)? The Journal of Academic Librarianship, 35(3), 274 -276 .

Doyle, C. S. (1992). Development of a model of information literacy outcome measures within National Education Goals of 1990 (Doctoral dissertation, Northern Arizona University). Retrieved from ProQuest Dissertations \& Theses. (Order No. 9307268).

Drucker, P. F. (1959). Landmarks of tomorrow. New York, NY: Harper, Inc.

Drucker, P. F. (1962, January 21). The economic race: A forecast for 1980: Will the Soviet Union go ahead of us, as Khrushchev claims? An expert offers his own prediction, looking to a U.S. very different from that of today. New York Times (1923-Current file), p. 183. Retrieved from http://search.proquest.com.www.libproxy.wvu.edu/docview/115959119/fulltextPDF/136 092572B124795264/1 ?accountid=2837

Drucker, P. F. (1993). Post-capitalist society. New York, NY: HarperCollins Publishers, Inc.

Drucker, P. F. (1994, November). The age of social transformation. The Atlantic Monthly, 274(5), 53-80.

Eisenberg, M. B., Lowe, C. A., \& Spitzer, K. L. (2004). Information literacy: Essential skills for the information age (2nd ed.). Westport, CT: Libraries Unlimited. 


\section{CONTENT DOMAIN FOR INFORMATION LITERACY}

Eschedor Voelker, T. J. (2006) The library and my learning community: First year students' impressions of library services. Reference \& User Services Quarterly, 46(2), 72-80.

Fisch, K. (2007). Did you know? Remixed by S. McLeod. [Video file]. Retrieved from http://www.youtube.com/watch?v=ljbI-363A2Q

Frostburg State University. (2004). Undergraduate education initiative: Recommendations for a distinctive undergraduate experience. Frostburg, MD: Frostburg State University.

Frostburg State University. (2011) Periodic review report prepared for the Commission on Higher Education of the Middle States Association of Colleges and Schools. Frostburg, MD: Frostburg State University.

Frostburg State University, Faculty Planning Group for Information Literacy. (2005). Basic proficiencies in information literacy. Retrieved from http://www.frostburg.edu /academic/slassessment/Basic\%20Skills/INFO_LITERACY_guide.pdf

Frostburg State University. Lewis J. Ort Library. (n. d.). Information literacy. Retrieved from http://www.frostburg.edu/dept/library/userserv/infolit.htm

Gardner, J. N., Decker, D., \& McNairy, F. G. (1986). Taking the library to freshman students via the freshman seminar concept. In G. B. McCabe \& B. Kreissman (Eds.), Advances in library administration and organization (Vol. 6, pp. 153-171). Greenwich, CT: JAI Press, Inc.

Goldgehn, L. A. (2004). Generation who, what, y? What you need to know about Generation Y. International Journal of Educational Advancement, 5(1), 24-34. doi:10.1057/palgrave.ijea.2140202

Grassian, E. S., \& Kaplowitz, J. R. (2009). Information literacy instruction: Theory and practice (2nd ed.). New York: Neal-Schuman. 


\section{CONTENT DOMAIN FOR INFORMATION LITERACY}

Gratch-Lindauer, B. (2002). Comparing the regional accreditation standards: Outcome assessment and other trends. The Journal of Academic Librarianship, 28(1/2), 14-25.

Gullikson, S. (2006). Faculty perceptions of “ACRL’s Information Literacy Competency Standards for Higher Education.” The Journal of Academic Librarianship, 32(6), 583592.

Harris, R. (2003). Power Google. Guilford, CT: McGraw-Hill Higher Education. Retrieved from http://highered.mcgrawhill.com/sites/dl/free/0079876543/100850/chapter1.pdf

Higher Learning Commission (2003). Handbook of accreditation (3rd ed.). Retrieved from http://www.ncahlc.org/information-for-institutions/publications.html

Horton, F. W., Jr. (2007). Understanding information literacy: A primer. (Information Society Division, Communication and Information Sector.) Paris: United Nations Educational, Scientific and Cultural Organization. Retrieved from UNESCO website: http://unesdoc.unesco.org/images/0015/001570/157020e.pdf

Huba, M. E., \& Freed, J. E. (2000). Learner-centered assessment on college campuses: Shifting the focus from teaching to learning. Needham Heights, MA: Allyn \& Bacon.

"information, n.". OED Online. November 2010. Oxford University Press. Retrieved from http://www.oed.com/view/Entry/95568?redirectedFrom=information\%20explosion

Jackson, K. M., \& Trochim, W. M. K. (2002). Concept mapping as an alternative approach for the analysis of open-ended survey responses. Organizational Research Methods, 5(4), 307-336. doi: 10.1177/109442802237114

Jackson, R. (2008). Information literacy and its relationship to cognitive development and reflective judgment. In: M. M. Watts (Ed.), Information literacy: One key to education (pp. 47-61). San Francisco: Jossey-Bass. 


\section{CONTENT DOMAIN FOR INFORMATION LITERACY}

Jones, E. A. (2002). Transforming the curriculum: Preparing students for a changing world. ASHE Higher Education Report Vol. 29, No 3. San Francisco: Jossey-Bass.

Jones, E. A., Voorhees, R. A., \& Paulson, K. (2002). Defining and assessing learning: Exploring competency-based initiatives. Report of the National Postsecondary Education Cooperative Working Group on Competency-Based Initiatives in Postsecondary Education. Washington, DC: U.S. Dept. of Education. Retrieved from http://nces.ed.gov/pubs2002/2002159.pdf

Kane, M., \& Trochim, W. M. K. (2007). Concept mapping for planning and evaluation. Thousand Oaks, CA: Sage.

“knowledge, n.” OED Online. March 2011. Retrieved from http://www.oed.com .www.libproxy.wvu.edu/view/Entry/104170?redirectedFrom=knowledge \%20worker\#eid40033264

Kronour, J. P. (2004). Preservice teaching standards: What skills should first-year teachers possess as they enter the field. (Doctoral dissertation, The University of Dayton). Retrieved from ProQuest Dissertations \& Theses. (Order No. 3125124).

Kuh, G. D., \& Gonyea, R. M. (2003). The role of the academic library in promoting student engagement in learning. College \& Research Libraries, 64(4), 256-282.

Kurzweil, R. (2005). The singularity is near: When humans transcend biology. New York: Viking.

Lawless, C., Smee, P., \& O’Shea, T. (1998). Using concept sorting and concept mapping in business and public administration, and in education: An overview. Educational Research, 40(2), 219-235. doi: 10.1080/0013188980400209 


\section{CONTENT DOMAIN FOR INFORMATION LITERACY}

Lindauer, B. G., Arp. L., \& Woodward, B. S. (2004). The three arenas of information literacy assessment. Reference \& User Services Quarterly, 44(2), 122-129.

Lindstrom, J., \& Shonrock, D. D. (2006). Faculty-librarian collaboration to achieve integration of information literacy. Reference \& User Services Quarterly, 46(1), 18-23.

Long, S. A. (2005). What's new in libraries? digital natives: If you aren't one, get to know one. New Library World, 106 (3/4), 187-189. doi: 10.1108/0307480051058781

Maryland Higher Education Commission. (2010). Minimum requirements for in-state degreegranting institutions. Code of Maryland Regulations, Title 13B, Subtitle 02, Academic Regulations, 1-45.

Maughan, P. D. (2001). Assessing information literacy among undergraduates: A discussion of the literature and the University of California-Berkeley assessment experience. College \& Research Libraries, 62(1), 71-85.

McAdoo, M. L. (2008). A case study of faculty perceptions of information literacy and its integration into the curriculum. (Doctoral dissertation, Indiana University of Pennsylvania). Retrieved from ProQuest Dissertations \& Theses. (Order No. 3320033).

McAdoo, M. L. (2010). Building bridges: Connecting faculty, students, and the college library. Chicago, IL: American Library Association.

McHale, T. (2005). Portrait of a digital native. Technology \& Learning, 26(2), 33-4.

Michalski, G. V. (1999). Stakeholder variation in perceptions about training program evaluation. (Doctoral dissertation, The University of Ottawa). Retrieved from ProQuest Dissertations \& Theses. (Order No. NQ45185). 


\section{CONTENT DOMAIN FOR INFORMATION LITERACY}

Middle States Commission on Higher Education. (2003). Developing research \& communication skills: Guidelines for information literacy in the curriculum. Philadelphia, PA: Middle States Commission on Higher Education.

Middle States Commission on Higher Education. (2009). Characteristics of excellence in higher education: Eligibility requirements and standards for accreditation. Philadelphia, PA: Middle States Commission on Higher Education.

National Commission on Excellence in Education. (1983). A nation at risk: The imperative for educational reform. A report to the nation and the Secretary of Education. Washington, DC: U.S. Government Printing Office.

Neely, T. Y. (2006). Information literacy assessment: Standard-based tools and assignments. Chicago: American Library Association.

New England Association of Schools and Colleges. (2005). Standards. Retrieved from http://cihe.neasc.org/standards_policies/standards/standards_html_version

Northwest Commission on Colleges and Universities. (2005). Accreditation standards. Retrieved from http://www.nwccu.org/Standards\%20and\%20Policies /Accreditation\%20Standards/Accreditation\%20Standards.htm

Number of words in the English language: 1,007,711. (2010, November 8). Global Language Monitor. Retrieved from http://www.languagemonitor.com

Oakleaf, M. (2009). The information literacy instruction assessment cycle: A guide for increasing student learning and improving librarian instructional skills. Journal of Documentation, 65(4), 539-260. doi:10.1108/00220410910970249

Palfrey, J., \& Gasser, U. (2008). Born digital: Understanding the first generation of digital natives. New York: Basic Books. 


\section{CONTENT DOMAIN FOR INFORMATION LITERACY}

Prensky, M. (2001). Digital natives, digital immigrants: Part 1. On the Horizon, 9(5), 1-6. doi:10.1108/10748120110424816

Rabine, J., \& Cardwell, C. (2000). Start making sense: Practical approaches to outcomes assessment for libraries. Research Strategies, 17, 319-335.

Rader, H. B. (2002). Information literacy 1973-2002: A selected literature review. Library Trends, 51, 242-259.

Rao, J. K., Alongi, J., Anderson, L. A., Jenkins, L., Stokes, G., \& Kane, M. (2005). Development of public health priorities for End-of-Life initiatives. American Journal of Preventive Medicine, 29, 453-460. doi: 10.1016/j.amepre.2005.08.014

Rising above the gathering storm, revisited: Rapidly approaching Category 5. By members of the 2005 "Rising Above the Gathering Storm" Committee; Prepared for the Presidents of the National Academy of Sciences, National Academy of Engineering, and Institute of Medicine. (2010). Washington, DC: The National Academies Press. Retrieved from http://www.nap.edu/catalog/12999.html

Rockman, I. F. (2002). Strengthening connections between information literacy, general education, and assessment efforts. Library Trends, 51(2), 185-198.

Rockman, I. F. (2004). Introduction: The importance of information literacy. In: I.F. Rockman \& Associates (Eds.), Integrating information literacy into the higher education curriculum (pp. 1-28). San Francisco: Jossey-Bass.

Salony, M. F. (1995). The history of bibliographic instruction: Changing trends from books to the electronic world. Reference Librarian, 51/52, 31-51.

Samson, S. (2010). Information literacy learning outcomes and student success. The Journal of Academic Librarianship, 36(3), 202-210. 


\section{CONTENT DOMAIN FOR INFORMATION LITERACY}

Saunders, L. (2007). Regional accreditation organizations' treatment of information literacy: Definitions, collaboration, and assessment. The Journal of Academic Librarianship, 33(3), 317-326.

Secretary's Commission on Achieving Necessary Skills (SCANS). (1991). What work requires of schools: A SCANS report for America 2000. Washington, DC: U.S. G.P.O.

Shuler, J. A. (2004). Ask not for whom the bells toll. Journal of Academic Librarianship, 30(2), $77-79$.

Snavely, L., \& Cooper, N. (1997). The information literacy debate. The Journal of Academic Librarianship, 23(1), 9-14.

Southern Association of Colleges and School. Commission on Colleges. (2008). The principles of accreditation: Foundations for quality enhancement (3rd ed). Retrieved from http://www.sacscoc.org/pdf/2008PrinciplesofAcreditation.pdf

Suskie, L. (2004). Assessing student learning: A common sense guide. Bolton, MA: Anker Publishing Co.

Tapscott, D. (1999). Educating the Net generation. Educational Leadership, 56(5), 5-11. Retrieved from http://web.ebscohost.com.www.libproxy.wvu.edu/ehost/pdfviewer /pdfviewer?sid=57f858f4-aa48-4fb9-9d46-b8e247a8ddc5 $\% 40$ sessionmgr114\&vid=6\&hid $=113$

Thompson, G. B. (2002). Information literacy accreditation mandates: What they mean for faculty and librarians. Library Trends, 51(2), 218-241.

Trochim, W. M. K. (1985). Pattern matching, validity, and conceptualization in program evaluation. Evaluation Review, 9(5), 575-604. doi:10.1177/0193841X8500900503 


\section{CONTENT DOMAIN FOR INFORMATION LITERACY}

Trochim, W. M. K. (1989a). Concept mapping: Soft science or hard art? Evaluation and Program Planning, 12(1), 87-110. Retrieved from http://www.socialresearchmethods.net/research/epp2/epp2.htm

Trochim, W. M. K. (1989b). An introduction to concept mapping for planning and evaluation. Evaluation and Program Planning, 12(1), 1-16. doi:10.1016/0149-7189(89)90016-5

Trochim, W. M. K., Milstein, B., Wood, B., Jackson, S., \& Pressler, V. (2003). Setting objectives for community and systems change: An application of concept mapping for planning a statewide health improvement initiative. Health Promotion Practice. doi: $10.1177 / 1524839903258020$.

VanderPol, D., Brown, J. M., \& Iannuzzi, P. (2008). Reforming the undergraduate experience. In: M. M. Watts (Ed.), Information literacy: One key to education (pp. 5-15). San Francisco: Jossey-Bass.

Walter, S., Ariew, S., Beasley, S., Tillman, M., \& Ver Steeg, J. (2000). Case studies in collaboration: Lessons from five exemplary programs. In D. Raspa \& D. Ward (Eds.), The collaborative imperative: Librarians and faculty working together in the information universe (pp. 39-78). Chicago, IL: Association of College and Research Libraries.

Warner, D. (2008). A disciplinary blueprint for the assessment of information literacy. Westport, CT: Libraries Unlimited.

Western Association of Colleges and Schools. (2001, 2008). WASC 2001: Handbook of accreditation. Retrieved from http://www.wascsenior.org/wasc /PDFs/080311_Updated.2001.Handbook.for.web.pdf 
Zurkowski, P. G. (1974). The information service environment relationships and priorities (Report No. NCLIS-NPLIS-5). National Commission on Libraries and Information Science. Washington, D.C.: National Program for Library and Information Services (ERIC Document Reproduction Service No. ED 100 391). Retrieved from http://eric.ed.gov/PDFS/ED100391.pdf 


\section{Appendix A}

List of ACRL Standards, Performance Indicators, and Outcomes for Information Literacy

\section{Standard One}

The information literate student determines the nature and extent of the information needed.

\section{Performance indicators:}

1. The information literate student defines and articulates the need for information.

Outcomes include:

a. Confers with instructors and participates in class discussions, peer workgroups, and electronic discussions to identify a research topic, or other information need.

b. Develops a thesis statement and formulates questions based on the information need.

c. Explores general information sources to increase familiarity with the topic.

d. Defines or modifies the information need to achieve a manageable focus.

e. Identifies key concepts and terms that describe the information need.

f. Recognizes that existing information can be combined with original thought, experimentation, and/or analysis to produce new information.

2. The information literate student identifies a variety of types and formats of potential sources for information.

\section{Outcomes Include:}

a. Knows how information is formally and informally produced, organized, and disseminated

b. Recognizes that knowledge can be organized into disciplines that influence the way information is accessed 
c. Identifies the value and differences of potential resources in a variety of formats (e.g., multimedia, database, website, data set, audio/visual, book)

d. Identifies the purpose and audience of potential resources (e.g., popular vs. scholarly, current vs. historical)

e. Differentiates between primary and secondary sources, recognizing how their use and importance vary with each discipline

f. Realizes that information may need to be constructed with raw data from primary sources

3. The information literate student considers the costs and benefits of acquiring the needed information.

\section{Outcomes Include:}

a. Determines the availability of needed information and makes decisions on broadening the information seeking process beyond local resources (e.g., interlibrary loan; using resources at other locations; obtaining images, videos, text, or sound)

b. Considers the feasibility of acquiring a new language or skill (e.g., foreign or discipline-based) in order to gather needed information and to understand its context

c. Defines a realistic overall plan and timeline to acquire the needed information

4. The information literate student reevaluates the nature and extent of the information need.

\section{Outcomes Include:}

a. Reviews the initial information need to clarify, revise, or refine the question

b. Describes criteria used to make information decisions and choices 
CONTENT DOMAIN FOR INFORMATION LITERACY

\section{Standard Two}

The information literate student accesses needed information effectively and efficiently.

\section{Performance Indicators:}

1. The information literate student selects the most appropriate investigative methods or information retrieval systems for accessing the needed information.

\section{Outcomes Include:}

a. Identifies appropriate investigative methods (e.g., laboratory experiment, simulation, fieldwork)

b. Investigates benefits and applicability of various investigative methods

c. Investigates the scope, content, and organization of information retrieval systems

d. Selects efficient and effective approaches for accessing the information needed from the investigative method or information retrieval system

2. The information literate student constructs and implements effectively-designed search strategies.

\section{Outcomes Include:}

a. Develops a research plan appropriate to the investigative method

b. Identifies keywords, synonyms and related terms for the information needed

c. Selects controlled vocabulary specific to the discipline or information retrieval source

d. Constructs a search strategy using appropriate commands for the information retrieval system selected (e.g., Boolean operators, truncation, and proximity for search engines; internal organizers such as indexes for books) 
e. Implements the search strategy in various information retrieval systems using different user interfaces and search engines, with different command languages, protocols, and search parameters

f. Implements the search using investigative protocols appropriate to the discipline

3. The information literate student retrieves information online or in person using a variety of methods.

\section{Outcomes Include:}

a. Uses various search systems to retrieve information in a variety of formats

b. Uses various classification schemes and other systems (e.g., call number systems or indexes) to locate information resources within the library or to identify specific sites for physical exploration

c. Uses specialized online or in person services available at the institution to retrieve information needed (e.g., interlibrary loan/document delivery, professional associations, institutional research offices, community resources, experts and practitioners)

d. Uses surveys, letters, interviews, and other forms of inquiry to retrieve primary information

4. The information literate student refines the search strategy if necessary.

\section{Outcomes Include:}

a. Assesses the quantity, quality, and relevance of the search results to determine whether alternative information retrieval systems or investigative methods should be utilized 


\section{CONTENT DOMAIN FOR INFORMATION LITERACY}

b. Identifies gaps in the information retrieved and determines if the search strategy should be revised

c. Repeats the search using the revised strategy as necessary

5. The information literate student extracts, records, and manages the information and its sources.

\section{Outcomes Include:}

a. Selects among various technologies the most appropriate one for the task of extracting the needed information (e.g., copy/paste software functions, photocopier, scanner, audio/visual equipment, or exploratory instruments)

b. Creates a system for organizing the information

c. Differentiates between the types of sources cited and understands the elements and correct syntax of a citation for a wide range of resources

d. Records all pertinent citation information for future reference

e. Uses various technologies to manage the information selected and organized

\section{Standard Three}

The information literate student evaluates information and its sources critically and incorporates selected information into his or her knowledge base and value system.

\section{Performance Indicators:}

1. The information literate student summarizes the main ideas to be extracted from the information gathered.

\section{Outcomes Include:}

a. Reads the text and selects main ideas

b. Restates textual concepts in his/her own words and selects data accurately 
c. Identifies verbatim material that can be then appropriately quoted

2. The information literate student articulates and applies initial criteria for evaluating both the information and its sources.

\section{Outcomes Include:}

a. Examines and compares information from various sources in order to evaluate reliability, validity, accuracy, authority, timeliness, and point of view or bias

b. Analyzes the structure and logic of supporting arguments or methods

c. Recognizes prejudice, deception, or manipulation

d. Recognizes the cultural, physical, or other context within which the information was created and understands the impact of context on interpreting the information

3. The information literate student synthesizes main ideas to construct new concepts.

\section{Outcomes Include:}

a. Recognizes interrelationships among concepts and combines them into potentially useful primary statements with supporting evidence

b. Extends initial synthesis, when possible, at a higher level of abstraction to construct new hypotheses that may require additional information

c. Utilizes computer and other technologies (e.g. spreadsheets, databases, multimedia, and audio or visual equipment) for studying the interaction of ideas and other phenomena

4. The information literate student compares new knowledge with prior knowledge to determine the value added, contradictions, or other unique characteristics of the information.

\section{Outcomes Include:}


a. Determines whether information satisfies the research or other information need

b. Uses consciously selected criteria to determine whether the information contradicts or verifies information used from other sources

c. Draws conclusions based upon information gathered

d. Tests theories with discipline-appropriate techniques (e.g., simulators, experiments)

e. Determines probable accuracy by questioning the source of the data, the limitations of the information gathering tools or strategies, and the reasonableness of the conclusions

f. Integrates new information with previous information or knowledge

g. Selects information that provides evidence for the topic

5. The information literate student determines whether the new knowledge has an impact on the individual's value system and takes steps to reconcile differences.

\section{Outcomes Include:}

a. Investigates differing viewpoints encountered in the literature

b. Determines whether to incorporate or reject viewpoints encountered

6. The information literate student validates understanding and interpretation of the information through discourse with other individuals, subject-area experts, and/or practitioners.

\section{Outcomes Include:}

a. Participates in classroom and other discussions

b. Participates in class-sponsored electronic communication forums designed to encourage discourse on the topic (e.g., email, bulletin boards, chat rooms) 
c. Seeks expert opinion through a variety of mechanisms (e.g., interviews, email, listservs)

7. The information literate student determines whether the initial query should be revised.

\section{Outcomes Include:}

a. Determines if original information need has been satisfied or if additional information is needed

b. Reviews search strategy and incorporates additional concepts as necessary

c. Reviews information retrieval sources used and expands to include others as needed

\section{Standard Four}

The information literate student, individually or as a member of a group, uses information effectively to accomplish a specific purpose.

\section{Performance Indicators:}

1. The information literate student applies new and prior information to the planning and creation of a particular product or performance.

\section{Outcomes Include:}

a. Organizes the content in a manner that supports the purposes and format of the product or performance (e.g. outlines, drafts, storyboards)

b. Articulates knowledge and skills transferred from prior experiences to planning and creating the product or performance

c. Integrates the new and prior information, including quotations and paraphrasings, in a manner that supports the purposes of the product or performance 
d. Manipulates digital text, images, and data, as needed, transferring them from their original locations and formats to a new context

2. The information literate student revises the development process for the product or performance.

Outcomes Include:

a. Maintains a journal or log of activities related to the information seeking, evaluating, and communicating process

b. Reflects on past successes, failures, and alternative strategies

3. The information literate student communicates the product or performance effectively to others.

\section{Outcomes Include:}

a. Chooses a communication medium and format that best supports the purposes of the product or performance and the intended audience

b. Uses a range of information technology applications in creating the product or performance

c. Incorporates principles of design and communication

d. Communicates clearly and with a style that supports the purposes of the intended audience

\section{Standard Five}

The information literate student understands many of the economic, legal, and social issues surrounding the use of information and accesses and uses information ethically and legally. Performance Indicators: 


\section{CONTENT DOMAIN FOR INFORMATION LITERACY}

1. The information literate student understands many of the ethical, legal and socioeconomic issues surrounding information and information technology.

\section{Outcomes Include:}

a. Identifies and discusses issues related to privacy and security in both the print and electronic environments

b. Identifies and discusses issues related to free vs. fee-based access to information

c. Identifies and discusses issues related to censorship and freedom of speech

d. Demonstrates an understanding of intellectual property, copyright, and fair use of copyrighted material

2. The information literate student follows laws, regulations, institutional policies, and etiquette related to the access and use of information resources.

\section{Outcomes Include:}

a. Participates in electronic discussions following accepted practices (e.g. "Netiquette")

b. Uses approved passwords and other forms of ID for access to information resources

c. Complies with institutional policies on access to information resources

d. Preserves the integrity of information resources, equipment, systems and facilities

e. Legally obtains, stores, and disseminates text, data, images, or sounds

f. Demonstrates an understanding of what constitutes plagiarism and does not represent work attributable to others as his/her own

g. Demonstrates an understanding of institutional policies related to human subjects research 


\section{CONTENT DOMAIN FOR INFORMATION LITERACY}

3. The information literate student acknowledges the use of information sources in communicating the product or performance.

\section{Outcomes Include:}

a. Selects an appropriate documentation style and uses it consistently to cite sources

b. Posts permission granted notices, as needed, for copyrighted material

Copyright 1997-2011 American Library Association. This document may be reprinted and distributed for non-commercial and educational purposes only, and not for resale. No resale use may be made of material on this web site at any time. All other rights reserved. 


\title{
Appendix B
}

\author{
Letter Given to Key Stakeholders to Confirm Participation in Study
}

\author{
West WirginiaUniversity \\ College of Human Resources and Education
}

\author{
August $16^{\text {th }}, 2011$ \\ Dear Participant:
}

\section{Introduction}

You have been asked to participate in this research study, which has been explained to you by Sebastián R. Díaz, Ph.D., J.D., and Lea Messman Mandicott, MLS. This study is being conducted by Sebastián R. Díaz, Ph.D., J.D., an Associate Professor in the Department of Technology, Learning, and Culture at West Virginia University (WVU), and Lea Messman Mandicott, MLS, a doctoral candidate in Higher Education Leadership at WVU.

\section{Purposes of the Study}

The purpose of this study is to explore the content domain of competencies desired for undergraduates with respect to Information Literacy. To this aim, a diverse group of stakeholders representing different perspectives on the topic Information Literacy will be convened for a brainstorming session to help conceptualize this domain.

\section{Description of Procedures}

For this study you will join a group of about 11 individuals for a brainstorming session that will last approximately 2 hours. You will be asked to identify What are the student learning outcomes for information literacy that Frostburg State University should expect of its graduates? As these learning outcomes are identified, they will be recorded by the group facilitator and put in a list. Once the final list of outcomes is determined, you will be asked to independently sort the items into groupings and label the piles. You will then be instructed to rank the items in regards to:

$$
\begin{aligned}
& \text { How relatively important do you believe this student learning outcome is for } \\
& \text { undergraduate students at FSU? (Very Important; Important; Neutral; } \\
& \text { Unimportant; Very Unimportant). } \\
& \text { Overall, how well does FSU's curriculum help students develop this particular } \\
& \text { student learning outcome? (Very Well, Well, Neutral, Poorly, Very Poorly). }
\end{aligned}
$$

Once this data is collected from all participants, the information will be constructed into visual concept maps that can be used to pinpoint issues and concerns needing more immediate attention. Additionally, this information can be used to design potential innovations for the FSU curriculum, and guide future research into Information Literacy.

\section{Confidentiality}

Any information about you that is obtained as a result of your participation in this research will be kept as confidential as legally possible. 
In any publications that result from this research, neither your name nor any information from which you might be identified will be published without your consent.

\section{Voluntary Participation}

Participation in this study is voluntary. You do not have to answer any of the questions presented to you. You are free to withdraw your consent to participate in this study at any time, and your refusal to participate in this study will not affect your job status, grades, or class standing.

\section{Contact Persons}

In the event you experience any consequences related to this research, you should contact Dr. Sebastián R. Díaz at (304) 293-2075. For more information about this research and about research-related risks or injury, you can contact also Dr. Díaz at (304) 293-2075. For information regarding your rights as a research subject, you may contact the Office of Research Compliance at (304) 293-7073.

Sincerely,

Sebastián R. Díaz, Ph.D., J.D.

Associate Professor 


\section{Appendix C}

List of Statements Generated by Key Stakeholders at Mid-Atlantic University

Using Concept Mapping/Pattern Matching

1. Proper documentation

2. Evaluating sources critically

3. Proper date of an article

4. Using search terms effectively

5. Where to look to find information

6. Definition of primary, secondary, tertiary sources

7. Identifying appropriate discipline databases \& resources

8. Online catalog

9. Critically assessing the credibility and thoroughness of a resource

10. Balance of the resource in regard to coverage

11. Understanding what they need to find

12. A basic search strategy

13. Effective use of the materials found

14. Understanding the physical space and content of the library

15. Synthesizing the content of the article

16. Balance to your paper in what you present

17. Effective communication of the information

18. Integrate the materials into a knowledge base

19. Interpret the data and findings

20. Drawing conclusions

21. Assessing internet pages (.com, .gov)

22. Understanding the ethics of information use

23. Using different strategies for understanding and comprehension

24. Awareness of security and personal privacy issues

25. Being able to formulate a strong thesis

26. Organizing, storing and backing up information

27. Being able to access the internet

28. Learning to pick out what extra resources can help them

29. Being able to analyze a text format (content,)

30. Ability to communicate information in a variety of ways to match learning style

31. Spelling \& grammar, correct punctuation, etc.

32. Effective use of research tools in print and digital (i.e., indexes, etc.)

33. Manual citation of references

34. Distinguishing between types of resources \& publications

35. Able to manage information results electronically

36. Have a healthy dose of skepticism

37. Being able to identify bias in a resource

38. Be able to evaluate the results of a web search

39. Be able to corroborate information

40. Narrow or revise search strategy and results

41. Being able to evaluate the substantiality of the study 
42. Understand the difference between statistical versus practical significance

43. Difference between quantitative and qualitative methods

44. Legal issues in the use of sources, copyright

45. Protocols for accessing private information

46. Social or scientific implications of the research being used

47. Effective personal interviewing

48. Organizing information for an effective oral presentation

49. Oral communication skills

50. Understanding of scholarly versus popular resources

51. Understand their medium and their audience to adjust information

52. Be able to construct attributive tags or signal phrases

53. Understanding the difference between a database and the Internet

54. Distinguish between abstracts, review articles and original research

55. Evaluating the quality of evidence

56. Understand the components of a research paper

57. Ability to summarize and synthesize the information in a resource

58. Data driven decision-making for some disciplines

59. Recognizing that the answer is a combination of many resources

60. Sequence of the scientific process

61. Identifying competing perspectives and responding to them effectively

62. Ability to use language for the appropriate audience

63. The ability to form an opinion

64. The ability to accept challenges of their own perspective and respond appropriately

65. The ability to challenge their own perspectives

66. Ability to conduct an inquiry

67. Primary scientific discovery - identify the topic first

68. Look for credible evidence of both sides of an argument

69. Reevaluate drafts and the "finished" product, conclusions, etc.

70. Avoiding information overload

71. Being able to do basic information seeking or research on anything

72. Be able to look for and find multiple explanations for the argument

73. Be able to integrate new, multiple types of information

74. How to structure the information need at the beginning - formulating a research question

75. Finding information for life after graduation

76. Recognize the limits of their knowledge

77. Time management \& prioritization of tasks

78. Autonomous in seeking information

79. Confidence

80. Ability to present personal information orally

January 18, 2012 


\section{Appendix D}

Survey to Key Stakeholders for Rating of 80 Outcomes by Importance and Efficacy Using Survey Monkey

Lea Messman-Mandicott Dissertation Survey

Exit this survey

\section{Lea Messman-Mandicott Dissertation}

This past week, you and a diverse group of stakeholders from Frostburg State University identified 80 items in response to the question: "What are the student learning outcomes for information literacy that Frostburg State University should expect of its graduates?"

To complete our data collection for this research project, we need you to rate each of the 80 items using the following questions:

1. How relatively important do you believe this student learning outcome is for undergraduate students at FSU? (Very Unimportant; Unimportant; Neutral; Important; Very Important).

2. Overall, how well does FSU's curriculum help students develop this particular student learning outcome? (Very Poorly, Poorly, Neutral, Well, Very Well).

The sections below will guide you through this rating process.

1. How relatively important do you believe this student learning outcome is for undergraduate students at FSU?

Proper documentation

Evaluating sources critically

Proper date of an article

Using search terms effectively

Where to look to find information

Definition of primary, secondary, tertiary sources

Identifying appropriate discipline databases \& resources

Online catalog

Critically assessing the credibility and thoroughness of a resource

Balance of the resource in regard to coverage

Understanding what they need to find

A basic search strategy

Effective use of the materials found

Understanding the physical space and content of the library

Synthesizing the content of the article

Balance to your paper in what you present

Effective communication of the information

Integrate the materials into a knowledge base

Interpret the data and findings

$\begin{array}{ccccc}\begin{array}{c}\text { Very } \\ \text { Unimportant }\end{array} & \text { Unimportant } & \text { Neutral } & \text { Important } & \begin{array}{c}\text { Very } \\ \text { Important }\end{array} \\ 0 & 0 & 0 & 0 & 0 \\ 0 & 0 & 0 & 0 & 0 \\ 0 & 0 & 0 & 0 & 0 \\ 0 & 0 & 0 & 0 & 0 \\ 0 & 0 & 0 & 0 & 0 \\ 0 & 0 & 0 & 0 & 0 \\ 0 & 0 & 0 & 0 & 0 \\ 0 & 0 & 0 & 0 & 0 \\ 0 & 0 & 0 & 0 & 0 \\ 0 & 0 & 0 & 0 & 0 \\ 0 & 0 & 0 & 0 & 0 \\ 0 & 0 & 0 & 0 & 0 \\ 0 & 0 & 0 & 0 & 0 \\ 0 & 0 & 0 & 0 & 0 \\ 0 & 0 & 0 & 0 & 0 \\ 0 & 0 & 0 & 0 & 0 \\ 0 & 0 & 0 & 0 & 0 \\ 0 & 0 & 0 & 0 & 0\end{array}$


Lea Messman-Mandicott Dissertation Survey

Ext this survey

\section{Lea Messman-Mandicott Dissertation}

2. How relatively important do you believe this student learning outcome is for undergraduate students at FSU?

Drawing conclusions

Assessing Internet pages (.com, gov)

Understanding the ethics of information use

Using different strategies for understanding and comprehension

Awareness of security and personal privacy issues

Being able to formulate a strong thesis

Organizing, storing and backing up information

Being able to access the Internet

Learning to pick out what extra resources can help them

Being able to analyze a text format (content,)

Ability to communicate information in a variety of ways to match learning style

Spelling \& grammar, correct punctuation, etc.

Effective use of research tools in print and digital (i.e., indexes, etc.)

Manual citation of references

Distinguishing between types of resources \& publications

Able to manage information results electronically

Have a healthy dose of skepticism

Being able to identify bias in a resource

Be able to evaluate the results of a web search

Be able to corroborate information

\begin{tabular}{|c|c|c|c|c|}
\hline $\begin{array}{c}\text { Very } \\
\text { Unimportant }\end{array}$ & Unimportant & Neutral & Important & $\begin{array}{c}\text { Very } \\
\text { Important }\end{array}$ \\
\hline 0 & 0 & 0 & 0 & 0 \\
\hline 0 & 0 & 0 & 0 & 0 \\
\hline 0 & 0 & 0 & 0 & 0 \\
\hline 0 & 0 & 0 & 0 & 0 \\
\hline 0 & 0 & 0 & 0 & 0 \\
\hline 0 & 0 & 0 & 0 & 0 \\
\hline 0 & 0 & 0 & 0 & 0 \\
\hline 0 & 0 & 0 & 0 & 0 \\
\hline 0 & 0 & 0 & 0 & 0 \\
\hline 0 & 0 & 0 & 0 & 0 \\
\hline 0 & 0 & 0 & 0 & 0 \\
\hline 0 & 0 & 0 & 0 & 0 \\
\hline 0 & 0 & 0 & 0 & 0 \\
\hline 0 & 0 & 0 & 0 & 0 \\
\hline 0 & 0 & 0 & 0 & 0 \\
\hline 0 & 0 & 0 & 0 & 0 \\
\hline 0 & 0 & 0 & 0 & 0 \\
\hline 0 & 0 & 0 & 0 & 0 \\
\hline 0 & 0 & 0 & 0 & 0 \\
\hline 0 & 0 & 0 & 0 & 0 \\
\hline
\end{tabular}




\section{Lea Messman-Mandicott Dissertation}

3. How relatively important do you believe this student learning outcome is for undergraduate students at FSU?

\begin{tabular}{|c|c|c|c|c|c|}
\hline & $\begin{array}{c}\text { Very } \\
\text { Unimportant }\end{array}$ & Unimportant & Neutral & Important & $\begin{array}{l}\text { Very } \\
\text { Important }\end{array}$ \\
\hline Narrow or revise search strategy and results & 0 & 0 & 0 . & 0 & 0 \\
\hline $\begin{array}{l}\text { Being able to evaluate the substantiality of the } \\
\text { study }\end{array}$ & 0 & 0 & 0 & 0 & 0 \\
\hline $\begin{array}{l}\text { Understand the difference between statistical } \\
\text { versus practical significance }\end{array}$ & 0 & 0 & 0 & 0 & 0 \\
\hline $\begin{array}{l}\text { Difference between quantitative and qualitative } \\
\text { methods }\end{array}$ & 0 & 0 & 0 & 0 & 0 \\
\hline Legal issues in the use of sources, copyright & 0 & 0 & 0 & 0 & 0 \\
\hline Protocols for accessing private information & 0 & 0 & 0 & 0 & 0 \\
\hline $\begin{array}{l}\text { Social or scientific implications of the research } \\
\text { being used }\end{array}$ & 0 & 0 & 0 & 0 & 0 \\
\hline Effective personal interviewing & 0 & 0 & 0 & 0 & 0 \\
\hline $\begin{array}{l}\text { Organizing information for an effective oral } \\
\text { presentation }\end{array}$ & $\mathrm{O}$ & 0 & 0 & 0 & 0 \\
\hline Oral communication skills & 0 & 0 & 0 & 0 & 0 \\
\hline $\begin{array}{l}\text { Understanding of scholarly versus popular } \\
\text { resources }\end{array}$ & 0 & 0 & 0 & 0 & 0 \\
\hline $\begin{array}{l}\text { Understand their medium and their audience to } \\
\text { adjust information }\end{array}$ & 0 & 0 & 0 & 0 & 0 \\
\hline $\begin{array}{l}\text { Be able to construct attributive tags or signal } \\
\text { phrases }\end{array}$ & 0 & 0 & 0 & 0 & 0 \\
\hline $\begin{array}{l}\text { Understanding the difference between a } \\
\text { database and the Internet }\end{array}$ & 0 & 0 & 0 & 0 & 0 \\
\hline $\begin{array}{l}\text { Distinguish between abstracts, review articles } \\
\text { and original research }\end{array}$ & 0 & 0 & 0 & 0 & 0 \\
\hline Evaluating the quality of evidence & 0 & 0 & 0 & 0 & 0 \\
\hline $\begin{array}{l}\text { Understand the components of a research } \\
\text { paper }\end{array}$ & 0 & 0 & 0 & 0 & 0 \\
\hline $\begin{array}{l}\text { Ability to summarize and synthesize the } \\
\text { information in a resource }\end{array}$ & 0 & 0 & 0 & 0 & 0 \\
\hline $\begin{array}{l}\text { Data driven decision-making for some } \\
\text { disciplines }\end{array}$ & 0 & 0 & 0 & 0 & 0 \\
\hline $\begin{array}{l}\text { Recognizing that the answer is a combination } \\
\text { of many resources }\end{array}$ & 0 & 0 & 0 & 0 & 0 \\
\hline & Previous Screen & Next Screen & & & \\
\hline
\end{tabular}




\section{Lea Messman-Mandicott Dissertation}

4. How relatively important do you believe this student learning outcome is for undergraduate students at FSU?

Sequence of the scientific process

Identifying competing perspectives and responding to them effectively

Ability to use language for the appropriate audience

The ability to form an opinion

The ability to accept challenges of their own perspective and respond appropriately

The ability to challenge their own perspectives

Ability to conduct an inquiry

Primary scientific discovery - identify the topic first

Look for credible evidence of both sides of an argument

Reevaluate drafts and the "finished" product, conclusions, etc.

Avoiding information overload

Being able to do basic information seeking or research on anything

Be able to look for and find multiple explanations for the argument

Be able to integrate new, multiple types of information

How to structure the information needed at the beginning - formulating a research question

Finding information for life after graduation

Recognize the limits of their knowledge

Time management \& prioritization of tasks

Autonomous in seeking information

Confidence

Ability to present personal information orally

\begin{tabular}{|c|c|c|c|c|}
\hline $\begin{array}{c}\text { Very } \\
\text { Unimportant }\end{array}$ & Unimportant & Neutral & Important & $\begin{array}{c}\text { Very } \\
\text { Important }\end{array}$ \\
\hline 0 & 0 & 0 & 0 & 0 \\
\hline 0 & 0 & 0 & 0 & 0 \\
\hline 0 & 0 & 0 & 0 & 0 \\
\hline 0 & 0 & 0 & 0 & 0 \\
\hline 0 & 0 & 0 & 0 & 0 \\
\hline 0 & 0 & 0 & 0 & 0 \\
\hline 0 & 0 & 0 & 0 & 0 \\
\hline 0 & 0 & 0 & 0 & 0 \\
\hline 0 & 0 & 0 & 0 & 0 \\
\hline 0 & 0 & 0 & 0 & 0 \\
\hline 0 & 0 & 0 & 0 & 0 \\
\hline 0 & 0 & 0 & 0 & 0 \\
\hline 0 & 0 & 0 & 0 & 0 \\
\hline 0 & 0 & 0 & 0 & 0 \\
\hline 0 & 0 & 0 & 0 & 0 \\
\hline 0 & 0 & 0 & 0 & 0 \\
\hline 0 & 0 & 0 & 0 & 0 \\
\hline 0 & 0 & 0 & 0 & 0 \\
\hline 0 & 0 & 0 & 0 & 0 \\
\hline 0 & 0 & 0 & 0 & 0 \\
\hline 0 & 0 & 0 & 0 & 0 \\
\hline
\end{tabular}


Lea Messman-Mandicott Dissertation Survey

Ext this survey

\section{Lea Messman-Mandicott Dissertation}

Whereas the survey up to now has asked you to rate the relative importance of each outcome, the remainder of the survey asks you to rate how well FSU's curriculum helps students develop each particular student learning outcome that you and other participants generated.

5. Overall, how well does FSU's curriculum help students develop this particular student learning outcome?

Proper documentation

\begin{tabular}{|c|c|c|c|c|}
\hline Very Poorly & Poorly & Neutral & Well & Very Well \\
\hline 0 & 0 & 0 & 0 & 0 \\
\hline 0 & 0 & 0 & 0 & 0 \\
\hline 0 & 0 & 0 & 0 & 0 \\
\hline 0 & 0 & 0 & 0 & 0 \\
\hline 0 & 0 & 0 & 0 & 0 \\
\hline 0 & 0 & 0 & 0 & 0 \\
\hline 0 & 0 & 0 & 0 & 0 \\
\hline 0 & 0 & 0 & 0 & 0 \\
\hline 0 & 0 & 0 & 0 & 0 \\
\hline 0 & 0 & 0 & 0 & 0 \\
\hline 0 & 0 & 0 & 0 & 0 \\
\hline 0 & 0 & 0 & 0 & 0 \\
\hline 0 & 0 & 0 & 0 & 0 \\
\hline 0 & 0 & 0 & 0 & 0 \\
\hline 0 & 0 & 0 & 0 & 0 \\
\hline 0 & 0 & 0 & 0 & 0 \\
\hline 0 & 0 & 0 & 0 & 0 \\
\hline 0 & 0 & 0 & 0 & 0 \\
\hline 0 & 0 & 0 & 0 & 0 \\
\hline
\end{tabular}




\section{Lea Messman-Mandicott Dissertation}

\section{Overall, how well does FSU's curriculum help students develop this particular student learning outcome?}

Drawing conclusions

Assessing Internet pages (.com, .gov)

Understanding the ethics of information use

Using different strategies for understanding and comprehension

Awareness of security and personal privacy issues

Being able to formulate a strong thesis

Organizing, storing and backing up information

Being able to access the Internet

Learning to pick out what extra resources can help them

Being able to analyze a text format (content,)

Ability to communicate information in a variety of ways to match learning style

Spelling \& grammar, correct punctuation, etc.

Effective use of research tools in print and digital (i.e., indexes, etc.)

Manual citation of references

Distinguishing between types of resources \& publications

Able to manage information results electronically

Have a healthy dose of skepticism

Being able to identify bias in a resource

$\mathrm{Be}$ able to evaluate the results of a web search

Be able to corroborate information

\begin{tabular}{|c|c|c|c|c|}
\hline Very Poorly & Poorly & Neutral & Well & Very Well \\
\hline 0 & 0 & 0 & 0 & 0 \\
\hline 0 & 0 & 0 & 0 & 0 \\
\hline 0 & 0 & 0 & 0 & 0 \\
\hline 0 & 0 & 0 & 0 & 0 \\
\hline 0 & 0 & 0 & 0 & 0 \\
\hline 0 & 0 & 0 & 0 & 0 \\
\hline 0 & 0 & 0 & 0 & 0 \\
\hline 0 & 0 & 0 & 0 & 0 \\
\hline 0 & 0 & 0 & 0 & 0 \\
\hline 0 & 0 & 0 & 0 & 0 \\
\hline 0 & 0 & 0 & 0 & 0 \\
\hline 0 & 0 & 0 & 0 & 0 \\
\hline 0 & 0 & 0 & 0 & 0 \\
\hline 0 & 0 & 0 & 0 & 0 \\
\hline 0 & 0 & 0 & 0 & 0 \\
\hline 0 & 0 & 0 & 0 & 0 \\
\hline 0 & 0 & 0 & 0 & 0 \\
\hline 0 & 0 & 0 & 0 & 0 \\
\hline 0 & 0 & 0 & 0 & 0 \\
\hline 0 & 0 & 0 & 0 & 0 \\
\hline
\end{tabular}




\section{Lea Messman-Mandicott Dissertation}

7. Overall, how well does FSU's curriculum help students develop this particular student learning outcome?

Narrow or revise search strategy and results Very Poorly Poorly Neutral Well Very Well

Being able to evaluate the substantiality of the study

Understand the difference between statistical versus practical significance

Difference between quantitative and qualitative methods

Legal issues in the use of sources, copyright

Protocols for accessing private information

Social or scientific implications of the research being used

Effective personal interviewing

Organizing information for an effective oral presentation

Oral communication skills

Understanding of scholarly versus popular resources

Understand their medium and their audience to adjust information

Be able to construct attributive tags or signal phrases

Understanding the difference between a database and the Internet

Distinguish between abstracts, review articles and original research

Evaluating the quality of evidence

Understand the components of a research

paper

Ability to summarize and synthesize the information in a resource

Data driven decision-making for some disciplines

Recognizing that the answer is a combination of many resources

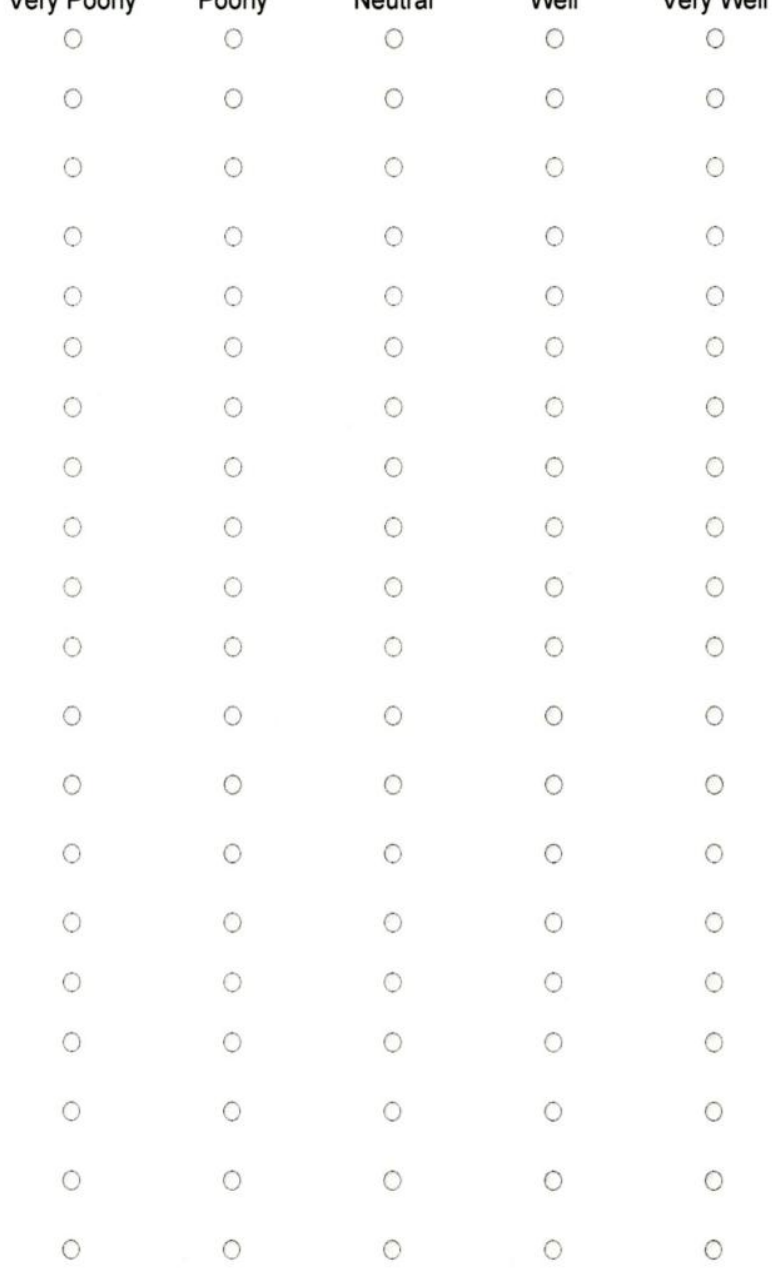




\section{Lea Messman-Mandicott Dissertation}

8. Overall, how well does FSU's curriculum help students develop this particular student learning outcome?

Sequence of the scientific process

\begin{tabular}{|c|c|c|c|c|}
\hline Very Poorly & Poorly & Neutral & Well & Very Well \\
\hline 0 & 0 & 0 & 0 & 0 \\
\hline 0 & 0 & 0 & 0 & 0 \\
\hline 0 & 0 & 0 & 0 & 0 \\
\hline 0 & 0 & 0 & 0 & 0 \\
\hline 0 & 0 & 0 & 0 & 0 \\
\hline 0 & 0 & 0 & 0 & 0 \\
\hline 0 & 0 & 0 & 0 & 0 \\
\hline 0 & 0 & 0 & 0 & 0 \\
\hline 0 & 0 & 0 & 0 & 0 \\
\hline 0 & 0 & 0 & 0 & 0 \\
\hline 0 & 0 & 0 & 0 & 0 \\
\hline 0 & 0 & 0 & 0 & 0 \\
\hline 0 & 0 & 0 & 0 & 0 \\
\hline 0 & 0 & 0 & 0 & 0 \\
\hline 0 & 0 & 0 & 0 & 0 \\
\hline 0 & 0 & 0 & 0 & 0 \\
\hline 0 & 0 & 0 & 0 & 0 \\
\hline 0 & 0 & 0 & 0 & 0 \\
\hline 0 & 0 & 0 & 0 & 0 \\
\hline 0 & 0 & 0 & 0 & 0 \\
\hline 0 & 0 & 0 & 0 & 0 \\
\hline
\end{tabular}

Ability to present personal information orally 


\section{Appendix E}

Hierarchical Cluster Tree or Dendrogram Created by the Hierarchical Cluster Analysis Showing Where the Clusters Split

81

Prory solentini discovery - identiry the to

74. How to structure the information needed at the

56. Understand the componemts of a research paper

6e. Ability to conduet an inquir

71. Boing able to do basid information sosking or

78. Autonomous in seeking intormation

40. Narrow or revise searen stratosy and result

so. Sequence of the scierntine process

28. Learning to plek out what extra resourees can

2E. Organing. Aforing and backing up intormetion

70. Avolding information overtoad

24. Awarenesso or security and personel privecy iss

11. Understanding what they need to rind

12. A basic search strategy

4. Ueing search tarme ortectivaly

7. Being abiat to accesss the intornet

45. Protocole for accessing private intormation 8. Onine catalog

14. Understanding the phrateal apace and comtent o

5. Mmore to look to intormation resul

32. Errective use or researen toots in print and a

7. kentirying appropriete diecipline dotabases a

21. Assesseing intornet pages (.com, gov)

53. Undersetanding the dirrerenoe between a datatsae

22 . Understanding the ethies of intormation use

44. Legat issues in the vese of sources, caprritint

1. Proper documerntation

33. Manuat eltation of rererences

75. Finding information for lire arter graduation

77. Time managememt a priornization or taske

25 . Being able to rormulate a wtrang thessim

S2. Be able to construct attributive tags or siana

16. Batance to vour paper in whent you presernt

31. speling a grammar oorect puncturtion ote.

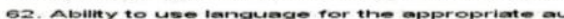

17. Errective communteation or the intormation

30. Ability to communicente information in a variet

48. Orsanizing information for an orrective orat p

51. Understand their medium and their audienoe to

Bo. Abillty to preseent persoonal information orally

49 Oral communication skitis

47. Errective personal interviewing

18. Integrete the moteriate into a knowiedge base 69. Reoveluate drarte and the "niniehed" product. o. connidenee

4.

42. Under stand the dirrerence between statistice 43. Dirror 39. Be abie to corroborate inrormation

SS. Evaluating the quaity or evidence

bo. Look rov creabite evidence or both sides or an

2. Evaluating sourcos oriticall,

7. Being abie to iderntiry bias in a resource

b. Critioally assessing the oredibility and thora

41. Being able to evaluate the substarniaity 2

72. bo alsie to look tor and nnd mumple explanen

10. Balance or the revource in regard to covernse

38. Be atsie to evaluate the resuns or a webseare

34. Distinaulsmina bet ween ivpes or resourcess a pu

64. Distinauian isotwean abstracts. reviow artioles

so. Understanding of scholariy varsus popular reses

6 6. Defintion of primary, secondary. tertiary sour

65. The ability to challenge thatr awn perspective -

36. Have a heathy dose or skepticism

61. Idemirying competing perspectives and respond

13. Efrective use of the matarials round

15. Symthesizing the cornternt or the artiele

19. interpret the date and nindings

57. Ability to summarize and syrnthesize the intorm

23. Using dirroront stratodies for under standing a

20. Drawing conclusion

se. Data diven deoision-making for some diseciplin

63. The ability to rorm an opintor

46. Soclat or scientifie impliontions of the reses

59. Recountzing that the answer is a combination o

73 Be able to integrate new. muntiple types or in

76. Pecoginizen the umits at their knowindas

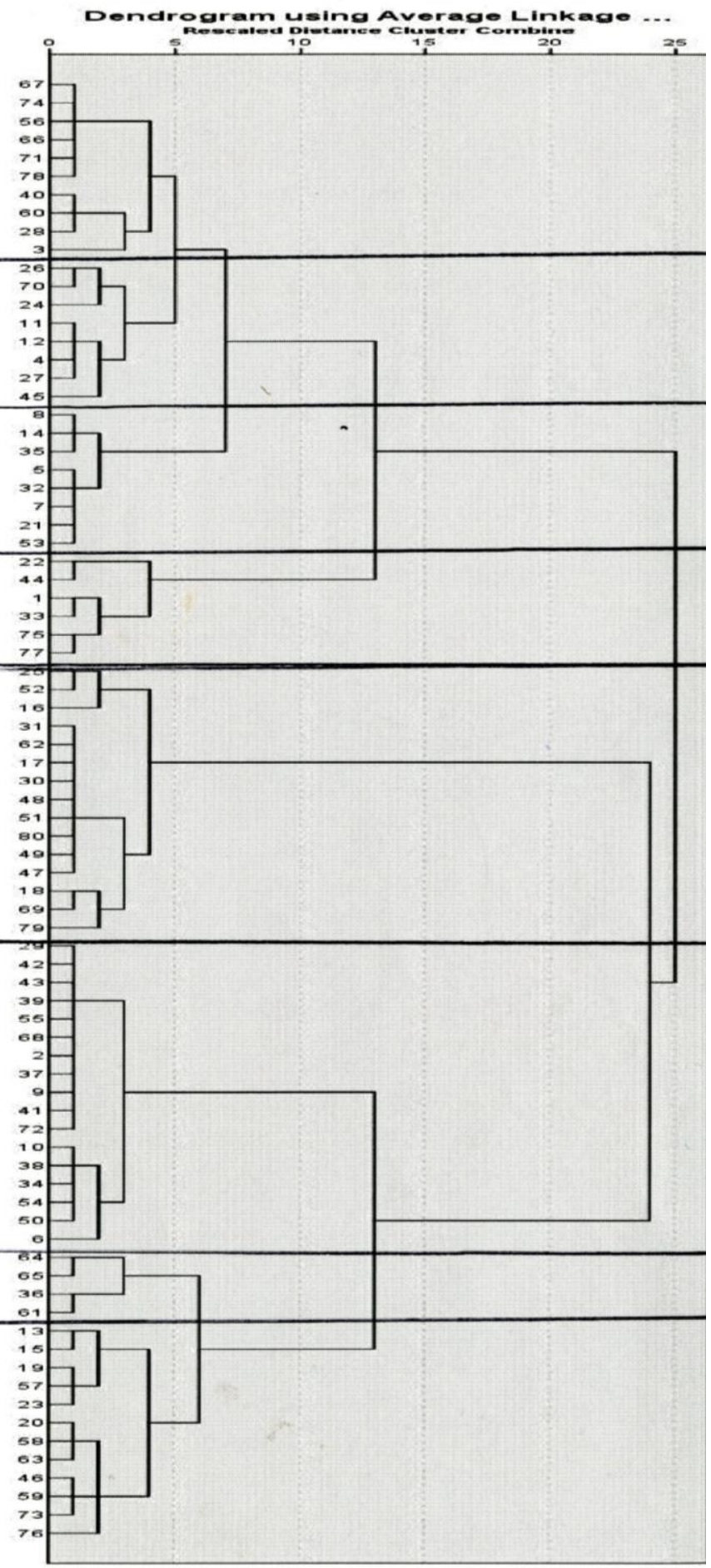


CONTENT DOMAIN FOR INFORMATION LITERACY

\section{Appendix F}

\section{Excel Spreadsheet Grouping Outcomes into Clusters Ranging from 5 to 10}

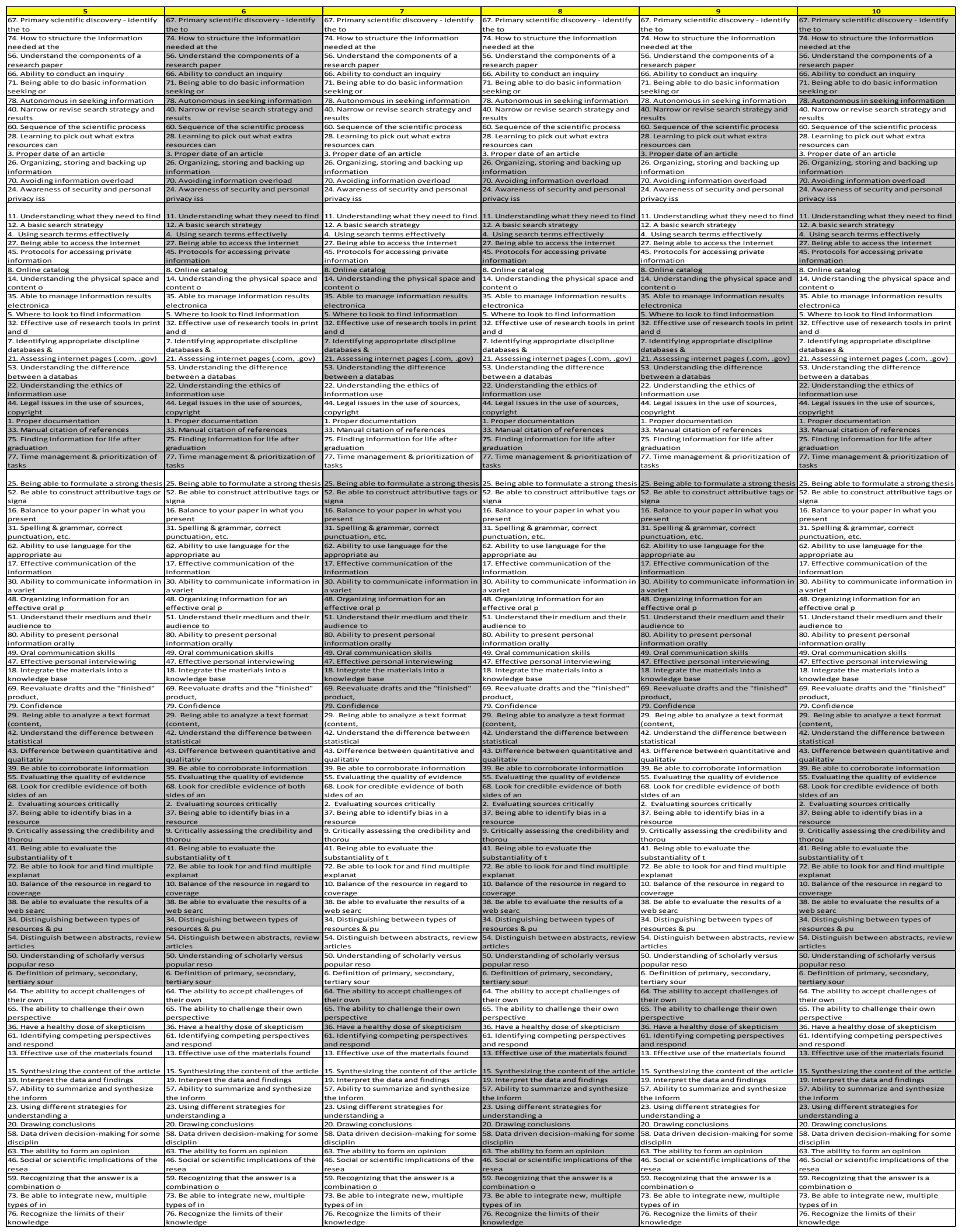




\section{CONTENT DOMAIN FOR INFORMATION LITERACY}

\section{Appendix G}

Mean Scores for Importance and Efficacy for the 80 Outcomes after Rating by Key Stakeholders

\begin{tabular}{|c|c|c|c|c|}
\hline Order & X Coordinate & Y Coordinate & Importance & Efficacy \\
\hline 1 & 0.222 & -1.567 1. Proper documentation & 4.64 & 3.86 \\
\hline 2 & -0.338 & 1.541 2. Evaluating sources critically & 4.71 & 2.93 \\
\hline 3 & 0.533 & 0.612 3. Proper date of an article & 4.21 & 3.64 \\
\hline 4 & 1.358 & 0.0614 . Using search terms effectively & 4.07 & 2.86 \\
\hline 5 & 1.168 & 0.4635 . Where to look to find information & 4.36 & 2.93 \\
\hline 6 & 0.751 & 1.174 6. Definition of primary, secondary, tertiary sour & 3.93 & 2.57 \\
\hline 7 & 1.060 & 0.859 7. Identifying appropriate discipline databases \& & 4.21 & 3.00 \\
\hline 8 & 1.599 & 0.576 8. Online catalog & 3.71 & 3.21 \\
\hline 9 & -0.228 & 1.456 9. Critically assessing the credibility and thorou & 4.50 & 3.08 \\
\hline 10 & 0.238 & 1.122 10. Balance of the resource in regard to coverage & 3.93 & 3.00 \\
\hline 11 & 1.256 & -0.26711 . Understanding what they need to find & 4.71 & 2.93 \\
\hline 12 & 1.204 & -0.118 12. A basic search strategy & 4.29 & 3.29 \\
\hline 13 & -0.482 & 0.002 13. Effective use of the materials found & 4.43 & 3.14 \\
\hline 14 & 1.790 & 0.46014 . Understanding the physical space and content & 3.36 & 2.69 \\
\hline 15 & -0.284 & -0.10215. Synthesizing the content of the article & 4.57 & 3.07 \\
\hline 16 & -0.394 & -1.283 16. Balance to your paper in what you present & 4.14 & 3.29 \\
\hline 17 & -1.020 & -1.332 17. Effective communication of the information & 4.64 & 3.14 \\
\hline 18 & -0.978 & -0.547 18. Integrate the materials into a knowledge base & 4.29 & 2.93 \\
\hline 19 & -0.798 & -0.058 19. Interpret the data and findings & 4.43 & 2.93 \\
\hline 20 & -1.359 & -0.239 20. Drawing conclusions & 4.57 & 3.14 \\
\hline 21 & 1.187 & 0.756 21. Assessing internet pages (.com, .gov) & 3.93 & 2.93 \\
\hline 22 & 1.286 & -1.43522 . Understanding the ethics of information use & 4.36 & 2.86 \\
\hline 23 & -0.772 & 0.472 23. Using different strategies for understanding a & 4.29 & 2.93 \\
\hline 24 & 1.664 & -1.00724 . Awareness of security and personal privacy iss & 3.79 & 2.86 \\
\hline 25 & -0.205 & -0.78825. Being able to formulate a strong thesis & 4.46 & 3.57 \\
\hline 26 & 1.460 & -0.52026 . Organizing, storing and backing up information & 3.86 & 2.93 \\
\hline 27 & 1.503 & -0.12127 . Being able to access the internet & 4.21 & 4.43 \\
\hline 28 & 0.622 & 0.072 28. Learning to pick out what extra resources can & 4.07 & 3.07 \\
\hline 29 & -0.102 & 1.193 29. Being able to analyze a text format (content, & 4.29 & 3.00 \\
\hline 30 & -0.944 & -1.36830 . Ability to communicate information in a variet & 3.93 & 2.71 \\
\hline 31 & -0.774 & -1.242 31. Spelling \& grammar, correct punctuation, etc. & 4.50 & 3.07 \\
\hline 32 & 1.286 & 0.527 32. Effective use of research tools in print and $d$ & 4.29 & 2.64 \\
\hline 33 & 0.183 & -1.339 33. Manual citation of references & 3.71 & 2.71 \\
\hline 34 & 0.279 & 1.509 34. Distinguishing between types of resources \& pl & 4.21 & 3.14 \\
\hline 35 & 1.531 & 0.303 35. Able to manage information results electronica & 3.50 & 2.86 \\
\hline 36 & -0.832 & 1.104 36. Have a healthy dose of skepticism & 4.00 & 2.86 \\
\hline 37 & -0.469 & 1.57537 . Being able to identify bias in a resource & 4.43 & 3.00 \\
\hline 38 & 0.323 & 1.234 38. Be able to evaluate the results of a web searc & 4.57 & 3.21 \\
\hline 39 & -0.553 & 1.377 39. Be able to corroborate information & 4.29 & 2.64 \\
\hline 40 & 0.941 & -0.02140. Narrow or revise search strategy and results & 4.14 & 3.00 \\
\hline 41 & -0.264 & 1.340 41. Being able to evaluate the substantiality of $t$ & 4.14 & 2.79 \\
\hline 42 & -0.048 & 1.136 42. Understand the difference between statistical & 3.86 & 2.21 \\
\hline 43 & -0.256 & 1.126 43. Difference between quantitative and qualitativ & 3.93 & 2.36 \\
\hline 44 & 1.210 & -1.33044 . Legal issues in the use of sources, copyright & 4.21 & 3.00 \\
\hline 45 & 1.873 & -0.32345. Protocols for accessing private information & 3.79 & 2.57 \\
\hline
\end{tabular}




\section{CONTENT DOMAIN FOR INFORMATION LITERACY}

\begin{tabular}{|c|c|c|c|c|}
\hline Order & X Coordinate & Y Coordinate & Importance & Efficacy \\
\hline 46 & -1.381 & 0.51746 . Social or scientific implications of the resea & 3.71 & 2.71 \\
\hline 47 & -1.214 & -1.289 47. Effective personal interviewing & 3.71 & 2.21 \\
\hline 48 & -0.918 & -1.572 48. Organizing information for an effective oral $p$ & 4.43 & 2.86 \\
\hline 49 & -1.022 & -1.523 49. Oral communication skills & 4.57 & 2.86 \\
\hline 50 & 0.366 & 1.377 50. Understanding of scholarly versus popular reso & 4.29 & 3.14 \\
\hline 51 & -0.918 & -1.57251 . Understand their medium and their audience to & 4.57 & 2.79 \\
\hline 52 & -0.371 & -0.69652. Be able to construct attributive tags or signa & 3.07 & 2.50 \\
\hline 53 & 1.199 & 1.014 53. Understanding the difference between a databa & 4.07 & 3.21 \\
\hline 54 & 0.181 & 1.474 54. Distinguish between abstracts, review articles & 4.21 & 3.14 \\
\hline 55 & -0.535 & 1.325 55. Evaluating the quality of evidence & 4.57 & 2.64 \\
\hline 56 & 0.409 & -0.40856 . Understand the components of a research pape & 4.07 & 3.08 \\
\hline 57 & -0.915 & 0.10057 . Ability to summarize and synthesize the inform & 4.64 & 3.29 \\
\hline 58 & -1.461 & -0.187 58. Data driven decision-making for some disciplin & 3.79 & 2.64 \\
\hline 59 & -1.258 & 0.355 59. Recognizing that the answer is a combination c & 4.21 & 2.79 \\
\hline 60 & 0.750 & -0.10460. Sequence of the scientific process & 3.57 & 2.79 \\
\hline 61 & -1.176 & 0.954 61. Identifying competing perspectives and responc & 4.29 & 2.71 \\
\hline 62 & -0.767 & -1.44162 . Ability to use language for the appropriate au & 4.50 & 3.07 \\
\hline 63 & -1.531 & 0.040 63. The ability to form an opinion & 4.29 & 3.43 \\
\hline 64 & -1.729 & 0.83464 . The ability to accept challenges of their own & 4.71 & 2.71 \\
\hline 65 & -1.612 & 0.98165 . The ability to challenge their own perspective & 4.64 & 2.50 \\
\hline 66 & 0.384 & -0.64966 . Ability to conduct an inquiry & 4.50 & 3.14 \\
\hline 67 & 0.597 & -0.82867 . Primary scientific discovery - identify the to & 3.71 & 2.93 \\
\hline 68 & -0.658 & 1.359 68. Look for credible evidence of both sides of an & 4.29 & 3.07 \\
\hline 69 & -0.898 & -0.766 69. Reevaluate drafts and the "finished" product, & 4.57 & 2.93 \\
\hline 70 & 1.234 & -0.71670 . Avoiding information overload & 3.29 & 2.79 \\
\hline 71 & 0.698 & -0.54571 . Being able to do basic information seeking or & 4.36 & 2.93 \\
\hline 72 & -0.404 & 1.372 72. Be able to look for and find multiple explanat & 4.14 & 2.86 \\
\hline 73 & -1.208 & 0.11373 . Be able to integrate new, multiple types of in & 4.36 & 3.00 \\
\hline 74 & 0.597 & -0.82874 . How to structure the information needed at the & 4.43 & 2.93 \\
\hline 75 & 0.546 & -1.65675 . Finding information for life after graduation & 4.07 & 3.07 \\
\hline 76 & -1.835 & 0.28076 . Recognize the limits of their knowledge & 4.36 & 2.57 \\
\hline 77 & 0.780 & -1.445 77. Time management \& prioritization of tasks & 4.36 & 2.64 \\
\hline 78 & 0.976 & -0.52878 . Autonomous in seeking information & 4.00 & 2.93 \\
\hline 79 & -1.417 & -0.808 79. Confidence & 3.93 & 3.43 \\
\hline 80 & -0.919 & -1.57280 . Ability to present personal information orally & 4.14 & 2.93 \\
\hline
\end{tabular}




\section{Appendix H}

Comparing Similarities between Concept Mapping/Pattern Matching Outcomes and the ACRL Information Literacy Competency Standards

\begin{tabular}{|c|c|}
\hline $\begin{array}{c}\text { ACRL Standards, Performance Indicators, \& } \\
\text { Outcomes }\end{array}$ & $\begin{array}{c}\text { Current Study's Concept Mapping/Pattern } \\
\text { Matching Clusters \& Outcomes }\end{array}$ \\
\hline $\begin{array}{l}\text { S1. The information literate student } \\
\text { determines the nature and extent of the } \\
\text { information needed. }\end{array}$ & C1: Research Process Cluster \\
\hline $\begin{array}{l}\text { P1. The information literate student defines } \\
\text { and articulates the need for information. }\end{array}$ & \\
\hline $\begin{array}{l}\text { a. Confers with instructors and participates } \\
\text { in class discussions, peer workgroups, and } \\
\text { electronic discussions to identify a } \\
\text { research topic, or other information need. }\end{array}$ & $\begin{array}{l}\text { 67. Primary scientific discovery - identify } \\
\text { the topic first } \\
74 \text {. How to structure the information need } \\
\text { at the beginning - formulating a research } \\
\text { question }\end{array}$ \\
\hline $\begin{array}{l}\text { b. Develops a thesis statement and } \\
\text { formulates questions based on the } \\
\text { information need. }\end{array}$ & $\begin{array}{l}\text { 25. Being able to formulate a strong thesis } \\
\text { 74. How to structure the information need } \\
\text { at the beginning - formulating a research } \\
\text { question }\end{array}$ \\
\hline $\begin{array}{l}\text { c. Explores general information sources to } \\
\text { increase familiarity with the topic. }\end{array}$ & \\
\hline $\begin{array}{l}\text { d. Defines or modifies the information } \\
\text { need to achieve a manageable focus. }\end{array}$ & $\begin{array}{l}\text { 40. Narrow or revise search strategy and } \\
\text { results } \\
\text { 70. Avoiding information overload }\end{array}$ \\
\hline $\begin{array}{l}\text { e. Identifies key concepts and terms that } \\
\text { describe the information need. }\end{array}$ & 4. Using search terms effectively \\
\hline $\begin{array}{l}\text { f. Recognizes that existing information can } \\
\text { be combined with original thought, } \\
\text { experimentation, and/or analysis to } \\
\text { produce new information. }\end{array}$ & $\begin{array}{l}\text { 59. Recognizing that the answer is a } \\
\text { combination of many resources }\end{array}$ \\
\hline $\begin{array}{l}\text { P2. The information literate student } \\
\text { identifies a variety of types and formats of } \\
\text { potential sources for information }\end{array}$ & \\
\hline $\begin{array}{l}\text { a. Knows how information is formally and } \\
\text { informally produced, organized, and } \\
\text { disseminated }\end{array}$ & \\
\hline $\begin{array}{l}\text { b. Recognizes that knowledge can be } \\
\text { organized into disciplines that influence } \\
\text { the way information is accessed }\end{array}$ & $\begin{array}{l}\text { 7. Identifying appropriate discipline } \\
\text { databases \& resources } \\
\text { 58. Data driven decision-making for some } \\
\text { disciplines }\end{array}$ \\
\hline
\end{tabular}




\begin{tabular}{|c|c|}
\hline $\begin{array}{l}\text { c. Identifies the value and differences of } \\
\text { potential resources in a variety of formats } \\
\text { (e.g., multimedia, database, website, data } \\
\text { set, audio/visual, book) }\end{array}$ & $\begin{array}{l}\text { 34. Distinguishing between types of } \\
\text { resources \& publications } \\
\text { 53. Understanding the difference } \\
\text { between a database and the Internet } \\
\text { 54. Distinguish between abstracts, review } \\
\text { articles and original research }\end{array}$ \\
\hline $\begin{array}{l}\text { d. Identifies the purpose and audience of } \\
\text { potential resources (e.g., popular vs. } \\
\text { scholarly, current vs. historical) }\end{array}$ & $\begin{array}{l}\text { 50. Understanding of scholarly versus } \\
\text { popular resources }\end{array}$ \\
\hline $\begin{array}{l}\text { e. Differentiates between primary and } \\
\text { secondary sources, recognizing how their } \\
\text { use and importance vary with each } \\
\text { discipline }\end{array}$ & $\begin{array}{l}\text { 6. Definition of primary, secondary, } \\
\text { tertiary sources }\end{array}$ \\
\hline $\begin{array}{l}\text { f. Realizes that information may need to be } \\
\text { constructed with raw data from primary } \\
\text { sources }\end{array}$ & \\
\hline $\begin{array}{l}\text { P3. The information literate student } \\
\text { considers the costs and benefits of acquiring } \\
\text { the needed information. }\end{array}$ & \\
\hline $\begin{array}{l}\text { a. Determines the availability of needed } \\
\text { information and makes decisions on } \\
\text { broadening the information seeking process } \\
\text { beyond local resources (e.g., interlibrary } \\
\text { loan; using resources at other locations; } \\
\text { obtaining images, videos, text, or sound). }\end{array}$ & $\begin{array}{l}\text { 14. Understanding the physical space and } \\
\text { content of the library }\end{array}$ \\
\hline $\begin{array}{l}\text { b. Considers the feasibility of acquiring a } \\
\text { new language or skill (e.g., foreign or } \\
\text { discipline-based) in order to gather needed } \\
\text { information and to understand its context. }\end{array}$ & \\
\hline $\begin{array}{l}\text { c. Defines a realistic overall plan and } \\
\text { timeline to acquire the needed information. }\end{array}$ & $\begin{array}{l}\text { 77. Time management } \& \text { prioritization of } \\
\text { tasks }\end{array}$ \\
\hline $\begin{array}{l}\text { P4. The information literate student } \\
\text { reevaluates the nature and extent of the } \\
\text { information need. }\end{array}$ & \\
\hline $\begin{array}{l}\text { a. Reviews the initial information need to } \\
\text { clarify, revise, or refine the question }\end{array}$ & $\begin{array}{l}\text { 40. Narrow or revise search strategy and } \\
\text { results }\end{array}$ \\
\hline $\begin{array}{l}\text { b. Describes criteria used to make } \\
\text { information decisions and choices }\end{array}$ & $\begin{array}{l}\text { 58. Data driven decision-making for some } \\
\text { disciplines }\end{array}$ \\
\hline $\begin{array}{l}\text { S2. The information literate student } \\
\text { accesses needed information effectively and } \\
\text { efficiently. }\end{array}$ & $\begin{array}{l}\text { C2: Technical Skills Cluster } \\
\text { C3: Selecting Sources Cluster }\end{array}$ \\
\hline $\begin{array}{l}\text { P1. The information literate student selects } \\
\text { the most appropriate investigative methods } \\
\text { or information retrieval systems for } \\
\text { accessing the needed information. }\end{array}$ & \\
\hline
\end{tabular}




\begin{tabular}{|c|c|}
\hline $\begin{array}{l}\text { a. Identifies appropriate investigative } \\
\text { methods (e.g., laboratory experiment, } \\
\text { simulation, fieldwork) }\end{array}$ & $\begin{array}{l}\text { 23. Using different strategies for } \\
\text { understanding and comprehension } \\
\text { 43. Difference between quantitative and } \\
\text { qualitative methods } \\
\text { 60. Sequence of the scientific process }\end{array}$ \\
\hline $\begin{array}{l}\text { b. Investigates benefits and applicability of } \\
\text { various investigative methods }\end{array}$ & $\begin{array}{l}\text { 43. Difference between quantitative and } \\
\text { qualitative methods }\end{array}$ \\
\hline $\begin{array}{l}\text { c. Investigates the scope, content, and } \\
\text { organization of information retrieval } \\
\text { systems }\end{array}$ & \\
\hline $\begin{array}{l}\text { d. Selects efficient and effective } \\
\text { approaches for accessing the information } \\
\text { needed from the investigative method or } \\
\text { information retrieval system }\end{array}$ & $\begin{array}{l}\text { 4. Using search terms effectively } \\
\text { 23. Using different strategies for } \\
\text { understanding and comprehension } \\
\text { 32. Effective use of research tools in print } \\
\text { and digital (i.e., indexes, etc.) }\end{array}$ \\
\hline $\begin{array}{l}\text { P2. The information literate student } \\
\text { constructs and implements effectively- } \\
\text { designed search strategies. }\end{array}$ & \\
\hline $\begin{array}{l}\text { a. Develops a research plan appropriate to } \\
\text { the investigative method }\end{array}$ & 12. A basic search strategy \\
\hline $\begin{array}{l}\text { b. Identifies keywords, synonyms and } \\
\text { related terms for the information needed }\end{array}$ & 4. Using search terms effectively \\
\hline $\begin{array}{l}\text { c. Selects controlled vocabulary specific to } \\
\text { the discipline or information retrieval } \\
\text { source }\end{array}$ & 4. Using search terms effectively \\
\hline $\begin{array}{l}\text { d. Constructs a search strategy using } \\
\text { appropriate commands for the information } \\
\text { retrieval system selected (e.g., Boolean } \\
\text { operators, truncation, and proximity for } \\
\text { search engines; internal organizers such as } \\
\text { indexes for books) }\end{array}$ & $\begin{array}{l}\text { 4. Using search terms effectively } \\
\text { 12. A basic search strategy }\end{array}$ \\
\hline $\begin{array}{l}\text { e. Implements the search strategy in } \\
\text { various information retrieval systems using } \\
\text { different user interfaces and search } \\
\text { engines, with different command } \\
\text { languages, protocols, and search } \\
\text { parameters }\end{array}$ & $\begin{array}{l}\text { 4. Using search terms effectively } \\
\text { 32. Effective use of research tools in print } \\
\text { and digital (i.e., indexes, etc.) } \\
\text { 53. Understanding the difference between a } \\
\text { database and the Internet }\end{array}$ \\
\hline $\begin{array}{l}\text { f. Implements the search using } \\
\text { investigative protocols appropriate to the } \\
\text { discipline }\end{array}$ & $\begin{array}{l}\text { 7. Identifying appropriate discipline } \\
\text { databases \& resources } \\
\text { 45. Protocols for accessing private } \\
\text { information }\end{array}$ \\
\hline $\begin{array}{l}\text { P3. The information literate student retrieves } \\
\text { information online or in person using a } \\
\text { variety of methods }\end{array}$ & \\
\hline
\end{tabular}




\begin{tabular}{|c|c|}
\hline $\begin{array}{l}\text { a. Uses various search systems to retrieve } \\
\text { information in a variety of formats }\end{array}$ & $\begin{array}{l}\text { 8. Online catalog } \\
\text { 27. Being able to access the internet } \\
\text { 32. Effective use of research tools in print } \\
\text { and digital (i.e., indexes, etc.) }\end{array}$ \\
\hline $\begin{array}{l}\text { b. Uses various classification schemes and } \\
\text { other systems (e.g., call number systems or } \\
\text { indexes) to locate information resources } \\
\text { within the library or to identify specific } \\
\text { sites for physical exploration }\end{array}$ & $\begin{array}{l}\text { 14. Understanding the physical space and } \\
\text { content of the library }\end{array}$ \\
\hline $\begin{array}{l}\text { c. Uses specialized online or in person } \\
\text { services available at the institution to } \\
\text { retrieve information needed (e.g., } \\
\text { interlibrary loan/document delivery, } \\
\text { professional associations, institutional } \\
\text { research offices, community resources, } \\
\text { experts and practitioners) }\end{array}$ & 5. Where to look to find information \\
\hline $\begin{array}{l}\text { d. Uses surveys, letters, interviews, and } \\
\text { other forms of inquiry to retrieve primary } \\
\text { information }\end{array}$ & $\begin{array}{l}\text { 6. Definition of primary, secondary, } \\
\text { tertiary sources }\end{array}$ \\
\hline $\begin{array}{l}\text { P4. The information literate student refines } \\
\text { the search strategy if necessary }\end{array}$ & \\
\hline $\begin{array}{l}\text { a. Assesses the quantity, quality, and } \\
\text { relevance of the search results to } \\
\text { determine whether alternative information } \\
\text { retrieval systems or investigative methods } \\
\text { should be utilized }\end{array}$ & $\begin{array}{l}\text { 38. Be able to evaluate the results of a } \\
\text { web search } \\
40 . \text { Narrow or revise search strategy and } \\
\text { results } \\
55 . \text { Evaluating the quality of evidence }\end{array}$ \\
\hline $\begin{array}{l}\text { b. Identifies gaps in the information } \\
\text { retrieved and determines if the search } \\
\text { strategy should be revised }\end{array}$ & $\begin{array}{l}\text { 40. Narrow or revise search strategy and } \\
\text { results }\end{array}$ \\
\hline $\begin{array}{l}\text { c. Repeats the search using the revised } \\
\text { strategy as necessary }\end{array}$ & $\begin{array}{l}40 . \text { Narrow or revise search strategy and } \\
\text { results }\end{array}$ \\
\hline \multicolumn{2}{|l|}{$\begin{array}{l}\text { P5. The information literate student extracts, } \\
\text { records, and manages the information and its } \\
\text { sources. }\end{array}$} \\
\hline \multicolumn{2}{|l|}{$\begin{array}{l}\text { a. Selects among various technologies the } \\
\text { most appropriate one for the task of } \\
\text { extracting the needed information (e.g., } \\
\text { copy/paste software functions, photocopier, } \\
\text { scanner, audio/visual equipment, or } \\
\text { exploratory instruments) }\end{array}$} \\
\hline $\begin{array}{l}\text { b. Creates a system for organizing the } \\
\text { information }\end{array}$ & $\begin{array}{l}\text { 26. Organizing, storing and backing up } \\
\text { information }\end{array}$ \\
\hline
\end{tabular}




\begin{tabular}{|c|c|}
\hline $\begin{array}{l}\text { c. Differentiates between the types of } \\
\text { sources cited and understands the elements } \\
\text { and correct syntax of a citation for a wide } \\
\text { range of resources }\end{array}$ & $\begin{array}{l}\text { 1. Proper documentation } \\
\text { 33. Manual citation of references }\end{array}$ \\
\hline $\begin{array}{l}\text { d. Records all pertinent citation } \\
\text { information for future reference }\end{array}$ & $\begin{array}{l}\text { 1. Proper documentation } \\
\text { 3. Proper date of an article }\end{array}$ \\
\hline $\begin{array}{l}\text { e. Uses various technologies to manage } \\
\text { the information selected and organized }\end{array}$ & $\begin{array}{l}\text { 26. Organizing, storing and backing up } \\
\text { information } \\
\text { 35. Able to manage information results } \\
\text { electronically }\end{array}$ \\
\hline $\begin{array}{l}\text { S3. The information literate student } \\
\text { evaluates information and its sources } \\
\text { critically and incorporates selected } \\
\text { information into his or her knowledge base } \\
\text { and value system. }\end{array}$ & C6: Evaluating Information Cluster \\
\hline $\begin{array}{l}\text { P1. The information literate student } \\
\text { summarizes the main ideas to be extracted } \\
\text { from the information gathered. }\end{array}$ & \\
\hline a. Reads the text and selects main ideas & $\begin{array}{l}\text { 19. Interpret the data and findings } \\
\text { 29. Being able to analyze a text format } \\
\text { (content,) } \\
\text { 57. Ability to summarize and synthesize } \\
\text { the information in a resource }\end{array}$ \\
\hline $\begin{array}{l}\text { b. Restates textual concepts in his/her own } \\
\text { words and selects data accurately }\end{array}$ & $\begin{array}{l}\text { 13. Effective use of the materials found } \\
\text { 15. Synthesizing the content of the article } \\
\text { 19. Interpret the data and findings } \\
\text { 57. Ability to summarize and synthesize } \\
\text { the information in a resource }\end{array}$ \\
\hline $\begin{array}{l}\text { c. Identifies verbatim material that can be } \\
\text { then appropriately quoted }\end{array}$ & $\begin{array}{l}\text { 13. Effective use of the materials found } \\
\text { 22. Understanding the ethics of information } \\
\text { use } \\
52 \text {. Be able to construct attributive tags or } \\
\text { signal phrases }\end{array}$ \\
\hline $\begin{array}{l}\text { P2. The information literate student } \\
\text { articulates and applies initial criteria for } \\
\text { evaluating both the information and its } \\
\text { sources. }\end{array}$ & \\
\hline
\end{tabular}




\begin{tabular}{|c|c|}
\hline $\begin{array}{l}\text { a. Examines and compares information } \\
\text { from various sources in order to evaluate } \\
\text { reliability, validity, accuracy, authority, } \\
\text { timeliness, and point of view or bias }\end{array}$ & $\begin{array}{l}\text { 2. Evaluating sources critically } \\
\text { 9. Critically assessing the credibility and } \\
\text { thoroughness of a resource } \\
\text { 10. Balance of the resource in regard to } \\
\text { coverage } \\
\text { 37. Being able to identify bias in a } \\
\text { resource } \\
41 \text {. Being able to evaluate the } \\
\text { substantiality of the study }\end{array}$ \\
\hline $\begin{array}{l}\text { b. Analyzes the structure and logic of } \\
\text { supporting arguments or methods }\end{array}$ & $\begin{array}{l}\text { 2. Evaluating sources critically } \\
\text { 9. Critically assessing the credibility and } \\
\text { thoroughness of a resource } \\
\text { 10. Balance of the resource in regard to } \\
\text { coverage } \\
\text { 41. Being able to evaluate the substantiality } \\
\text { of the study } \\
\text { 42. Understand the difference between } \\
\text { statistical versus practical significance }\end{array}$ \\
\hline $\begin{array}{l}\text { c. Recognizes prejudice, deception, or } \\
\text { manipulation }\end{array}$ & 37. Being able to identify bias in a resource \\
\hline $\begin{array}{l}\text { d. Recognizes the cultural, physical, or } \\
\text { other context within which the information } \\
\text { was created and understands the impact of } \\
\text { context on interpreting the information }\end{array}$ & $\begin{array}{l}\text { 46. Social or scientific implications of the } \\
\text { research being used }\end{array}$ \\
\hline $\begin{array}{l}\text { P3. The information literate student } \\
\text { synthesizes main ideas to construct new } \\
\text { concepts. }\end{array}$ & \\
\hline $\begin{array}{l}\text { a. Recognizes interrelationships among } \\
\text { concepts and combines them into } \\
\text { potentially useful primary statements with } \\
\text { supporting evidence }\end{array}$ & $\begin{array}{l}\text { 15. Synthesizing the content of the article } \\
\text { 19. Interpret the data and findings } \\
\text { 20. Drawing conclusions } \\
\text { 25. Being able to formulate a strong } \\
\text { thesis } \\
\text { 57. Ability to summarize and synthesize } \\
\text { the information in a resource } \\
\text { 73. Be able to integrate new, multiple types } \\
\text { of information }\end{array}$ \\
\hline $\begin{array}{l}\text { b. Extends initial synthesis, when possible, } \\
\text { at a higher level of abstraction to construct } \\
\text { new hypotheses that may require additional } \\
\text { information }\end{array}$ & $\begin{array}{l}28 . \text { Learning to pick out what extra } \\
\text { resources can help them } \\
73 \text {. Be able to integrate new, multiple types } \\
\text { of information }\end{array}$ \\
\hline $\begin{array}{l}\text { c. Utilizes computer and other technologies } \\
\text { (e.g. spreadsheets, databases, multimedia, } \\
\text { and audio or visual equipment) for } \\
\text { studying the interaction of ideas and other } \\
\text { phenomena }\end{array}$ & \\
\hline
\end{tabular}




\begin{tabular}{|c|c|}
\hline $\begin{array}{l}\text { P4. The information literate student } \\
\text { compares new knowledge with prior } \\
\text { knowledge to determine the value added, } \\
\text { contradictions, or other unique } \\
\text { characteristics of the information. }\end{array}$ & \\
\hline $\begin{array}{l}\text { a. Determines whether information satisfies } \\
\text { the research or other information need }\end{array}$ & $\begin{array}{l}\text { 2. Evaluating sources critically } \\
\text { 28. Learning to pick out what extra } \\
\text { resources can help them } \\
\text { 40. Narrow or revise search strategy and } \\
\text { results }\end{array}$ \\
\hline $\begin{array}{l}\text { b. Uses consciously selected criteria to } \\
\text { determine whether the information } \\
\text { contradicts or verifies information used } \\
\text { from other sources }\end{array}$ & $\begin{array}{l}\text { 39. Be able to corroborate information } \\
61 \text {. Identifying competing perspectives } \\
\text { and responding to them effectively } \\
72 . \text { Be able to look for and find multiple } \\
\text { explanations for the argument }\end{array}$ \\
\hline $\begin{array}{l}\text { c. Draws conclusions based upon } \\
\text { information gathered }\end{array}$ & $\begin{array}{l}\text { 20. Drawing conclusions } \\
\text { 58. Data driven decision-making for some } \\
\text { disciplines } \\
\text { 63. The ability to form an opinion }\end{array}$ \\
\hline $\begin{array}{l}\text { d. Tests theories with discipline- } \\
\text { appropriate techniques (e.g., simulators, } \\
\text { experiments) }\end{array}$ & 39. Be able to corroborate information \\
\hline $\begin{array}{l}\text { e. Determines probable accuracy by } \\
\text { questioning the source of the data, the } \\
\text { limitations of the information gathering } \\
\text { tools or strategies, and the reasonableness } \\
\text { of the conclusions }\end{array}$ & $\begin{array}{l}\text { 2. Evaluating sources critically } \\
\text { 9. Critically assessing the credibility and } \\
\text { thoroughness of a resource } \\
\text { 10. Balance of the resource in regard to } \\
\text { coverage } \\
\text { 41. Being able to evaluate the substantiality } \\
\text { of the study }\end{array}$ \\
\hline $\begin{array}{l}\text { f. Integrates new information with } \\
\text { previous information or knowledge }\end{array}$ & $\begin{array}{l}\text { 18. Integrate the materials into a } \\
\text { knowledge base } \\
57 \text {. Ability to summarize and synthesize } \\
\text { the information in a resource } \\
59 \text {. Recognizing that the answer is a } \\
\text { combination of many resources } \\
73 \text {. Be able to integrate new, multiple } \\
\text { types of information }\end{array}$ \\
\hline $\begin{array}{l}\text { g. Selects information that provides } \\
\text { evidence for the topic }\end{array}$ & $\begin{array}{l}\text { 55. Evaluating the quality of evidence } \\
\text { 68. Look for credible evidence of both } \\
\text { sides of an argument }\end{array}$ \\
\hline $\begin{array}{l}\text { P5. The information literate student } \\
\text { determines whether the new knowledge has } \\
\text { an impact on the individual's value system } \\
\text { and takes steps to reconcile differences. }\end{array}$ & \\
\hline
\end{tabular}




\begin{tabular}{|c|c|}
\hline $\begin{array}{l}\text { a. Investigates differing viewpoints } \\
\text { encountered in the literature }\end{array}$ & $\begin{array}{l}\text { 61. Identifying competing perspectives } \\
\text { and responding to them effectively } \\
68 \text {. Look for credible evidence of both } \\
\text { sides of an argument } \\
72 \text {. Be able to look for and find multiple } \\
\text { explanations for the argument }\end{array}$ \\
\hline $\begin{array}{l}\text { b. Determines whether to incorporate or } \\
\text { reject viewpoints encountered }\end{array}$ & $\begin{array}{l}\text { 61. Identifying competing perspectives } \\
\text { and responding to them effectively } \\
65 \text {. The ability to challenge their own } \\
\text { perspectives }\end{array}$ \\
\hline $\begin{array}{l}\text { P6. The information literate student validates } \\
\text { understanding and interpretation of the } \\
\text { information through discourse with other } \\
\text { individuals, subject-area experts, and/or } \\
\text { practitioners. }\end{array}$ & \\
\hline $\begin{array}{l}\text { a. Participates in classroom and other } \\
\text { discussions }\end{array}$ & \\
\hline $\begin{array}{l}\text { b. Participates in class-sponsored electronic } \\
\text { communication forums designed to } \\
\text { encourage discourse on the topic (e.g., } \\
\text { email, bulletin boards, chat rooms) }\end{array}$ & $\begin{array}{l}\text { 17. Effective communication of the } \\
\text { information } \\
\text { 30. Ability to communicate information in } \\
\text { a variety of ways to match learning style }\end{array}$ \\
\hline $\begin{array}{l}\text { c. Seeks expert opinion through a variety of } \\
\text { mechanisms (e.g., interviews, email, } \\
\text { listservs) }\end{array}$ & \\
\hline $\begin{array}{l}\text { P7. The information literate student } \\
\text { determines whether the initial query should } \\
\text { be revised. }\end{array}$ & \\
\hline $\begin{array}{l}\text { a. Determines if original information need } \\
\text { has been satisfied or if additional } \\
\text { information is needed }\end{array}$ & $\begin{array}{l}\text { 69. Reevaluate drafts and the "finished" } \\
\text { product, conclusions, etc. }\end{array}$ \\
\hline $\begin{array}{l}\text { b. Reviews search strategy and } \\
\text { incorporates additional concepts as } \\
\text { necessary }\end{array}$ & $\begin{array}{l}\text { 40. Narrow or revise search strategy and } \\
\text { results }\end{array}$ \\
\hline $\begin{array}{l}\text { c. Reviews information retrieval sources } \\
\text { used and expands to include others as } \\
\text { needed }\end{array}$ & $\begin{array}{l}\text { 28. Learning to pick out what extra } \\
\text { resources can help them }\end{array}$ \\
\hline $\begin{array}{l}\text { S4. The information literate student, } \\
\text { individually or as a member of a group, } \\
\text { uses information effectively to accomplish a } \\
\text { specific purpose. }\end{array}$ & $\begin{array}{l}\text { C5. Communication Cluster } \\
\text { C8. Information Utilization Cluster }\end{array}$ \\
\hline $\begin{array}{l}\text { P1. The information literate student applies } \\
\text { new and prior information to the planning } \\
\text { and creation of a particular product or } \\
\text { performance. }\end{array}$ & \\
\hline
\end{tabular}




\begin{tabular}{|c|c|}
\hline $\begin{array}{l}\text { a. Organizes the content in a manner that } \\
\text { supports the purposes and format of the } \\
\text { product or performance (e.g. outlines, } \\
\text { drafts, storyboards) }\end{array}$ & $\begin{array}{l}\text { 16. Balance to your paper in what you } \\
\text { present } \\
\text { 48. Organizing information for an } \\
\text { effective oral presentation } \\
\text { 51. Understand their medium and their } \\
\text { audience to adjust information } \\
\text { 56. Understand the components of a } \\
\text { research paper }\end{array}$ \\
\hline \multicolumn{2}{|l|}{$\begin{array}{l}\text { b. Articulates knowledge and skills } \\
\text { transferred from prior experiences to } \\
\text { planning and creating the product or } \\
\text { performance }\end{array}$} \\
\hline $\begin{array}{l}\text { c. Integrates the new and prior } \\
\text { information, including quotations and } \\
\text { paraphrasings, in a manner that supports } \\
\text { the purposes of the product or performance }\end{array}$ & $\begin{array}{l}\text { 13. Effective use of the materials found } \\
57 . \text { Ability to summarize and synthesize } \\
\text { the information in a resource } \\
59 \text {. Recognizing that the answer is a } \\
\text { combination of many resources } \\
\text { 73. Be able to integrate new, multiple } \\
\text { types of information }\end{array}$ \\
\hline $\begin{array}{l}\text { d. Manipulates digital text, images, and } \\
\text { data, e. as needed, transferring them from } \\
\text { their original locations and formats to a } \\
\text { new context }\end{array}$ & $\begin{array}{l}\text { 35. Able to manage information results } \\
\text { electronically }\end{array}$ \\
\hline \multicolumn{2}{|l|}{$\begin{array}{l}\text { P2. The information literate student revises } \\
\text { the development process for the product or } \\
\text { performance. }\end{array}$} \\
\hline \multicolumn{2}{|l|}{$\begin{array}{l}\text { a. Maintains a journal or log of activities } \\
\text { related to the information seeking, } \\
\text { evaluating, and communicating process }\end{array}$} \\
\hline $\begin{array}{l}\text { b. Reflects on past successes, failures, and } \\
\text { alternative strategies }\end{array}$ & $\begin{array}{l}65 . \text { The ability to challenge their own } \\
\text { perspectives } \\
69 . \text { Reevaluate drafts and the "finished" } \\
\text { product, conclusions, etc }\end{array}$ \\
\hline \multicolumn{2}{|l|}{$\begin{array}{l}\text { P3. The information literate student } \\
\text { communicates the product or performance } \\
\text { effectively to others. }\end{array}$} \\
\hline $\begin{array}{l}\text { a. Chooses a communication medium and } \\
\text { format that best supports the purposes of } \\
\text { the product or performance and the } \\
\text { intended audience }\end{array}$ & $\begin{array}{l}\text { 17. Effective communication of the } \\
\text { information } \\
30 \text {. Ability to communicate information } \\
\text { in a variety of ways to match learning } \\
\text { style } \\
51 \text {. Understand their medium and their } \\
\text { audience to adjust information } \\
62 \text {. Ability to use language for the } \\
\text { appropriate audience }\end{array}$ \\
\hline
\end{tabular}




\begin{tabular}{|c|c|}
\hline $\begin{array}{l}\text { b. Uses a range of information technology } \\
\text { applications in creating the product or } \\
\text { performance }\end{array}$ & \\
\hline $\begin{array}{l}\text { c. Incorporates principles of design and } \\
\text { communication }\end{array}$ & $\begin{array}{l}\text { 17. Effective communication of the } \\
\text { information } \\
\text { 31. Spelling \& grammar, correct } \\
\text { punctuation, etc }\end{array}$ \\
\hline $\begin{array}{l}\text { d. Communicates clearly and with a style } \\
\text { that supports the purposes of the intended } \\
\text { audience }\end{array}$ & $\begin{array}{l}\text { 17. Effective communication of the } \\
\text { information } \\
30 \text {. Ability to communicate information } \\
\text { in a variety of ways to match learning } \\
\text { style } \\
\text { 49. Oral communication skills } \\
51 \text {. Understand their medium and their } \\
\text { audience to adjust information } \\
62 \text {. Ability to use language for the } \\
\text { appropriate audience } \\
80 \text {. Ability to present personal information }\end{array}$ \\
\hline $\begin{array}{l}\text { S5. The information literate student } \\
\text { understands many of the economic, legal, } \\
\text { and social issues surrounding the use of } \\
\text { information and accesses and uses } \\
\text { information ethically and legally. }\end{array}$ & C4. Information Ethics Cluster \\
\hline $\begin{array}{l}\text { P1. The information literate student } \\
\text { understands many of the ethical, legal and } \\
\text { socio-economic issues surrounding } \\
\text { information and information technology. }\end{array}$ & \\
\hline $\begin{array}{l}\text { a. Identifies and discusses issues related to } \\
\text { privacy and security in both the print and } \\
\text { electronic environments }\end{array}$ & $\begin{array}{l}\text { 24. Awareness of security and personal } \\
\text { privacy issues } \\
\text { 45. Protocols for accessing private } \\
\text { information }\end{array}$ \\
\hline $\begin{array}{l}\text { b. Identifies and discusses issues related to } \\
\text { free vs. fee-based access to information }\end{array}$ & \\
\hline $\begin{array}{l}\text { c. Identifies and discusses issues related to } \\
\text { censorship and freedom of speech }\end{array}$ & \\
\hline $\begin{array}{l}\text { d. Demonstrates an understanding of } \\
\text { intellectual property, copyright, and fair } \\
\text { use of copyrighted material }\end{array}$ & $\begin{array}{l}\text { 22. Understanding the ethics of } \\
\text { information use } \\
\text { 44. Legal issues in the use of sources, } \\
\text { copyright }\end{array}$ \\
\hline $\begin{array}{l}\text { P2. The information literate student follows } \\
\text { laws, regulations, institutional policies, and } \\
\text { etiquette related to the access and use of } \\
\text { information resources. }\end{array}$ & \\
\hline $\begin{array}{l}\text { a. Participates in electronic discussions } \\
\text { following accepted practices (e.g. } \\
\text { "Netiquette") }\end{array}$ & \\
\hline
\end{tabular}




\begin{tabular}{|c|c|}
\hline $\begin{array}{l}\text { b. Uses approved passwords and other } \\
\text { forms of ID for access to information } \\
\text { resources }\end{array}$ & $\begin{array}{l}\text { 45. Protocols for accessing private } \\
\text { information }\end{array}$ \\
\hline $\begin{array}{l}\text { c. Complies with institutional policies on } \\
\text { access to information resources }\end{array}$ & $\begin{array}{l}\text { 45. Protocols for accessing private } \\
\text { information }\end{array}$ \\
\hline $\begin{array}{l}\text { d. Preserves the integrity of information } \\
\text { resources, equipment, systems and } \\
\text { facilities }\end{array}$ & \\
\hline $\begin{array}{l}\text { e. Legally obtains, stores, and disseminates } \\
\text { text, data, images, or sounds }\end{array}$ & $\begin{array}{l}\text { 22. Understanding the ethics of } \\
\text { information use } \\
\text { 44. Legal issues in the use of sources, } \\
\text { copyright }\end{array}$ \\
\hline $\begin{array}{l}\text { f. Demonstrates an understanding of what } \\
\text { constitutes plagiarism and does not } \\
\text { represent work attributable to others as } \\
\text { his/her own }\end{array}$ & $\begin{array}{l}\text { 22. Understanding the ethics of } \\
\text { information use } \\
\text { 44. Legal issues in the use of sources, } \\
\text { copyright } \\
52 . \text { Be able to construct attributive tags or } \\
\text { signal phrases }\end{array}$ \\
\hline $\begin{array}{l}\text { g. Demonstrates an understanding of } \\
\text { institutional policies related to human } \\
\text { subjects research }\end{array}$ & \\
\hline $\begin{array}{l}\text { P3. The information literate student } \\
\text { acknowledges the use of information sources } \\
\text { in communicating the product or } \\
\text { performance. }\end{array}$ & \\
\hline $\begin{array}{l}\text { a. Selects an appropriate documentation } \\
\text { style and uses it consistently to cite sources }\end{array}$ & $\begin{array}{l}\text { 1. Proper documentation } \\
\text { 3. Proper date of an article } \\
\text { 33. Manual citation of references }\end{array}$ \\
\hline $\begin{array}{l}\text { b. Posts permission granted notices, as } \\
\text { needed, for copyrighted material }\end{array}$ & $\begin{array}{l}\text { 22. Understanding the ethics of } \\
\text { information use } \\
\text { 44. Legal issues in the use of sources, } \\
\text { copyright }\end{array}$ \\
\hline
\end{tabular}

Note. $\mathrm{S}=$ ACRL Standard; $\mathrm{P}=$ ACRL Performance Indicator; $\mathrm{C}=$ Cluster. Adapted from Association for College \& Research Libraries, 2000, Information literacy competency standards for higher education, p. 8-14. Copyright 1997-2011 American Library Association. This document may be reprinted and distributed for non-commercial and educational purposes only, and not for resale. All other rights reserved. 


\section{Appendix I}

\section{Survey Monkey Results for Importance of Each Outcome by Number of Responses}

\begin{tabular}{|c|c|c|c|c|c|}
\hline & $\begin{array}{c}\text { Very } \\
\text { Unimportant }\end{array}$ & Unimportant & Neutral & Important & $\begin{array}{c}\text { Very } \\
\text { Important }\end{array}$ \\
\hline Outcome & 1 & 2 & 3 & 4 & 5 \\
\hline 1. Proper documentation & & & & 5 & 9 \\
\hline 2. Evaluating sources critically & & & & 4 & 10 \\
\hline 3. Proper date of an article & & & 2 & 7 & 5 \\
\hline 4. Using search terms effectively & & & 2 & 9 & 3 \\
\hline 5. Where to look to find information & & & 1 & 7 & 6 \\
\hline $\begin{array}{l}\text { 6. Definition of primary, secondary, } \\
\text { tertiary sources }\end{array}$ & & 1 & 3 & 6 & 4 \\
\hline $\begin{array}{l}\text { 7. Identifying appropriate discipline } \\
\text { databases \& resources }\end{array}$ & & & 3 & 5 & 6 \\
\hline 8. Online catalog & & 1 & 5 & 5 & 3 \\
\hline $\begin{array}{l}\text { 9. Critically assessing the credibility and } \\
\text { thoroughness }\end{array}$ & & & 1 & 5 & 8 \\
\hline $\begin{array}{l}\text { 10. Balance of the resource in regard to } \\
\text { coverage }\end{array}$ & & & 4 & 7 & 3 \\
\hline 11. understanding what they need to find & & & & 4 & 10 \\
\hline 12. A basic search strategy & & & 1 & 8 & 5 \\
\hline 13. Effective use of the materials found & & & 1 & 6 & 7 \\
\hline $\begin{array}{l}\text { 14. Understanding the physical space and } \\
\text { content of the library }\end{array}$ & 1 & 2 & 4 & 5 & 2 \\
\hline 15. Synthesizing the content of the article & & & & 6 & 8 \\
\hline $\begin{array}{l}\text { 16. Balance to your paper in what you } \\
\text { present }\end{array}$ & & & 2 & 8 & 4 \\
\hline $\begin{array}{l}\text { 17. Effective communication of the } \\
\text { information }\end{array}$ & & & & 5 & 9 \\
\hline $\begin{array}{l}\text { 18. Integrate the materials into a } \\
\text { knowledge base }\end{array}$ & & 1 & 1 & 5 & 7 \\
\hline 19. Interpret the data and findings & & & & 8 & 6 \\
\hline 20. Drawing conclusions & & & & 6 & 8 \\
\hline 21. Assessing internet pages (.com, .gov) & & 1 & 4 & 4 & 5 \\
\hline $\begin{array}{l}\text { 22. Understanding the ethics of } \\
\text { information use }\end{array}$ & & & 3 & 3 & 8 \\
\hline $\begin{array}{l}\text { 23. Using different strategies for } \\
\text { understanding and comprehension }\end{array}$ & & & 1 & 8 & 5 \\
\hline $\begin{array}{l}\text { 24. Awareness of security and personal } \\
\text { privacy issues }\end{array}$ & & 2 & 4 & 3 & 5 \\
\hline $\begin{array}{l}\text { 25. Being able to formulate a strong } \\
\text { thesis }\end{array}$ & & & 1 & 5 & 7 \\
\hline $\begin{array}{l}\text { 26. Organizing, storing and backing up } \\
\text { information }\end{array}$ & & & 4 & 8 & 2 \\
\hline 27. Being able to access the internet & & 1 & 1 & 6 & 6 \\
\hline $\begin{array}{l}\text { 28. Learning to pick out what extra } \\
\text { resources can help them }\end{array}$ & & & 2 & 9 & 3 \\
\hline $\begin{array}{l}\text { 29. Being able to analyze a text format } \\
\text { (content,) }\end{array}$ & & & 1 & 8 & 5 \\
\hline
\end{tabular}


CONTENT DOMAIN FOR INFORMATION LITERACY

\begin{tabular}{|c|c|c|c|c|c|}
\hline & $\begin{array}{c}\text { Very } \\
\text { Unimportant }\end{array}$ & Unimportant & Neutral & Important & $\begin{array}{c}\text { Very } \\
\text { Important }\end{array}$ \\
\hline Outcome & 1 & 2 & 3 & 4 & 5 \\
\hline $\begin{array}{l}\text { 30. Ability to communicate information in } \\
\text { a variety of ways to match learning style }\end{array}$ & & 2 & 2 & 5 & 5 \\
\hline $\begin{array}{l}\text { 31. Spelling \& grammar, correct } \\
\text { punctuation, etc }\end{array}$ & & & 1 & 5 & 8 \\
\hline $\begin{array}{l}\text { 32. Effective use of research tools in } \\
\text { print and digital (i.e., indexes, etc.) }\end{array}$ & & & 1 & 8 & 5 \\
\hline 33. Manual citation of references & 2 & & 1 & 8 & 3 \\
\hline $\begin{array}{l}\text { 34. Distinguishing between types of } \\
\text { resources \& publications }\end{array}$ & & & 2 & 7 & 5 \\
\hline $\begin{array}{l}\text { 35. Able to manage information results } \\
\text { electronically }\end{array}$ & & 2 & 5 & 5 & 2 \\
\hline 36. Have a healthy dose of skepticism & & & 3 & 8 & 3 \\
\hline $\begin{array}{l}\text { 37. Being able to identify bias in a } \\
\text { resource }\end{array}$ & & & 1 & 6 & 7 \\
\hline $\begin{array}{l}\text { 38. Be able to evaluate the results of a } \\
\text { web search }\end{array}$ & & & & 6 & 8 \\
\hline 39. Be able to corroborate information & & & 1 & 8 & 5 \\
\hline $\begin{array}{l}\text { 40. Narrow or revise search strategy and } \\
\text { results }\end{array}$ & & & 2 & 8 & 4 \\
\hline $\begin{array}{l}\text { 41. Being able to evaluate the } \\
\text { substantiality of the study }\end{array}$ & & & 3 & 6 & 5 \\
\hline $\begin{array}{l}\text { 42. Understand the difference between } \\
\text { statistical versus practical significance }\end{array}$ & & 1 & 4 & 5 & 4 \\
\hline $\begin{array}{l}\text { 43. Difference between quantitative and } \\
\text { qualitative methods }\end{array}$ & & 1 & 3 & 6 & 4 \\
\hline $\begin{array}{l}\text { 44. Legal issues in the use of sources, } \\
\text { copyright }\end{array}$ & & & 2 & 7 & 5 \\
\hline $\begin{array}{l}\text { 45. Protocols for accessing private } \\
\text { information }\end{array}$ & & 2 & 3 & 5 & 4 \\
\hline $\begin{array}{l}\text { 46. Social or scientific implications of the } \\
\text { research being used }\end{array}$ & & 1 & 5 & 5 & 3 \\
\hline 47. Effective personal interviewing & & 2 & 4 & 4 & 4 \\
\hline $\begin{array}{l}\text { 48. Organizing information for an } \\
\text { effective oral presentation }\end{array}$ & & & & 8 & 6 \\
\hline 49. Oral communication skills & & & 2 & 2 & 10 \\
\hline $\begin{array}{l}\text { 50. Understand of scholarly versus } \\
\text { popular resources }\end{array}$ & & & 1 & 8 & 5 \\
\hline $\begin{array}{l}\text { 51. Understand their medium and their } \\
\text { audience to adjust information }\end{array}$ & & & 2 & 2 & 10 \\
\hline $\begin{array}{l}\text { 52. Be able to construct attributive tags } \\
\text { or signal phrases }\end{array}$ & 1 & 2 & 7 & 3 & 1 \\
\hline $\begin{array}{l}\text { 53. Understanding the difference } \\
\text { between a database and the Internet }\end{array}$ & & & 3 & 7 & 4 \\
\hline $\begin{array}{l}\text { 54. Distinguish between abstracts, review } \\
\text { articles and original research }\end{array}$ & & & 3 & 5 & 6 \\
\hline
\end{tabular}


CONTENT DOMAIN FOR INFORMATION LITERACY

\begin{tabular}{|c|c|c|c|c|c|}
\hline & $\begin{array}{c}\text { Very } \\
\text { Unimportant }\end{array}$ & Unimportant & Neutral & Important & $\begin{array}{c}\text { Very } \\
\text { Important }\end{array}$ \\
\hline Outcome & 1 & 2 & 3 & 4 & 5 \\
\hline 55. Evaluating the quality of evidence & & & 1 & 4 & 9 \\
\hline $\begin{array}{l}\text { 56. Understand the components of a } \\
\text { research paper }\end{array}$ & & & 1 & 11 & 2 \\
\hline $\begin{array}{l}\text { 57. Ability to summarize and synthesize } \\
\text { the information in a resource }\end{array}$ & & & & 5 & 9 \\
\hline $\begin{array}{l}\text { 58. Data driven decision-making for some } \\
\text { disciplines }\end{array}$ & & 1 & 6 & 2 & 5 \\
\hline $\begin{array}{l}\text { 59. Recognizing that the answer is a } \\
\text { combination of many resources }\end{array}$ & & & 2 & 7 & 5 \\
\hline 60. Sequence of the scientific process & & 2 & 4 & 6 & 2 \\
\hline $\begin{array}{l}\text { 61. Identifying competing perspectives } \\
\text { and responding to them effectively }\end{array}$ & & & 1 & 8 & 5 \\
\hline $\begin{array}{l}\text { 62. Ability to use language for the } \\
\text { appropriate audience }\end{array}$ & & & 1 & 5 & 8 \\
\hline 63.The ability to form an opinion & 1 & & & 6 & 7 \\
\hline $\begin{array}{l}\text { 64. The ability to accept challenges of } \\
\text { their own perspective and respond } \\
\text { appropriately }\end{array}$ & & & & 4 & 10 \\
\hline $\begin{array}{l}\text { 65. The ability to challenge their own } \\
\text { perspectives }\end{array}$ & & & & 5 & 9 \\
\hline 66. Ability to conduct an inquiry & & & & 7 & 7 \\
\hline $\begin{array}{l}\text { 67. Primary scientific discovery - identify } \\
\text { the topic first }\end{array}$ & & 2 & 3 & 6 & 3 \\
\hline $\begin{array}{l}\text { 68. Look for credible evidence of both } \\
\text { sides of an argument }\end{array}$ & & & 2 & 6 & 6 \\
\hline $\begin{array}{l}\text { 69. Reevaluate drafts and the "finished" } \\
\text { product, conclusions, etc. }\end{array}$ & & & & 6 & 8 \\
\hline 70. Avoiding information overload & 1 & 2 & 5 & 4 & 2 \\
\hline $\begin{array}{l}\text { 71. Being able to basic information } \\
\text { seeking or research on anything }\end{array}$ & & & 2 & 5 & 7 \\
\hline $\begin{array}{l}\text { 72. Be able to look for and find multiple } \\
\text { explanations for the argument }\end{array}$ & & & 3 & 6 & 5 \\
\hline $\begin{array}{l}\text { 73. Be able to integrate new, multiple } \\
\text { types of information }\end{array}$ & & & 1 & 7 & 6 \\
\hline $\begin{array}{l}\text { 74. How to structure information need at } \\
\text { the beginning - formulating a research } \\
\text { question }\end{array}$ & & & 1 & 6 & 7 \\
\hline $\begin{array}{l}\text { 75. Finding information for life after } \\
\text { graduation }\end{array}$ & & 2 & 2 & 3 & 7 \\
\hline $\begin{array}{l}\text { 76. Recognize the limits of their } \\
\text { knowledge }\end{array}$ & & & 1 & 7 & 6 \\
\hline $\begin{array}{l}\text { 77. Time management } \& \text { prioritization of } \\
\text { tasks }\end{array}$ & & & 2 & 5 & 7 \\
\hline 78. Autonomous in seeking information & & & 4 & 6 & 4 \\
\hline 79. Confidence & & 3 & 1 & 4 & 6 \\
\hline $\begin{array}{l}\text { 80. Ability to present personal information } \\
\text { orally }\end{array}$ & & 2 & 1 & 4 & 7 \\
\hline & 6 & 36 & 156 & 467 & 454 \\
\hline
\end{tabular}




\section{Appendix J}

\section{Survey Monkey Results for Efficacy for Each Outcome by Number of Responses}

\begin{tabular}{|c|c|c|c|c|c|}
\hline & Very Poorly & Poorly & Neutral & Well & Very Well \\
\hline Outcome & 1 & 2 & 3 & 4 & 5 \\
\hline 1. Proper documentation & 1 & 1 & 1 & 7 & 4 \\
\hline 2. Evaluating sources critically & 2 & 3 & 5 & 2 & 2 \\
\hline 3. Proper date of an article & & & 6 & 7 & 1 \\
\hline 4. Using search terms effectively & 1 & 4 & 5 & 4 & \\
\hline 5. Where to look to find information & 1 & 4 & 4 & 5 & \\
\hline $\begin{array}{l}\text { 6. Definition of primary, secondary, } \\
\text { tertiary sources }\end{array}$ & 3 & 3 & 5 & 3 & \\
\hline $\begin{array}{l}\text { 7. Identifying appropriate discipline } \\
\text { databases \& resources }\end{array}$ & & 5 & 4 & 5 & \\
\hline 8. Online catalog & 1 & 2 & 5 & 5 & 1 \\
\hline $\begin{array}{l}\text { 9. Critically assessing the credibility and } \\
\text { thoroughness }\end{array}$ & 1 & 3 & 4 & 4 & 1 \\
\hline $\begin{array}{l}\text { 10. Balance of the resource in regard to } \\
\text { coverage }\end{array}$ & & 2 & 10 & 2 & \\
\hline 11. understanding what they need to find & 1 & 3 & 6 & 4 & \\
\hline 12. A basic search strategy & & 5 & 2 & 5 & 2 \\
\hline 13. Effective use of the materials found & & 3 & 6 & 5 & \\
\hline $\begin{array}{l}\text { 14. Understanding the physical space and } \\
\text { content of the library }\end{array}$ & 4 & 1 & 3 & 5 & \\
\hline 15. Synthesizing the content of the article & & 4 & 5 & 5 & \\
\hline $\begin{array}{l}\text { 16. Balance to your paper in what you } \\
\text { present }\end{array}$ & & 1 & 8 & 5 & \\
\hline $\begin{array}{l}\text { 17. Effective communication of the } \\
\text { information }\end{array}$ & & 3 & 7 & 3 & 1 \\
\hline $\begin{array}{l}\text { 18. Integrate the materials into a } \\
\text { knowledge base }\end{array}$ & 1 & 3 & 7 & 2 & 1 \\
\hline 19. Interpret the data and findings & & 4 & 8 & 1 & 1 \\
\hline 20. Drawing conclusions & & 4 & 5 & 4 & 1 \\
\hline 21. Assessing internet pages (.com, .gov) & 2 & 2 & 5 & 5 & \\
\hline $\begin{array}{l}\text { 22. Understanding the ethics of } \\
\text { information use }\end{array}$ & 1 & 4 & 5 & 4 & \\
\hline $\begin{array}{l}\text { 23. Using different strategies for } \\
\text { understanding and comprehension }\end{array}$ & & 3 & 10 & & 1 \\
\hline $\begin{array}{l}\text { 24. Awareness of security and personal } \\
\text { privacy issues }\end{array}$ & & 5 & 6 & 3 & \\
\hline $\begin{array}{l}\text { 25. Being able to formulate a strong } \\
\text { thesis }\end{array}$ & & 1 & 5 & 7 & 1 \\
\hline $\begin{array}{l}\text { 26. Organizing, storing and backing up } \\
\text { information }\end{array}$ & 2 & 1 & 7 & 4 & \\
\hline 27. Being able to access the internet & & & 1 & 6 & 7 \\
\hline $\begin{array}{l}\text { 28. Learning to pick out what extra } \\
\text { resources can help them }\end{array}$ & & 4 & 5 & 5 & \\
\hline $\begin{array}{l}\text { 29. Being able to analyze a text format } \\
\text { (content,) }\end{array}$ & & 3 & 9 & 1 & 1 \\
\hline
\end{tabular}


CONTENT DOMAIN FOR INFORMATION LITERACY

\begin{tabular}{|c|c|c|c|c|c|}
\hline & Very Poorly & Poorly & Neutral & Well & Very Well \\
\hline Outcome & 1 & 2 & 3 & 4 & 5 \\
\hline $\begin{array}{l}\text { 30. Ability to communicate information in } \\
\text { a variety of ways to match learning style }\end{array}$ & 1 & 7 & 2 & 3 & 1 \\
\hline $\begin{array}{l}\text { 31. Spelling \& grammar, correct } \\
\text { punctuation, etc }\end{array}$ & 3 & 1 & 4 & 4 & 2 \\
\hline $\begin{array}{l}\text { 32. Effective use of research tools in } \\
\text { print and digital (i.e., indexes, etc.) }\end{array}$ & & 8 & 3 & 3 & \\
\hline 33. Manual citation of references & 2 & 2 & 8 & 2 & \\
\hline $\begin{array}{l}\text { 34. Distinguishing between types of } \\
\text { resources \& publications }\end{array}$ & & 2 & 10 & 3 & \\
\hline $\begin{array}{l}\text { 35. Able to manage information results } \\
\text { electronically }\end{array}$ & 1 & 4 & 6 & 2 & 1 \\
\hline 36. Have a healthy dose of skepticism & & 4 & 8 & 2 & \\
\hline $\begin{array}{l}\text { 37. Being able to identify bias in a } \\
\text { resource }\end{array}$ & & 5 & 5 & 3 & 1 \\
\hline $\begin{array}{l}\text { 38. Be able to evaluate the results of a } \\
\text { web search }\end{array}$ & & 4 & 5 & 3 & 2 \\
\hline 39. Be able to corroborate information & 3 & 2 & 7 & 1 & 1 \\
\hline $\begin{array}{l}\text { 40. Narrow or revise search strategy and } \\
\text { results }\end{array}$ & 1 & 3 & 6 & 3 & 1 \\
\hline $\begin{array}{l}\text { 41. Being able to evaluate the } \\
\text { substantiality of the study }\end{array}$ & 2 & 3 & 6 & 2 & 1 \\
\hline $\begin{array}{l}\text { 42. Understand the difference between } \\
\text { statistical versus practical significance }\end{array}$ & 5 & 4 & 3 & 1 & 1 \\
\hline $\begin{array}{l}\text { 43. Difference between quantitative and } \\
\text { qualitative methods }\end{array}$ & 4 & 3 & 6 & & 1 \\
\hline $\begin{array}{l}\text { 44. Legal issues in the use of sources, } \\
\text { copyright }\end{array}$ & & 4 & 6 & 4 & \\
\hline $\begin{array}{l}\text { 45. Protocols for accessing private } \\
\text { information }\end{array}$ & 2 & 5 & 4 & 3 & \\
\hline $\begin{array}{l}\text { 46. Social or scientific implications of the } \\
\text { research being used }\end{array}$ & 1 & 6 & 4 & 2 & 1 \\
\hline 47. Effective personal interviewing & 5 & 4 & 2 & 3 & \\
\hline $\begin{array}{l}\text { 48. Organizing information for an } \\
\text { effective oral presentation }\end{array}$ & 1 & 5 & 4 & 3 & 1 \\
\hline 49. Oral communication skills & 1 & 5 & 4 & 3 & 1 \\
\hline $\begin{array}{l}\text { 50. Understand of scholarly versus } \\
\text { popular resources }\end{array}$ & 1 & 3 & 4 & 5 & 1 \\
\hline $\begin{array}{l}\text { 51. Understand their medium and their } \\
\text { audience to adjust information }\end{array}$ & 1 & 6 & 3 & 3 & 1 \\
\hline $\begin{array}{l}\text { 52. Be able to construct attributive tags } \\
\text { or signal phrases }\end{array}$ & 3 & 2 & 8 & 1 & \\
\hline $\begin{array}{l}\text { 53. Understanding the difference } \\
\text { between a database and the Internet }\end{array}$ & 1 & 1 & 6 & 6 & \\
\hline $\begin{array}{l}\text { 54. Distinguish between abstracts, review } \\
\text { articles and original research }\end{array}$ & 1 & 2 & 6 & 4 & 1 \\
\hline
\end{tabular}




\begin{tabular}{|c|c|c|c|c|c|}
\hline & Very Poorly & Poorly & Neutral & Well & Very Well \\
\hline Outcome & 1 & 2 & 3 & 4 & 5 \\
\hline 55. Evaluating the quality of evidence & 1 & 6 & 5 & 1 & 1 \\
\hline $\begin{array}{l}\text { 56. Understand the components of a } \\
\text { research paper }\end{array}$ & & 4 & 5 & 3 & 1 \\
\hline $\begin{array}{l}\text { 57. Ability to summarize and synthesize } \\
\text { the information in a resource }\end{array}$ & & 3 & 6 & 3 & 2 \\
\hline $\begin{array}{l}\text { 58. Data driven decision-making for some } \\
\text { disciplines }\end{array}$ & 2 & 4 & 5 & 3 & \\
\hline $\begin{array}{l}\text { 59. Recognizing that the answer is a } \\
\text { combination of many resources }\end{array}$ & & 6 & 6 & 1 & 1 \\
\hline 60. Sequence of the scientific process & 3 & 1 & 7 & 2 & 1 \\
\hline $\begin{array}{l}\text { 61. Identifying competing perspectives } \\
\text { and responding to them effectively }\end{array}$ & 3 & 2 & 6 & 2 & 1 \\
\hline $\begin{array}{l}\text { 62. Ability to use language for the } \\
\text { appropriate audience }\end{array}$ & 1 & 2 & 6 & 5 & \\
\hline 63. The ability to form an opinion & & 3 & 4 & 5 & 2 \\
\hline $\begin{array}{l}\text { 64. The ability to accept challenges of } \\
\text { their own perspective and respond } \\
\text { appropriately }\end{array}$ & 2 & 5 & 3 & 3 & 1 \\
\hline $\begin{array}{l}\text { 65. The ability to challenge their own } \\
\text { perspectives }\end{array}$ & 3 & 5 & 3 & 2 & 1 \\
\hline 66. Ability to conduct an inquiry & & 4 & 5 & 4 & 1 \\
\hline $\begin{array}{l}\text { 67. Primary scientific discovery - identify } \\
\text { the topic first }\end{array}$ & & 3 & 9 & 2 & \\
\hline $\begin{array}{l}\text { 68. Look for credible evidence of both } \\
\text { sides of an argument }\end{array}$ & & 4 & 6 & 3 & 1 \\
\hline $\begin{array}{l}\text { 69. Reevaluate drafts and the "finished" } \\
\text { product, conclusions, etc. }\end{array}$ & 1 & 5 & 4 & 2 & 2 \\
\hline 70. Avoiding information overload & 1 & 2 & 10 & 1 & \\
\hline $\begin{array}{l}\text { 71. Being able to basic information } \\
\text { seeking or research on anything }\end{array}$ & 3 & 1 & 5 & 4 & 1 \\
\hline $\begin{array}{l}\text { 72. Be able to look for and find multiple } \\
\text { explanations for the argument }\end{array}$ & 1 & 4 & 5 & 4 & \\
\hline $\begin{array}{l}\text { 73. Be able to integrate new, multiple } \\
\text { types of information }\end{array}$ & 1 & 3 & 6 & 3 & 1 \\
\hline $\begin{array}{l}\text { 74. How to structure information need at } \\
\text { the beginning - formulating a research } \\
\text { question }\end{array}$ & 1 & 3 & 7 & 2 & 1 \\
\hline $\begin{array}{l}\text { 75. Finding information for life after } \\
\text { graduation }\end{array}$ & 1 & 2 & 7 & 3 & 1 \\
\hline $\begin{array}{l}\text { 76. Recognize the limits of their } \\
\text { knowledge }\end{array}$ & 3 & 3 & 5 & 3 & \\
\hline $\begin{array}{l}\text { 77. Time management \& prioritization of } \\
\text { tasks }\end{array}$ & 2 & 4 & 5 & 3 & \\
\hline 78. Autonomous in seeking information & & 4 & 7 & 3 & \\
\hline 79. Confidence & & 1 & 8 & 3 & 2 \\
\hline \multirow[t]{2}{*}{$\begin{array}{l}\text { 80. Ability to present personal information } \\
\text { orally }\end{array}$} & 1 & 4 & 5 & 3 & 1 \\
\hline & 90 & 264 & 439 & 260 & 65 \\
\hline
\end{tabular}

